\title{
NATURAL AND SYNTHETIC ESTROGENS IN WASTEWATER TREATMENT PLANT EFFLUENT AND THE COASTAL OCEAN
}

\author{
By \\ David R. Griffith \\ M.E.Sc., Yale University, 2007 \\ B.A., Bowdoin College, 2000 \\ Submitted in partial fulfillment of the requirements for the degree of \\ Doctor of Philosophy \\ at the \\ MASSACHUSETTS INSTITUTE OF TECHNOLOGY \\ and the \\ WOODS HOLE OCEANOGRAPHIC INSTITUTION
}

September 2013

(C2013 David R. Griffith. All rights reserved. The author hereby grants to MIT and WHOI permission to reproduce and to distribute publicly paper and electronic copies of this thesis document in whole or in part in any medium now known or hereafter created.

Author

Joint Program in Oceanography/Applied Ocean Science and Engineering Massachusetts Institute of Technology and Woods Hole Oceanographic Institution

August 5, 2013

Certified by

Philip M. Gschwend

Ford Professor of Civil and Environmental Engineering, MIT

Thesis Supervisor

Certified by

Heidi M. Nepf

Professor of Civil and Environmental Engineering, MIT

Chair, Departmental Committee for Graduate Students

Accepted by

Elizabeth B. Kujawinski Associate Scientist of Marine Chemistry and Geochemistry, WHOI

Chair, Joint Committee for Chemical Oceanography Woods Hole Oceanographic Institution 


\title{
NATURAL AND SYNTHETIC ESTROGENS IN WASTEWATER TREATMENT PLANT EFFLUENT AND THE COASTAL OCEAN
}

\author{
By
}

\author{
David R. Griffith
}

\begin{abstract}
Submitted to the Department of Civil and Environmental Engineering (MIT) and the Joint Committee for Chemical Oceanography (WHOI) on August 5, 2013 in partial fulfillment of the requirements for the degree of Doctor of Philosophy in the field of Environmental Chemistry and Chemical Oceanography
\end{abstract}

\begin{abstract}
Steroidal estrogens are potent endocrine disrupting chemicals that are naturally excreted by vertebrates (e.g., humans and fish) and can enter natural waters through the discharge of treated and raw sewage. Because estrogens are detrimental to aquatic organisms at picomolar concentrations, many studies have measured so-called "free" estrogen concentrations in wastewater effluents, rivers, and lakes. Yet, to our knowledge, no studies have characterized the broader range of estrogens that includes free, conjugated, and halogenated forms.
\end{abstract}

Conjugated estrogens are important because they can be easily converted to potent free forms by bacteria in wastewater treatment plants and receiving waters. And halogenated estrogens, produced during wastewater disinfection, are only slightly less potent than free estrogens but much more likely to bioaccumulate.

We have developed a tandem mass spectrometry method that is capable of simultaneously quantifying free, conjugated, and halogenated estrogens at picomolar levels in wastewater effluent and coastal seawater. The method was validated using treated effluent from the greater Boston metropolitan area, where we found that halogenated estrogens represented over $50 \%$ of the total estrogen discharge flux. A kinetic model of estrogen halogenation was used to predict the distribution of free and halogenated forms in wastewater effluent and suggested that chlorinated estrogens may be formed en route to the wastewater treatment plant.

In the receiving waters of Massachusetts Bay, we detected a range of conjugated, free, and halogenated forms at concentrations that were well-predicted by dilution near the sewage outfall. Farther downstream, we found significantly higher estrone concentrations which points to large inputs of estrogens from sources other than sewage. 
Finally, we have used compound-specific measurements of ${ }^{13} \mathrm{C}$ and ${ }^{14} \mathrm{C}$ in commercial and pharmaceutical estrogen preparations to evaluate the potential for using carbon isotopes to distinguish between synthetic and endogenous steroids in wastewater and other environmental matrices. Our results show that synthetic estrogens and progestogens exhibit significantly depleted $\delta^{13} \mathrm{C}$ values $(\sim-30 \%)$ compared to endogenous steroids (-16\%o to $-26 \%$ ). This isotopic difference should make it possible to apportion synthetic and endogenous hormone sources in complex environments.

Thesis Supervisor: Philip M. Gschwend

Title: Ford Professor of Civil and Environmental Engineering, MIT 
To my parents:

\section{Penny Ingram Griffith and \\ James Richmond Griffith}

For your love, support, and patience 


\section{ACKNOWLEDGMENTS}

This research was supported by a U.S. Environmental Protection Agency STAR graduate fellowship (FP-91713401), NSF grants to T. Eglinton (OCE-0851350 and OCE-0402533) and W. Martin (OCE-0526389), the Ocean Ventures Fund and Coastal Ocean Institute at the Woods Hole Oceanographic Institution, the Martin Family Society of Fellows for Sustainability (MIT), and MIT Sea Grant (NA10OAR4170086).

I am fortunate to have stumbled into two wonderful advisors. Their complementary strengths have given me a unique perspective into environmental and geochemical systems, and together they have taught me to think critically and experiment deliberately. Without their help, I would not be thinking the way I am today, and for that, I owe them a huge debt.

Only after meeting Tim Eglinton did I seriously consider pursuing a PhD. His good nature, intellectual curiosity, and generosity were infectious, and I am grateful for the flexibility he granted me to pursue research that I could own and love.

Like many who hear Phil Gschwend speak about chemicals and the environment, I was immediately hooked by his logic, enthusiasm, and dedication to education. He has been an inspiration to me and a tremendous advisor throughout.

Thank you, both.

It has been a great experience to work with so many generous, talented, hard-working people during my time in the Joint Program.

Liz Kujawinski kindly welcomed me into her lab and gave me valuable space and advice during my time at WHOI. I could not have asked for a better mentor for all things analytical, instrumental, or career-related.

Hiroshi Matsufuji responded to a stranger's email about a synthesis protocol by offering to send milligrams worth of precious, pure, chlorinated estrogen standards. A package from Japan arrived two days later, and these compounds opened many exciting avenues of research.

I had the great fortune to work with two of the best technical scientists in the Joint Program - Daniel Montluçon and John MacFarlane. They were indispensible in just about every aspect of my work, especially as partners in the field and mentors in the lab. Thank you for teaching me how to foil caps properly, wire and plumb, keep a clean notebook, and judiciously re-appropriate underutilized equipment. And thank you for your friendship and good humor throughout. 
I am thankful to those who went out of their way to help me: to Ann McNichol, for helping me access the resources and expertise at NOSAMS; to Lukas Wacker and Xiaojuan (Yvonne) Feng, for helping with ${ }^{14} \mathrm{C}$ measurements at ETH-Zurich; to Valier Galy, for your generosity with lab space and GC access; to Suni Shah, for taking a neglected project to a new and very interesting place; and to Ann Tarrant for your enthusiasm in our collaboration.

To the FT-MS facility at WHOI and members of the Kujawinski lab, particularly Melissa Kido Soule for her patience and assistance developing and troubleshooting the estrogen analytical method, and to Krista Longnecker for her advice in the lab and for putting up with my surprise arrivals at WHOI.

I am indebted to many others who helped at key moments:

Lisa Wong - effluent sampling

Bill Martin - sediment coretop model development

Dwight Stoll - LC discussions

Robie Macdonald and Jeomshik Hwang - Arctic Ocean discussions and protocols

Steve Manganini - Arctic Ocean sediment traps and in situ pumping preparations

Andrea Burke and David Glover $-{ }^{14} \mathrm{C}$ coretop modeling MATLAB advice

Joanne Goudreau $-{ }^{210} \mathrm{~Pb}$ measurements

Lonny Lippsett and Chris Reddy - class on communicating

Amy Caracappa-Qubeck - graphics

Carl Johnson - MS and filter discussions

Helen Fredricks - LC-MS/MS troubleshooting

Ben Scandella - enthusiasm for debugging MATLAB code

The scientists and staff at NOSAMS $-{ }^{14} \mathrm{C}$ measurements

I would also like to thank the many anonymous birth control pill providers in the U.S., Switzerland, and the Netherlands. Chapter 4 could not have happened without your help.

I have relied heavily my colleagues for help in the field:

OC-437: Jenny Arbuszewski, Peter deMenocal, Daniel Montluçon, Ellen Roosen, Thomas Wagner, Henry Wu

MB-1010: Adam Bockelie, Tracey Hayse, Sarah Jane White

Deer Island: Lisa Wong, Mike Mikelson, Andrea Rex

CCGS Louis S. St Laurent: Kristina Brown, Will Burt, Mike Dempsey, Jim Dunn, Rick

Krishfield, Will Ostrom, Michiyo Yamamoto-Kawai, Sarah Zimmermann

MB-1210: John MacFarlane, Jan-Hendrik Hehemann, Ben Scandella, Dan Prendergast

MB-1305: John MacFarlane, Loretta Fernandez, Anthony Carrasquillo, Mason Stahl,

Dan Prendergast, Kyle Delwiche

Thank you to the directors and administrators at WHOI and MIT, who keep us fed, housed, and reimbursed with smiles and good humor - in the WHOI Academic Programs 
office: Jim Yoder, Meg Tivey, Marsha Armando, Julia Westwater, Tricia Gebbie, Valerie Caron, Michelle McCafferty, Christine Charette, and Lea Fraser; in the MIT JP office:

Ronni Schwartz and Carol Sprague; in the WHOI MCG office: Donna Mortimer, Sheila Clifford, Gaynor Andrews, and Mary Murphy; in the MIT CEE office: Kris Kipp, Pat Dixon, and Jeanette Marchocki; and in the Parsons Lab: Vicki Murphy, Sheila Frankel, and Jim Long.

I've learned a great deal from my classmates and colleagues. I am particularly indebted to members of the supergroup, past and present members of the Gschwend lab (Des Plata, Dave Kuo, Loretta Fernandez, Xanat Flores-Cervantes, Patricia Tcaciuc, Jordon Hemingway, Dan Prendergast, Jen Apell), my classmates in the Fye Trailer, in room 48208, and in the Parsons community as a whole.

Of course, the biggest and most profound thanks go to my family and friends who have supported me and kept me steady throughout this program and in life.

Thank you, all. 


\section{TABLE OF CONTENTS}

Chapter 1: An introduction to steroidal estrogens ............................................. 23

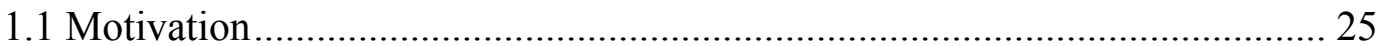

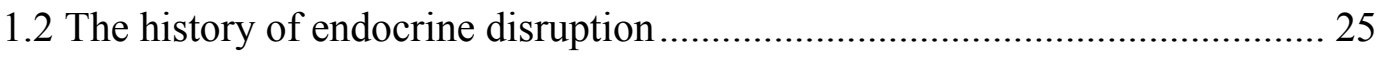

1.3 A range of estrogen-like chemicals......................................................... 26

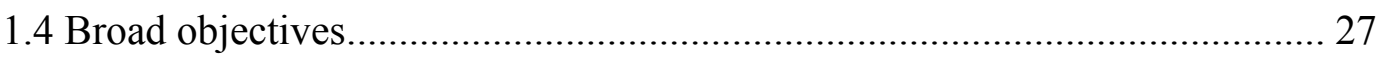

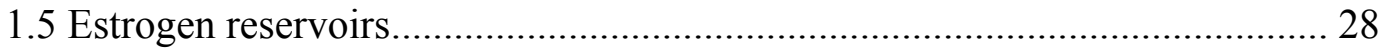

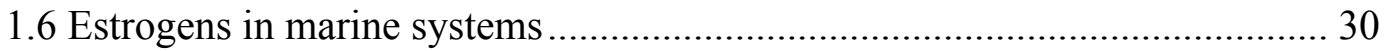

1.7 Preliminary assessment of estrone (E1) in Massachusetts Bay ..................... 33

1.8 Distinguishing between natural and synthetic estrogens in the environment. 35

Chapter 2: Free, conjugated, and halogenated estrogens in secondary treated wastewater effluent

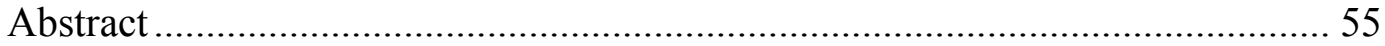

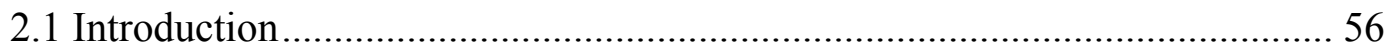

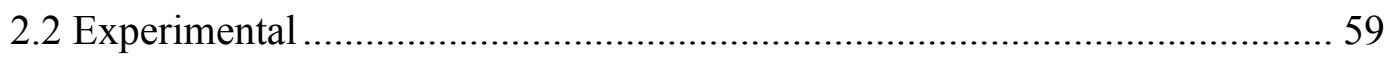

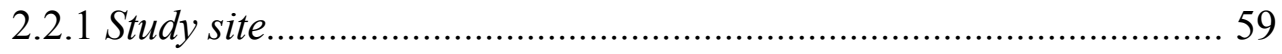

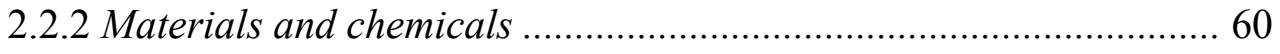

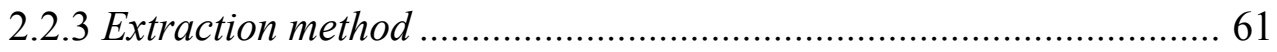

2.2.4 UHPLC-MS/MS analytical method ............................................ 62

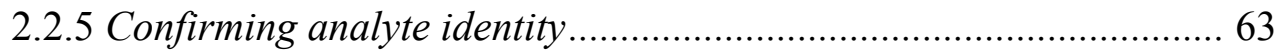

2.2.6 Correcting for sample processing losses and matrix effects ........... 63

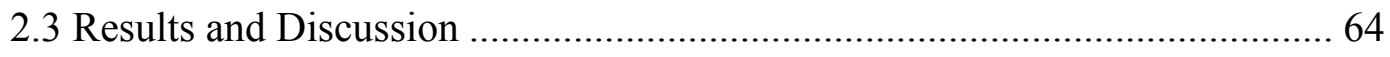

2.3.1 Mobile phase composition and column temperature ...................... 64

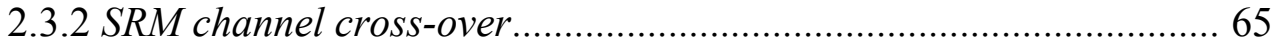

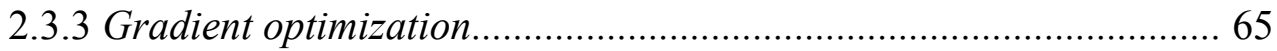

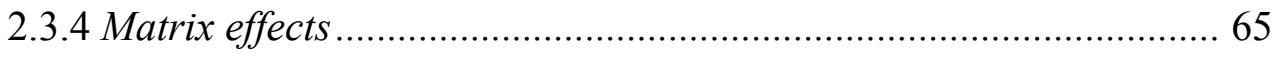

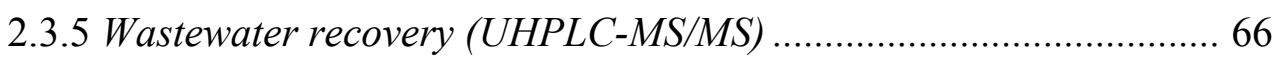

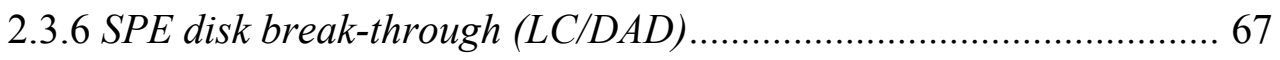

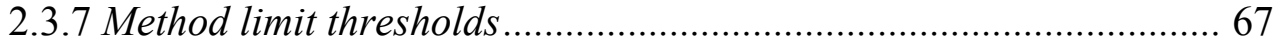


2.3.8 Estrogen concentration and potency in treated wastewater effluent 68

2.3.9 Saltwater intrusion and estrogen halogenation ............................ 70

2.3.10 Halogenation kinetics.................................................................. 70

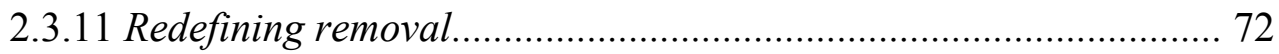

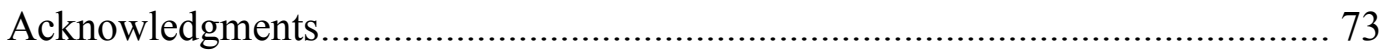

Chapter 3: Steroidal estrogen sources and fate in a sewage-impacted coastal ocean Massachusetts Bay, USA ………………….................................................... 91

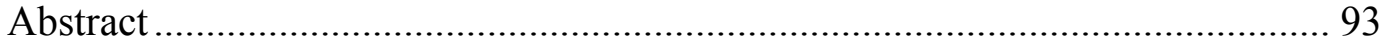

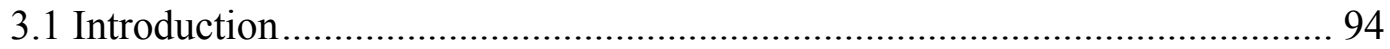

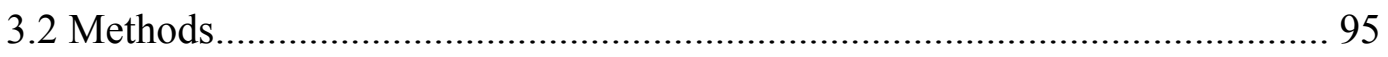

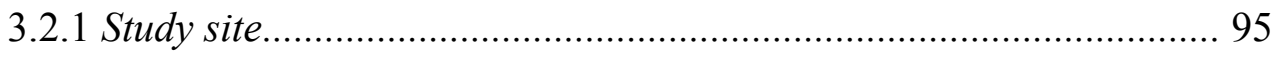

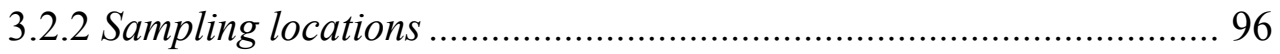

3.2.3 Effluent samples and tracers ....................................................... 98

3.2.4 Standards and solvents .................................................................. 98

3.2.5 Seawater collection and extraction ................................................ 99

3.2.6 Analysis of estrogens ................................................................... 100

3.2.7 Analysis of carbamazepine and caffeine …………………............. 101

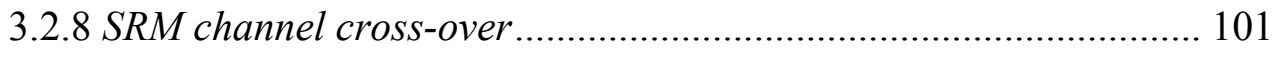

3.2.9 Analyte quantification ..................................................................... 101

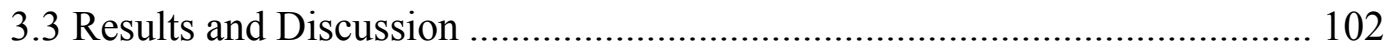

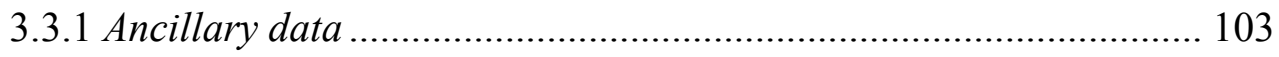

3.3.2 Characterizing the source function (DITP effluent)....................... 103

3.3.3 Estrogens in Massachusetts Bay .................................................. 104

3.3.4 Tracers indicate variable DITP influence at station PLM............... 105

3.3.5 Estrogen fate in Massachusetts Bay ............................................... 107

3.3.6 Modeling nearfield E1 concentrations ............................................. 107

3.3.7 Influence of sampling timescales..................................................... 108

3.3.8 E1 production between stations DS1 and DS2 .............................. 109

3.3.9 Modeling E1 concentrations at stations DS1 and DS2 ................. 110 
3.3.10 Calculating background E1 ranges using independent dilution calculations

3.3.11 Massachusetts Bay box model revisited ........................................ 111

3.3.12 Estrogens in coastal systems ....................................................... 113

3.3.13 Estrogenicity in Massachusetts Bay due to steroidal estrogens... 113

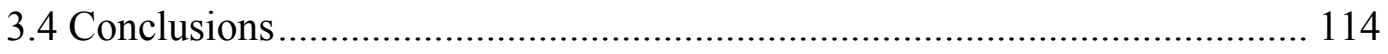

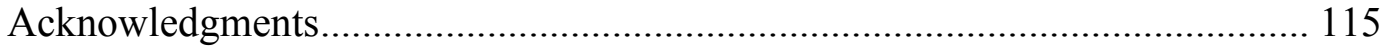

\section{Chapter 4: Carbon isotopic $\left({ }^{13} \mathrm{C}\right.$ and $\left.{ }^{14} \mathrm{C}\right)$ composition of synthetic estrogens and}

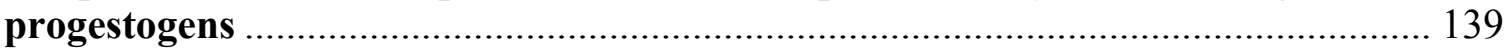

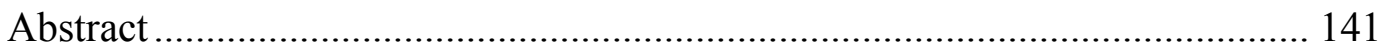

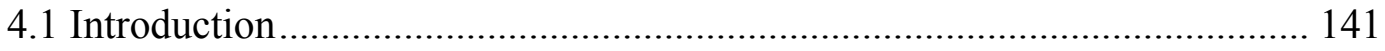

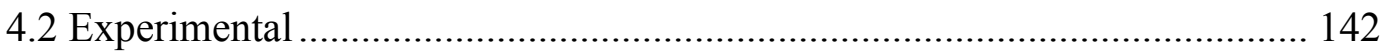

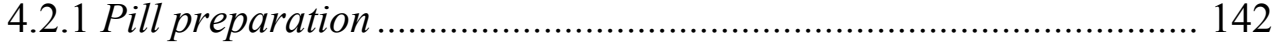

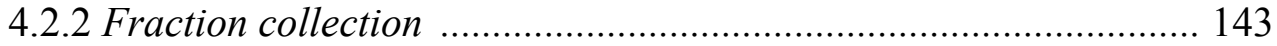

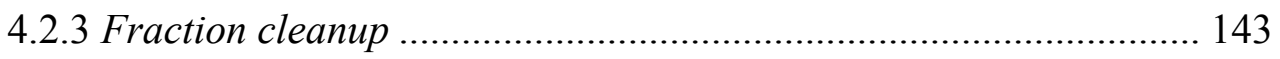

4.2.4 Fraction purity and blank assessment .......................................... 143

4.2.5 Quantification and combustion ..................................................... 143

4.2.6 Column bleed corrections ............................................................... 144

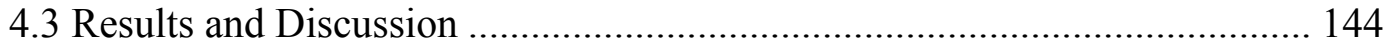

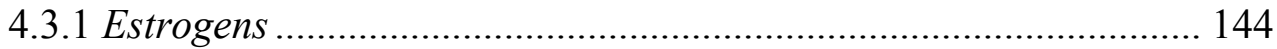

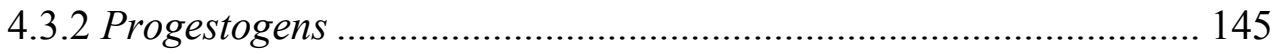

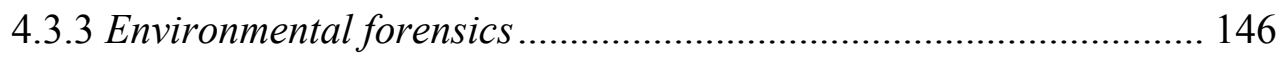

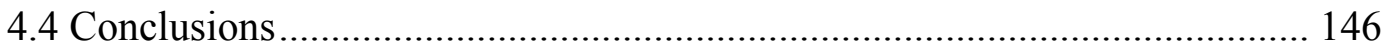

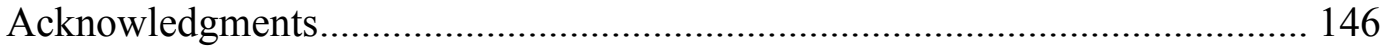

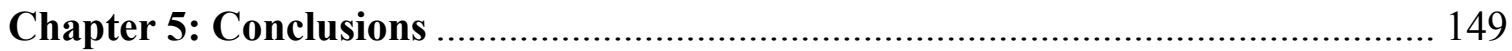

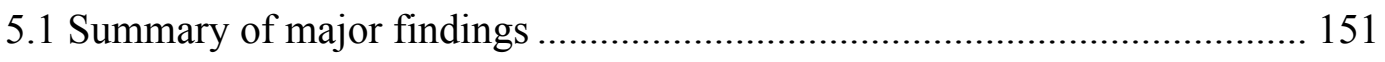

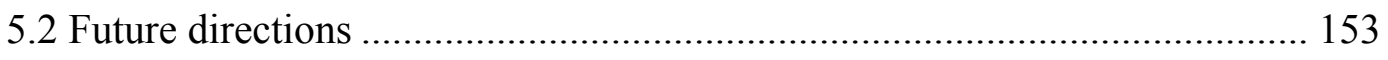

5.2.1 Seasonal and background estrogen sources in Massachusetts Bay 153

5.2.2 Improving tools for predicting environmental concentrations........ 153 
Appendix A: Literature survey of coastal estrogen levels

Appendix B: Solid phase extraction disk break-through experiments ...

Appendix C: Pyrene sorption into cellular lipids and onto laboratory plastics

Appendix D: GC-FID and GC-TOF/MS traces of standards and pill extracts

Appendix E: UV-visible spectra of conjugated, free, and brominated estrogens... 177 


\section{LIST OF FIGURES}

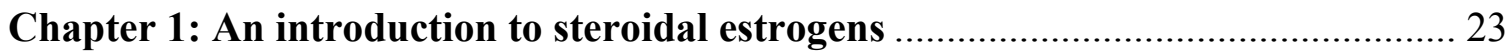

Figure 1. Steroid carbon numbering and ring labels............................................ 39

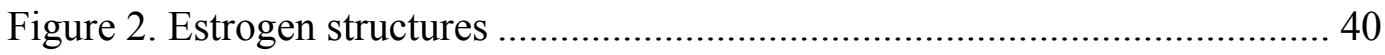

Figure 3. Estrogen families exhibit different binding affinities and potential to sorb onto sediments and bioaccumulate .............................................................. 41

Figure 4. Study sites: Deer Island Treatment Plant and Massachusetts Bay ........ 42

Figure 5. Preliminary mass balance model of a single estrogen family (E1) in Massachusetts Bay ………............................................................................... 43

Figure SI-1. Summary of coastal ocean estrone (E1) concentrations .................... 44

Appendix SI-1. Estrone (E1) mass balance model for Massachusetts Bay .......... 45

Chapter 2: Free, conjugated, and halogenated estrogens in secondary treated wastewater effluent

Figure 1. Procedural flow chart for extracting and quantifying estrogens in wastewater effluent

Figure 2. Ammonium fluoride increases the response factor of free and brominated estrogens in negative mode electrospray ionization using a neat standard solution at $1 \mu \mathrm{g} \mathrm{mL} L^{-1}$

Figure 3. Estrogens in Deer Island Treatment Plant wastewater final effluent on four days in 2012

Figure SI-1. UHPLC-MS/MS selected reaction monitoring (SRM) chromatograms show the separation of 25 estrogens in a wastewater sample ................................. 77

Figure SI-2. Determination of method limit thresholds $\left(\mathrm{L}_{\mathrm{C}}, \mathrm{L}_{\mathrm{D}}\right.$, and $\left.\mathrm{L}_{\mathrm{Q}}\right)$........... 78

Figure SI-3. Modeled E2 halogenation in the DITP disinfection basin seeded only with E2

Figure SI-4. Measured E2 family concentrations in DITP effluent could only be fit by a kinetic model of estrogen halogenation that allowed for diClE2 production prior to the start of disinfection

Chapter 3: Steroidal estrogen sources and fate in a sewage-impacted coastal ocean Massachusetts Bay, USA

Figure 1. Sampling locations in Massachusetts Bay.

Figure 2. A selected reaction monitoring (SRM) chromatogram of Massachusetts

Bay seawater spiked at $500 \mathrm{pg} \mathrm{L}^{-1}$

Figure 3. Estrogen concentrations in Deer Island Treatment Plant final effluent118 
Figure 4. Estrogen concentrations in Massachusetts Bay during the May 2013 sampling campaigns

Figure 5. Sewage tracers in Massachusetts Bay

Figure 6. Estrogen concentrations at station PLM in Massachusetts Bay in October 2012 and May 2013

Figure 7. Measured estrogen concentrations are compared to modeled concentrations at stations DS1 and DS2 in Massachusetts Bay

Figure SI-1. Depth profiles of temperature, salinity, dissolved oxygen, turbidity, and $\mathrm{pH}$ at the nearfield station PLM

Chapter 4: Carbon isotopic $\left({ }^{13} \mathrm{C}\right.$ and $\left.{ }^{14} \mathrm{C}\right)$ composition of synthetic estrogens and progestogens

Figure 1. Chemical structures of (a) estrogens, (b) progestogens, and (c) steroidal precursors

Figure 2. Flow chart for isolating, confirming purity, and analyzing the carbon isotopic composition of estrogens and progestogens in oral contraceptive pills 143

Figure 3. Characteristic carbon isotope values for a variety of estrogens and progestogens isolated from oral contraceptive pills or purchased as authentic standards

Appendix B: Solid phase extraction disk break-through experiments

Figure B-1. Percent recovery of three estrogens (E2-3S, E2, and monoBrE2) from water using solid phase extraction disks

Appendix D: GC-FID and GC-TOF/MS traces of EE2 standards and pill extracts171

Figure D-1. GC-FID chromatograms: EE2 positive control pill extracts and a column bleed blank extract confirm the purity of each extract after silica gel clean up and just prior to closed-tube combustion for ${ }^{13} \mathrm{C}$ and ${ }^{14} \mathrm{C}$ analysis

Figure D-2. GC-TOF/MS total ion chromatogram with inset mass spectra for the three peaks of the EE2 positive control sample

Appendix E: UV-visible spectra of conjugated, free, and brominated estrogens... 177

Figure E-1. Representative UV-visible spectra of five estrogen families 180 


\section{LIST OF TABLES}

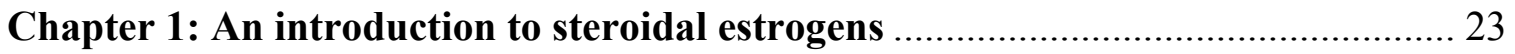

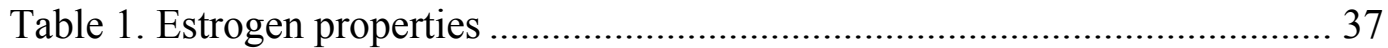

Table SI-1. Mass balance parameters for E1 in Massachusetts Bay................... 38

Chapter 2: Free, conjugated, and halogenated estrogens in secondary treated

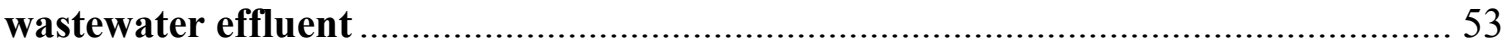

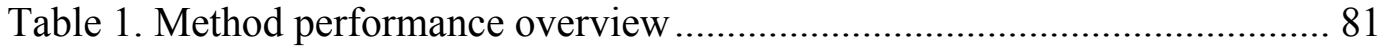

Table SI-1. Deer Island Treatment Plant wastewater effluent characteristics ...... 82

Table SI-2. UHPLC-MS/MS analytical method parameters ............................. 83

Table SI-3. Estrogen concentrations in Deer Island Treatment Plant wastewater effluent collected in March and May 2012 ..................................................... 84

Chapter 3: Steroidal estrogen sources and fate in a sewage-impacted coastal ocean -

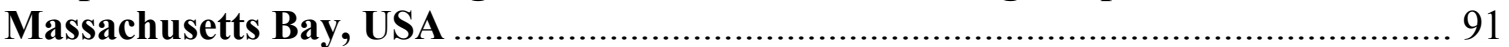

Table 1. Sewage tracer UHPLC-MS/MS analytical method parameters............ 124

Table 2. Sewage tracer concentrations in Massachusetts Bay and Deer Island

Treatment Plant effluent ........................................................................... 125

Table 3. Estimating potential additional E1 sources to Massachusetts Bay ....... 126

Table SI-1. Station locations during MB-1305 field campaigns and location of the

Deer Island Treatment Plant diffuser line ..................................................... 127

Table SI-2. Estrogen UHPLC-MS/MS analytical method parameters .............. 128

Table SI-3. The characteristics of Massachusetts Bay water............................ 129

Table SI-4. Nutrient measurements in Massachusetts Bay............................. 130

Table SI-5. Measurements of organic carbon and nitrogen concentrations and isotopic ratios in Massachusetts Bay …......................................................... 131

Table SI-6. Estrogen concentrations in Deer Island Treatment Plant wastewater effluent collected in October 2012 and May 2013

Table SI-7. Estrogen concentrations in Massachusetts Bay in October 2012 and May 2013

Chapter 4: Carbon isotopic $\left({ }^{13} \mathrm{C}\right.$ and $\left.{ }^{14} \mathrm{C}\right)$ composition of synthetic estrogens and progestogens

Table 1. Estrogen-specific carbon isotope values for oral contraceptive pills and authentic standards 
Table 2. Progestogen-specific carbon isotope values for oral contraceptive pills and authentic standards

Appendix A: Literature survey of coastal estrogen levels....................................... 157

Table A-1. Summary of coastal ocean estrogen concentrations .......................... 159

Appendix C: Pyrene sorption into cellular lipids and onto laboratory plastics..... 167

Table C-1. Estimated losses of estrogens from a typical cell-based reporter assay due to partitioning into cellular lipids and time-dependent losses to polystyrene vessel walls 


\section{LIST OF ACRONYMS}

$\mathrm{ACN}$ acetonitrile

AMS accelerator mass spectrometry BOD biological oxygen demand

BPA bisphenol A

COD chemical oxygen demand

$\mathrm{CSO}$ combined sewer overflow

DCM dichloromethane

DITP Deer Island Treatment Plant EDC . endocrine disrupting chemical

EEq estradiol equivalent

ER estrogen receptor

ESI electrospray ionization

EtOAc ethyl acetate

GC/FID gas chromatography flame ionization detection GC/IRMS gas chromatography isotope ratio mass spectrometry GC/TOF-MS gas chromatography time of flight mass spectrometry LC/DAD. liquid chromatography diode array detection

LC-MS liquid chromatography mass spectrometry $\mathrm{L}_{\mathrm{C}}$ critical level

$\mathrm{L}_{\mathrm{D}}$ or $\mathrm{LOD}$ detection limit $\mathrm{L}_{\mathrm{Q}}$ quantification limit MDL method detection limit

$\mathrm{MeOH}$ methanol

MGD million gallons per day MS/MS tandem mass spectrometry MWRA Massachusetts Water Resources Authority

PNEC predicted no-effect concentration POC particulate organic carbon 
PON. particulate organic nitrogen

PSU .practical salinity unit

PTFE polytetrafluoroethylene

RT retention time

SDB-XC .cross-linked styrene divinylbenzene SIM selected ion monitoring SIS surrogate internal standard

$\mathrm{S} / \mathrm{N}$ signal to noise ratio

SPE solid phase extraction

SRM selected reaction monitoring

TMACl tetramethylammonium chloride TSS total suspended solids

UHPLC ultra high performance liquid chromatography WWTP . wastewater treatment plant

YES .yeast estrogen screen assay 


\section{ESTROGEN ABREVIATIONS}

E3-3G

estriol-3-glucuronide

E1-3G estrone-3-glucuronide

E2-3G 17ß-estradiol-3-glucuronide

EE2-3G

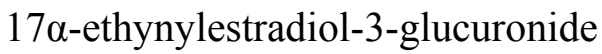

E1-3S estrone-3-sulfate

E2-3S 17ß-estradiol-3-sulfate EE2-3S $17 \alpha$-ethynylestradiol-3-sulfate

E3 estriol monoClE3 4-chloro-estriol E1 estrone

E2 17ß-estradiol EE2 $17 \alpha$-ethynylestradiol diClE3 2,4-dichloro-estriol monoClE1 4-chloro-estrone monoBrEE2 2-bromo-17 $\alpha$-ethynylestradiol monoBrE2 2-bromo-17ß-estradiol monoClEE2 4-chloro-17 $\alpha$-ethynylestradiol monoClE2 4-chloro-17ß-estradiol diClE1 2,4-dichloro-estrone

diClEE2 2,4-dichloro-17 $\alpha$-ethynylestradiol diClE2 2,4-dichloro-17ß-estradiol diBrEE2 2,4-dibromo-17 $\alpha$-ethynylestradiol diBrE2 2,4-dibromo-17ß-estradiol 


\section{Chapter 1}

An introduction to steroidal estrogens 


\subsection{Motivation}

Estrogens are potent steroidal hormones that are key for the normal growth and development of all vertebrates. Estrogens are naturally excreted from the body, mainly as conjugated forms that contain attached sulfate and glucuronide groups, but these forms can be rapidly converted back into potent forms by bacteria in wastewater treatment plants (WWTPs) and the environment. During wastewater disinfection, estrogens may react with chlorine or bromine to create halogenated forms. Estrogens are also manufactured for use as pharmaceuticals (e.g., birth control and hormone replacement therapy) and to enhance livestock production. All of these natural and synthetic estrogens are released into the environment through myriad routes including sewage and livestock effluent (Shore and Shemesh 2003). And since estrogens are potent enough to severely affect natural populations and individual organisms in receiving waters and have been found in treated drinking water, it is crucial that we better characterize the range of estrogens being released into the environment.

\subsection{The history of endocrine disruption}

Endocrine disruption has been comprehensively reviewed in other publications (Tyler, Jobling et al. 1998; Sumpter and Johnson 2005; Williams, Keller et al. 2009; Snyder and Benotti 2010; Bergman, Heindel et al. 2013). An endocrine disrupting chemical (EDC) is defined as "an exogenous substance or mixture that alters function(s) of the endocrine system and consequently causes adverse health effects in an intact organism, or its progeny, or (sub) populations" (IPCS 2002). The brief summary that follows is focused on the history of EDCs in terms of their occurrence in wastewater and effects on wildlife.

As a class of steroidal hormone, estrogens were first discovered in the 1920s and 1930s (Morgan and Moynihan 2000). Non-steroidal chemicals with appropriate size and chemical character were known to mimic steroids as early as the 1940s (Schueler 1946), and by the 1950s, studies had made direct links between endocrine disruption and specific plant-derived and synthetic chemicals (Levin, Burns et al. 1951; Fisher, Keasling 
et al. 1952). As public interest grew and analytical capabilities improved through the 1960s and 1970s, increasing numbers of chemicals were identified in wastewaters, rivers, and lakes. Many of these chemicals were pharmaceuticals and steroidal hormones that were excreted by humans and survived wastewater treatment (e.g., Stumm-Zollinger and Fair 1965; Hignite and Azarnoff 1977). By the 1990s and 2000s, scientists were able to make direct connections between fish abnormalities and endocrine disrupting chemicals in water (Tyler, Jobling et al. 1998; Kidd, Blanchfield et al. 2007; Bergman, Heindel et al. 2013). These effects, which include the feminization of males and impaired reproductive fitness, have been observed at both the individual and population levels.

\subsection{A range of estrogen-like chemicals}

Knowing the affinity between a chemical and an estrogen receptor is a first step in understanding a chemical's estrogenic potency. Some compounds bind strongly (e.g., $17 \alpha$-ethynylestradiol), while others bind weakly (e.g., bisphenol A), and this difference is a direct reflection of chemical structure (Fang, Tong et al. 2001). Still, the net strength of a hormonal response, and thus a chemical's overall potency, is mediated by many physiological and environmental variables (Bergman, Heindel et al. 2013).

Human estrogen receptors (ER) are expressed in living tissue to different degrees. Each receptor (e.g., ER $\alpha, E R \beta$ ) also exhibits a unique binding affinity for each individual estrogen or estrogen-mimic (Kuiper, Carlsson et al. 1997; Kuiper, Lemmen et al. 1998).

In general, chemicals that bind well to estrogen receptors share some common features. The 3-dimensional shape and electronic structure of the ligand binding domain of an estrogen receptor determines which chemicals will bind strongly (Brzozowski, Pike et al. 1997). Key characteristics include molecular size, a hydrophobic central molecular core, and functional groups (like hydroxyl groups) that have H-bond donating ability at either end of the molecule (Schueler 1946; Anstead, Carlson et al. 1997; Fang, Tong et al. 2001).

Since chemical structures are so diverse, binding affinity can vary by many orders of magnitude. Typically, the estrogen $17 \beta$-estradiol (E2) is treated as the reference for 
estrogen receptor binding affinity (sometimes called "estrogenicity"), and binding by other chemicals is measured relative to E2 and expressed in terms of E2 equivalents (EEq; Table 1). The estrogen used in most oral contraceptive pills, EE2, is one chemical that binds more strongly than E2 (EEq 1.3; (Liu, Kanjo et al. 2009)).

Yet, the vast majority of natural and synthetic chemicals have some structural feature that precludes strong binding with the estrogen receptor. For example, estrone (E1; EEq 0.3), is a potent "free" form but lacks an H-bond donor on the D-ring (Liu, Kanjo et al. 2009). Similarly, the sulfate conjugate, estrone-3-sulfate (E1-3S; EEq < 0.01), lacks an H-bond donor on the D-ring but is also considerably larger and more polar than the free form, E1 (Kuiper, Carlsson et al. 1997). A common chemical additive, bisphenol A (BPA; EEq 0.0001), has two H-bond donor groups but non-optimal shape (Fang, Tong et al. 2001). Finally, phytoestrogens (EEq 0.0007), which are plantderived chemicals present at high concentrations in many food products (NCEH 2005; Stanford, Snyder et al. 2010), have a molecular core that is typically more polar than that of steroidal estrogens (Fang, Tong et al. 2001).

Estrogenic effects are related to both environmental concentration (activity) and binding affinity. Indeed, chemicals like BPA, which are often present at high concentrations $\left(\mu \mathrm{g} \mathrm{L}^{-1}\right)$ in the environment may be a lesser risk than low level $\left(\mathrm{ng} \mathrm{\textrm {L } ^ { - 1 }}\right)$ constituents, like steroidal estrogens, that have $10^{3}-10^{4}$ times stronger affinity for estrogen receptors. Still, chemicals do not exist in isolation. In the end we should work towards understanding the effect of realistic mixtures of chemicals on organisms as well as the relevant mechanisms of interaction with endocrine systems as a whole.

\subsection{Broad objectives}

The main objective of this thesis is to evaluate whether we should consider a wider range of steroidal estrogens in environments that receive estrogenic mixtures capable of harming organisms. Most research energy has been devoted to characterizing potent free estrogens. We seek to understand the importance of other likely forms, particularly conjugated and halogenated estrogens. In systems where estrogens pose a 
threat, effective solutions will require a better understanding of the sources and fate of estrogens. Thus, we also investigate whether carbon isotopes may provide a way to track synthetic and natural estrogens in complex environments.

\subsection{Estrogen reservoirs}

When we measure only free estrogens (e.g., E1, E2, estriol (E3), and EE2) in wastewater effluents, rivers, lakes, oceans, or groundwater, do we have the full picture? Or, have we neglected important reservoirs of estrogens by not looking for conjugated and halogenated forms?

Thousands of studies have described free estrogens in wastewaters and natural waters. The reasons that few of these studies have also considered conjugated or halogenated estrogens are threefold. First, conjugates and halogenated forms are thought to be less important because they bind less strongly to estrogen receptors. Second, authentic standards of most halogenated estrogens are not commercially available. Finally, methods that target a wide range of chemical structures are challenging to optimize and validate.

There is strong evidence that conjugates and halogenated forms are important. Conjugates have polar groups that are attached to the free estrogen skeleton at carbon number 3, 16, or 17 (Figure 1; Figure 2; (Axelson, Sahlberg et al. 1981)) to aid with excretion from the body. Most human and animal estrogens are excreted as sulfate or glucuronide conjugates (Figure 2). Typically, the conjugates are much less potent than free estrogens (Figure 3; (Burgess 2003)), and hence are generally "missed" by screening tests. There is also evidence that WWTPs may even be a net source of the sulfate conjugates E1-3S and E2-3S to the effluent stream implying these conjugates are being formed from free and glucuronide forms (Schlusener and Bester 2008). To date, there have been only a few studies of the fate of conjugates in sewers and WWTPs (Gomes, Scrimshaw et al. 2009 and references therein), and none that investigate the fate of estrogen conjugates in marine environments. 
Chlorinated derivatives of estrogens (Figure 2) are also formed during wastewater disinfection processes (Nakamura, Kuruto-Niwa et al. 2007). They are more hydrophobic (e.g., $\log \mathrm{K}_{\mathrm{ow}}$ of 2,4-dichloro-estradiol is estimated to be 5.23 , more than an order of magnitude higher than estradiol and thus encouraging bioaccumulation) and more acidic than the corresponding native estrogens (e.g., the pKa of estradiol is 10.71, while its 2,4dichloro derivative is estimated to have a pKa of 7.43 (Table 1)). Despite the widespread use of chlorine to disinfect wastewater, only a small number of studies have considered the importance of chlorinated estrogens in wastewater effluents and the environment $(\mathrm{Hu}$, Cheng et al. 2003; Moriyama, Matsufuji et al. 2004; Nakamura, Shiozawa et al. 2006; Nakamura, Kuruto-Niwa et al. 2007; Wu, Hu et al. 2009). In a Japanese WWTP, Nakamura et al. (2007) showed that chlorinated E1 derivatives were present in effluent at concentrations up to $50 \%$ that of the free form (E1).

Typically, estrogens exhibit unchanged or slightly decreased estrogenic activity upon chlorination (Mukawa, Suzuki et al. 1988; Moriyama, Matsufuji et al. 2004; Nakamura, Shiozawa et al. 2006). Yet the actual chemical activity of chlorinated derivatives may be even greater than reported since none of the studies corrected for the sorption of chlorinated estrogens onto vessel walls due to greater hydrophobic character $\left(\log \mathrm{K}_{\mathrm{OW}} \sim 4\right.$ - 6; Table 1).

The hydrophobicity of halogenated estrogens also means they are more likely to accumulate on particulate organic matter and in sediments. High particulate/sedimentary estrogen activity may disproportionately affect benthic organisms, filter feeders, and demersal fish. In addition, studies of halogenated phenols (e.g., Abrahamsson and Klick 1991) suggest that dehalogenation by microorganisms in anoxic sediments could convert halogenated estrogens into potent free forms.

Together, existing studies of conjugates and chlorinated derivatives suggest that we are missing a significant piece of the puzzle when it comes to the mass balances, cycling, and environmental impacts of estrogens in coastal ecosystems.

Conjugates may be quickly converted into potent free forms by bacteria in sewers, treatment plants, and receiving waters, and chlorinated forms have been observed in some 
wastewaters at concentrations on par with free forms. Moreover, it is likely that brominated forms would also form in wastewaters containing bromide and treated with chlorine. Yet, to date no method exists for simultaneously measuring free, conjugated, and halogenated estrogens.

Chapter 2 will describes a method for simultaneously measuring 23 steroidal estrogens, including free forms (4), conjugated forms (7), and halogenated forms (12) in wastewater treatment plant effluent.

The estrogen literature is dominated by descriptive studies, which characterize the concentrations of free estrogens in certain particular wastewater plants, rivers, or lakes. Fewer studies have sought to characterize the processes that control the fate of estrogens in environmental systems. And, to our knowledge, none have addressed estrogen fate in a coastal ocean impacted by sewage.

\subsection{Estrogens in marine systems}

There is a paucity of measurements of estrogens in marine systems (Figure SI-1; Appendix A). But despite literally thousands of published studies on estrogens and endocrine disruptors in the environment, we remain largely uninformed about the sources, concentrations, fates, and effects of estrogens in marine ecosystems (Scott, Katsiadaki et al. 2006; Scott, Sanders et al. 2007). This is an incredible situation since we know these compounds are routinely discharged to coastal seas, and even parts per trillion estrogen levels may substantially impact aquatic organisms and pose threats to human health through seafood consumption (Caldwell, Mastrocco et al. 2008; Johnson, Lomax et al. 2008).

There are large gaps in our understanding of the effects of sewage-derived estrogens on marine organisms, including fishes and mammals.

Some scientists suggest that potent endocrine disruptors such as estrogens are deleterious to vertebrates at any non-zero level, even when those levels fall below our detection limits. This assertion seems extreme, especially in light of the fact that marine 
vertebrates must excrete estrogens into their surroundings and often aggregate into schools and shoals.

Nonetheless, we increase the risk of damaging our aquatic and marine ecosystems and the ecosystem services they provide when we proceed without first characterizing total estrogen concentration and understanding how estrogen conjugates behave differently with respect to transport and toxicology. The speciation of estrogens between "free" and conjugated forms also has important implications for their bioaccumulation potential and, thus, the risk to human health via consumption of fish and bivalves. In addition, we must improve our knowledge of coastal estrogen cycling so that we might protect the quality of our drinking water more effectively and efficiently.

Steroidal estrogens are ubiquitous signaling chemicals, so we would expect natural background levels to exist in seawater. Yet there are almost no measurements of these levels. A single water sample from the North Pacific contained E1 concentrations of $0.052 \mathrm{ng} \mathrm{L}^{-1}$ based on a highly specific immunoassay method (Atkinson, Atkinson et al. 2003). While limited in scope, this value provides a benchmark from which to evaluate estrogen concentrations in coastal ocean environments impacted by sewage. If observed estrogen levels exceed background values, then this would point to additional sources and the potential for ecosystem harm.

After reviewing substantial literature, Caldwell et al. (2008) consider fish reproduction as the most relevant and measurable endpoint and they come to a predicted no-effect concentration (PNEC) for $17 \alpha$-ethynylestradiol (EE2) of $0.35 \mathrm{ng} \mathrm{L}^{-1}$. Likewise, Gross-Sorokin et al. (2006) concluded PNEC levels of $0.1 \mathrm{ng} \mathrm{L}^{-1}$ for EE2, $1 \mathrm{ng} \mathrm{L}^{-1}$ for $\mathrm{E} 2$, and $3 \mathrm{ng} \mathrm{L}^{-1}$ for E1. Moreover, Kidd et al. (2007) found that chronic exposures to only 5 - $6 \mathrm{ng} \mathrm{L}{ }^{-1}$ EE2 caused the collapse of a minnow population in their experimental lake system, implying lower concentrations are needed to avoid chronic effects. Hence, many studies identify ng $\mathrm{L}^{-1}$ concentrations as critical levels in various aquatic organisms, including fish, amphibians, gastropods, and amphipods (Caldwell, Mastrocco et al. 2008); and these studies still do not consider the implications of juvenile exposure or the possibility that the estrogens act synergistically. 
Additionally, these water-based exposures do not consider diet-based doses. Dussault et al. (2009) recently reported EE2 bioaccumulation in animals such as midges (Chironomus tentans) and amphipods (Hyallela azteca), the types of animals that may serve as prey for fish. Redhorse suckers (Moxostoma macrolepidotum) living near a wastewater outfall were also found to bioaccumulate EE2 (Al-Ansari, Saleem et al. 2010). Further, Al-Ansari et al. inferred that these higher-trophic-level fish exhibited bioenrichment of this estrogen, implying a food chain exposure route. Perhaps most disturbing is the fact that lipid-normalized EE2 concentrations among this redhorse sucker population were several times higher than what we expect for women taking oral contraceptives. Hence, it is not obvious that evaluation of seawater concentrations of estrogens (i.e., $\sim$ ng L ${ }^{-1}$ levels) will be sufficient to know whether discharges may be damaging coastal ecosystems and will be leading to significant human exposures.

Moreover, as the Boston wastewater is chlorinated, the production of chlorinated (and perhaps brominated, since bromine-containing haloforms have been found in Deer Island effluents; Figure 4) estrogens during treatment with hypochlorite at Deer Island is almost certain (Hu, Cheng et al. 2003; Moriyama, Matsufuji et al. 2004; Nakamura, Shiozawa et al. 2006; Nakamura, Kuruto-Niwa et al. 2007; Wu, Hu et al. 2009). This is important because the bioaccumulation potentials (based on larger $\mathrm{K}_{\mathrm{OW}}$ values; Table 1) of chlorinated (and brominated) estrogens are even higher than those of the parent estrogens (Figure 3). And the literature indicates that the chlorinated compounds exhibit similar or only slightly lower estrogenic activity than free estrogens (Figure 3; (Moriyama, Matsufuji et al. 2004; Nakamura, Shiozawa et al. 2006)).

Due to all these considerations (e.g., possible synergistic effects, levels of chronic exposures, food web enrichments, contributions of chlorinated derivatives), estrogen loading to coastal areas such as Massachusetts Bay (Figure 4) may be significant with respect to biological effects even at sub-ng $\mathrm{L}^{-1}$ concentrations. If the risks associated with certain estrogens are deemed to be unacceptable for human or ecosystem health, then the fate model we develop will also be useful for designing and assessing mitigation strategies including source controls, treatment options, and re-design of synthetic 
estrogen structures. And if (chlorinated) estrogens are accumulating in marine food webs, entering our seafood supply, and compromising human health, then we would be wise to begin to understand the sources and fate of these compounds in the marine environment. Hence, the chief goal of this work is to develop a mass balance understanding of the free, conjugated, and halogenated estrogens, considering the specific environmental processes that control their concentrations in a coastal ocean ecosystem.

\subsection{Preliminary assessment of estrone (E1) in Massachusetts Bay}

In order to begin to assess estrogen levels and the likelihood of adverse effects in a representative coastal ecosystem, a preliminary mass balance was formulated for E1 in a steady state, well-mixed Massachusetts Bay (Figure 5; Appendix SI-1; Table SI-1). To estimate the steady state concentrations, we considered sewage inputs and removals via flushing, sorption and settling, loss to the atmosphere, photodegradation, and biotransformation. This model focuses on the "water column compartment" of Massachusetts Bay (see Shea 1995), and is tuned by the estimated effluent composition and chemical properties of E1. Our initial calculations assume that Deer Island effluent is the only source of E1, thereby ignoring inputs from other municipalities, combined sewer overflows (CSOs), and natural estrogens in the feces and urine of marine vertebrate populations. Calculations suggest that removals by sedimentation and air-sea gas exchange are negligible compared to flushing with water from the Gulf of Maine and biodegradation. We note that biodegradation rate constants have only been determined

for microcosms allowed to acclimatize to $\mu \mathrm{g} \mathrm{L}^{-1}$ estrogen spiking levels, which are orders of magnitude higher than typical environmental concentrations (Jurgens, Holthaus et al. 2002; Ying and Kookana 2003; Ying and Kookana 2005; Ying, Toze et al. 2008). Thus the biodegradation rate constant we use $\left(10 \mathrm{y}^{-1}\right.$; (Ying and Kookana 2003)) may be a gross overestimate since initial estrogen concentrations were orders of magnitude higher than those expected in Massachusetts Bay, conjugated and chlorinated forms were not considered, and rates were determined after long lag periods ( $\sim 2$ weeks). Due to relatively small $\mathrm{K}_{\mathrm{OW}}$ values (Table 1), it is unlikely that sorption to particles and 
subsequent loss to bed sediments is a major sink of estrogens. This will be particularly true for the more polar conjugates, but less so for chlorinated derivatives which are more hydrophobic. We can also safely neglect air - water exchange for these estrogen species due to very small Henry's constant values (Table 1). The resulting mass balance takes the form,

$$
\begin{aligned}
& \frac{d C_{t o t}}{d t}=\frac{Q_{i n} C_{i n}}{V_{\text {bay }}}-k_{\text {flush }} C_{\text {tot }}-k_{\text {settle }} f_{\text {solid }} C_{\text {tot }}-k_{\text {degrade }} f_{\text {water }} C_{\text {tot }}
\end{aligned}
$$

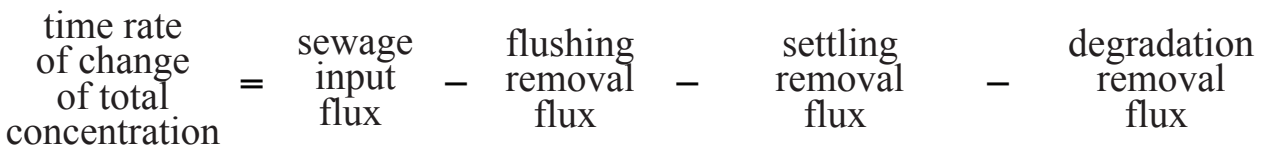

where $k_{f l u s h}, k_{\text {settle }}$, and $k_{\text {degrade }}$ are rate constants that correspond to flushing, sedimentation, and degradation, respectively, and $f_{\text {solid }}$ and $f_{\text {water }}$ represent the fraction of the compound on sinking particles and dissolved in the water. In this case $k_{\text {degrade }}$ likely reflects a combination of processes including biodegradation $\left(k_{b i o}\right)$ and photodegradation $\left(k_{\text {photodeg }}\right)$. We can solve the mass balance equation for each form of E1 at steady-state conditions, and then combine the results to calculate " $\left[\mathrm{E}_{1}\right]_{\text {tot }}$ " in Massachusetts Bay $(0.16$ ng $\left.\mathrm{L}^{-1}\right)$. This estimate includes free $(\mathrm{E} 1 ; 19 \%)$, conjugated (E1-3S; $\left.72 \%\right)$, and chlorinated (monochloro-E1; $9 \%$ ) derivatives. Yet this simple model assumes that E1-3S and monochloro-E1 are the only E1 derivatives, and that both biodegrade with the same rate as the free form $\left(k_{b i o}=10 \mathrm{y}^{-1}\right)$. These estimates also ignore the likelihood that some portion of E1-3S in Massachusetts Bay will be converted to the potent free form by sewage-derived bacterial communities (Gomes, Scrimshaw et al. 2009). As a result, we expect that concentrations near the outfall (before far-field mixing) will be $\sim 10 \mathrm{x}$ higher, likely of the order $1-10 \mathrm{ng} \mathrm{\textrm {L } ^ { - 1 }}$.

Chapter 3 will test model accuracy by quantifying the full suite of natural and synthetic estrogens and their conjugated and halogenated derivatives in the receiving waters and sediments of Massachusetts Bay, USA. To the best of our knowledge, this will be the first time that free, conjugated, and chlorinated estrogens have been measured simultaneously in coastal seawater. These measurements will serve as a test of predicted 
estrogen distributions in Massachusetts Bay and provide context for evaluating risks to human and ecosystem health by highlighting the relative importance of sewage-derived and natural estrogen sources.

\subsection{Distinguishing between natural and synthetic estrogens in the environment}

Finally, in those systems where estrogen levels are deemed problematic, it will be desirable to know the relative contributions from synthetic versus endogenous estrogens in order to design cost-effective solutions.

Mitigation strategies could include source control and/or enhanced removal during treatment. For example, if synthetic pharmaceuticals were the problem source, then one could encourage pharmaceutical design for improved environmental degradability or promote efforts to improve unused pharmaceutical disposal programs. If endogenous estrogens were the problem source, then it may be preferable to invest in wastewater treatment technologies or improve sewer infrastructure to reduce leaks and CSOs.

A key factor for successful application of this approach will be the ability to accurately distinguish between synthetic and endogenous estrogens in very complex environmental matrices (e.g., wastewater, seawater, soils, sediments). In some cases this is possible by conventional analytical chemical means since pharmaceuticals often have unique structures. For example, the estrogen used in most oral contraceptive pills, EE2, is unique in that it contains an ethynyl group at carbon position 17. In other cases, synthetic estrogens are indistinguishable from endogenous forms based solely on chemical structure (e.g., E2 used in hormone replacement therapies).

However, slight variations in isotopic composition have been shown to help discriminate between otherwise structurally identical compounds. In fact, the relative abundance of stable carbon isotopes $\left({ }^{12} \mathrm{C},{ }^{13} \mathrm{C}\right)$ is used routinely to identify synthetic steroid doping in athletics and livestock applications. 
Chapter 4 will present evidence that synthetic hormones have distinct carbon isotope $\left({ }^{12} \mathrm{C},{ }^{13} \mathrm{C},{ }^{14} \mathrm{C}\right)$ signatures, which could be used to apportion sources of synthetic and endogenous estrogens and progestogens to wastewater and natural waters. 


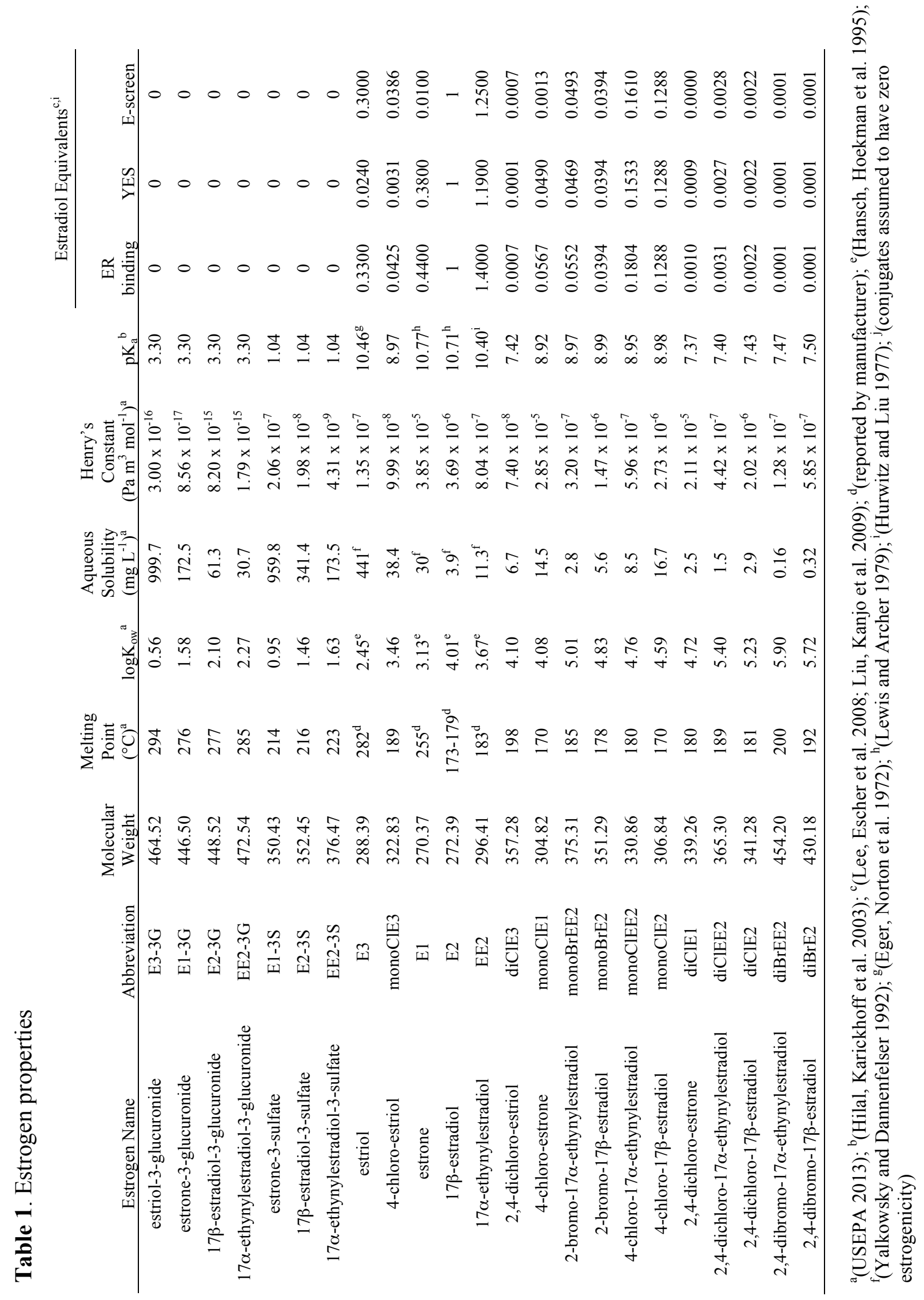


Table SI-1. Mass balance parameters for E1 in Massachusetts Bay

\begin{tabular}{|c|c|c|c|}
\hline Symbol & Definition & Value & Source \\
\hline $\mathrm{C}_{\mathrm{w}}$ & $\begin{array}{l}\text { Steady State concentration dissolved } \\
\text { in MA Bay }\end{array}$ & $2 \mathrm{pg} \mathrm{L}^{-1}$ & Eqn (2) \\
\hline$\overline{Q_{\text {in }}}$ & $\begin{array}{l}\text { Input from Deer Island WWTP } \\
\text { effluent }\end{array}$ & $4.9 \times 10^{12} \mathrm{ng} \mathrm{y}^{-1}$ & $\begin{array}{l}\text { Assuming an average flow of } 360 \\
\text { MGD and } 93 \% \text { receives secondary } \\
\text { treatment (Delaney and Rex } 2007) \text {; } \\
{[\mathrm{E} 1]_{\text {influent }} \sim 58 \mathrm{ng} \mathrm{L}^{-1} ;[\mathrm{E} 1]_{\text {effluent }} \sim} \\
6.3 \mathrm{ng} \mathrm{L}^{-1} \text { (Chimchirian, Suri et al. } \\
2007)\end{array}$ \\
\hline $\mathrm{V}_{\text {bay }}$ & Volume of MA Bay & $1.28 \times 10^{11} \mathrm{~m}^{3}$ & $\mathrm{~A}_{\text {bay }}$ and $\mathrm{D}_{\text {avg }}$ \\
\hline$A_{\text {bay }}$ & Surface area of MA Bay & $3.2 \times 10^{9} \mathrm{~m}^{2}$ & (Gustafsson, Long et al. 2001) \\
\hline $\mathrm{D}_{\text {avg }}$ & Average depth of MA Bay & $35 \mathrm{~m}$ & (Jiang and Zhou 2008) \\
\hline $\mathrm{k}_{\text {flush }}$ & Rate constant for advection (flushing) & $12 \mathrm{y}^{-1}$ & (Gustafsson, Long et al. 2001) \\
\hline $\mathrm{k}_{\mathrm{deg}}$ & Biodegradation rate constant & $10 \mathrm{y}^{-1}$ & $\begin{array}{l}\text { Estimate based on a reported aerobic } \\
\text { biodegradation rate for } E_{2} \text { in marine } \\
\text { sediment (Ying and Kookana 2003) }\end{array}$ \\
\hline $\mathrm{s}$ & Sedimentation rate & $0.31 \mathrm{~cm} \mathrm{y}^{-1}$ & (Gustafsson and Gschwend 1998) \\
\hline$\Phi$ & Porosity of surface sediments & 0.73 & (Gustafsson and Gschwend 1998) \\
\hline$\rho_{\mathrm{s}}$ & Solid sediment density & $2.5 \mathrm{~g} \mathrm{~cm}^{-3}$ & (Shea 1995) \\
\hline [TSS] & Total suspended solid concentration & $1 \mathrm{mg} \mathrm{L}^{-1}$ & (Hyde, O'Reilly et al. 2007) \\
\hline $\mathrm{C}_{\text {tot }}$ & $\begin{array}{l}\text { Total concentration including both } \\
\text { dissolved and particulate phases }\end{array}$ & N/A & $\mathrm{C}_{\mathrm{tot}}=\mathrm{C}_{\mathrm{w}}+\mathrm{C}_{\mathrm{s}}$ \\
\hline $\mathrm{C}_{\mathrm{s}}$ & Steady state concentration on solids & $\mathrm{N} / \mathrm{A}$ & $\mathrm{C}_{\mathrm{s}}=\mathrm{f}_{\mathrm{s}} \mathrm{C}_{\mathrm{tot}}$ \\
\hline $\mathrm{f}_{\mathrm{s}}$ & $\begin{array}{l}\text { Fraction of E1 in the particulate } \\
\text { (solid) phase }\end{array}$ & $5 \times 10^{-6}$ & $\begin{aligned} \mathrm{f}_{\mathrm{s}} & =\mathrm{C}_{\mathrm{s}} \mathrm{M}_{\mathrm{s}} /\left(\mathrm{C}_{\mathrm{s}} \mathrm{M}_{\mathrm{s}}+\mathrm{C}_{\mathrm{w}} \mathrm{V}_{\mathrm{w}}\right) \\
& =\left(\mathrm{K}_{\mathrm{d}}[\mathrm{TSS}]\right) /\left(1+\mathrm{K}_{\mathrm{d}}[\mathrm{TSS}]\right)\end{aligned}$ \\
\hline$f_{w}$ & Fraction of E1 in the dissolved phase & 0.999995 & $\begin{aligned} \mathrm{f}_{\mathrm{w}} & =\mathrm{C}_{\mathrm{w}} \mathrm{V}_{\mathrm{w}} /\left(\mathrm{C}_{\mathrm{s}} \mathrm{M}_{\mathrm{s}}+\mathrm{C}_{\mathrm{w}} \mathrm{V}_{\mathrm{w}}\right) \\
& =\left(1 /\left(1+\mathrm{K}_{\mathrm{d}}[\mathrm{TSS}]\right)\right.\end{aligned}$ \\
\hline $\mathrm{K}_{\mathrm{d}}$ & Solid-water distribution coefficient & $\sim 5 \mathrm{~L} \mathrm{~kg}^{-1}$ & $\begin{array}{l}\text { Estimate based on upper Mississippi } \\
\text { River sediment (Lee, Strock et al. } \\
\text { 2003) }\end{array}$ \\
\hline
\end{tabular}


Figure 1. Steroid carbon numbering and ring labels (Morgan and Moynihan 2000).

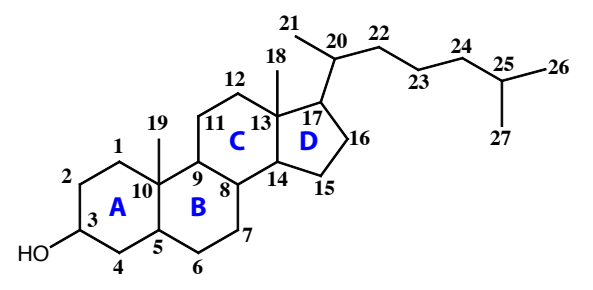


Figure 2. Estrogen structures
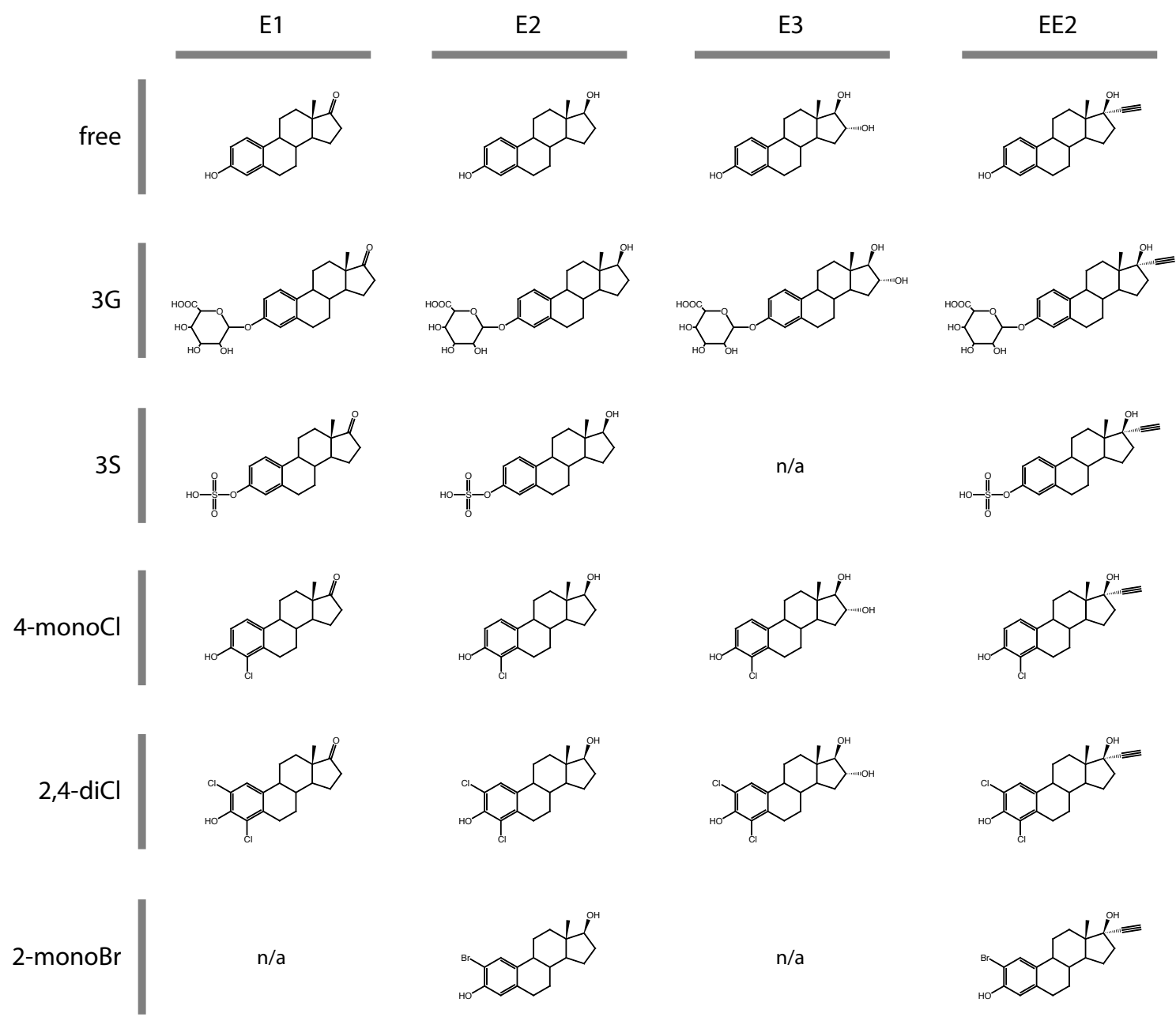

$n / a$
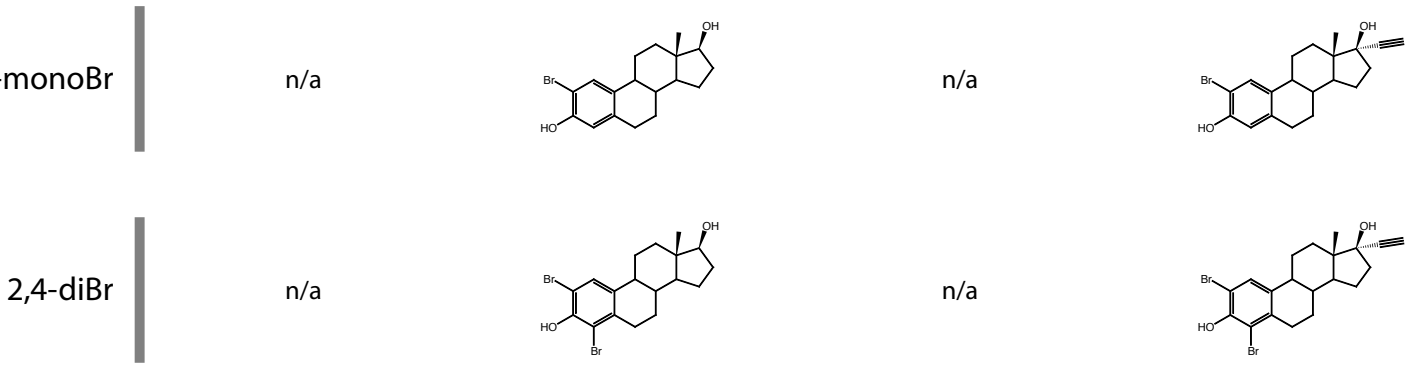

n/a

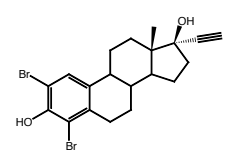


Figure 3. Estrogen families exhibit different binding affinities (y-axis) and potential to sorb onto sediments and bioaccumulate (x-axis) (Griffith 2011).

\section{ESTROGENS COME IN SEVERAL 'FLAVORS'}

Estrogens are hormones that are essential for growth and development, but even minuscule amounts of excess estrogen can have detrimental health impacts on living things. The core of estrogens is composed of 18 carbon atoms bonded together into four rings. Slight chemical differences in the first ring produce significant changes in the estrogens' potency.
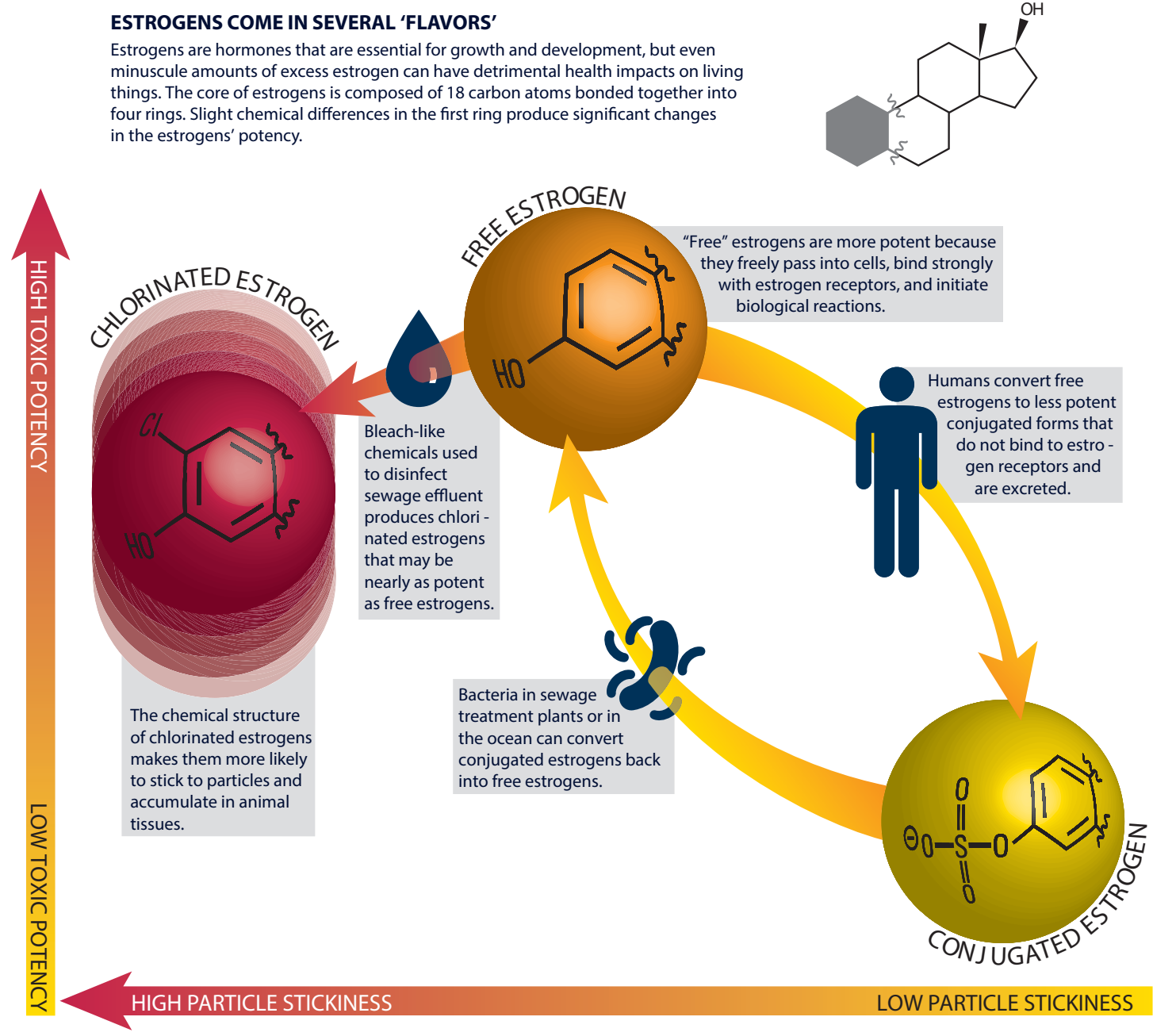
Figure 4. Study sites: Deer Island Treatment Plant and Massachusetts Bay.
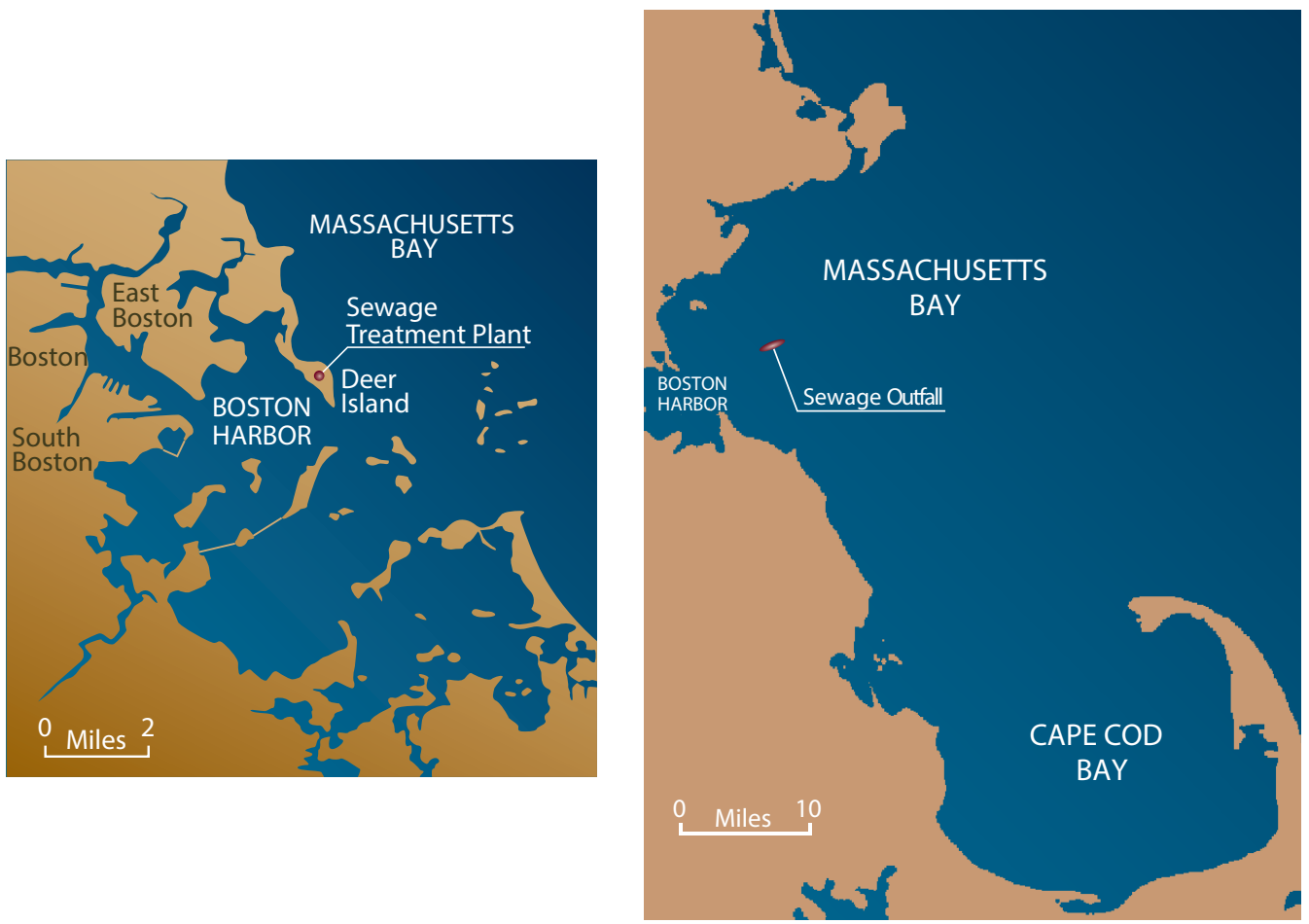
Figure 5. Preliminary mass balance model of a single estrogen family (E1) in Massachusetts Bay. The model assumes a single well-mixed box at steady state. The only input of E1 is Deer Island WWTP effluent (mixed uniformly throughout the bay) where the lower bound is the measured effluent concentration of free E1 (MWRA, unpublished) and the upper bound includes estimates of conjugated and chlorinated E1 inputs (Baronti, Curini et al. 2000; Nakamura, Kuruto-Niwa et al. 2007). Removal occurs by advection (into the Gulf of Maine), biodegradation, and sedimentation. Calculations suggest that removal by sedimentation and to the atmosphere will be negligible. Due to the nature of mixing we expect that actual concentrations near the outfall will be $\sim 10 \mathrm{x}$ higher.

\section{Massachusetts Bay}

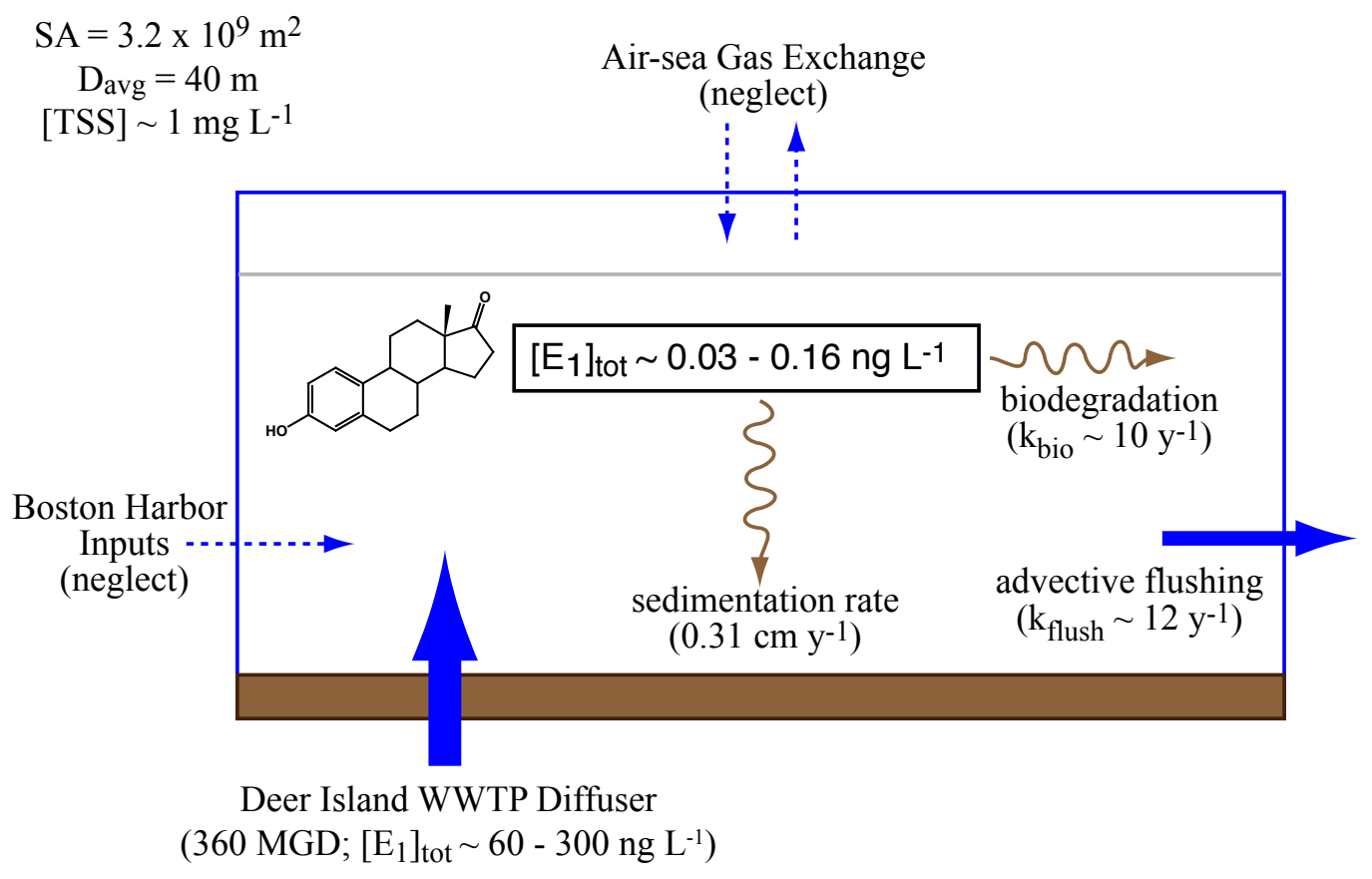


Figure SI-1. Summary of coastal ocean estrone (E1) concentrations. Single measurements are shown as circles. When multiple measurements were reported, the full range is shown as a bar. Concentrations from the current study (Massachusetts Bay and Boston Harbor) are shown in orange. See Appendix A for references and additional details.

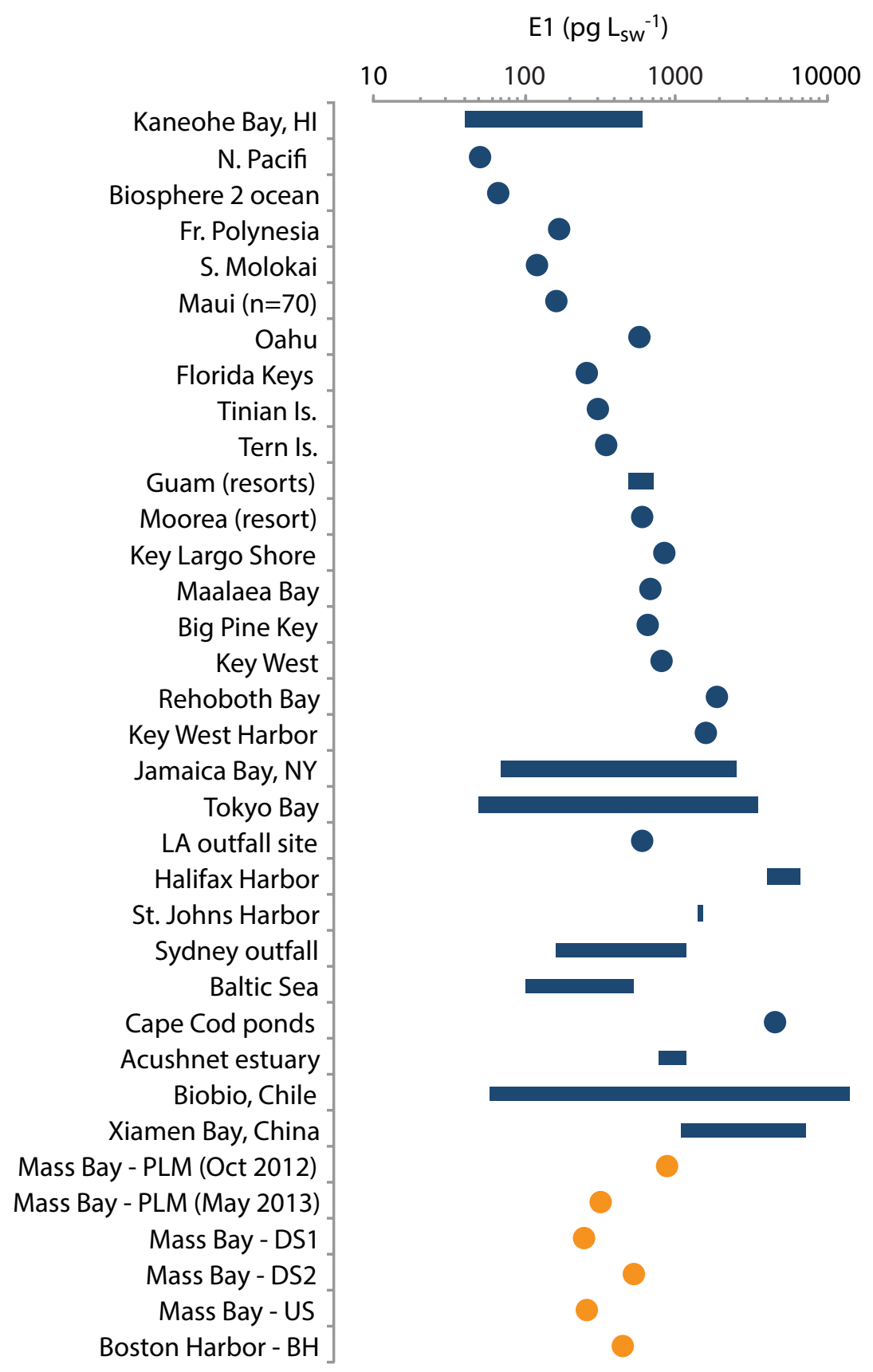


Appendix SI-1. Estrone (E1) mass balance model for Massachusetts Bay

The following expression was used to estimate the steady state concentration of dissolved estrone (E1) in Massachusetts Bay assuming a single well-mixed box at steady state. The only input of E1 is Deer Island WWTP effluent, and removal occurs by advection (flushing into the Gulf of Maine), biodegradation, and sedimentation. Calculations suggest that removal by sedimentation will be negligible.

$$
\frac{d C_{w}}{d t}=\frac{Q_{i n}}{V_{b a y}}-k_{f l u s h} C_{t o t}-\frac{s(1-\Phi) \rho_{s} A_{b a y}}{[T S S] V_{b a y}} C_{s}-k_{\mathrm{deg}} C_{t o t}
$$

$\mathrm{C}_{\text {tot }}$ is the total $\mathrm{E} 1$ concentration in MA bay, and $\mathrm{C}_{\mathrm{w}}$ and $\mathrm{C}_{\mathrm{s}}$ are those portions of $\mathrm{E} 1$ in the dissolved and particulate phases respectively. After $\mathrm{C}_{\text {tot }}$ and $\mathrm{C}_{\mathrm{s}}$ are expressed in terms of $\mathrm{C}_{\mathrm{w}}$ (see Table SI-1) and steady state is assumed, the solution for $\mathrm{C}_{\mathrm{w}}$ yields:

$$
C_{w}=\frac{Q_{\text {in }} / V_{\text {bay }}}{1 / f_{w}\left(k_{\text {flush }}+s(1-\Phi) \rho_{s} f_{s}\left(1 /[T S S] D_{\text {avg }}\right)+k_{\text {deg }}\right)}
$$




\section{REFERENCES}

Abrahamsson, K. and S. Klick (1991). "Degradation of halogenated phenols in anoxic natural marine sediments." Marine Pollution Bulletin 22(5): 227-233.

Al-Ansari, A. M., A. Saleem, et al. (2010). "Bioaccumulation of the pharmaceutical 17 alpha-ethinylestradiol in shorthead redhorse suckers (Moxostoma macrolepidotum) from the St. Clair River, Canada." Environmental Pollution 158(8): 2566-2571.

Anstead, G. M., K. E. Carlson, et al. (1997). "The estradiol pharmacophore: Ligand structure-estrogen receptor binding affinity relationships and a model for the receptor binding site." Steroids 62(3): 268-303.

Atkinson, S., M. J. Atkinson, et al. (2003). "Estrogens from sewage in coastal marine environments." Environmental Health Perspectives 111(4): 531-535.

Axelson, M., B. L. Sahlberg, et al. (1981). "Analysis of profiles of conjugated steroids in urine by ion-exchange separation and gas chromatography-mass spectrometry." Journal of Chromatography 224(3): 355-370.

Baronti, C., R. Curini, et al. (2000). "Monitoring natural and synthetic estrogens at activated sludge sewage treatment plants and in a receiving river water." Environmental Science \& Technology 34(24): 5059-5066.

Bergman, A., J. J. Heindel, et al. (2013). State of the sceince of endocrine disrupting chemicals 2012. Geneva, Switzerland, United Nations Environment Programme and the World Health Organization.

Brzozowski, A. M., A. C. W. Pike, et al. (1997). "Molecular basis of agonism and antagonism in the oestrogen receptor." Nature 389(6652): 753-758.

Burgess, C. (2003). "Estrogens in coastal waters - The sewage source." Environmental Health Perspectives 111(4): A232-A232.

Caldwell, D. J., F. Mastrocco, et al. (2008). "Derivation of an aquatic predicted no-effect concentration for the synthetic hormone, 17 alpha-ethinyl estradiol." Environmental Science \& Technology 42(19): 7046-7054.

Chimchirian, R. F., R. P. S. Suri, et al. (2007). "Free synthetic and natural estrogen hormones in influent and effluent of three municipal wastewater treatment plants." Water Environment Research 79(9): 969-974. 
Delaney, M. F. and A. C. Rex (2007). Contaminant Monitoring of Deer Island Treatment Plant Effluent: 2000-2005. Boston, Massachusetts Water Resources Authority: 40.

Dussault, E. B., V. K. Balakrishnan, et al. (2009). "Bioaccumulation of the synthetic hormone 17 alpha-ethinylestradiol in the benthic invertebrates Chironomus tentans and Hyalella azteca." Ecotoxicology and Environmental Safety 72(6): $1635-1641$.

Eger, C. H., D. A. Norton, et al. (1972). "Molecular interactions of hormonal steroids participation of 17-beta side-chain of corticosteroids in formation of complexes with Co(II) .2." Steroids 20(4): 361-381.

Fang, H., W. D. Tong, et al. (2001). "Structure-activity relationships for a large diverse set of natural, synthetic, and environmental estrogens." Chemical Research in Toxicology 14(3): 280-294.

Fisher, A. L., H. H. Keasling, et al. (1952). "Estrogenic action of some DDT analogues." Proceedings of the Society for Experimental Biology and Medicine 81(2): 439441.

Gomes, R. L., M. D. Scrimshaw, et al. (2009). "Fate of Conjugated Natural and Synthetic Steroid Estrogens in Crude Sewage and Activated Sludge Batch Studies." Environmental Science \& Technology 43(10): 3612-3618.

Griffith, D. R. (2011). From sewers to the seafloor. Oceanus. Woods Hole, MA, USA, Woods Hole Oceanographic Institution. 49: 30-33.

Gustafsson, O. and P. M. Gschwend (1998). "The flux of black carbon to surface sediments on the New England continental shelf." Geochimica Et Cosmochimica Acta 62(3): 465-472.

Gustafsson, O., C. M. Long, et al. (2001). "Fate of Linear alkylbenzenes released to the coastal environment near Boston Harbor." Environmental Science \& Technology 35(10): 2040-2048.

Hansch, C., D. Hoekman, et al. (1995). "The expanding role of quantitative structureactivity relationships (QSAR) in toxicology." Toxicology Letters 79(1-3): 45-53.

Hignite, C. and D. L. Azarnoff (1977). "Drugs and drug metabolites as environmental contaminants - chlorophenoxyisobutyrate and salicylic acid in sewage water effluent." Life Sciences 20(2): 337-341. 
Hilal, S. H., S. W. Karickhoff, et al. (2003). Prediction of Chemical Reactivity Parameters and Physical Properties of Organic Compounds from Molecular Structure Using SPARC. . U. S. E. P. Agency. Athens, GA: 158.

Hu, J. Y., S. J. Cheng, et al. (2003). "Products of aqueous chlorination of 17 betaestradiol and their estrogenic activities." Environmental Science \& Technology 37(24): 5665-5670.

Hurwitz, A. R. and S. T. Liu (1977). "Determination of aqueous solubility and pKa values of estrogens." Journal of Pharmaceutical Sciences 66(5): 624-627.

Hyde, K. J. W., J. E. O'Reilly, et al. (2007). "Validation of SeaWiFS chlorophyll a in Massachusetts Bay." Continental Shelf Research 27(12): 1677-1691.

IPCS (2002). Global assessment of the state-of-the-science of endocrine disruptors. Geneva, Switzerland, International Programme on Chemical Safety, World Health Organization and United Nations Environment Programme.

Jiang, M. S. and M. Zhou (2008). The Massachusetts Bay Hydrodynamic Model: 2005 Simulation. Boston, Massachusetts Water Resources Authority: 58.

Johnson, L. L., D. P. Lomax, et al. (2008). "Xenoestrogen exposure and effects in English sole (Parophrys vetulus) from Puget Sound, WA." Aquatic Toxicology 88(1): 2938 .

Jurgens, M. D., K. I. E. Holthaus, et al. (2002). "The potential for estradiol and ethinylestradiol degradation in English rivers." Environmental Toxicology and Chemistry 21(3): 480-488.

Kidd, K. A., P. J. Blanchfield, et al. (2007). "Collapse of a fish population after exposure to a synthetic estrogen." Proceedings of the National Academy of Sciences of the United States of America 104(21): 8897-8901.

Kuiper, G., B. Carlsson, et al. (1997). "Comparison of the ligand binding specificity and transcript tissue distribution of estrogen receptors alpha and beta." Endocrinology 138(3): 863-870.

Kuiper, G., J. G. Lemmen, et al. (1998). "Interaction of estrogenic chemicals and phytoestrogens with estrogen receptor beta." Endocrinology 139(10): 4252-4263.

Lee, L. S., T. J. Strock, et al. (2003). "Sorption and dissipation of testosterone, estrogens, and their primary transformation products in soils and sediment." Environmental Science \& Technology 37(18): 4098-4105. 
Lee, Y., B. I. Escher, et al. (2008). "Efficient removal of estrogenic activity during oxidative treatment of waters containing steroid estrogens." Environmental Science \& Technology 42(17): 6333-6339.

Levin, E., J. F. Burns, et al. (1951). "Estrogenic, androgenic and gonadotrophic activity in wheat germ oil." Endocrinology 49(3): 289-301.

Lewis, K. M. and R. D. Archer (1979). "pKa values of estrone, 17-beta-estradiol and 2methoxyestrone." Steroids 34(5): 485-499.

Liu, Z. H., Y. Kanjo, et al. (2009). "Removal mechanisms for endocrine disrupting compounds (EDCs) in wastewater treatment - physical means, biodegradation, and chemical advanced oxidation: A review." Science of the Total Environment 407(2): 731-748.

Morgan, B. P. and M. S. Moynihan (2000). Steroids. Kirk-Othmer Encyclopedia of Chemical Technology, John Wiley \& Sons, Inc.

Moriyama, K., H. Matsufuji, et al. (2004). "Identification and behavior of reaction products formed by chlorination of ethynylestradiol." Chemosphere 55(6): 839847.

Mukawa, F., T. Suzuki, et al. (1988). "Estrogen and androgen receptor binding affinity of 10-beta-chloro-estrene derivatives." Journal of Steroid Biochemistry and Molecular Biology 31(5): 867-870.

Nakamura, H., R. Kuruto-Niwa, et al. (2007). "Formation of chlorinated estrones via hypochlorous disinfection of wastewater effluent containing estrone." Chemosphere 66(8): 1441-1448.

Nakamura, H., T. Shiozawa, et al. (2006). "By-products produced by the reaction of estrogens with hypochlorous acid and their estrogen activities." Journal of Health Science 52(2): 124-131.

NCEH (2005). Third national report on human exposure to environmental chemicals. Atlanta, GA: 467.

Schlusener, M. P. and K. Bester (2008). "Behavior of steroid hormones and conjugates three sewage treatment plants." Clean-Soil Air Water 36(1): 25-33.

Schueler, F. W. (1946). "Sex hormonal action and chemical constitution." Science 103(2669): 221-223. 
Scott, A. P., I. Katsiadaki, et al. (2006). "Vitellogenin in the blood plasma of male cod (Gadus morhua): A sign of oestrogenic endocrine disruption in the open sea?" Marine Environmental Research 61(2): 149-170.

Scott, A. P., M. Sanders, et al. (2007). "Evidence for estrogenic endocrine disruption in an offshore flatfish, the dab (Limanda limanda L.)." Marine Environmental Research 64(2): 128-148.

Shea, D. (1995). Multimedia fate model of organic contaminants in Massachusetts Bay. Boston, Massachusetts Water Resources Authority: 20.

Shore, L. S. and M. Shemesh (2003). "Naturally produced steroid hormones and their release into the environment." Pure and Applied Chemistry 75(11-12): 18591871.

Snyder, S. A. and M. J. Benotti (2010). "Endocrine disruptors and pharmaceuticals: implications for water sustainability." Water Science and Technology 61(1): 145154.

Stanford, B. D., S. A. Snyder, et al. (2010). "Estrogenic activity of US drinking waters: A relative exposure comparison." Journal American Water Works Association 102(11): 55-65.

Stumm-Zollinger, E. and G. M. Fair (1965). "Biodegradation of steroid hormones." J. Water Pollut Control Fed 37(11): 1506-1510.

Sumpter, J. P. and A. C. Johnson (2005). "Lessons from endocrine disruption and their application to other issues concerning trace organics in the aquatic environment." Environmental Science \& Technology 39(12): 4321-4332.

Tyler, C. R., S. Jobling, et al. (1998). "Endocrine disruption in wildlife: A critical review of the evidence." Critical Reviews in Toxicology 28(4): 319-361.

USEPA (2013). Estimation Programs Interface Suite for Microsoft Windows, v 4.11. U. S. E. P. Agency.

Williams, R. J., V. D. J. Keller, et al. (2009). "A national risk assessment for intersex in fish arising from steroid estrogens." Environmental Toxicology and Chemistry 28(1): 220-230.

Wu, Q. Y., H. Y. Hu, et al. (2009). "Effect of Chlorination on the Estrogenic/Antiestrogenic Activities of Biologically Treated Wastewater." Environmental Science \& Technology 43(13): 4940-4945. 
Yalkowsky, S. H. and R. M. Dannenfelser (1992). The AQUASOL DATABASE of aqueous solubility, Version 5. Tucson, AZ, USA, University of Arizona, College of Pharmacy.

Ying, G. G. and R. S. Kookana (2003). "Degradation of five selected endocrinedisrupting chemicals in seawater and marine sediment." Environmental Science \& Technology 37(7): 1256-1260.

Ying, G. G. and R. S. Kookana (2005). "Sorption and degradation of estrogen-likeendocrine disrupting chemicals in soil." Environmental Toxicology and Chemistry 24(10): 2640-2645.

Ying, G. G., S. Toze, et al. (2008). "Decay of endocrine-disrupting chemicals in aerobic and anoxic groundwater." Water Research 42(4-5): 1133-1141. 


\section{Chapter 2}

\section{Free, conjugated, and halogenated estrogens in secondary treated wastewater effluent}

David R. Griffith ${ }^{\mathrm{a}}$, Melissa C. Kido Soule ${ }^{\mathrm{b}}$, Hiroshi Matsufuji ${ }^{\mathrm{c}}$, Timothy I. Eglinton ${ }^{\mathrm{d}}$, Elizabeth B. Kujawinski ${ }^{b}$, and Philip M. Gschwend ${ }^{\mathrm{e}}$

${ }^{a}$ MIT/WHOI Joint Program in Oceanography, MIT/WHOI, USA

${ }^{b}$ Marine Chemistry and Geochemistry, Woods Hole Oceanographic Institution, USA

${ }^{c}$ College of Bioresource Sciences, Nihon University, Japan

${ }^{d}$ Geological Institute, ETH-Zürich, Switzerland

${ }^{e}$ Civil and Environmental Engineering, Massachusetts Institute of Technology, USA

In review at Environmental Science \& Technology 


\begin{abstract}
Steroidal estrogens are potent endocrine-disrupting chemicals that enter natural waters through the discharge of treated and raw sewage. Because estrogens are detrimental to aquatic organisms at sub-ng $\mathrm{L}^{-1}$ concentrations, many studies have measured so-called "free" estrogen concentrations in wastewater effluents, rivers, and lakes. Other forms of estrogens are also of potential concern since conjugated estrogens can be easily converted to potent free estrogens by bacteria in wastewater treatment plants and receiving waters, and halogenated estrogens are likely produced during wastewater disinfection. Yet, to our knowledge, no studies have characterized free, conjugated, and halogenated estrogens concurrently. We have developed a method that is capable of simultaneously quantifying free, conjugated, and halogenated estrogens in treated wastewater effluent. Detection limits (from $200 \mathrm{~mL}$ samples) were $0.13-1.3 \mathrm{ng}$ $\mathrm{L}^{-1}$ (free), $0.11-1.0 \mathrm{ng} \mathrm{L}^{-1}$ (conjugated), and $0.18-18 \mathrm{ng} \mathrm{L}^{-1}$ (halogenated). An aqueous phase additive, ammonium fluoride, was used to increase electrospray (negative mode) ionization efficiency of free and halogenated estrogens by a factor of 20 and 2.6, respectively. The method was validated using treated effluent from the greater Boston metropolitan area, where we consistently found concentrations of 2-bromo-17 $\beta$-estradiol and 2,4-dichloro-17 $\beta$-estradiol on par with or greater than free estrogen concentrations.
\end{abstract}




\subsection{Introduction}

Steroidal estrogens are potent endocrine-disrupting chemicals (EDCs), designed to be biologically active and known to disrupt the normal growth and development of aquatic organisms at sub-ng L ${ }^{-1}$ concentrations (Caldwell, Mastrocco et al. 2008; Johnson, Lomax et al. 2008; Velicu and Suri 2009). Estrogens have been measured in rivers, lakes, estuaries, oceans, sewage effluents, septic system discharges, groundwater,

and drinking water, with concentrations ranging up to $\mu \mathrm{g} \mathrm{L}^{-1}$ levels (Desbrow, Routledge et al. 1998; Snyder, Villeneuve et al. 2001; Soto, Calabro et al. 2004).

There are a variety of ways that estrogens can enter aquatic environments. Terrestrial and aquatic vertebrates produce and excrete estrogens naturally (Kolodziej, Harter et al. 2004; Rolland, Hunt et al. 2005). Moreover, certain vertebrates such as cattle may also receive synthetic estrogen supplements to boost milk production or growth, and their associated waste products often run into rivers and lakes (Hanselman, Graetz et al. 2003; Chimchirian, Suri et al. 2007; Kang and Price 2009). If sludge and manure are applied to agricultural fields, then estrogens may enter surface and groundwater by runoff and infiltration (Khanal, Xie et al. 2006). Numerous studies have measured estrogen concentrations in natural waters, but very few have characterized relative contributions from natural (cattle, fish, etc.) and sewage sources.

Estrogens are susceptible to removal by biodegradation or sorption to sewage sludge in wastewater treatment plants (WWTPs), where secondary treatment can reduce estrogen concentrations by $\sim 85 \%$ (Johnson and Sumpter 2001) and final effluents typically contain $n g \mathrm{~L}^{-1}$ concentrations of individual estrogens. Despite the many published studies on estrogens in WWTPs and the environment, we lack a comprehensive understanding of the diversity and distribution of steroidal estrogens in WWTP effluents.

Estrogens belong to a class of steroid hormone that includes a variety of chemical forms and exhibits a range of properties related to phase partitioning, reactivity, and potency. Free estrogens are the most potent form due to characteristic structures that permit strong binding with estrogen receptors in the body. Free estrogens include naturally occurring compounds such as estrone (E1), 17 $\beta$-estradiol (E2), and estriol (E3), 
and synthetically derived $17 \alpha$-ethynylestradiol (EE2). Estrogens are excreted by vertebrates largely in forms that have added glucuronide and sulfate groups. These socalled conjugated estrogens are larger and more polar than free estrogens, and consequently they have very low binding affinity for estrogen receptors rendering them biologically inactive (Anstead, Carlson et al. 1997; Fang, Tong et al. 2001). However, conjugates can be converted to the potent free form by sewage-derived bacterial communities (Gomes, Scrimshaw et al. 2009).

Another estrogen form, chlorinated estrogens, are produced during wastewater disinfection processes (Nakamura, Kuruto-Niwa et al. 2007) as hypochlorite reacts with free estrogens. Despite the widespread use of chlorine to disinfect wastewater, we know very little about the concentration and behavior of chlorinated estrogens in wastewater effluent. Chlorinated estrogens are more hydrophobic than their corresponding free estrogens, indicative of a greater tendency for chlorinated estrogens to bioaccumulate. For example, the $\log K_{\mathrm{OW}}$ of diClE2 (5.23; (USEPA 2013)) is more than an order of magnitude higher than E2 (4.01; (Hansch, Hoekman et al. 1995)), . The fact that chlorinated estrogens are more acidic than free estrogens (e.g., $\mathrm{pK}_{\mathrm{a}}$ of diClE2 and E2 are 7.43 and 10.71, respectively (Lewis and Archer 1979; Hilal, Karickhoff et al. 2003)) also has implications for sorption and photochemical degradation processes.

Despite the large potential flux of chlorinated estrogens from wastewater treatment plants into receiving waters, only a few studies have considered the importance of chlorinated estrogens in wastewater effluents and the environment $(\mathrm{Hu}$, Cheng et al. 2003; Moriyama, Matsufuji et al. 2004; Nakamura, Shiozawa et al. 2006; Nakamura, Kuruto-Niwa et al. 2007; Wu, Hu et al. 2009). In a Japanese WWTP employing secondary treatment and disinfection by hypochlorite, Nakamura et al. (2007) found chlorinated estrogens in effluent at concentrations $\left(4-15 \mathrm{ng} \mathrm{L}^{-1}\right)$ up to $50 \%$ of the free form. The study focused exclusively on E1 and its chlorinated derivatives (monoClE1 and diClE1), relying on detection by selected ion monitoring (SIM) and quantification by an external calibration approach. Therefore, it is possible that other chlorinated estrogens 
were present and that wastewater matrix effects could have biased chlorinated E1 concentrations to lower values.

Estrogens are reported to exhibit unchanged or decreased estrogenic activity upon chlorination (Mukawa, Suzuki et al. 1988; Hu, Cheng et al. 2003; Moriyama, Matsufuji et al. 2004; Nakamura, Shiozawa et al. 2006; Lee, Escher et al. 2008; Liu, Kanjo et al. 2009). Yet the actual estrogenic activity of chlorinated derivatives may be even greater than reported since none of these studies corrected for the sorption of chlorinated estrogens onto vessel walls due to its greater hydrophobic character $\left(\log \mathrm{K}_{\mathrm{OW}} \sim 4-6\right.$; (USEPA 2013)).

Estrogens can also react with hypobromite to form brominated derivatives. Hypobromite is rapidly formed in WWTPs and seawater when hypochlorite reacts with bromide ion (Wong and Davidson 1977; Lee and Von Gunten 2009). This reaction has a reported second-order rate constant of $1.55 \times 10^{3} \mathrm{M}^{-1} \mathrm{~s}^{-1}$ (Kumar and Margerum 1987). Thus, when seawater (carrying $\sim 1 \mathrm{mM}$ bromide) leaks into coastal cities' sewers, hypobromite may react quickly with estrogens to form brominated estrogens. Small amounts of hypobromite may also be formed during drinking water treatment since bromide is a minor constituent of source waters $(\sim 10 \mu \mathrm{M}$; (Vengosh and Pankratov 1998, and references therein)). Moreover, both chlorinated and brominated phenols are known to form in bromide-containing waters treated with hypochlorite (Rook 1974; Rook 1976; Petrovic, Diaz et al. 2001; Acero, Piriou et al. 2005).

If halogenated estrogens represent an important component of the estrogen flux into the environment, then we may need to evaluate the fate and mass balance of estrogens in WWTPs and receiving waters. Moreover, if synergistic effects, chronic exposures, and food web enrichments are significant, then even sub-ng $\mathrm{L}^{-1}$ halogenated estrogen concentrations could have significant biological effects. Therefore our efforts to characterize estrogen sources and fates should include halogenated forms in addition to conjugates and free forms.

This study describes a method for measuring a wide range of steroidal estrogens (free, conjugated, brominated, and chlorinated) in wastewater effluent. The goal was to 
design a relatively simple extraction protocol and an instrumental method that targets a wide range of estrogens in a single analytical run. The method was validated for effluent from a typical large WWTP that employs activated sludge secondary treatment and chlorine-based disinfection by analyzing this effluent after known standard additions were made. Time-series samples were collected in order to accurately characterize the estrogen flux delivered from this WWTP into Massachusetts Bay, U.S.A.

\subsection{Experimental}

\subsubsection{Study site}

The Deer Island Treatment Plant (DITP) is a large secondary treatment facility that handles the greater Boston metropolitan area's sewage and roadway runoff. Briefly, treatment at DITP involves primary settling tanks, secondary treatment by biologically activated sludge, disinfection by chlorination, followed by dechlorination using sodium bisulfite. The Deer Island sewage outfall delivers, on average, 360 million gallons per day (MGD; $15.8 \mathrm{~m}^{3} \mathrm{~s}^{-1}$ ) of treated effluent to Massachusetts Bay (15 km offshore; $30 \mathrm{~m}$ water depth) via a $2 \mathrm{~km}$ long diffuser, which dilutes effluent by $\sim 100$-fold (Delaney and Rex 2007; Hunt, Mansfield et al. 2010).

Wastewater ( $\mathrm{pH} \sim 6.6$ ) grab samples (“GRAB”) were collected from DITP at the final effluent sampling spigot on the mornings of 14 March (10 AM, dry weather, "DI1203”), 30 March (9:30 AM, dry weather, "DI-1203b”), and 16 May 2012 (10 AM, wet weather, "DI-1205"), and during the afternoon of 31 May 2012 (3 PM, dry weather, "DI$1205 b$ "). Since direct access to the ocean outfall is not possible, final effluent samples collected at DITP are chlorinated and dechlorinated on site in a 450' long sampling loop system designed to simulate contact times in the disinfection basin and outfall tunnel.

Flow-weighted composite final effluent samples (“COMP”) were also collected for 24-hour periods ending at 7 AM on 30 March (DI-1203b), 16 May (DI-1205), and 31 May (DI-1205b), 2012. Each composite sample was stored in the dark at $4{ }^{\circ} \mathrm{C}$ during collection. The composite sample from 16 May (DI-1205) captured a large rain event (max flow $731 \mathrm{MGD}$ or $32.0 \mathrm{~m}^{3} \mathrm{~s}^{-1}$ ) overnight. Thus the DI-1205 samples (GRAB and 
COMP) had significantly lower chloride, chemical oxygen demand (COD), and total suspended solids (TSS) than other samples. A summary of the characteristics of DITP effluent for each sample, including flow, chloride ion concentration, $\mathrm{pH}$, and a variety of other chemical parameters was provided by the Massachusetts Water Resources Authority and can be found in Table SI-1.

\subsubsection{Materials and chemicals}

Estrogen standards were acquired from the following sources: Sigma-Aldrich (Saint Louis, MO, USA): estrone (E1), 99 \%; 17ß-estradiol (E2), $\geq 98$ \%; estriol (E3), 98 $\%$; $17 \alpha$-ethynylestradiol (EE2), $99 \%$; estrone-3-sulfate (E1-3S), $99.5 \%$; 17ß-estradiol3-sulfate (E2-3S), $99.5 \%$; estriol-3- $\beta$-D-glucuronide (E3-3G), $99 \%$; $17 \beta$-estradiol-3- $\beta$ D-glucuronide (E2-3G), 99 \%. Steraloids (Newport, RI, USA): estrone-3-glucuronide (E1-3G); 17 $\alpha$-ethynylestradiol-3-glucuronide (EE2-3G); $17 \alpha$-ethynylestradiol-3-sulfate (EE2-3S); 2-bromo-17 $\beta$-estradiol (monoBrE2); 2,4-dibromo-17 $\beta$-estradiol (diBrE2); 2bromo-17 $\alpha$-ethynylestradiol (monoBrEE2); 2,4-dibromo-17 $\alpha$-ethynylestradiol (diBrEE2). The purity of these estrogens was confirmed by melting point and thin layer chromatography at Steraloids. Cambridge Isotope Laboratories (Andover, MA, USA): 2,4,16,16- $d 4$-estrone (E1- $d 4$ ), $\geq 98 \%$; 2,4,16,16- $d 4$-estrone-3-sulfate (E1-3S- $d 4$ ), $\geq 98$ $\%$. Dr. Hiroshi Matsufuji (Nihon University, Kanagawa, Japan): 4-chloro-estrone (monoClE1); 2,4-dichloro-estrone (diClE1); 4-chloro-17ß-estradiol (monoClE2); 2,4dichloro-17 $\beta$-estradiol (diClE2); 4-chloro-estriol (monoClE3); 2,4-dichloro-estriol (diClE3); 4-chloro-17 $\alpha$-ethynylestradiol (monoClEE2); 2,4-dichloro-17 $\alpha$ ethynylestradiol (diClEE2). These chlorinated estrogen standards were synthesized and purified according to the procedures in Moriyama et al. (2004), and the identity and purity of chlorinated estrogens was confirmed by ${ }^{13} \mathrm{C}$ NMR in 2004 and by liquid chromatography mass spectrometry (LC-MS; full scan $m / z 170-1000$ ) in 2011. All estrogen standards and stock solutions were stored at $-20^{\circ} \mathrm{C}$.

The solvents used to condition solid phase extraction (SPE) disks and elute estrogens were isopropyl alcohol (Mallinckrodt AR), acetone (JTBaker Ultra Resi- 
Analyzed), and methanol (MeOH; JTBaker Ultra Resi-Analyzed). High purity, deionized, low-carbon laboratory water (Aquafine Corp.; $\mathrm{pH}$ 6.1) was used throughout this study. Artificial seawater ( $\mathrm{pH}$ 7.9) was made according to a standard recipe (Eaton, Franson et al. 2005).

\subsubsection{Extraction method}

Wastewater effluent samples of $200 \mathrm{~mL}$ were collected in pre-baked $\left(450{ }^{\circ} \mathrm{C} ; 5 \mathrm{~h}\right)$ amber round glass bottles with Teflon-lined caps (Figure 1). Surrogate internal standards (SIS; $0.75 \mathrm{ng} \mu \mathrm{L}^{-1}$; E1-d4 and E1-3S-d4) were added in $2.4 \mu \mathrm{L}$ of MeOH immediately to samples using a calibrated Eppendorf pipet, and bottles were capped and swirled to mix. Samples remained on ice until solid phase extraction in the laboratory $(\sim 2-3$ hours later). Samples used for the matrix-matched calibration curves were spiked with $2.7 \mu \mathrm{L}$ of a $\mathrm{MeOH}$ solution containing a mixture of 23 estrogens, prepared at 9 concentration levels, from $0.0037 \mathrm{ng} \mu \mathrm{L}^{-1}$ (STD1) to $37 \mathrm{ng} \mu \mathrm{L}^{-1}$ (STD9).

Solid phase extraction disks (Empore SDB-XC (cross-linked styrene divinylbenzene on Teflon support); 47mm; 3M, St. Paul, MN) were placed in one of five glass filtration units on a 5-port vacuum manifold and conditioned with $10 \mathrm{~mL}$ acetone, $10 \mathrm{~mL}$ isopropyl alcohol, and $10 \mathrm{~mL} \mathrm{MeOH}$, followed by $50 \mathrm{~mL}$ water. SPE disks were wet-loaded with sample, and sample bottles were rinsed with $2 \times 5 \mathrm{~mL}$ clean water, which was then transferred to the filtration reservoir. After loading (200 mL samples), the SPE disks were dried for 20 min by continuing to pull a vacuum, and then disks were eluted with $\mathrm{MeOH}(2 \times 10 \mathrm{~mL})$ into amber glass vials. The extract was blown down to $1 \mathrm{~mL}$ under $\mathrm{N}_{2}$ in a $40{ }^{\circ} \mathrm{C}$ water bath, reduced to dryness by vacuum centrifugation, and reconstituted in $30 \mu \mathrm{L} \mathrm{MeOH}$. This solution was mixed by vortexing before addition of water $(70 \mu \mathrm{L})$, transfer to a pre-baked $\left(450^{\circ} \mathrm{C} ; 5 \mathrm{~h}\right)$ vial with insert, and storage at $-20^{\circ} \mathrm{C}$ until analysis.

Extraction efficiency and SPE disk break-through experiments were conducted with water containing representative estrogens (E2-3S, E2, monoBrE2) spiked at concentrations of $1-40 \mu \mathrm{g} \mathrm{L}^{-1}$. Measurements were made by liquid chromatography 
coupled to UV-visible diode array detection (LC/DAD). Estrogens were separated on a Thermo® Hypersil GOLD aQ ${ }^{\mathrm{TM}}$ column $(250$ x $4.6 \mathrm{~mm}$ i.d., $5 \mu \mathrm{m}$ particle size $)$ by isocratic elution using $70 \% \mathrm{MeOH}$ in water. The LC/DAD instrument (Hewlett Packard 1050 series; Palo Alto, CA, USA) monitored three wavelengths corresponding to the secondary absorbance maximum of each estrogen (E2-3S: $270 \mathrm{~nm}, \mathrm{E} 2: 280 \mathrm{~nm}$, and monoBrE2: $285 \mathrm{~nm})$ and collected full UV-visible $(190-350 \mathrm{~nm})$ spectra at the base and apex of each peak.

\subsubsection{UHPLC-MS/MS analytical method}

Standards, quality control (QC) samples, and unknown extracts were analyzed using an ultra high performance liquid chromatograph (UHPLC; Thermo ${ }^{\circledR}$ PAL autosampler and Accela pump) coupled via electrospray ionization (negative ion mode) to a triple-quadrupole mass spectrometer (MS/MS; Thermo ${ }^{\circledR}$ TSQ Vantage $\left.{ }^{\mathrm{TM}}\right)$ at the Woods Hole Oceanographic Institution FT-MS Facility. Selected reaction monitoring (SRM) conditions (s-lens, collision energy) were optimized individually for each estrogen (Table SI-2). Quantitation and confirmation SRM transitions (50 total; Table SI2) were chosen to maximize analyte signals and minimize matrix interferences. Mass calibration was performed using polytyrosine-1,3,6 (CS Bio, Menlo Park, CA, USA) infused directly into the mass spectrometer.

Separation of estrogens was achieved on a Thermo ${ }^{\circledR}$ Hypersil GOLD aQ ${ }^{\mathrm{TM}}$ column (100 x $2.1 \mathrm{~mm}$ i.d., $1.9 \mu \mathrm{m}$ particle size $)$ with an Ultrashield UHPLC pre-column filter. The flow path length was minimized and made of stainless steel tubing where possible. The column and pre-column filter were insulated $\left(30^{\circ} \mathrm{C}\right)$ within a Hot Pocket column heater (Thermo Scientific; Waltham, MA, USA). The mobile phase consisted of (A) water (amended with $1 \mathrm{mM}$ ammonium fluoride) and (B) methanol; the $\mathrm{pH}$ of the starting mobile phase $(30 \% \mathrm{MeOH})$ was 6.5 . We used a linear $7 \% \mathrm{~min}^{-1}$ gradient over $10 \min (30 \%-100 \% \mathrm{MeOH})$ with a short $0.7 \mathrm{~min}$ hold at $30 \% \mathrm{MeOH}$, a $3.3 \mathrm{~min}$ hold at $100 \% \mathrm{MeOH}$, and a $6.5 \mathrm{~min}$ equilibration $(30 \% \mathrm{MeOH})$ period before the next injection. LC flow rates were $375 \mu \mathrm{L} \mathrm{min}^{-1}$ during the gradient and $450 \mu \mathrm{L} \mathrm{min}^{-1}$ during 
the $\mathrm{MeOH}$ wash and equilibration periods. The auto-injector utilized a low-carry-over dynamic load and wash method with separate organic (50:50 acetonitrile/MeOH) and aqueous (95:5 water/acetonitrile) wash steps. Injection volumes were $10 \mu \mathrm{L}$. The analytical method readily separated and detected all the target estrogens for the DITP wastewater effluent extract spiked at $\sim 100 \mathrm{ng} \mathrm{mL}^{-1}$ (Figure SI-1).

Estrogen concentrations were determined by the method of standard addition (Boyd, Basic et al. 2008) for those samples collected on 14 March ("DI-1203”). Matrixmatched calibration curves $\left(0.1-1000 \mathrm{ng} \mathrm{mL}^{-1}, \mathrm{R}^{2}>0.997\right)$ were normalized with surrogate internal standards and used to determine estrogen concentrations in wastewater effluent collected on all other sampling days.

\subsubsection{Confirming analyte identity}

The identity of each analyte peak was confirmed by assuring that the peak met the following criteria compared to an appropriate authentic standard: 1) quantitation and confirmation SRM peak ratio within $20 \%$ (Li, Campbell et al. 1996) or $50 \%$ for lowabundance samples (Commission 2002); 2) retention time within $2 \%$ (Li, Campbell et al. 1996).

\subsubsection{Correcting for sample processing losses and matrix effects}

In addition to matrix effects and extraction losses, it is possible that glucuronide conjugates could be degraded by $\beta$-glucuronidase between wastewater collection and extraction (Ternes, Kreckel et al. 1999; D'Ascenzo, Di Corcia et al. 2003; Reddy, Iden et al. 2005). Similarly, other estrogens would be vulnerable to transformations prior to extraction. Thus, it was desirable to spike all samples with the deuterated surrogate internal standards as soon as possible to correct for the combined effects of sample transport, extraction, ionization suppression/enhancement, and instrumental variability. Matrix effect and percent recovery data were not used to correct effluent concentrations. Rather, matrix-matched calibration curves were used (Kang, Hick et al. 2007; Boyd, 
Basic et al. 2008), and instrumental response was normalized to the appropriate SIS (E1$3 \mathrm{~S}-d 4$ for all conjugates; E1- $d 4$ for all free and halogenated forms).

\subsection{Results and Discussion}

\subsubsection{Mobile phase composition and column temperature}

In designing a method able to detect sub-ng $\mathrm{L}^{-1}$ concentrations of a wide range of estrogens in wastewater, it is essential to maximize analytical signals by optimizing mobile phase conditions and instrumental settings. In particular, we sought a way to increase signal intensity of free and halogenated estrogens $\left(\mathrm{pK}_{\mathrm{a}} \sim 7-11\right.$; (Hilal, Karickhoff et al. 2003)), which have lower ionization efficiencies than conjugated estrogens. Recent work has shown that fluoride ions promote gas-phase deprotonation of neutral steroids (Rannulu and Cole 2012), and ammonium fluoride $\left(\mathrm{NH}_{4} \mathrm{~F}\right)$ can be used as a mobile phase additive to enhance signal intensity for a variety of metabolites (Yanes, Tautenhahn et al. 2011). In our own tests, we found that the addition of ammonium fluoride (1 mM per Yanes et al. (2011)) to the aqueous mobile phase (water) increased the response factor of free and brominated estrogens by factors of 20 and 2.6, respectively (Figure 2). Response factors for conjugated estrogens were the same or slightly lower under these conditions, yet the instrument was inherently more sensitive to these forms of estrogens since they are mostly ionized at environmental and mobile phase $\mathrm{pH}$. Using acetonitrile ( $\mathrm{ACN}$ ) in place of $\mathrm{MeOH}$ as the organic mobile phase has been shown to increase ionization efficiency for estrogens during negative ionization mode electrospray (Benijts, Dams et al. 2002; Reddy, Iden et al. 2005). Therefore, we tested $\mathrm{ACN}$, both alone and with ammonium fluoride $(1 \mathrm{mM})$, but found minimal differences in chromatographic separation and signal intensity compared to $\mathrm{MeOH}$ (Figure 2).

Since analyte retention times initially varied by $5-10 \%$ due to laboratory temperature fluctuations over the course of long sequence runs, we installed a column heating jacket and tested a range of column temperatures $\left(25-40{ }^{\circ} \mathrm{C}\right)$. We found that 30 ${ }^{\circ} \mathrm{C}$ was the best compromise between retention time stability and ion signal strength for our suite of estrogens. 


\subsubsection{SRM channel cross-over}

We investigated the extent to which each authentic estrogen standard contributed to signal response in all other monitored SRM channels. So-called SRM channel "crossover"'(or signal bleed) can result from impurities in authentic standards, isotopic artifacts, or instrumental settings (e.g., $\mathrm{m} / \mathrm{z}$ resolution). We quantified SRM channel cross-over by injecting individual estrogen standards at equal concentrations, monitoring all SRM transitions, and comparing peak areas. These tests demonstrated that for any single SRM channel, the target estrogen contribution was typically 2000x larger than the contribution from any non-target estrogen and $75 \mathrm{x}$ larger than the combined contribution from all nontarget estrogens. Contributions from deuterated surrogate internal standards were negligible, except for a $1.6 \%$ contribution from E1-3S- $d 4$ to the SRM channel for E2-3S.

\subsubsection{Gradient optimization}

Several mobile phase gradients were tested, including simple gradients of varied steepness $\left(2-9 \% \mathrm{~min}^{-1}\right)$, and complex gradients containing multiple isocratic holds. The chosen gradient $\left(7 \% \mathrm{~min}^{-1}\right)$ had the advantages of (1) greatly reducing analysis time without sacrificing separation or sensitivity of other estrogens, and (2) separating EE2 from a large co-eluting wastewater matrix interference. It is possible that this matrix interference, which is present in both of the SRM channels used to monitor EE2 and elutes very close to EE2, could lead to overestimates of EE2 in similar wastewater matrices. This is remarkable given the expected high degree of selectivity of UHPLCMS/MS instruments.

\subsubsection{Matrix effects}

We expected to observe significant and variable matrix effects due to the chemical complexity of wastewater effluent, the diverse suite of target analytes, and a relatively non-selective solid phase extraction protocol without additional clean-up steps. The International Union of Pure and Applied Chemistry (IUPAC) defines a matrix effect 
as "the combined effect of all components of the sample other than the analyte on the measurement of the quantity" (IUPAC 2012). This broad definition would include matrix effects on sample extraction efficiency as well as instrumental response. However, in this study, we follow the convention described by Matuszewski et al. (2003), where matrix effects refer only to the instrumental response (e.g., ion suppression or enhancement), while percent recovery (or recovery efficiency) is used to characterize the extraction procedure (see below).

Since it was not practical to obtain or produce a wastewater matrix that was free of estrogens, we calculated matrix effects based on the ratio of the response factors (calibration curve slope) for estrogens spiked into wastewater matrix extracts and neat solvent (Kang, Hick et al. 2007). The matrix effects observed in this study (see Table 1) are consistent with ion suppression reported in other studies of estrogens in wastewater matrices (Kang, Hick et al. 2007; Backe and Field 2012). Notably, glucuronide conjugates exhibit severe ion suppression, which is likely the result of high concentrations of co-eluting polar interferences near the solvent front.

\subsubsection{Wastewater recovery (UHPLC-MS/MS)}

The range of estrogen percent recovery from spiked $\left(\sim 33 \mathrm{ng} \mathrm{L}^{-1}\right)$ wastewater samples was $68-136 \%$ with the exception of the glucuronide conjugates, which varied between $12-25 \%$ (Table 1). In low-carbon deionized water and artificial seawater, E3$3 \mathrm{G}\left(\log \mathrm{K}_{\mathrm{OW}}=0.56\right)$ was poorly recovered, yet the other three glucuronides $\left(\log \mathrm{K}_{\mathrm{OW}}=\right.$ $1.58-2.27)$ were recovered at $89-107 \%$. The halogenated estrogens generally had lower recoveries in low-carbon deionized water and artificial seawater compared to wastewater. In artificial seawater, the glucuronides and free estrogens also exhibited significantly higher percent recoveries. This may be related to salt-induced ionization enhancement in the LC source or enhanced sorption onto the SPE disks due to complexation with cations in seawater. 


\subsubsection{SPE disk break-through (LC/DAD)}

We investigated the influence of disk type (Empore SDB-XC and carbon; 3M, St. Paul, MN), extraction flow rate $\left(25-200 \mathrm{~mL} \mathrm{~min}^{-1}\right)$, sample volume $(0.85-8 \mathrm{~L})$, ionic strength ( $0-0.7 \mathrm{M}$ as $\mathrm{NaCl}, \mathrm{CaCl}_{2}$, and $\mathrm{MgCl}_{2}$ ), $\mathrm{pH}$ (5.76 - 11.50), and elution solvents (methanol, 80:20 dichloromethane (DCM)/MeOH, and 5mM tetramethylammonium chloride (TMACl) in 80:20 DCM/MeOH) on estrogen extraction efficiency (see Appendix B). Representative estrogens of each class (conjugated: E2-3S, free: E2, and halogenated: monoBrE2) were spiked into water, extracted with SPE disks, eluted, and analyzed by $\mathrm{LC} / \mathrm{DAD}$. These tests demonstrated satisfactory recoveries of all three classes of estrogens over a wide range of salinity, $\mathrm{pH}$, flow, and water volume (Appendix B). Disk material seemed to be the determining factor for efficient extraction. On SDB$\mathrm{XC}$ disks, E2 and monoBrE2 were extracted more efficiently $(80-120 \%)$ than the more polar E2-3S (60 - $90 \%$ ). While carbon disks eliminated problems related to breakthrough, the recovery of all estrogens (E2-3S, E2, and monoBrE2) from carbon was low $(30-60 \%)$ due to inefficient removal of estrogens from the disk despite the use of strong eluting solvents (e.g., 5mM TMACl in 80:20 DCM/MeOH; (Gentili, Perret et al. 2002)), long soak times, and backflush elution. Given this limitation, SDB-XC disks were chosen for this study.

\subsubsection{Method limit thresholds}

The critical level $\left(\mathrm{L}_{\mathrm{C}}\right)$, detection limit $\left(\mathrm{L}_{\mathrm{D}}\right)$, and quantification limit $\left(\mathrm{L}_{\mathrm{Q}}\right)($ Currie 1995) were calculated for each analyte (Table 1) using prediction intervals at the 95\% confidence level and exponential functions to model the fact that the variance of instrumental response increases with concentration (i.e., heteroscedasticity) (see Gibbons, Coleman et al. 1997) following Zorn et al. (1999) (Figure SI-2). We chose not to use the standard EPA method detection limit (MDL) definition because it is based on variance at a single concentration, does not consider data heteroscedasticity, and requires that analytes are not present in the blank matrix. $\mathrm{L}_{\mathrm{C}}, \mathrm{L}_{\mathrm{D}}$, and $\mathrm{L}_{\mathrm{Q}}$ are defined as follows (Currie 1995): 
$\mathrm{L}_{\mathrm{C}}$ is the level at which the probability of a false negative is $5 \%$ (for $\alpha=0.05$ ).

$L_{D}$ is the level at which the probability of a false positive is $5 \%$ (for $\beta=0.05$ ).

$\mathrm{L}_{\mathrm{Q}}$ is the level corresponding to 10 times the standard deviation at $\mathrm{L}_{\mathrm{C}}$.

The $L_{D}$ values for the conjugated estrogens in this study (see Table 1) are $\sim 2-10 \mathrm{x}$ higher than MDLs (based on $\mathrm{S} / \mathrm{N}=3$ ) reported by Reddy et al. (2005) and Koh et al. (2007), which is not surprising given that our method does not employ the same extensive clean up steps. Yet, the $\mathrm{L}_{\mathrm{D}}$ values reported here are in line with other studies reporting limits of detection (LOD) for estrogens in WWTP effluent (Gentili, Perret et al. 2002; D'Ascenzo, Di Corcia et al. 2003; Gomes, Birkett et al. 2005; Zuehlke, Duennbier et al. 2005; Schlusener and Bester 2008; Sun, Yong et al. 2009).

Our ability to target a wide range of estrogens with minimal sample preparation steps comes at the cost of relatively high method limit thresholds for some analytes. For example, the $\mathrm{L}_{\mathrm{Q}}$ thresholds for diClE3 $\left(27 \mathrm{ng} \mathrm{L}^{-1}\right)$ and diBrEE2 $\left(18 \mathrm{ng} \mathrm{L}^{-1}\right)$ are higher than one would expect for a typical effluent. The relatively high $\mathrm{L}_{\mathrm{Q}}$ of some other analytes (e.g., E1, E2, monoBrE2, and diClE2) is a function of the greater uncertainty in extrapolating experimental variance from a high ambient concentration to zero concentration (Zorn, Gibbons et al. 1999) (see Figure SI-2).

\subsubsection{Estrogen concentration and potency in treated wastewater effluent}

We found a wide range of estrogens in DITP effluent at all sampling times (Figure 3; Table SI-3). Free estrogen concentrations were consistent with other wastewater effluents (Gentili, Perret et al. 2002; D'Ascenzo, Di Corcia et al. 2003; Lagana, Bacaloni et al. 2004; Zuehlke, Duennbier et al. 2005; Nakamura, Kuruto-Niwa et al. 2007; Lien, Chen et al. 2009), but we found generally lower concentrations of sulfate conjugates than expected based on previous studies (Koh, Chiu et al. 2007; Schlusener and Bester 2008; Gomes, Scrimshaw et al. 2009). In contrast, halogenated forms, especially monoBrE2 and diClE2, were present at unexpectedly high concentrations - on par with, or greater than, free forms. Moreover, this trend was consistent across a range of sampling times and DITP conditions. 
Estrogen concentrations for each grab sample (GRAB) and its corresponding 24hour composite sample (COMP) were remarkably similar for many analytes. Exceptions include E1 and E2, which were consistently higher in grab samples, and monoBrE2, which was always higher in composite samples. These observations could be explained by free estrogen degradation and continued bromination reactions during composite sample holding times.

Had we focused only on free estrogens, we would have missed $60-70 \%$ of the total estrogen load in DITP effluent on a molar basis. In fact, we find that over half of all measured steroidal estrogens were present in the halogenated form. This finding likely applies to most wastewater systems that contain bromide ion and rely on chlorine for disinfection, and should help in reevaluating estrogen fate during transport through sewers and wastewater treatment plants. The prevalence of halogenated forms observed here also warrants closer examination of whether these more hydrophobic forms may pose a risk to organisms via bioaccumulation and increased exposure in sewage-impacted waters.

Studies have found that halogenated estrogens typically have lower estrogenic potency than free forms as measured by estrogen receptor binding affinity, YES assay, and E-screen tests (Lee, Escher et al. 2008; Liu, Kanjo et al. 2009). Yet, it is not clear that these tests adequately control for potency underestimation biases due to sorption of hydrophobic estrogens onto test materials (see Appendix C). And, while steric hindrance between halogen atoms on estrogen's aromatic ring and the estrogen receptor would be expected to reduce binding strength, electron-withdrawing properties of halogen atoms might increase binding strength by increasing the H-bond donation capacity of the phenolic OH group (Anstead, Carlson et al. 1997; Fang, Tong et al. 2001).

If we combine available empirical potency data for estrogens (Lee, Escher et al. 2008; Liu, Kanjo et al. 2009) with measured concentrations, we find that the total normalized concentration of estrogens in Deer Island effluent is $14-22 \mathrm{ng}$ E2 equivalents $\mathrm{L}^{-1}$, as measured by ER binding, YES, and E-screen. To this total, monohalo 
forms (monoBrE2 and monoClEE2) contribute about $10 \%$, while free forms (especially E1, E2, and EE2) make up the remainder.

\subsubsection{Saltwater intrusion and estrogen halogenation}

DITP monitors daily chloride ion concentration for a variety of purposes including evaluating saltwater intrusion into the system. For our sampling dates, chloride ion concentrations ranged between $316-725 \mathrm{mg} \mathrm{L}^{-1}$ in the influent and $359-548 \mathrm{mg} \mathrm{L}^{-1}$ in the effluent (pers comm, Lisa Wong, MWRA, August 30, 2012). If seawater contains $\sim 19500 \mathrm{mg} \mathrm{L}^{-1}$ chloride and source water to the plant (drinking water) contains $\sim 23 \mathrm{mg}$ $\mathrm{L}^{-1}$ chloride (pers comm, Andrea Rex, MWRA, June 3, 2011), a mass balance calculation suggests that influent contained $1.5-3.6 \%$ seawater on our sampling days. Seawater contribution to influent was highest during the DI-1205b sampling when diBrE2 and diClE2 were at their maximum (Figure 3). In fact, excluding the DI-1203 time point, diClE2 concentrations are positively correlated with influent seawater contribution $\left(\mathrm{R}^{2}=\right.$ $0.90)$. In contrast, monoBrE2 does not correlate $\left(R^{2}=0.04\right)$ with seawater contribution, perhaps because it is readily formed in the presence of hypobromite, even at low levels (Acero, Piriou et al. 2005).

Reddy et al. (2005) suggest that the loss of tritiated E2-3G in influent over $2 \mathrm{~h}$ period was due to conversion to free estrogens (E1 and E2). Others have also seen conversion of glucuronides to sulfates and free forms (D'Ascenzo, Di Corcia et al. 2003). We see the opposite trend - higher glucuronide concentrations, and considerably lower sulfate concentrations than previous studies have reported for secondary treated wastewater effluent (D'Ascenzo, Di Corcia et al. 2003; Reddy, Iden et al. 2005). It remains an open question whether conjugates might also undergo significant conversion to halogenated forms, especially in wastewater treated with hypochlorite.

\subsubsection{Halogenation kinetics}

In order to investigate the relative abundance of free and halogenated forms observed in DITP effluent, we constructed and tested a model of estrogen halogenation 
kinetics. The model includes the following suite of reactions as described in detail previously (Acero, Piriou et al. 2005): (1) acid-base equilibria of estrogen (phenol / phenolate), hypohalite ( $\left.\mathrm{HOX} / \mathrm{OX}^{-}\right)$, and ammonia $\left(\mathrm{NH}^{4+} / \mathrm{NH}_{3}\right)$ species; (2) reactions of hypohalite with ammonia and natural organic matter; (3) formation of hypobromite $\left(\mathrm{HOBr} / \mathrm{OBr}^{-}\right)$by reactions between hypochlorite $\left(\mathrm{HOCl} / \mathrm{OCl}^{-}\right)$and bromide ion $\left(\mathrm{Br}^{-}\right)$; and (4) estrogen chlorination and bromination. Since the slight structural differences between estrogen families (e.g., E1, E2, E3, and EE2) are positioned far away from the reactive phenolic A-ring, all estrogen halogenation rate constants were set equal to those determined for the EE2 family (Lee and Von Gunten 2009). The model was tested by confirming that outputs matched those of Acero (2005) when run under the same conditions and with the same rate constants.

We exercised the model with the E2 family of estrogens since this family exhibited the broadest range of observed halogenated forms in DITP. The average concentrations of E2, monoBrE2, diBrE2, and diClE2 in DITP effluent were 23, 96, 18, and $46 \mathrm{pM}$, respectively. Full scan spectral analysis (retention time, $\mathrm{m} / \mathrm{z}$, and characteristic isotopic pattern) indicated the presence of 2,4-bromo-chloro-17 $\beta$-estradiol (diBrClE2), but we lacked the appropriate standard for quantifying diBrClE2. Using realistic (or directly measured) conditions for the DITP disinfection basin, the model was unable to reproduce the observed relative abundances of all four species in the E2 family. In particular, it was not possible to simulate the relatively high diClE2 concentrations without severely affecting the relative abundances of E2, monoBrE2, and diBrE2 (e.g., Figure SI-3).

It is possible that estrogens are halogenated in toilets and sewers prior to arriving at the DITP since the Boston potable water supply arrives at homes with $\sim 1 \mathrm{mg} \mathrm{L}^{-1}$ free chlorine concentrations (MWRA 2012). To test the hypothesis that significant halogenation of estrogens could occur prior to the wastewater disinfection basin, we exercised the model using realistic (or directly measured) conditions for tap water and transport through sewers. While the model output was sensitive to initial conditions, in many cases it was able to simulate estrogen halogenation dominated by mono- and di- 
chloro estrogens. When the tap/sewer and disinfection basin models were run in series, we found it possible to exactly simulate the observed values in effluent, but only if we allowed for significant diClE2 inputs to DITP (Figure SI-4).

Despite the uncertainties inherent in these modeling efforts, our results are consistent with the observed relative abundance of the halogenated forms of E2, and point to the potential for measurable estrogen halogenation in toilets and during transport through sewers.

\subsubsection{Redefining removal}

This work demonstrates that halogenated estrogens can be an important component of wastewater effluent estrogen loads and should be considered in estrogen flux calculations. Our findings also support the idea that metrics of micropollutant "removal" depend strongly on our ability to identify, measure, and characterize the full suite of transformation by-products and metabolites produced during wastewater treatment (Stadler, Ernstoff et al. 2012). 


\section{Acknowledgments}

We are indebted to Lisa Wong, Andrea Rex, Mike Mickelson, and the staff at the Massachusetts Water Resources Authority for their generous assistance with collecting samples and data from Deer Island Treatment Plant. We also thank James Hunter, Anthony Carrasquillo, Sean Kessler, and Benjamin Scandella who helped design and debug the kinetic model described here, as well as David Sedlak for his thoughtful insights. This work was supported by the Martin Family Society of Fellows for Sustainability, the Ocean Ventures Fund and Coastal Ocean Institute at the Woods Hole Oceanographic Institution, MIT Sea Grant, and by a U.S. Environmental Protection Agency STAR graduate fellowship (FP-91713401). 
Figure 1. Procedural flow chart for extracting and quantifying estrogens in wastewater effluent.

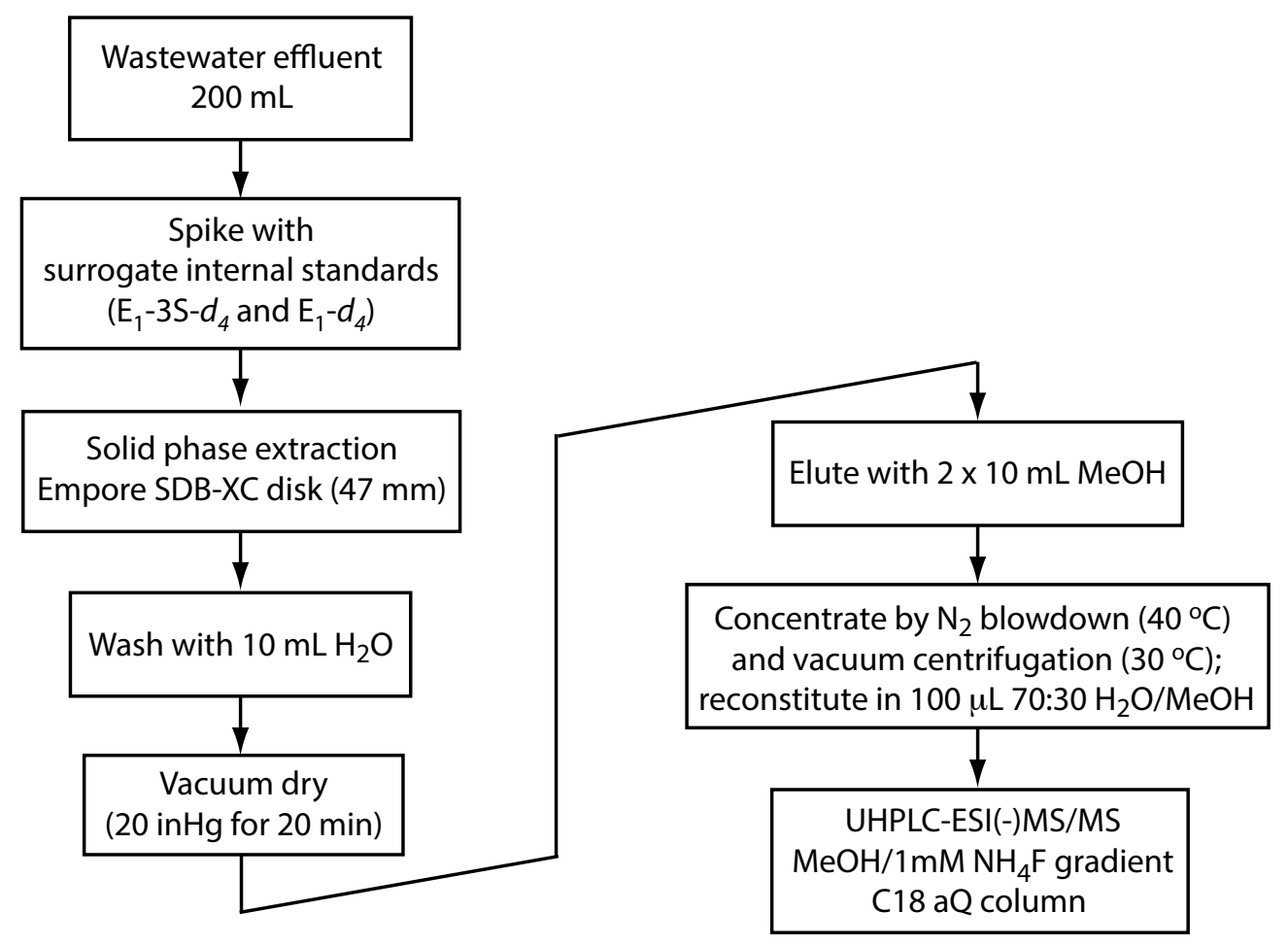


Figure 2. Ammonium fluoride increases the response factor of free and brominated estrogens in negative mode electrospray ionization using a neat standard solution at $1 \mu \mathrm{g}$ $\mathrm{mL}^{-1}$.

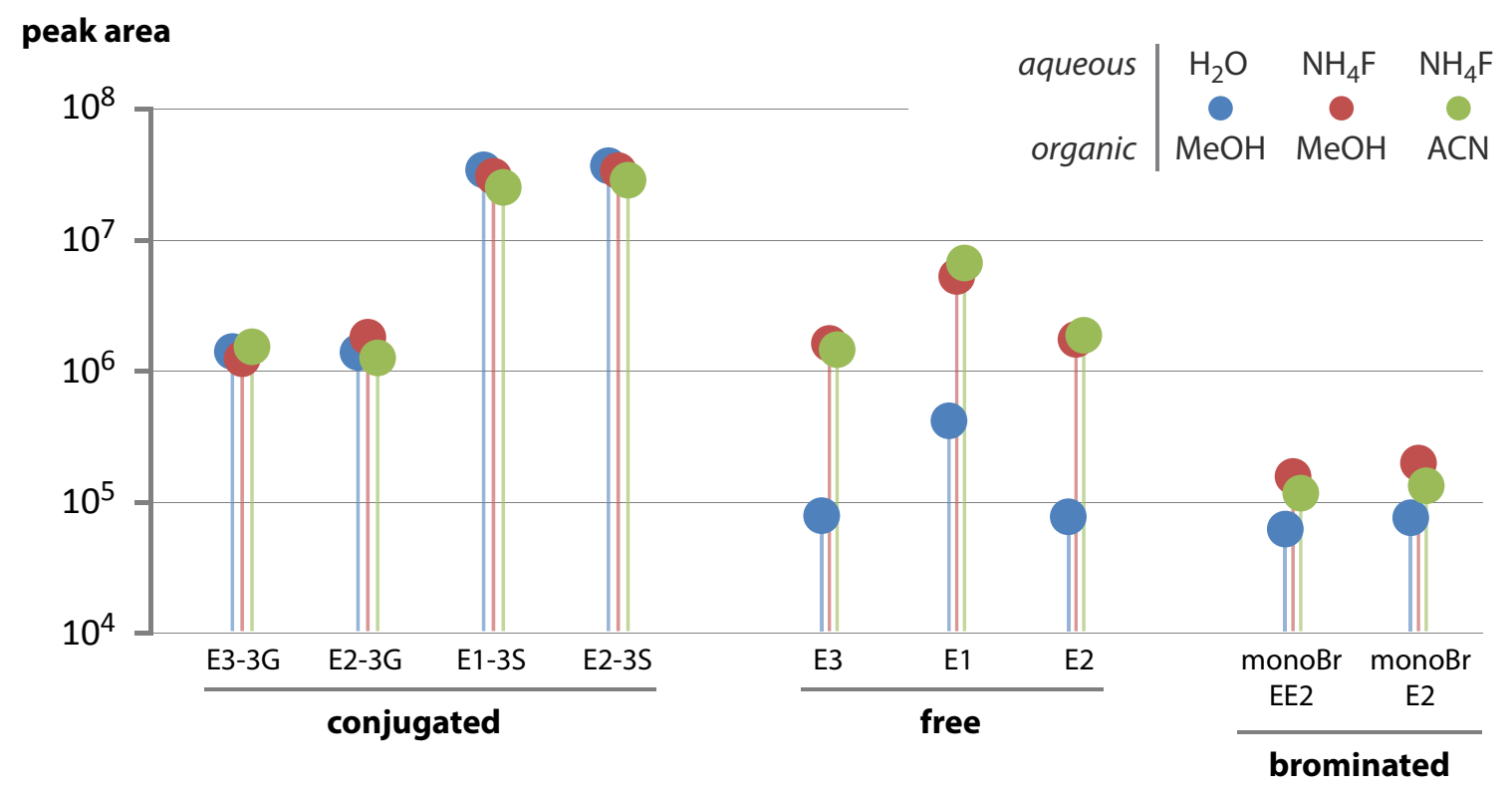


Figure 3. Estrogens in Deer Island Treatment Plant wastewater final effluent on four days in 2012 (14 March, 30 March, 16 May, and 31 May). Grab samples and 24-h composite samples are designated "GRAB" and "COMP," respectively, and estrogens are ordered by LC retention time. A single asterisk (*) denotes that no peaks were detected. A double asterisk $(* *)$ denotes anomalously high quantification limit thresholds $\left(\mathrm{L}_{\mathrm{C}}, \mathrm{L}_{\mathrm{D}}\right.$, and $\mathrm{L}_{\mathrm{Q}}$ ) due to co-eluting matrix interferences.

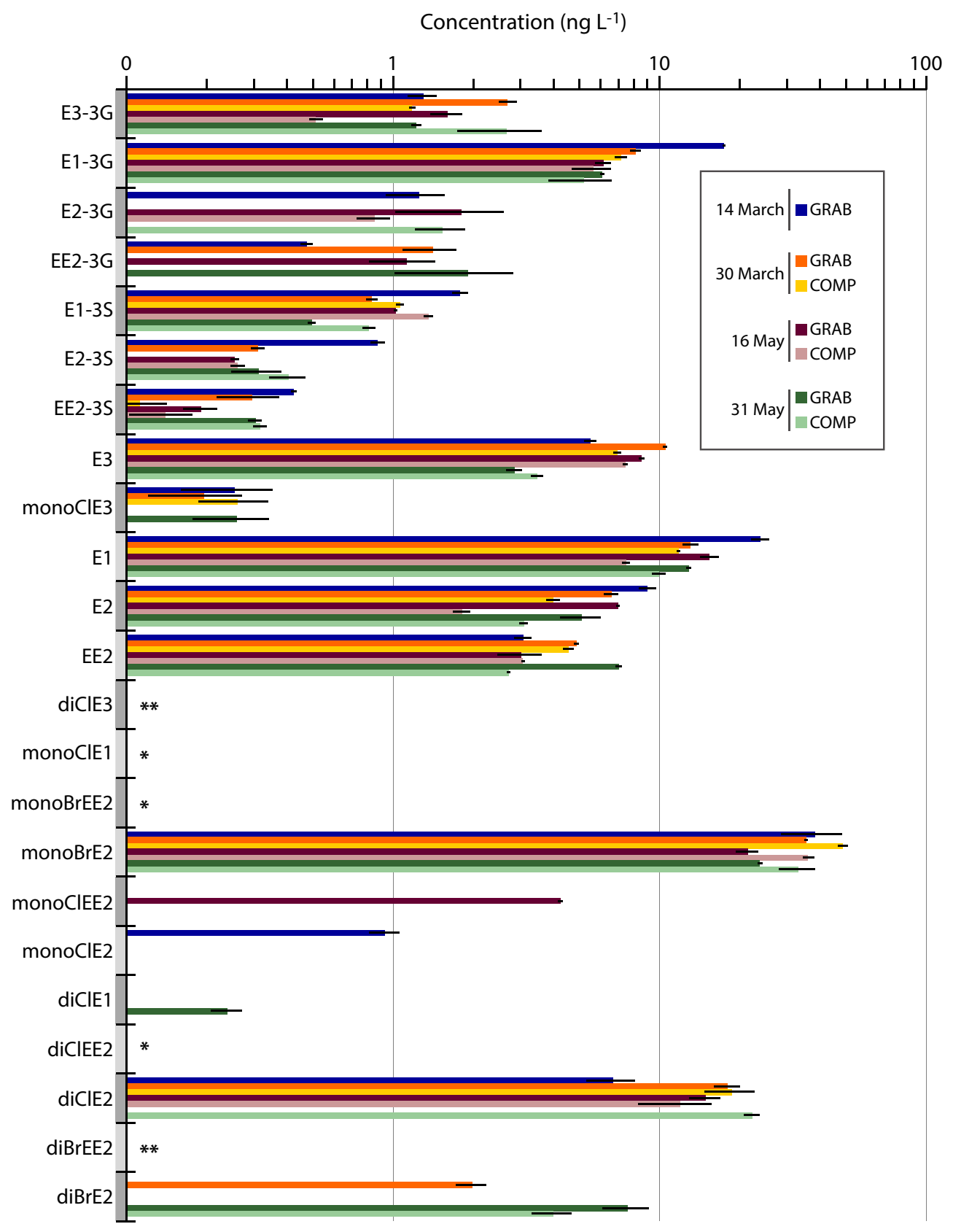


Figure SI-1. UHPLC-MS/MS selected reaction monitoring (SRM) chromatograms show the separation of 25 estrogens in a wastewater sample spiked at $100 \mathrm{ng} \mathrm{mL}^{-1}$. Retention times (minutes) are shown above each peak, while chemical structures and characteristic precursor/product ion transitions used for quantitation are shown beside each trace.
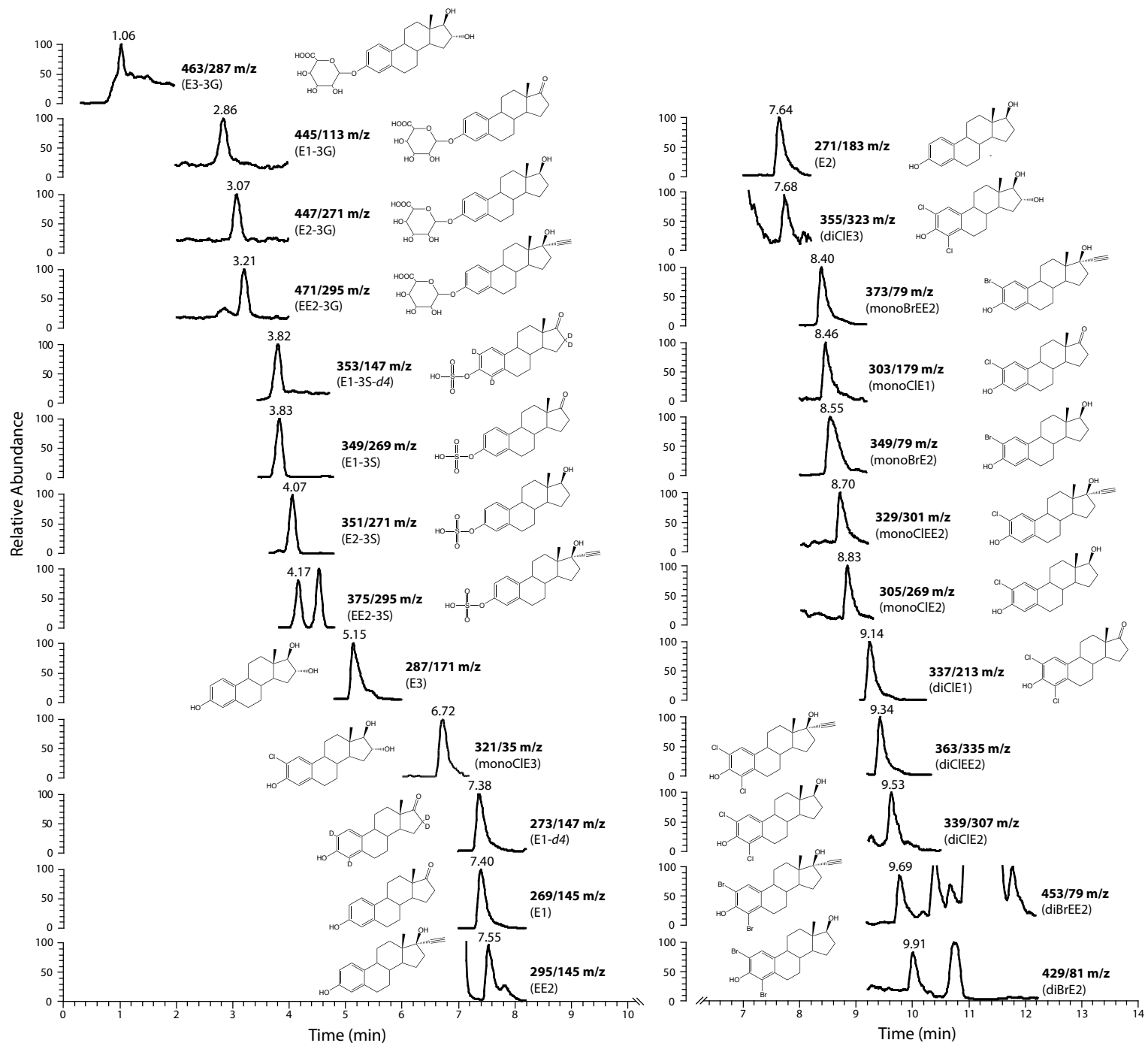
Figure SI-2. Determination of method limit thresholds $\left(\mathrm{L}_{\mathrm{C}}, \mathrm{L}_{\mathrm{D}}\right.$, and $\left.\mathrm{L}_{\mathrm{Q}}\right)$ following Zorn et al. (1999).

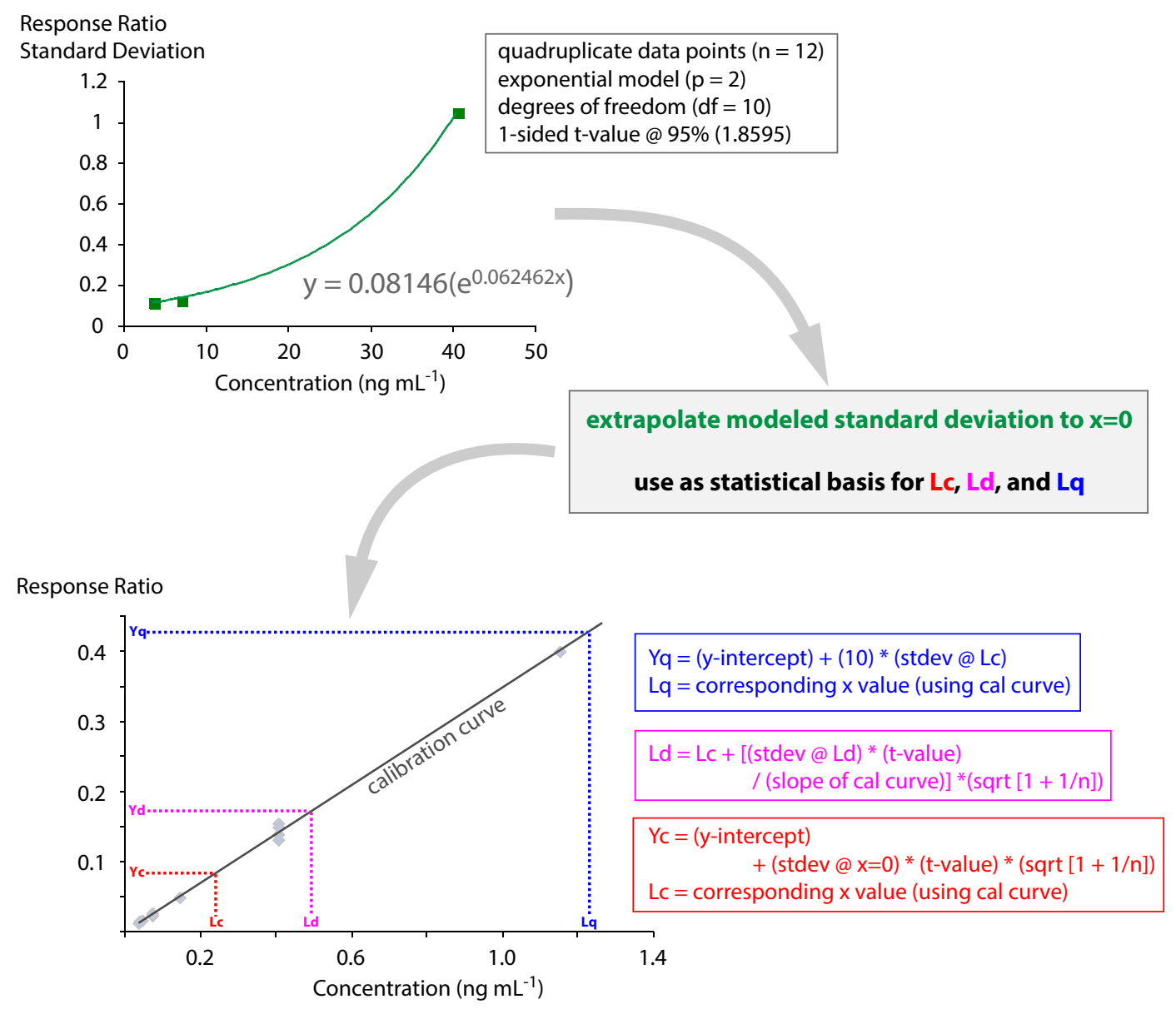


Figure SI-3. A kinetic model of E2 halogenation - seeded only with E2 (200 pM) - was unable to match the observed relative abundances of E2 and its halogenated derivatives in the DITP disinfection basin. In this example, the ratio of monoBrE2 to diBrE2 to diClE2 is correct at $\sim 20 \mathrm{~min}$, but E2 concentrations are far out of line with observations.

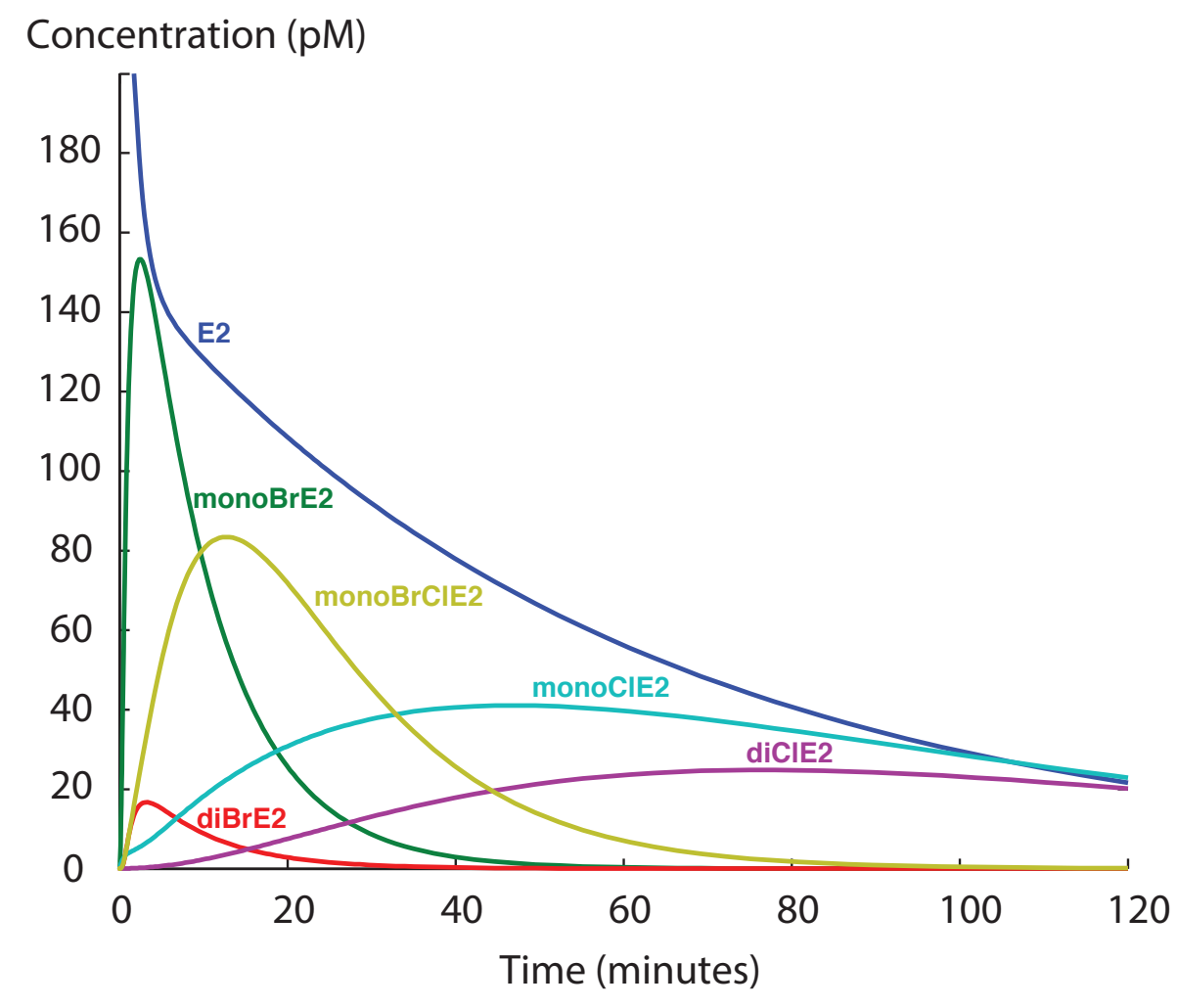


Figure SI-4. Measured E2 family concentrations (bars \pm 1 SD) in DITP effluent could only be fit by a kinetic model of estrogen halogenation (lines) that allowed for diClE2 production prior to the start of disinfection (at time zero). The plot shows modeled trends as treated effluent moves through the DITP disinfection basin (residence time $\sim 45 \mathrm{~min}$ ).

\section{Concentration (pM)}

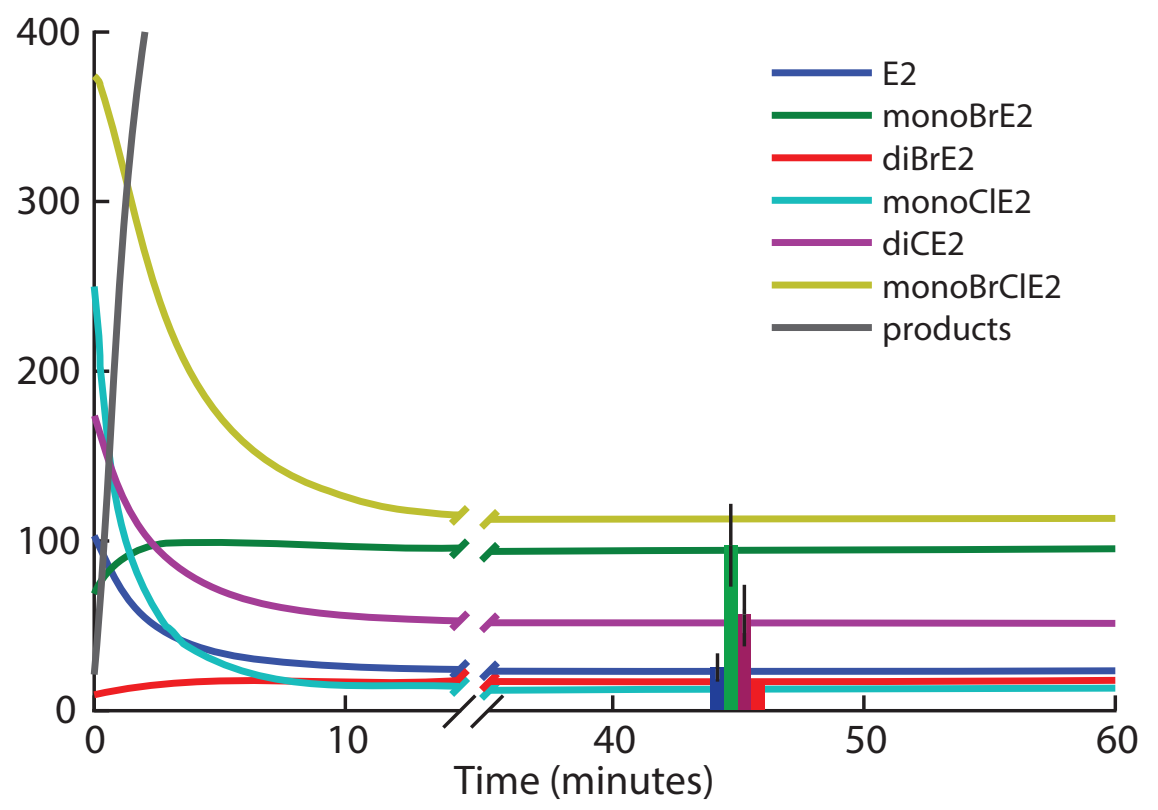


Table 1. Method performance overview

\begin{tabular}{|c|c|c|c|c|c|c|c|}
\hline \multirow[b]{2}{*}{ Analyte } & \multicolumn{3}{|c|}{$\begin{array}{l}\text { Method Limit Thresholds } \\
\text { (ng L }{ }^{-1} \text { effluent) }\end{array}$} & \multirow[b]{2}{*}{$\operatorname{ME}(\%)^{b}$} & \multicolumn{3}{|c|}{$\operatorname{RE}(\%)^{\mathrm{c}}$} \\
\hline & $\mathrm{L}_{\mathrm{C}}$ & $\mathrm{L}_{\mathrm{D}}$ & $\mathrm{L}_{\mathrm{Q}}$ & & WW & MQ & SW \\
\hline E3-3G & 0.46 & 1.00 & 2.55 & 2 & 12 & 17 & 55 \\
\hline E1-3G & 0.06 & 0.11 & 0.29 & 7 & 25 & 89 & 104 \\
\hline E2-3G & 0.28 & 0.57 & 1.48 & 6 & 14 & 91 & 105 \\
\hline EE2-3G & 0.11 & 0.23 & 0.60 & 9 & 20 & 91 & 107 \\
\hline E1-3S- $d 4$ & $\mathrm{n} / \mathrm{a}$ & $\mathrm{n} / \mathrm{a}$ & $\mathrm{n} / \mathrm{a}$ & 61 & 136 & 68 & 110 \\
\hline E1-3S & 0.23 & 0.47 & 1.21 & 74 & 104 & 106 & 109 \\
\hline E2-3S & 0.14 & 0.30 & 0.77 & 72 & 101 & 98 & 106 \\
\hline EE2-3S & 0.07 & 0.13 & 0.34 & 74 & 101 & 97 & 106 \\
\hline E3 & 0.06 & 0.13 & 0.34 & 123 & 129 & 118 & 198 \\
\hline monoClE3 & 0.09 & 0.18 & 0.45 & 33 & 85 & 74 & 113 \\
\hline $\mathrm{E} 1-d 4$ & $\mathrm{n} / \mathrm{a}$ & $\mathrm{n} / \mathrm{a}$ & $\mathrm{n} / \mathrm{a}$ & 99 & 117 & 76 & 86 \\
\hline E1 & 0.64 & 1.31 & 3.39 & 107 & 108 & 104 & 130 \\
\hline E2 & 0.55 & 1.13 & 2.92 & 67 & 114 & 111 & 156 \\
\hline EE2 & 0.26 & 0.54 & 1.39 & 39 & 120 & 75 & 82 \\
\hline diClE3 & 8.96 & 17.9 & 27.4 & 40 & 82 & 82 & 148 \\
\hline monoClE1 & 0.69 & 1.51 & 3.30 & 96 & 102 & 56 & 55 \\
\hline monoBrEE2 & 0.66 & 1.43 & 3.14 & 35 & 101 & 44 & 37 \\
\hline monoBrE2 & 1.48 & 3.19 & 8.18 & 64 & 111 & 64 & 65 \\
\hline monoClEE2 & 0.19 & 0.38 & 0.84 & 41 & 99 & 49 & 42 \\
\hline monoClE2 & 0.25 & 0.52 & 1.33 & 64 & 68 & 74 & 75 \\
\hline diClE1 & 0.17 & 0.34 & 0.88 & 102 & 95 & 66 & 68 \\
\hline diClEE2 & 0.38 & 0.81 & 2.09 & 67 & 89 & 55 & 55 \\
\hline diClE2 & 1.37 & 2.93 & 7.36 & 90 & 80 & 56 & 84 \\
\hline diBrEE2 & 5.98 & 12.0 & 18.3 & 60 & 82 & 38 & 36 \\
\hline diBrE2 & 1.06 & 2.31 & 5.79 & 85 & 69 & 62 & 66 \\
\hline $\mathrm{pH}$ & & & & & 6.6 & 6.1 & 7.9 \\
\hline
\end{tabular}

${ }^{a}$ Method Limit Thresholds $\left(\mathrm{L}_{\mathrm{C}}, \mathrm{L}_{\mathrm{D}}, \mathrm{L}_{\mathrm{Q}}\right)$ as calculated by a calibration method that models the standard deviation of the response ratio as a function of concentration (Zorn, Gibbons et al. 1999).

${ }^{\mathrm{b}} \mathrm{ME}(\%)=$ matrix effect as determined by dividing the analyte response factor (calibration line slope) in wastewater by the corresponding response factor in neat solvent (Matuszewski, Constanzer et al. 2003; Kang, Hick et al. 2007). The average relative standard deviation of calculated matrix effects is $5 \%$.

${ }^{\mathrm{c}} \mathrm{RE}(\%)=$ percent recovery from wastewater effluent (WW), artificial seawater (SW), and low-carbon deionized water (MQ) per Matuszewski et al (2003). This definition of RE, therefore, reflects only sample handling and extraction steps. Peak areas for this set of calculations are not normalized to SIS peak area. Since SW recoveries are referenced to neat solvent, the effect of ionic strength on ionization efficiency in the mass spectrometer is unknown, but could explain why this set displays a wider range of recoveries.

$\mathrm{n} / \mathrm{a}=$ not applicable 


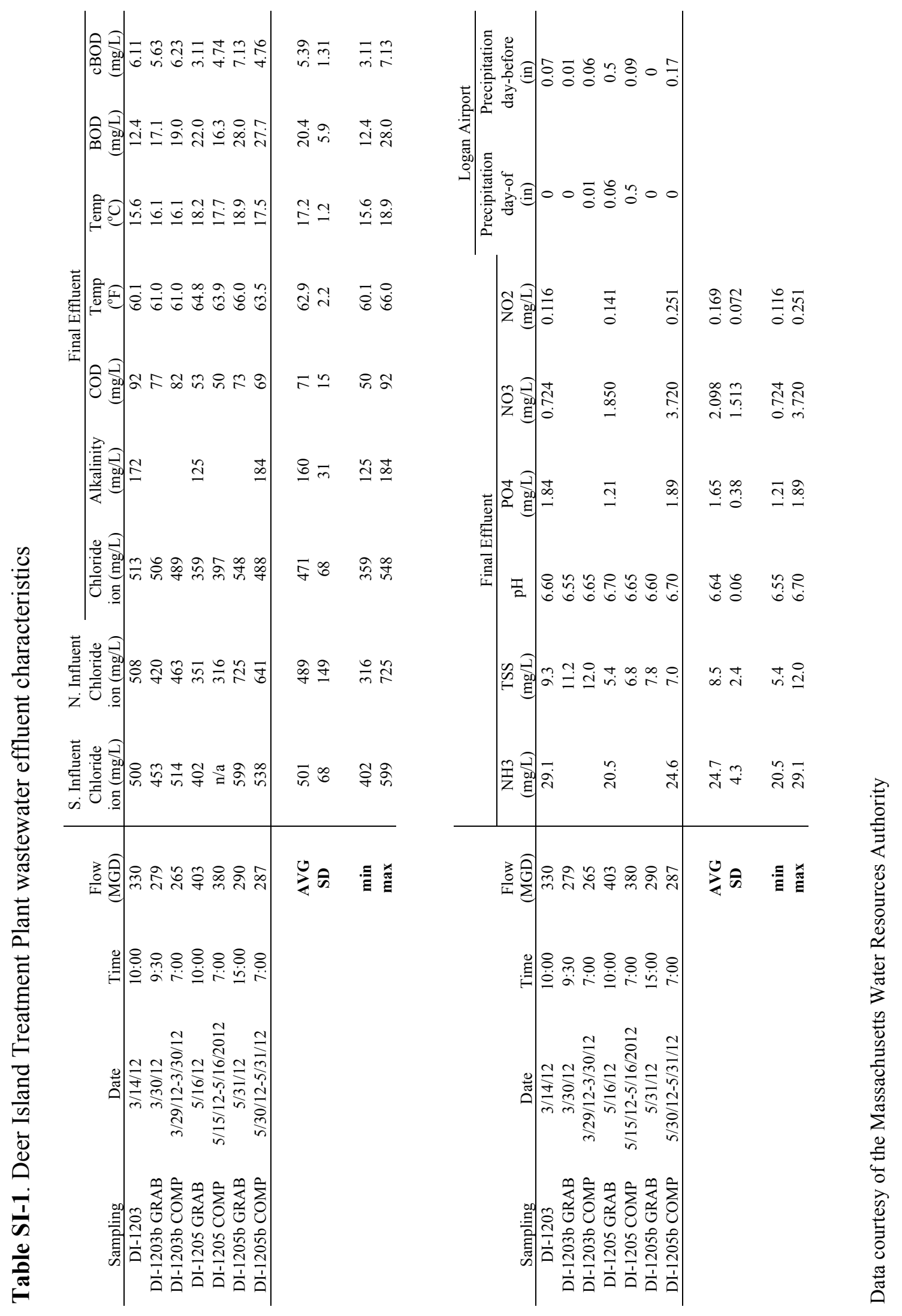


Table SI-2. UHPLC-MS/MS analytical method parameters

\begin{tabular}{|c|c|c|c|c|c|c|c|}
\hline Analyte & $\begin{array}{c}\mathrm{RT} \\
(\mathrm{min})\end{array}$ & $\begin{array}{c}\text { precursor } \\
(m / z)\end{array}$ & $\begin{array}{c}\text { product } \\
(m / z)\end{array}$ & $\begin{array}{c}Q= \\
\text { quant ion }\end{array}$ & $\begin{array}{c}\text { SRM } \\
\text { collision E }\end{array}$ & S-lens & polarity \\
\hline \multirow[t]{2}{*}{ E3-3G } & 1.06 & 463 & 113 & & 21 & 87 & neg \\
\hline & & 463 & 287 & Q & 42 & 87 & neg \\
\hline \multirow{2}{*}{ E1-3G } & 2.86 & 445 & 113 & Q & 21 & 90 & neg \\
\hline & & 445 & 269 & & 40 & 90 & neg \\
\hline \multirow[t]{2}{*}{ E2-3G } & 3.07 & 447 & 113 & & 21 & 92 & neg \\
\hline & & 447 & 271 & Q & 42 & 92 & neg \\
\hline \multirow[t]{2}{*}{ EE2-3G } & 3.21 & 471 & 113 & & 22 & 78 & neg \\
\hline & & 471 & 295 & Q & 39 & 79 & neg \\
\hline \multirow[t]{2}{*}{ E1-3S } & 3.83 & 349 & 145 & & 55 & 79 & neg \\
\hline & & 349 & 269 & Q & 33 & 79 & neg \\
\hline \multirow[t]{2}{*}{ E2-3S } & 4.07 & 351 & 145 & & 56 & 79 & neg \\
\hline & & 351 & 271 & Q & 35 & 79 & neg \\
\hline \multirow[t]{2}{*}{ E1-3S- $d 4$} & 3.82 & 353 & 147 & Q & 55 & 73 & neg \\
\hline & & 353 & 273 & & 33 & 73 & neg \\
\hline \multirow{2}{*}{ EE2-3S } & 4.17 & 375 & 145 & & 58 & 85 & neg \\
\hline & & 375 & 295 & Q & 34 & 85 & neg \\
\hline \multirow[t]{2}{*}{ E3 } & 5.15 & 287 & 143 & & 54 & 80 & neg \\
\hline & & 287 & 171 & Q & 37 & 80 & neg \\
\hline \multirow{2}{*}{ monoClE3 } & 6.72 & 321 & 35 & Q & 31 & 81 & neg \\
\hline & & 321 & 285 & & 30 & 81 & neg \\
\hline \multirow[t]{2}{*}{ E1 } & 7.4 & 269 & 143 & & 55 & 50 & neg \\
\hline & & 269 & 145 & Q & 39 & 50 & neg \\
\hline \multirow{2}{*}{ E2 } & 7.64 & 271 & 145 & & 41 & 50 & neg \\
\hline & & 271 & 183 & Q & 42 & 50 & neg \\
\hline \multirow[t]{2}{*}{$\mathrm{E} 1-d 4$} & 7.38 & 273 & 145 & & 57 & 77 & neg \\
\hline & & 273 & 147 & Q & 39 & 77 & neg \\
\hline \multirow[t]{2}{*}{ EE2 } & 7.55 & 295 & 145 & Q & 40 & 50 & neg \\
\hline & & 295 & 159 & & 36 & 50 & neg \\
\hline \multirow[t]{2}{*}{ diClE3 } & 7.68 & 355 & 323 & Q & 39 & 78 & neg \\
\hline & & 357 & 325 & & 39 & 78 & neg \\
\hline \multirow{2}{*}{ monoClE1 } & 8.46 & 303 & 179 & $\mathrm{Q}$ & 40 & 50 & neg \\
\hline & & 303 & 267 & & 29 & 50 & neg \\
\hline \multirow[t]{2}{*}{ monoClEE2 } & 8.7 & 329 & 293 & & 30 & 50 & neg \\
\hline & & 329 & 301 & Q & 26 & 50 & neg \\
\hline \multirow[t]{2}{*}{ monoBrE2 } & 8.55 & 349 & 79 & Q & 39 & 88 & neg \\
\hline & & 351 & 81 & & 38 & 88 & neg \\
\hline \multirow[t]{2}{*}{ monoBrEE2 } & 8.4 & 373 & 79 & Q & 38 & 87 & neg \\
\hline & & 375 & 81 & & 39 & 79 & neg \\
\hline \multirow[t]{2}{*}{ monoClE2 } & 8.83 & 305 & 35 & & 27 & 76 & neg \\
\hline & & 305 & 269 & Q & 31 & 76 & neg \\
\hline diClE1 & 9.14 & 337 & 213 & Q & 41 & 50 & neg \\
\hline & & 339 & 215 & & 40 & 50 & neg \\
\hline diClE2 & 9.53 & 339 & 307 & Q & 38 & 85 & neg \\
\hline & & 341 & 309 & & 39 & 84 & neg \\
\hline diClEE2 & 9.34 & 363 & 335 & Q & 29 & 83 & neg \\
\hline & & 365 & 337 & & 29 & 82 & neg \\
\hline diBrE2 & 9.91 & 429 & 79 & & 44 & 50 & neg \\
\hline & & 429 & 81 & Q & 42 & 50 & neg \\
\hline diBrEE2 & 9.69 & 453 & 79 & Q & 46 & 78 & neg \\
\hline & & 453 & 81 & & 45 & 78 & neg \\
\hline
\end{tabular}




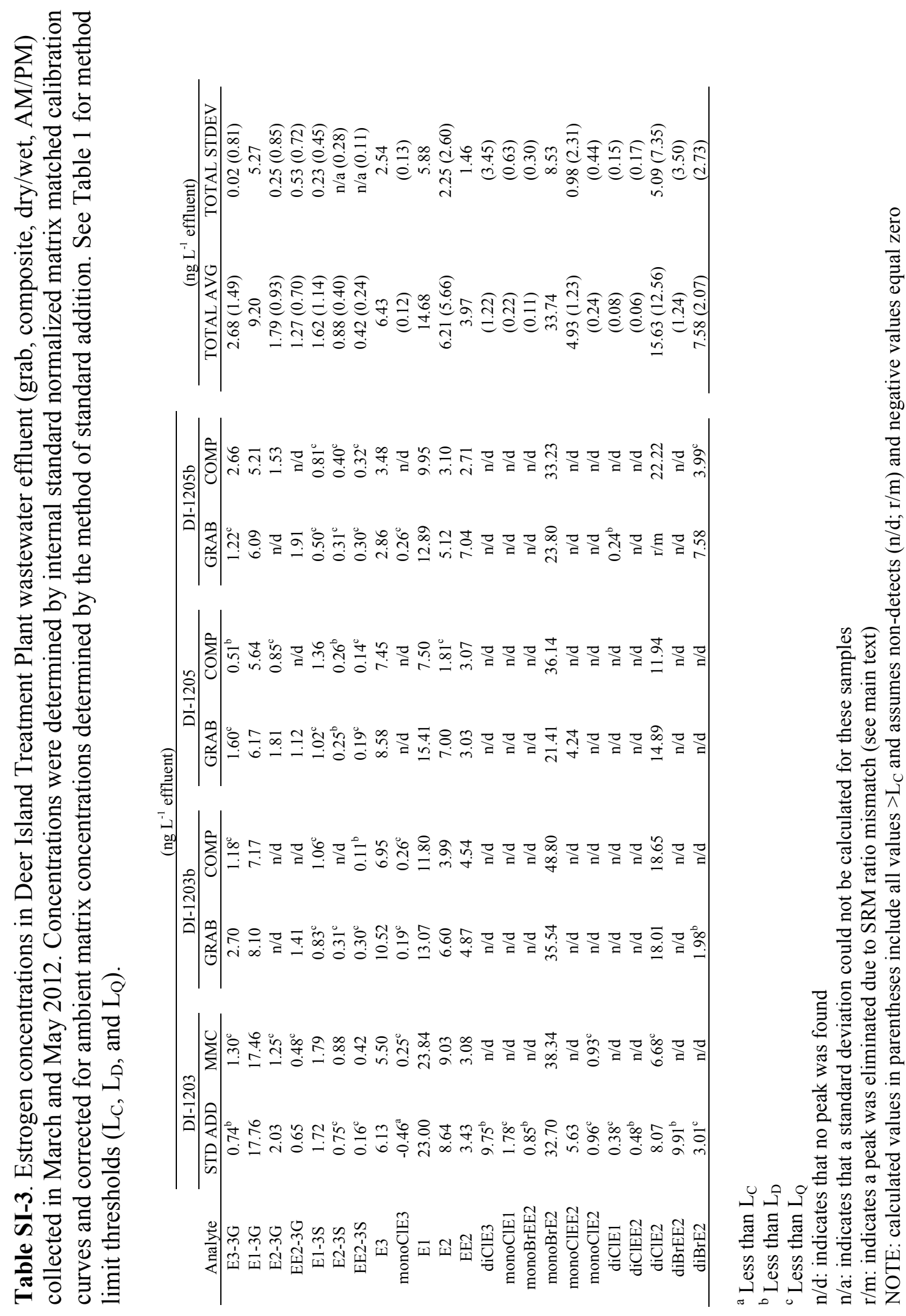




\section{REFERENCES}

Acero, J. L., P. Piriou, et al. (2005). "Kinetics and mechanisms of formation of bromophenols during drinking water chlorination: Assessment of taste and odor development." Water Research 39(13): 2979-2993.

Anstead, G. M., K. E. Carlson, et al. (1997). "The estradiol pharmacophore: Ligand structure-estrogen receptor binding affinity relationships and a model for the receptor binding site." Steroids 62(3): 268-303.

Backe, W. J. and J. A. Field (2012). "Is SPE Necessary for Environmental Analysis? A Quantitative Comparison of Matrix Effects from Large-Volume Injection and Solid-Phase Extraction Based Methods." Environmental Science \& Technology 46(12): 6750-6758.

Benijts, T., R. Dams, et al. (2002). "Analysis of estrogenic contaminants in river water using liquid chromatography coupled to ion trap based mass spectrometry." Rapid Communications in Mass Spectrometry 16(14): 1358-1364.

Boyd, R. K., C. Basic, et al. (2008). Trace Quantitative Analysis by Mass Spectrometry. West Sussex, England, John Wiley \& Sons Ltd.

Caldwell, D. J., F. Mastrocco, et al. (2008). "Derivation of an aquatic predicted no-effect concentration for the synthetic hormone, 17 alpha-ethinyl estradiol." Environmental Science \& Technology 42(19): 7046-7054.

Chimchirian, R. F., R. P. S. Suri, et al. (2007). "Free synthetic and natural estrogen hormones in influent and effluent of three municipal wastewater treatment plants." Water Environment Research 79(9): 969-974.

Commission, E. (2002). "Commission Decision 2002/657/EC implementing Council Directive 96/23/EC concerning the performance of analytical methods and the interpretation of results." Official Journal of the European Union L 125: 10-32.

Currie, L. A. (1995). "Nomenclature in evaluation of analytical methods including detection and quantification capabilities (IUPAC recommendations 1995)." Pure and Applied Chemistry 67(10): 1699-1723.

D'Ascenzo, G., A. Di Corcia, et al. (2003). "Fate of natural estrogen conjugates in municipal sewage transport and treatment facilities." Science of the Total Environment 302(1-3): 199-209.

Delaney, M. F. and A. C. Rex (2007). Contaminant Monitoring of Deer Island Treatment Plant Effluent: 2000-2005. Boston, Massachusetts Water Resources Authority: 40. 
Desbrow, C., E. J. Routledge, et al. (1998). "Identification of estrogenic chemicals in STW effluent. 1. Chemical fractionation and in vitro biological screening." Environmental Science \& Technology 32(11): 1549-1558.

Eaton, A. D., M. A. H. Franson, et al., Eds. (2005). Standard methods for the examination of water and wastewater. Washington, D.C. , American Public Health Association.

Fang, H., W. D. Tong, et al. (2001). "Structure-activity relationships for a large diverse set of natural, synthetic, and environmental estrogens." Chemical Research in Toxicology 14(3): 280-294.

Gentili, A., D. Perret, et al. (2002). "Analysis of free estrogens and their conjugates in sewage and river waters by solid-phase extraction then liquid chromatographyelectrospray-tandem mass spectrometry." Chromatographia 56(1-2): 25-32.

Gibbons, R. D., D. E. Coleman, et al. (1997). "An alternative minimum level definition for analytical quantification." Environmental Science \& Technology 31(7): 20712077.

Gomes, R. L., J. W. Birkett, et al. (2005). "Simultaneous determination of natural and synthetic steroid estrogens and their conjugates in aqueous matrices by liquid chromatography/mass spectrometry." International Journal of Environmental Analytical Chemistry 85(1): 1-14.

Gomes, R. L., M. D. Scrimshaw, et al. (2009). "Fate of Conjugated Natural and Synthetic Steroid Estrogens in Crude Sewage and Activated Sludge Batch Studies." Environmental Science \& Technology 43(10): 3612-3618.

Hansch, C., D. Hoekman, et al. (1995). "The expanding role of quantitative structureactivity relationships (QSAR) in toxicology." Toxicology Letters 79(1-3): 45-53.

Hanselman, T. A., D. A. Graetz, et al. (2003). "Manure-borne estrogens as potential environmental contaminants: A review." Environmental Science \& Technology 37(24): 5471-5478.

Hilal, S. H., S. W. Karickhoff, et al. (2003). Prediction of Chemical Reactivity Parameters and Physical Properties of Organic Compounds from Molecular Structure Using SPARC. . U. S. E. P. Agency. Athens, GA: 158.

Hu, J. Y., S. J. Cheng, et al. (2003). "Products of aqueous chlorination of 17 betaestradiol and their estrogenic activities." Environmental Science \& Technology 37(24): 5665-5670. 
Hunt, C. D., A. D. Mansfield, et al. (2010). "Plume tracking and dilution of effluent from the Boston sewage outfall." Marine Environmental Research 70(2): 150-161.

IUPAC (2012). Compendium of chemical terminology (gold book). Research Triangle Park, N.C., International Union of Pure and Applied Chemistry.

Johnson, A. C. and J. P. Sumpter (2001). "Removal of endocrine-disrupting chemicals in activated sludge treatment works." Environmental Science \& Technology 35(24): 4697-4703.

Johnson, L. L., D. P. Lomax, et al. (2008). "Xenoestrogen exposure and effects in English sole (Parophrys vetulus) from Puget Sound, WA." Aquatic Toxicology 88(1): 2938 .

Kang, J., L. A. Hick, et al. (2007). "Using calibration approaches to compensate for remaining matrix effects in quantitative liquid chromatography/electrospray ionization multistage mass spectrometric analysis of phytoestrogens in aqueous environmental samples." Rapid Communications in Mass Spectrometry 21(24): 4065-4072.

Kang, J. G. and W. E. Price (2009). "Occurrence of phytoestrogens in municipal wastewater and surface waters." Journal of Environmental Monitoring 11(8): 1477-1483.

Khanal, S. K., B. Xie, et al. (2006). "Fate, transport, and biodegradation of natural estrogens in the environment and engineered systems." Environmental Science \& Technology 40(21): 6537-6546.

Koh, Y. K. K., T. Y. Chiu, et al. (2007). "Determination of steroid estrogens in wastewater by high performance liquid chromatography - tandem mass spectrometry." Journal of Chromatography A 1173(1-2): 81-87.

Kolodziej, E. P., T. Harter, et al. (2004). "Dairy wastewater, aquaculture, and spawning fish as sources of steroid hormones in the aquatic environment." Environmental Science \& Technology 38(23): 6377-6384.

Kumar, K. and D. W. Margerum (1987). "Kinetics and mechanism of general-acidassisted oxidation of bromide by hypochlorite and hypochlorous acid." Inorganic Chemistry 26(16): 2706-2711.

Lagana, A., A. Bacaloni, et al. (2004). "Analytical methodologies for determining the occurrence of endocrine disrupting chemicals in sewage treatment plants and natural waters." Analytica Chimica Acta 501(1): 79-88. 
Lee, Y., B. I. Escher, et al. (2008). "Efficient removal of estrogenic activity during oxidative treatment of waters containing steroid estrogens." Environmental Science \& Technology 42(17): 6333-6339.

Lee, Y. and U. Von Gunten (2009). "Transformation of 17 alpha-Ethinylestradiol during Water Chlorination: Effects of Bromide on Kinetics, Products, and Transformation Pathways." Environmental Science \& Technology 43(2): 480487.

Lewis, K. M. and R. D. Archer (1979). "pKa values of estrone, 17-beta-estradiol and 2methoxyestrone." Steroids 34(5): 485-499.

Li, L. Y. T., D. A. Campbell, et al. (1996). "Acceptance criteria for ultratrace HPLCtandem mass spectrometry: Quantitative and qualitative determination of sulfonylurea herbicides in soil." Analytical Chemistry 68(19): 3397-3404.

Lien, G. W., C. Y. Chen, et al. (2009). "Comparison of electrospray ionization, atmospheric pressure chemical ionization and atmospheric pressure photoionization for determining estrogenic chemicals in water by liquid chromatography tandem mass spectrometry with chemical derivatizations." Journal of Chromatography A 1216(6): 956-966.

Liu, Z. H., Y. Kanjo, et al. (2009). "Removal mechanisms for endocrine disrupting compounds (EDCs) in wastewater treatment - physical means, biodegradation, and chemical advanced oxidation: A review." Science of the Total Environment 407(2): 731-748.

Matuszewski, B. K., M. L. Constanzer, et al. (2003). "Strategies for the assessment of matrix effect in quantitative bioanalytical methods based on HPLC-MS/MS." Analytical Chemistry 75(13): 3019-3030.

Moriyama, K., H. Matsufuji, et al. (2004). "Identification and behavior of reaction products formed by chlorination of ethynylestradiol." Chemosphere 55(6): 839847.

Mukawa, F., T. Suzuki, et al. (1988). "Estrogen and androgen receptor binding affinity of 10-beta-chloro-estrene derivatives." Journal of Steroid Biochemistry and Molecular Biology 31(5): 867-870.

MWRA (2012). Water quality update - an analysis of March 2012 sampling data, Massachusetts Water Resources Authority: 9.

Nakamura, H., R. Kuruto-Niwa, et al. (2007). "Formation of chlorinated estrones via hypochlorous disinfection of wastewater effluent containing estrone."

Chemosphere 66(8): 1441-1448. 
Nakamura, H., T. Shiozawa, et al. (2006). "By-products produced by the reaction of estrogens with hypochlorous acid and their estrogen activities." Journal of Health Science 52(2): 124-131.

Petrovic, M., A. Diaz, et al. (2001). "Simultaneous determination of halogenated derivatives of alkylphenol ethoxylates and their metabolites in sludges, river sediments, and surface, drinking, and wastewaters by liquid chromatographymass spectrometry." Analytical Chemistry 73(24): 5886-5895.

Rannulu, N. S. and R. B. Cole (2012). "Novel fragmentation pathways of anionic adducts of steroids formed by electrospray anion attachment involving regioselective attachment, regiospecific decompositions, charge-induced pathways, and iondipole complex interactions." Journal of the American Society for Mass Spectrometry 23: $1558-1568$.

Reddy, S., C. R. Iden, et al. (2005). "Analysis of steroid conjugates in sewage influent and effluent by liquid chromatography-tandem mass spectrometry." Analytical Chemistry 77(21): 7032-7038.

Rolland, R. M., K. E. Hunt, et al. (2005). "Assessing reproductive status of right whales (Eubalaena glacialis) using fecal hormone metabolites." General and Comparative Endocrinology 142(3): 308-317.

Rook, J. J. (1974). "Formation of haloforms during chlorination of natural waters." Water Treatment and Examination 23: 234-243.

Rook, J. J. (1976). "Haloforms in drinking water." Journal American Water Works Association 68(3): 168-172.

Schlusener, M. P. and K. Bester (2008). "Behavior of steroid hormones and conjugates three sewage treatment plants." Clean-Soil Air Water 36(1): 25-33.

Snyder, S. A., D. L. Villeneuve, et al. (2001). "Identification and quantification of estrogen receptor agonists in wastewater effluents." Environmental Science \& Technology 35(18): 3620-3625.

Soto, A. M., J. M. Calabro, et al. (2004). "Androgenic and estrogenic activity in water bodies receiving cattle feedlot effluent in eastern Nebraska, USA." Environmental Health Perspectives 112(3): 346-352.

Stadler, L. B., A. S. Ernstoff, et al. (2012). "Micropollutant Fate in Wastewater Treatment: Redefining "Removal"." Environmental Science \& Technology 46(19): 10485-10486. 
Sun, L., W. Yong, et al. (2009). "Simultaneous determination of 15 steroidal oral contraceptives in water using solid-phase disk extraction followed by high performance liquid chromatography-tandem mass spectrometry." Journal of Chromatography A 1216(28): 5416-5423.

Ternes, T. A., P. Kreckel, et al. (1999). "Behaviour and occurrence of estrogens in municipal sewage treatment plants - II. Aerobic batch experiments with activated sludge." Science of the Total Environment 225(1-2): 91-99.

USEPA (2013). Estimation Programs Interface Suite for Microsoft Windows, v 4.11. U. S. EPA.

Velicu, M. and R. Suri (2009). "Presence of steroid hormones and antibiotics in surface water of agricultural, suburban and mixed-use areas." Environmental Monitoring and Assessment 154(1-4): 349-359.

Vengosh, A. and I. Pankratov (1998). "Chloride/bromide and chloride/fluoride ratios of domestic sewage effluents and associated contaminated ground water." Ground Water 36(5): 815-824.

Wong, G. T. F. and J. A. Davidson (1977). "Fate of Chlorine in Sea-water." Water Research 11(11): 971-978.

Wu, Q. Y., H. Y. Hu, et al. (2009). "Effect of Chlorination on the Estrogenic/Antiestrogenic Activities of Biologically Treated Wastewater." Environmental Science \& Technology 43(13): 4940-4945.

Yanes, O., R. Tautenhahn, et al. (2011). "Expanding Coverage of the Metabolome for Global Metabolite Profiling." Analytical Chemistry 83(6): 2152-2161.

Zorn, M. E., R. D. Gibbons, et al. (1999). "Evaluation of approximate methods for calculating the limit of detection and limit of quantification." Environmental Science \& Technology 33(13): 2291-2295.

Zuehlke, S., U. Duennbier, et al. (2005). "Determination of estrogenic steroids in surface water and wastewater by liquid chromatography-electrospray tandem mass spectrometry." Journal of Separation Science 28(1): 52-58. 


\section{Chapter 3}

Steroidal estrogen sources and fate in a sewage-impacted coastal ocean - Massachusetts Bay, USA 


\begin{abstract}
Estrogens are known to be potent endocrine disrupting chemicals that are commonly found in wastewater effluents at $\mathrm{ng} \mathrm{L}^{-1}$ levels. Yet, we know very little about the distribution and fate of estrogens in coastal oceans that receive wastewater inputs from megacities. This study characterizes, for the first time, a wide range of steroidal estrogens in sewage-impacted seawater using a novel ultra high performance liquid chromatography (UHPLC) tandem mass spectrometry (MS/MS) method together with the method of standard addition. In Massachusetts Bay, we find conjugated, free, and halogenated estrogens at concentrations that are consistent with dilution at sites close to the sewage source. At a site 6 miles downstream of the sewage source, we observe E1 concentrations $\left(0.5 \mathrm{ng} \mathrm{L}^{-1}\right)$ that are nearly double the nearfield concentrations despite 9fold dilution of carbamazepine, which was used as a conservative sewage tracer. Our results point to background estrone (E1) concentrations of $0.2-0.3 \mathrm{ng} \mathrm{L}^{-1}$, derived largely from sources unrelated to wastewater effluent.
\end{abstract}




\subsection{Introduction}

Steroidal estrogens are known to disrupt the normal development of fish at sub-ng $\mathrm{L}^{-1}$ levels. And while much is known about the concentration of estrogens in rivers, lakes, and wastewater treatment plant (WWTP) effluents, much less is known about estrogen levels in coastal oceans, which often receive large treated and untreated sewage discharges from coastal cities.

Estrogens can take a variety of forms. To date, research has focused on the distribution and toxicity of free (i.e., non-conjugated) estrogens (Baronti, Curini et al. 2000; Kolpin, Furlong et al. 2002; Johnson, Williams et al. 2007; Kidd, Blanchfield et al. 2007). Yet we know that most human and animal estrogens are excreted as sulfate or glucuronide conjugates, which have polar groups that are attached to the free estrogen skeleton at carbon number 3, 16, or 17 (Axelson, Sahlberg et al. 1981) to aid with excretion from the body. Conjugates are much less potent than free estrogens (Burgess 2003), yet, during their time in sewers, WWTPs, and receiving waters, conjugated estrogens can be transformed by bacteria back into the highly potent free forms (Gomes, Scrimshaw et al. 2009).

The properties of free and conjugated estrogens vary widely (see Table 1 in Chapter 1), causing very large differences with respect to their involvement in specific fate processes. To date, there have been only a few studies of the fate of conjugates in sewers and WWTPs (Gomes, Scrimshaw et al. 2009 and references therein), and none that investigate the fate of estrogen conjugates in marine environments.

Halogenated derivatives of estrogens are also formed during wastewater disinfection with chlorine (Nakamura, Kuruto-Niwa et al. 2007). Chlorinated and brominated estrogens are more likely to bioaccumulate (larger $\mathrm{K}_{\mathrm{OW}}$ ) and also more acidic than free estrogens (see Table 1 in Chapter 1). Typically, estrogens exhibit unchanged or slightly decreased estrogenic activity upon chlorination (Mukawa, Suzuki et al. 1988; Moriyama, Matsufuji et al. 2004; Nakamura, Shiozawa et al. 2006). Despite the widespread use of chlorine to disinfect wastewater, only a few studies have considered the importance of chlorinated estrogens in wastewater effluents and the environment $(\mathrm{Hu}$, 
Cheng et al. 2003; Moriyama, Matsufuji et al. 2004; Nakamura, Shiozawa et al. 2006; Nakamura, Kuruto-Niwa et al. 2007; Wu, Hu et al. 2009). Recent work (Chapter 2) has demonstrated that chlorinated and brominated estrogens may represent a large portion of the estrogen load delivered by wastewater treatment plants to receiving waters.

Yet, the mass balance, cycling, and environmental impacts of halogenated estrogens (in addition to free and conjugated forms) in sewage-impacted coastal ecosystems remains unclear.

Massachusetts Bay is a well-characterized coastal system within the Gulf of Maine that receives large wastewater discharges, contains diverse recreational and commercial fisheries, and is home to protected marine mammal populations.

This study examines the distribution of steroidal estrogens in Massachusetts Bay by characterizing concentrations near the sewage outfall, as well as up- and down-current of the sewage plume. Estrogen dynamics are investigated by comparing measured concentrations in Massachusetts Bay to modeled values after accounting for inputs from the Deer Island Treatment Plant (DITP) and dilution based on the conservative sewage tracer, carbamazepine. This analysis enables us to ascertain whether natural background estrogens and/or sources beyond the Deer Island outfall are important contributors, as well as to understand how different estrogen species (free vs. conjugated vs. halogenated) respond to transport and transformation processes controlling their environmental distributions.

\subsection{Methods}

\subsubsection{Study site}

Massachusetts Bay is a semi-enclosed embayment that is surrounded by the greater Boston metropolitan area and includes an open boundary with the Gulf of Maine (Figure 1). Massachusetts Bay has an average depth of $35 \mathrm{~m}$ and an area of approximately $3200 \mathrm{~km}^{2}$ (Gustafsson, Long et al. 2001; Jiang and Zhou 2008). It receives significant nutrient and pollutant loads from adjacent Boston Harbor and the DITP outfall located $15 \mathrm{~km}$ offshore (Figure 1). Massachusetts Bay is also home to Stellwagen Bank 
National Marine Sanctuary and near to the Cape Cod Bay Right Whale Sanctuary. The DITP outfall delivers, on average, 360 million gallons per day (MGD; $15.8 \mathrm{~m}^{3} \mathrm{~s}^{-1}$ ) of treated wastewater effluent to Mass Bay via a $2 \mathrm{~km}$-long diffuser on the seafloor at a water depth of $34 \mathrm{~m}$ (Delaney and Rex 2007). Dilution factors are approximately 150:1 at the diffuser line, and increase to $>1000: 1$ in the eastern part of the Bay (Hunt, Mansfield et al. 2010).

During the summer, when Massachusetts Bay is vertically stratified, effluent rises to $\sim 15 \mathrm{~m}$ below the water surface where it is trapped by the pycnocline and transported laterally by currents in the bay. In all other seasons, when stratification is weak or nonexistent, the effluent plume mixes throughout the water column as it rises towards the surface.

\subsubsection{Sampling locations}

We collected Massachusetts Bay water at a depth of $10-12 \mathrm{~m}$ from aboard the M/V Columbia Point during times of relatively weak stratification - on 17 October 2012 (MB-1210), 8 May 2013 (MB-1305a), 9 May 2013 (MB-1305b), and 15 May 2013 (MB1305c). Station locations (Table SI-1) were chosen so as to characterize initial mixing in the nearfield (near the diffuser) and to capture the effect of additional dilution and degradation as water moved away from the diffuser.

The nearfield plume station ("PLM") was located $~ 100 \mathrm{~m}$ down-current of the diffuser, but since tidal currents varied over the course of a day, the physical location of this station also varied (Figure 1). Station PLM was occupied on both 17 October 2012 and 8 May 2013.

An up-current (or upstream) station ("US") and a Boston Harbor station ("BH") were chosen so as to capture representative source water to station PLM. These sites were sampled on 15 May 2013, and care was taken to confirm that winds (Boston Logan Airport; National Weather Service) and currents pushed water to the East-Southeast in the preceding 48 hours to minimize any possible contributions from nearfield PLM water to station US. Current direction and velocity forecasts in Massachusetts Bay were taken 
from a hydrodynamic transport model (Chen, Liu et al. 2003; Chen, Beardsley et al. 2009) that is available online (porpoise1.smast.umassd.edu:8080/fvcomwms/).

The down-current (or downstream) stations "DS1" and "DS2" were located approximately 1 and 6 nautical miles $(1.8$ and $11 \mathrm{~km})$ down-current of station PLM based on net water flow in the $24-48$ hours following PLM sampling. At an estimated net current velocity of $0.04 \mathrm{~m} \mathrm{~s}^{-1}$, approximate travel times between the nearfield PLM station and stations DS1 and DS2 are $13 \mathrm{~h}$ and $78 \mathrm{~h}$, respectively.

During each sampling cruise, ancillary data were collected using a calibrated YSI 6890 multi-sensor that measured temperature, conductivity, $\mathrm{pH}$, turbidity, and dissolved oxygen. Profile data were recorded at each station to characterize water column stratification, identify any obvious signals of a wastewater plume, and inform decisions about sampling depth.

Unfiltered seawater was collected from depth at each station for subsequent measurements of nutrients (ammonium, nitrate, nitrite, phosphate, and silicate) as well as organic carbon and nitrogen concentrations and isotope $\left({ }^{13} \mathrm{C}\right.$ and $\left.{ }^{15} \mathrm{~N}\right)$ ratios.

Nutrient samples $(30 \mathrm{~mL})$ were filtered immediately through $47 \mathrm{~mm}$ polytetrafluoroethylene (PTFE) membrane filters ( $0.2 \mu \mathrm{m}$, Omnipore; EMD Millipore, Burlington, MA, USA) and stored at $4{ }^{\circ} \mathrm{C}$ (for $9-16$ days) until analysis at the Nutrient Analytical Facility at the Woods Hole Oceanographic Institution. Dissolved organic carbon (DOC) samples were filtered through pre-baked $\left(450{ }^{\circ} \mathrm{C} ; 5 \mathrm{~h}\right) 47 \mathrm{~mm} \mathrm{GF} / \mathrm{F}$ filters $\left(0.7 \mu \mathrm{m}\right.$; Whatman/GE Healthcare, Kent, UK) into pre-baked $\left(450{ }^{\circ} \mathrm{C} ; 5 \mathrm{~h}\right)$ amber glass bottles $(100 \mathrm{~mL})$, acidified to $\mathrm{pH} 3$ using concentrated hydrochloric acid $(\mathrm{HCl})$, and analyzed at the Luce Laboratory of Environmental Chemistry at the Woods Hole Research Center. $\mathrm{GF} / \mathrm{F}$ filters were stored at $-20{ }^{\circ} \mathrm{C}$, acidified by $\mathrm{HCl}$ fuming (Hwang, Montlucon et al. 2009), and analyzed for particulate organic carbon and nitrogen (POC and PON) abundance and isotopic composition at the Stable Isotope Laboratory at the Marine Biological Laboratory. 


\subsubsection{Effluent samples and tracers}

Final effluent (grab and 24-h flow-weighted composite) samples were collected from DITP on four days in March and May 2012 (DI-1203, DI-1203b, DI-1205, and DI1205b; see Chapter 2). Additional DITP (grab and 24-h composite) samples were collected on 26 October 2012 (DI-1210) and 16 May 2013 (DI-1305) to coincide with Massachusetts Bay fieldwork (MB-1210 and MB-1305).

The influence of DITP effluent in Massachusetts Bay waters is expected to vary in space and time according to discharge flow rates and current dynamics (Hunt, Mansfield et al. 2010). Thus, it was important to quantify the contributions from DITP effluent to each Massachusetts Bay sample. A variety of conservative sewage tracers have been proposed (Dickenson, Snyder et al. 2011). In this study, we quantify sewage contributions using the common pharmaceutical, carbamazepine, which is used to treat epilepsy, schizophrenia, and bipolar disorder. Carbamazepine has been shown to behave conservatively in coastal waters (Benotti and Brownawell 2007; Nakada, Kiri et al. 2008), is known to be a consistent and ubiquitous component of wastewater effluent (Dickenson, Snyder et al. 2011), and had been previously detected in DITP effluent (in August and September 2007) at 240 - $360 \mathrm{ng} \mathrm{L}^{-1}$ (pers comm, Andrea Rex, MWRA, November 20,2009). We monitored caffeine as an alternate sewage tracer since it is known to degrade in natural waters with photodegradation and biodegradation half-lives of 12 and 231 days, respectively (Buerge, Poiger et al. 2003).

\subsubsection{Standards and solvents}

The source and purity of each estrogen standard is described in detail in Chapter

2. Carbamazepine and caffeine standards were purchased from Sigma-Aldrich (Saint Louis, MO, USA). Carbamazepine- $d 10$ (98 \%) was purchased from Cambridge Isotope Laboratories (Andover, MA, USA) and used as a surrogate internal standard (SIS).

SPE disk conditioning and elution solvents were isopropyl alcohol (Mallinckrodt AR), acetone (JTBaker Ultra Resi-Analyzed), methanol (MeOH; JTBaker Ultra ResiAnalyzed), and deionized, low-carbon laboratory water (Aquafine Corp.; $\mathrm{pH}$ 6.1). 
Injection solution and mobile phase solvents (methanol, acetonitrile, and water) were Optima ${ }^{\circledR}$ LC/MS grade from Thermo Fisher Scientific (Waltham, MA, USA).

\subsubsection{Seawater collection and extraction}

Seawater samples were pumped onboard $\left(\sim 2 \mathrm{~L} \mathrm{~min}^{-1}\right)$ by a positive displacement pump (Fultz Pumps, Inc., Lewistown, PA, USA) that had stainless steel and PTFE contact surfaces and was connected to a $50 \mathrm{ft}$ length of solvent-cleaned aluminum tubing (1/4 in o.d.), which was attached to a $293 \mathrm{~mm}$ stainless steel filter holder containing a pre-baked $\left(450{ }^{\circ} \mathrm{C} ; 5 \mathrm{~h}\right) \mathrm{GF} / \mathrm{F}$ filter $(0.7 \mu \mathrm{m}$; Whatman/GE Healthcare, Kent, UK). The filtrate was split between two $\sim 20$ L glass carboys that had been soap and water cleaned, rinsed with deionized water, and rinsed $3 \mathrm{x}$ with sample water before collection. Each set of carboys was covered in black plastic throughout filling and processing.

Once filled, each carboy was spiked with estrogen and carbamazepine SIS spiking mixtures $(2.40 \pm 0.01 \mu \mathrm{L}$ in methanol or acetonitrile $)$ and the appropriate 23 -standard estrogen spiking mixture $(2.70 \pm 0.01 \mu \mathrm{L}$ in methanol). At station PLM, two sets of two carboys were filled simultaneously and treated as duplicates to be spiked at the same level. At all other stations, two sets of two carboys were filled sequentially and each individual carboy was spiked at one of 4 spiking levels. Spike level 0 received only the SIS mixtures. Spike levels 1, 2, and 3 received the SIS mixtures plus the 23-estrogen mixture containing each estrogen at a nominal mass of $0.1,1$, and $10 \mathrm{ng}$, respectively. Carboys were swirled for 30 seconds to mix spikes evenly into the sample.

Spiked seawater samples were then pumped through $90 \mathrm{~mm}$ diameter solid phase extraction (SPE) disks (Empore SDB-XC; 3M, St. Paul, MN, USA) previously conditioned with acetone, methanol, and low-carbon water. SPE disks were enclosed in a stainless steel filtration apparatus at the end of a stainless steel line containing a pressure gauge, a PTFE bellows pulse dampener (Blacoh, Riverside, CA, US), and a stainless steel metering pump (LMI Milton Roy, Acton, MA, USA) with a PTFE diaphragm. Sample flow rate through SPE disks was $250-300 \mathrm{~mL} \mathrm{~min}^{-1}$, pressures were kept below 30 psi, and only one disk was used per carboy. 
Loaded SPE disks were dried by vacuum for 20 minutes $(20 \mathrm{inHg})$ while still enclosed in the filter holder, then folded in half, enclosed in a pre-baked $\left(450{ }^{\circ} \mathrm{C} ; 5 \mathrm{~h}\right)$ aluminum foil pouch, and stored at $-20{ }^{\circ} \mathrm{C}$ until eluted in the laboratory.

After warming to room temperature, disks were eluted in a pre-baked $\left(450{ }^{\circ} \mathrm{C} ; 5\right.$ h) and solvent-cleaned $90 \mathrm{~mm}$ glass filtration apparatus (EMD Millipore, Burlington, MA, USA) using two $20 \mathrm{~mL}$ aliquots of methanol. For each aliquot, $2 \mathrm{~mL}$ were pulled through the disk, which was allowed to sit for $1 \mathrm{~min}$ before the remaining $18 \mathrm{~mL}$ were pulled through. The eluate from each disk was collected in a pre-baked $\left(450{ }^{\circ} \mathrm{C} ; 5 \mathrm{~h}\right) 60$ $\mathrm{mL}$ amber vial and concentrated to $\sim 1 \mathrm{~mL}$ under $\mathrm{N}_{2}$ at $40{ }^{\circ} \mathrm{C}$. This extract was transferred to a $13 \times 100 \mathrm{~mL}$ glass tube and reduced to near-dryness by vacuum centrifugation at $30{ }^{\circ} \mathrm{C}$, and reconstituted in $60 \mu \mathrm{L}$ of $\mathrm{MeOH}$. This solution was mixed by vortexing and allowed to sit overnight at $4{ }^{\circ} \mathrm{C}$ before adding $140 \mu \mathrm{L}$ of water and vortexing to mix. The resulting opaque brown solution was transferred to a pre-baked $\left(450{ }^{\circ} \mathrm{C} ; 5 \mathrm{~h}\right)$ vial with insert and stored at $-20^{\circ} \mathrm{C}$ until analysis, which took place within a week.

\subsubsection{Analysis of estrogens}

Estrogens were separated by ultra high performance liquid chromatography (UHPLC) and detected by tandem mass spectrometry (MS/MS) at the Woods Hole Oceanographic Institution FT-MS Facility. The electrospray ion source was operated in negative ion mode, and two precursor-product transitions were monitored for each estrogen. Instrumental conditions, mobile phases, gradients, flow rates, and selected reaction monitoring (SRM) parameters were the same as previously reported (Table SI-2; see also Chapter 2). An example chromatogram of Massachusetts Bay seawater extract

spiked with 23 estrogens at $500 \mathrm{pg} \mathrm{L}^{-1}$ (Figure 2) shows how retention time, instrumental response, and matrix interferences vary between SRM channels. 


\subsubsection{Analysis of carbamazepine and caffeine}

Carbamazepine and caffeine were analyzed following Miao et al. (2003) by injecting sample extracts a second time after reconfiguring the instrument. The electrospray ion source was operated in positive mode, and separation was achieved using a Thermo ${ }^{\circledR}$ Hypersil GOLD C8 column $(150 \times 2.1 \mathrm{~mm}$ i.d., $5 \mu \mathrm{m}$ particle size $)$ fitted with a guard cartridge and a pre-column filter and kept at $30{ }^{\circ} \mathrm{C}$ within a Hot Pocket column heater (Thermo Scientific; Waltham, MA, USA). The mobile phase consisted of (A) water (10 mM ammonium acetate and $0.1 \% \mathrm{v} / \mathrm{v}$ formic acid) and (B) $2: 3$ acetonitrile/methanol. We used a linear gradient over $9 \min (30 \%-100 \% \mathrm{~B})$ followed by a $4 \mathrm{~min}$ hold at $100 \% \mathrm{~B}$ and a 7 min equilibration ( $30 \% \mathrm{~B}$ ) prior to the next injection. LC flow rates were $200 \mu \mathrm{L} \mathrm{min}{ }^{-1}$ throughout. Two SRM transitions (Table 1) were monitored for each analyte, and peak areas were normalized by the SIS, carbamazepine- $d 10$.

\subsubsection{SRM channel cross-over}

SRM channel cross-over is the extent to which one compound, such as an internal standard, contributes to signal response in SRM channels of other analytes. This is common when an isotopically-labeled compound is added as a surrogate internal standard and contains small amounts of unlabeled impurities. We confirmed that contributions from SIS spikes to analyte SRM channels were generally negligible except for a small (1.6 \%) contribution from E1-3S- $d 4$ to the SRM channel for E2-3S (see Chapter 2). We also adjusted carbamazepine peak areas for small contributions from carbamazepine- $d 10$ impurities $(0.27 \%)$.

\subsubsection{Analyte quantification}

We used the method of standard addition (Boyd, Basic et al. 2008) to determine estrogen concentrations in Massachusetts Bay. Uncertainties were determined at the $95 \%$ $(\mathrm{p}=0.05)$ confidence level assuming homoscedastic data. In some cases only the highest spike level $\left(\sim 500 \mathrm{pg} \mathrm{L}^{-1}\right)$ peaks were large enough to quantitate due to matrix 
interferences and/or signal suppression, and standard addition concentrations were not reported for these analytes. In other cases, 95\% confidence limits on calculated standard addition concentrations bracketed zero concentration due to large uncertainties in the slope and intercept of the standard addition relationship.

Quantitation of estrogens in DITP effluent follows the procedure outlined in Chapter 2 using matrix-matched calibration curves from March 2012 (DI-1203) with two surrogate internal standards (E1- $d 4$ and E1-3S- $d 4)$.

Confirmation ion SRM data were analyzed separately and used to check that quantitation/confirmation ion ratios were within acceptable limits (see Chapter 2). Standard addition calculations were also repeated with confirmation ions and used as an additional check on results derived from quantitation ions.

Carbamazepine and caffeine concentrations in seawater and wastewater were quantified using SIS normalized neat (pure) solvent calibration curves. Since the SIS, carbamazepine- $d 10$, was not added to samples prior to May 2013, we only report carbamazepine and caffeine data for DI-1305 and MB-1305 samples. Yet, we did detect both tracers in repeat injections of previously archived samples from October 2012 (MB1210 and DI-1210), and quantification by external calibration (i.e., no SIS normalization) allowed us to make a rough estimate of dilution at station PLM during MB-1210.

\subsection{Results and Discussion}

We detected a wide range of estrogens in treated wastewater effluent and Massachusetts Bay seawater. Near the DITP diffuser line, estrogen concentrations were well approximated by simple dilution of effluent, with the exception of halogenated estrogens that exhibited highly variable DITP effluent concentrations. The analyses that follow suggest additional estrogen inputs to Massachusetts Bay from non-sewage sources, especially in offshore waters. 


\subsubsection{Ancillary data}

At each station, depth profiles of temperature, salinity, dissolved oxygen, turbidity, and $\mathrm{pH}$ confirmed that the water column was weakly stratified during the May 2013 sampling campaign (Figure SI-1; Table SI-3). Ammonium measurements were generally well correlated with the sewage tracers, carbamazepine and caffeine (Table 2; Table SI-4). The concentrations of dissolved and particulate organic carbon were consistent with previous measurements taken in Massachusetts Bay (Gustafsson, Long et al. 2001) and together suggest that sorption of estrogens onto particles and removal by settling is negligible for even the most hydrophobic estrogens (Table SI-5).

\subsubsection{Characterizing the source function (DITP effluent)}

To characterize a major source of estrogens to Massachusetts Bay, we measured the same suite of estrogens in DITP effluent on 6 days between March 2012 and May 2013. We consistently found E1, E2, E3, E1-3S, E2-3S, and diClE2 in DITP effluent (Figure 3). In contrast, several conjugated and halogenated forms were detected at high concentrations only on certain sampling dates. In particular, we observed sporadic but significant concentrations of E1-3G, monoBrE2, monoClEE2, and diBrE2.

A kinetic model of estrogen halogenation was developed to describe the particular distribution of the E2 family observed in March - May 2012 (see Chapter 2). During this period, monoBrE2 and diClE2 were dominant forms, but the model was only able to match the relative abundances of E2 and its halogenated forms by invoking chlorination upstream of the wastewater treatment plant in addition to the disinfection basin. We found that our model was highly sensitive to initial conditions, and thus it was not surprising that halogenated estrogen distributions varied with sampling time and wastewater characteristics (e.g., ammonium, bromide, hypochlorite, etc).

During May 2013 we observed concentrations of EE2 that were approximately 10 times higher than expected (Figure 3). Based on current usage of oral contraception, we estimate that EE2 concentrations in Deer Island influent from excretion by women living in the metropolitan Boston area should be $\sim 2 \mathrm{ng} \mathrm{L}^{-1}$ (Johnson and Williams 2004). This 
estimate does not consider other therapeutic uses of EE2 (e.g., hormone replacement therapy) nor sources such as unused drug disposal in toilets.

The cause of anomalously high EE2 is unknown, but may be related to a dumping event captured by the May 2013 sampling. To explain the observed EE2 concentration, given the average flow rate on that day (283 MGD; $12.4 \mathrm{~m}^{3} \mathrm{~s}^{-1}$ ), would require $\sim 30 \mathrm{~g}$ (or 1 million pills) of additional EE2 over 24 hours. Similar results for triplicate grab and 24h composite samples suggest that the extra EE2 would have become well mixed by the time it reached the final effluent stage.

Neither EE2 conjugate (EE2-3G or EE2-3S) could be reported for the May sampling due to quantitation/confirmation ion ratios that were $3-10$ times larger than expected, on average. Barring the influence of a co-eluting matrix interference, the apparent absence of EE2 conjugates in May 2013 lends support to the idea that the extra EE2 was dumped rather than excreted.

Because of the temporal variability of estrogen concentrations in DITP effluent (Figure 3; Table SI-6; Chapter 2 Table SI-3), only concurrent DITP measurements were used to define the DITP source function to Massachusetts Bay for the modeling efforts described below.

\subsubsection{Estrogens in Massachusetts Bay}

We detected a variety of estrogens in Massachusetts Bay water, both near the diffuser (station PLM) and farther afield - in Boston Harbor (station BH), up-current of the diffuser (station US), and also down-current of the diffuser (stations DS1 and DS2; Figure 4; Table SI-7). We consistently found E1 at several hundred $\mathrm{pg} \mathrm{L}^{-1}$ as well as E2, E1-3S, and E2-3S at lower levels throughout Massachusetts Bay (Figure 4; Table SI-7). We also found monoBrE2 $\left(82 \mathrm{pg} \mathrm{L}^{-1}\right)$ and diClE2 $\left(1020 \mathrm{pg} \mathrm{L}^{-1}\right)$ at station DS-2 and PLM, respectively. Sporadic detection of halogenated forms in the bay is consistent with the observed variability of halogenated estrogen levels in DITP effluent and highlights the importance of analyzing 24-h flow-weighted composite effluent samples from DITP on 
multiple days to accurately characterize estrogen fluxes (Ort, Lawrence et al. 2010; Teerlink, Hering et al. 2012).

In Massachusetts Bay, many of the 23 estrogens were not detected or had concentrations that were statistically indistinguishable from zero at the $95 \%$ confidence level. Typically, this resulted from large uncertainties in our standard addition calculations due to limited samples, truncated calibration curves, and/or matrix interferences. While we cannot report the definitive presence of estrogens whose uncertainty brackets zero concentration, we should also not conclude that this implies their absence. As we saw with wastewater effluent (Chapter 2), limits of detection can be influenced by a range of matrix interferences that can suppress ionization in the electrospray source or simply mask analyte peaks, even in putatively selective SRM channels, and especially with complex, highly concentrated samples.

\subsubsection{Tracers indicate variable DITP influence at station PLM}

The extraction time required for large-volume samples $(60-90 \mathrm{~min})$ combined with shifting tides and plume dynamics near the diffuser raised the possibility that each sample set taken at station PLM could reflect different relative proportions of DITP effluent. This could bias the results of standard addition calculations if the variability in the ambient matrix were large compared to spiking levels.

In October 2012, tracer concentrations were similar (11-16\% coefficient of variation) in the four samples taken at station PLM, so we assume that DITP contributions to all MB-1210 nearfield samples were equal. Consistently low ammonium concentrations for MB-1210 samples also support this assumption (Table SI-4).

In contrast, tracer data from May 2013 (MB-1305a; Table 2; Table SI-4) suggest that station PLM high spike samples (PLM-2 and PLM-3) contained larger relative proportions of DITP effluent than low spike samples (PLM-0 and PLM-1; Figure 5). Attempts to correct response ratios such that each spike level reflected the same DITP contribution were hindered by not knowing the relative proportions of spiked and background estrogens in analyte peaks. 
We characterized the potential range of this bias for E1 at station PLM using two complementary approaches. In the first, we calculated an ambient E1 concentration for each of the 8 samples collected at PLM independently by subtracting the known spike concentration from the extract concentration determined by calibration against SISnormalized E1 standards in neat solvent. Using this method, we calculated $270 \pm 120 \mathrm{pg}$ $\mathrm{L}^{-1}$ of ambient E1 at station PLM. Notably, we calculated similar values regardless of spike level, and since E1 matrix effects are relatively small in both wastewater effluent and artificial seawater ( 8 and $30 \%$ signal enhancement, respectively; see Chapter 2), the limitations of neat solvent calibration are likely to be minor.

In the second approach, we applied the method of standard addition separately to low spike samples and high spike samples. This approach takes standard addition to an extreme (where two levels define the standard addition line), but it has the advantage of nullifying the influence of variable tracer levels in our case. At station PLM, standard addition calculations yielded $\mathrm{E} 1$ concentrations of $30 \pm 15 \mathrm{pg} \mathrm{L}^{-1}$ (low spike set), $630 \pm$ $150 \mathrm{pg} \mathrm{L}^{-1}$ (high spike set), and $323 \pm 63 \mathrm{pg} \mathrm{L}^{-1}$ (full set). When compared to the average carbamazepine concentrations of each set, the high spike and full set exhibit similar carbamazepine:E1 ratios (4-5), whereas the low spike ratio (20) is significantly larger. This discrepancy suggests that the low spike result $\left(30 \mathrm{pg} \mathrm{L}^{-1}\right)$ underestimates the E1 concentration at station PLM. This hypothesis is supported by the fact that simple dilution of DITP effluent yields E1 concentrations closer to $300 \mathrm{pg} \mathrm{L}^{-1}$ (see below). Neat solvent calibration suggests similar ambient levels $\left(270 \mathrm{pg} \mathrm{L}^{-1}\right)$. Moreover, we calculate $263 \mathrm{pg} \mathrm{L}^{-1}$ E1 by standard addition at the up-current station (US), which, along with stations DS1, DS2, and BH, was unaffected by variable tracer levels since all spike level samples were collected within a 30 min window. In the analyses that follow, at station PLM we use standard addition concentrations determined from the full set of spike levels (e.g., $\mathrm{E} 1=323 \pm 63 \mathrm{pg} \mathrm{L}^{-1}$ ). 


\subsubsection{Estrogen fate in Massachusetts Bay}

Massachusetts Bay sampling stations were chosen to follow the DITP plume as it mixed into bay water and moved with prevailing currents. Over time, we expected that estrogens within this plume would be removed by dilution, photodegradation, and biodegradation. Sewage tracers were used to predict estrogen concentrations after physical mixing (i.e., dilution) and thereby highlight potential additional sources or sinks of estrogens in Massachusetts Bay.

\subsubsection{Modeling nearfield E1 concentrations}

We modeled nearfield water (station PLM) as a binary mixture of DITP effluent and water from station US, which represents the up-current (or "up-stream") end-member and also captures contributions from the South Essex wastewater treatment plant (Salem, MA) ocean outfall. At station PLM, we used the conservative tracer, carbamazepine (Table 2), to determine the fractional contribution from DITP effluent and station US water. The average dilution factor (535-fold) at station PLM is higher than expected for the core of the effluent plume ( 100-fold dilution; (Hunt, Mansfield et al. 2010)). This finding is consistent with enhanced plume mixing in a weakly stratified water column and the fact that half of the samples (low spike set) included in the average were collected from the edge of the plume, where carbamazepine concentrations were significantly lower (Figure 5).

Using the same approach, salinity (Table 2) predicts 182-fold dilution at station PLM. This calculation is highly sensitive to the salinity at station US (31.74 PSU) such that if the salinity of the mixing parcel were reduced to 31.63 PSU by larger contributions from the Merrimack River, then salinity and carbamazepine would predict identical dilution factors at station PLM.

After 535 -fold dilution of DI effluent $\left(15660 \pm 2790 \mathrm{pg} \mathrm{L}^{-1} \mathrm{E} 1\right)$ with station US

water $\left(263 \pm 12 \mathrm{pg} \mathrm{L}^{-1} \mathrm{E} 1\right)$ the carbamazepine-based model predicts an E1 concentration at station PLM of $292 \pm 13 \mathrm{pg} \mathrm{L}^{-1}$, which agrees well with the measured value at this location ( $\left.323 \pm 63 \mathrm{pg} \mathrm{L}^{-1} \mathrm{E} 1\right)$. Sensitivity tests of this dilution model suggest that even 
extreme assumptions about the temporal variability of DITP effluent carbamazepine concentrations (150 - $400 \mathrm{ng} \mathrm{L}^{-1}$; (Dickenson, Snyder et al. 2011)) have little effect (4- 7 $\%$ ) on modeled E1 at station PLM since dilution is large in all cases and modeled concentrations remain strongly dependent on mixing parcel (station US) estrogen levels.

The same dilution factor (535x) was applied to all estrogens, and the general agreement between modeled and measured values (Figure 6) suggests that dilution is the dominant process controlling estrogen concentrations near the diffuser. Even the remarkably high diClE2 concentrations observed at station PLM on 8 May 2013 (MB1305a) are reasonably well predicted by the model, given the high diClE2 concentrations in DITP effluent on 16 May 2013 (DI-1305).

In October 2012, carbamazepine and caffeine concentrations were, respectively, 180 and 1300 times higher in DITP effluent than at station PLM. Because of the limitations of these non-SIS-corrected tracer data and the absence of an up-current station, we model estrogen levels at station PLM in October (MB-1210) by assuming that the dilution factor $(535 \mathrm{x})$ and composition of station US water are identical to the May 2013 sampling (Figure 6).

\subsubsection{Influence of sampling timescales}

Mismatched water parcels and timescales between effluent samples and seawater samples are one likely cause of discrepancies between measured and modeled (dilution only) concentrations at station PLM. Yet for estrogens with consistent concentrations in DITP (Figure 3; E1, E2, E1-3S, E2-3S), we would expect that the parcel-timescale mismatch would be less pronounced since loadings are relatively stable. Indeed, we see that measured concentrations of these same estrogens at PLM agree well with our model based on dilution of wastewater collected several days later. In fact, this suggests that estrogens not modeled well at station PLM (e.g., EE2-3S, E3, and various halogenated estrogens; Figure 6) are species whose formation and loading to the bay are more sensitive to WWTP and sewer water conditions, including source water composition, 
flow rates, bacterial activity, and levels of residual chlorine, bromide, natural organic matter, and ammonium.

Poorly modeled species may also indicate uncharacterized sources such as combined sewer overflows, whose signal might be evident in Boston Harbor after large rainfall events. And although we see little direct evidence for some of these poorly modeled estrogens at station $\mathrm{BH}$, we sampled during relatively dry weather and during an incoming tide when CSO influence would be expected to be small. Nonetheless, it is possible that the PLM station could exhibit characteristics of different water masses discharged from $\mathrm{BH}$ or other areas of the bay at earlier times.

\subsubsection{E1 production between stations DS1 and DS2}

Counter intuitively, as water was transported away from the diffuser (towards station DS1 and DS2) and diluted further (Figure 5), E1 concentrations increased (Figure 7). The observed offshore increase could be caused by additional estrogen sources, estrogen inter-conversion, sewage tracer artifacts, or temporal variability in tracers and estrogens.

This offshore increase in E1 is unlikely to be an artifact of non-conservative carbamazepine behavior for a several reasons. Photodegradation is ruled out since samples were collected well below the photic zone. Sorption of carbamazepine to particles and settling is unlikely given its small octanol-water partition coefficient (log $\mathrm{K}_{\mathrm{OW}}=2.45$ (Nakada, Tanishima et al. 2006)) and the low suspended solid concentrations in Massachusetts Bay (TSS $1 \mathrm{mg} \mathrm{L}^{-1}$ (Hyde, O'Reilly et al. 2007)). And finally, microbial degradation of carbamazepine would be negligible over the short timescale $(\sim 1$ - 3 days) between PLM and DS2 (Nakada, Kiri et al. 2008).

Although E1 could be produced by E2 degradation and/or deconjugation of E1conjugates during transit away from the diffuser, even the complete transformation of all the E2 and conjugated estrogens at station PLM would only explain 10\% of the E1 increase offshore. Moreover, E2 concentrations also increase significantly offshore (Figure 7). 
An alternative explanation is that productive waters farther offshore (e.g., Stellwagen Bank) contribute relatively high ambient concentrations of E1 derived from extant fish and whale populations. To investigate this possibility, we begin by comparing measured E1 concentrations at downstream stations, DS1 and DS2, to concentrations expected by dilution alone.

\subsubsection{Modeling E1 concentrations at stations DS1 and DS2}

The down-current stations were modeled as mixtures of station PLM water and hypothetical "clean" (zero tracer, zero estrogen) water (Figure 7). Subsequent dilution calculations based on caffeine and carbamazepine data independently suggest at least 3 8x dilution between PLM and the downstream stations. Yet, measured estrogen concentrations at DS1 and DS2 were significantly higher than dilution alone would suggest, and this was true for E1, E2, and E1-3S (Figure 7). Unfortunately, trends for many other estrogens, including diBrE2, were masked by large propagated uncertainties associated with standard addition calculations.

Nonetheless, these results suggest that Massachusetts Bay seawater contains significant background levels of E1 and E2 derived from offshore sources that are likely unrelated to DITP effluent. Other studies have found that coastal ocean E1 concentrations can range from 40 - $800 \mathrm{pg} \mathrm{L}^{-1}$ (Atkinson, Atkinson et al. 2003; Beck, Bruhn et al. 2005), but none have yet been in a position to distinguish between sewage-derived and natural sources.

\subsubsection{Calculating background E1 ranges using independent dilution calculations}

It is possible that dilution-based estimates of background estrogen concentrations in Massachusetts Bay would be sensitive to our assumptions about tracer concentration in the mixing (background) water. Therefore, we calculated E1 concentrations in a theoretical mixing water parcel for each of a series of dilution steps (DI - PLM, PLM DS1, DS1 - DS2) assuming a maximum range of carbamazepine concentrations in the mixing parcel. 
At stations near the diffuser (PLM and DS1) and for all possible carbamazepine concentrations, we calculate a maximum range of $227-323 \mathrm{pg} \mathrm{L}^{-1} \mathrm{E} 1$ in the mixing parcel, which is consistent with the "background" station US (263 pg L $\left.{ }^{-1} \mathrm{E} 1\right)$. It is a different story farther offshore at station DS2, where we calculate a maximum range of $524-2010 \mathrm{pg} \mathrm{L}^{-1} \mathrm{E} 1$ in the mixing parcel. These results suggest that ambient E1 levels in Massachusetts Bay are $\sim 275 \pm 50 \mathrm{pg} \mathrm{L}^{-1}$ near the outfall and potentially $2-7$ times greater in offshore waters close to Stellwagen Bank.

\subsubsection{Massachusetts Bay box model revisited}

To investigate potential sources of high background E1 concentrations ( 227 $\left.2010 \mathrm{pg} \mathrm{L}^{-1}\right)$, we constructed a simple well-mixed box model of Massachusetts Bay in which the primary E1 input is DITP effluent and removal processes are flushing $\left(k_{f l u s h}=\right.$ $\left.12 \mathrm{y}^{-1}\right)$, biodegradation $\left(k_{\text {deg }}=10 \mathrm{y}^{-1}\right)$, and sedimentation (see Chapter 1). When exercised with average DITP fluxes, our model predicts $\sim 2 \mathrm{pg} \mathrm{L}^{-1} \mathrm{E} 1$ in the bay, which is much lower than measured values. And, even if biodegradation is reduced to zero and the average depth of water into which the effluent is mixed is restricted to $10 \mathrm{~m}$, the model still only predicts $19 \mathrm{pg} \mathrm{L}^{-1} \mathrm{E} 1$. In fact, under this scenario, the model can only match observations if E1 levels in DITP effluent average $200 \mathrm{ng} \mathrm{L}^{-1}$, vastly more than we have measured (14 $\left.\pm 3 \mathrm{ng} \mathrm{L}^{-1}\right)$ in grab and 24-hr composite samples at DITP over the course of 14 months. This implies that the model described above is missing a significant source of E1.

Other likely sources of E1 to Massachusetts Bay include combined sewer overflows, Charles River water, and leaking sewers - all delivered via Boston Harbor. In addition, we expect that the South Essex wastewater treatment plant effluent might also contribute estrogens to Massachusetts Bay. In fact, station US was located in order to capture any up-current contributions from this sewage source to station PLM. The South Essex WWTP discharges 30 MGD $\left(1.3 \mathrm{~m}^{3} \mathrm{~s}^{-1}\right)$ of treated effluent into Salem Sound 1.4 mi offshore, and likely has similar concentrations of estrogens to DITP since they employ similar treatment processes (Perkins 2008). Moreover, these additional sources of 
estrogens would include both E1 as well as estrogens that can be converted to E1 via deconjugation or degradation (e.g., E1-conjugates and E2).

If we include all of the above sources in the model at measured concentrations (Boston Harbor, DITP effluent) or expected ranges (South Essex WWTP) and best-guess parameters are used (e.g., $k_{f l u s h}=12 \mathrm{y}^{-1}, k_{\text {deg }}=10 \mathrm{y}^{-1}$ ), our model predicts 18 pg L $^{-1} \mathrm{E} 1$ in Massachusetts Bay. The level increases to $165 \mathrm{pg} \mathrm{L}^{-1}$ if the model is run using parameter and concentration values at the extreme edge of their practical ranges to push the model towards an upper limit estimate. And still, the model falls short of observed E1 concentrations in Massachusetts Bay.

Under best-guess assumptions our expanded-source box model requires additional E1 contributions of $70 \mathrm{~kg} \mathrm{y}^{-1}$ (or $5.5 \mu \mathrm{g} \mathrm{m}^{-3} \mathrm{y}^{-1}$ ). Potential sources include marine vertebrates (e.g., fish and whales), Merrimack River discharge, sewer leakage and CSOs, septic system discharge, and sewage discharge from boats. Estimates suggest that marine vertebrates and Merrimack River sources could account for the missing E1 source needed to balance our box model of Massachusetts Bay (Table 3).

Relatively low salinity (31.16 PSU) at station DS2 points to freshwater contributions, but even if we assume that DS2 is a binary mixture of DS1 water (31.59 PSU) and freshwater from the Merrimack River (zero salinity, $3 \mathrm{ng} \mathrm{L}^{-1} \mathrm{E} 1$ (Williams, Johnson et al. 2003)), concentration estimates at DS2 only reach $290 \mathrm{pg} \mathrm{L}^{-1} \mathrm{E} 1$, which is far below the observed concentration $\left(524 \mathrm{pg} \mathrm{L}^{-1}\right)$. In addition, we have likely overestimated Merrimack River estrogen sources since biodegradation during transport away from the river mouth and into Massachusetts Bay was not considered.

Vertebrate biomass seems the most plausible source given the proximity of highly productive waters of Stellwagen Bank and the observed increase in E1 at station DS2. Moreover, the combined excrement and urine of shoaling fish (Makris, Ratilal et al. 2006) and large whales (Roman and McCarthy 2010), could create transient estrogen hotspots. Subsequent studies should characterize fish-specific steroidal markers (e.g., 11ketotestosterone; (Borg 1994)) and expand spatial coverage to test the hypothesis that marine vertebrates are the dominant source of estrogen in Massachusetts Bay. 


\subsubsection{Estrogens in coastal systems}

Since all marine vertebrates excrete steroidal estrogens, it is not surprising to find background levels in seawater. Yet very few studies have measured marine estrogen concentrations, and until now, none had characterized conjugated, free, and halogenated forms at the same location. The most-commonly detected estrogen in other studies has been estrone (E1). E1 concentrations in Massachusetts Bay are generally in the same range as previous studies have found (Appendix A). The bounds of this range include a single water sample from the North Pacific that contained E1 concentrations of $52 \mathrm{pg} \mathrm{L}^{-1}$ (Atkinson, Atkinson et al. 2003) and three Halifax Harbor samples containing $6600 \pm 900$ pg L ${ }^{-1}$ E1 (Saravanabhavan, Helleur et al. 2009). Based on all previous data, E1 concentrations in Massachusetts Bay seem to be typical for coastal areas, while concentrations of other estrogens (E2, EE2, E1-3S) are lower in Massachusetts Bay and Boston Harbor than elsewhere.

\subsubsection{Estrogenicity in Massachusetts Bay due to steroidal estrogens}

We can determine the estrogenicity of Massachusetts Bay water at each site by multiplying the concentration of each estrogen by its particular binding affinity for an estrogen receptor (similar among vertebrates) and calculating a sum that is normalized to E2. Among the Massachusetts Bay samples we found that the sum total E2 equivalent concentration for the suite of estrogens measured here ranged between $0.1-0.4 \mathrm{ng} \mathrm{L}^{-1}$. These levels are near the threshold thought to cause harm to fish, and they still don't consider any of the weakly estrogenic chemicals known to persist in sewage-impacted waters. Free estrogens contribute between $96-100 \%$ of the estrogenicity due to steroidal estrogens measured in Massachusetts Bay waters; halogenated forms make up the remainder. 


\subsection{Conclusions}

This study is the first of its kind to measure a large suite of steroidal estrogens in coastal seawater. We find that estrogen concentrations near a large sewage outfall depend strongly on the degree of effluent dilution. We observe a wide range of estrogens in Massachusetts Bay, including free, conjugated and halogenated forms. Two of the dominant halogenated forms in DITP effluent - monoBrE2 and diClE2 - were also found in the receiving waters of Massachusetts Bay, but their fate was difficult to determine due to large uncertainties related to sampling and analytical limitations. On the other hand, there is strong evidence suggesting high ambient E1 concentrations from sources unrelated to sewage effluent, especially at the offshore station near Stellwagen Bank.

This work was carried out while the bay was well-mixed or weakly stratified, which represents a high-dilution scenario characteristic of fall, winter, and spring conditions. Stratified conditions in the summer are known to trap the rising DITP effluent plume at mid-depths and could result in higher estrogen concentrations. It is also likely that estrogen removal by biodegradation would be enhanced during the summer. Moreover, seasonal fish and whale aggregations have the potential to greatly influence local ambient estrogen concentrations and alter the relative balance between sewagederived and ambient estrogens. Therefore, investigating the spatial variability and seasonal dynamics of estrogens in coastal waters such as Massachusetts Bay should receive high priority for future study. 


\section{Acknowledgments}

We thank Lisa Wong, Andrea Rex, and Mike Mickelson at the Massachusetts Water Resources Authority, as well as Captain Russell Bowles, Captain Chris Sweeney and the crew of the $M / V$ Columbia Point. For their assistance during Massachusetts Bay sampling trips and in the laboratory, we thank Adam Bockelie, Anthony Carrasquillo, Jamie Collins, Kyle Delwiche, Loretta Fernandez, Tracey Hayse, Jan-Hendrik Hehemann, John MacFarlane, Daniel Prendergast, Benjamin Scandella, Mason Stahl, Daniel Prendergast, and Sarah Jane White. We also thank E. Eric Adams for helpful discussions. Funding for this work was provided by the Martin Family Society of Fellows for Sustainability, the Ocean Ventures Fund and Coastal Ocean Institute at the Woods Hole Oceanographic Institution, MIT Sea Grant (NA10OAR4170086), and by a U.S. Environmental Protection Agency STAR graduate fellowship (FP-91713401). 
Figure 1. Sampling locations in Massachusetts Bay. The black line indicates the Deer Island Treatment Plant outfall diffuser line, and the red ellipse encloses PLM sites from MB-1210 and MB-1305. The PLM sites were located $~ 100 \mathrm{~m}$ down-current of the diffuser line at the time of sampling. Depth contours are given in meters, and the green area of the inset indicates the Stellwagen Bank Marine Sanctuary.

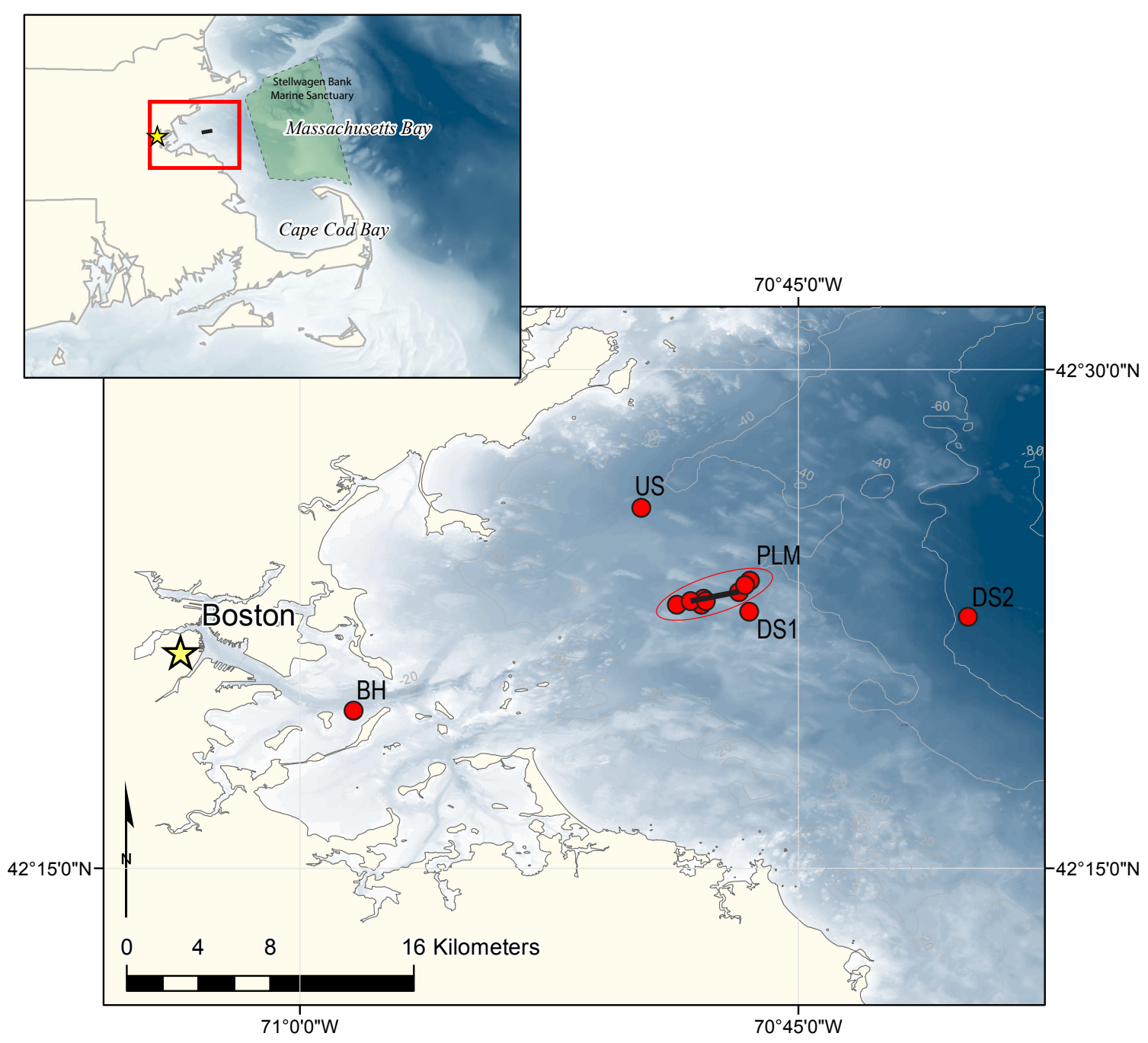


Figure 2. A selected reaction monitoring (SRM) chromatogram of Massachusetts Bay seawater spiked with 23 steroidal estrogens $\left(500 \mathrm{pg} \mathrm{L}^{-1}\right)$ highlights the range of instrumental responses (where normalization level, NL, refers to the signal size at a relative abundance of 100) and the presence of matrix interferences in certain SRM channels. Precursor/product transitions are shown to the right of each trace, and retention times are shown at the apex of each analyte peak.

Relative Abundance
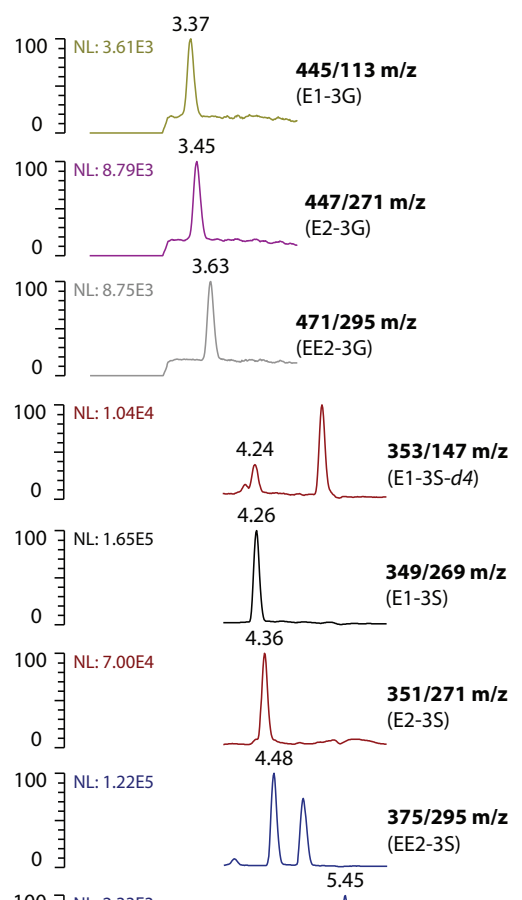

$100 \exists \mathrm{NL} \cdot 7.00 \mathrm{E} 4$

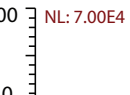

$100 \exists \mathrm{NL}: 1.22 \mathrm{E} 5$

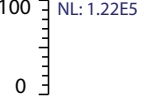

(1)

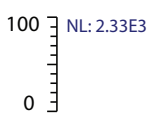
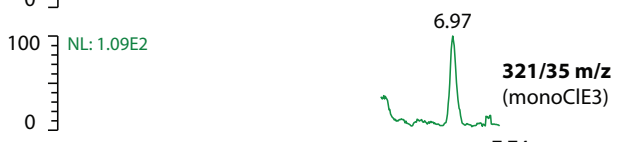

100 当 NL: 2.35E3

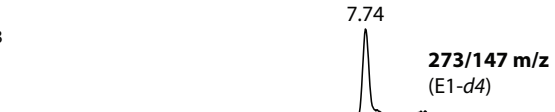

100 每 NL: 3.76E4

100 每 NL: 5.04E3
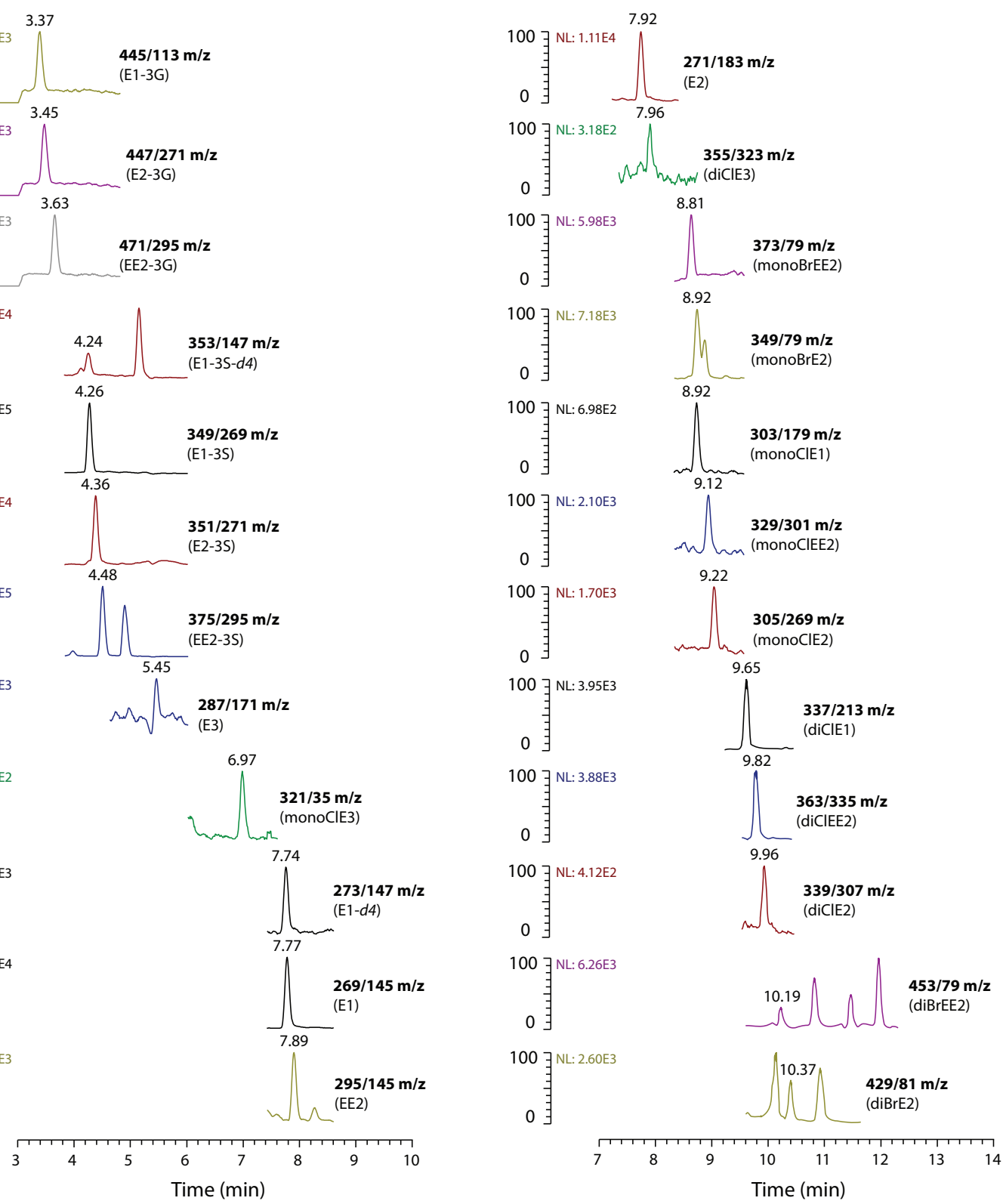
Figure 3. Estrogen concentrations in Deer Island Treatment Plant final effluent from March-May 2012 (DI-1203-1205b; grab and 24-h composite samples; red), October 2012 (DI-1210; grab samples; blue), and May 2013 (DI-1305; grab and 24-h composite samples; olive). The letters "nd" denote that no peaks were detected, and error bars show \pm 1 standard deviation. See Table SI-6 for values.

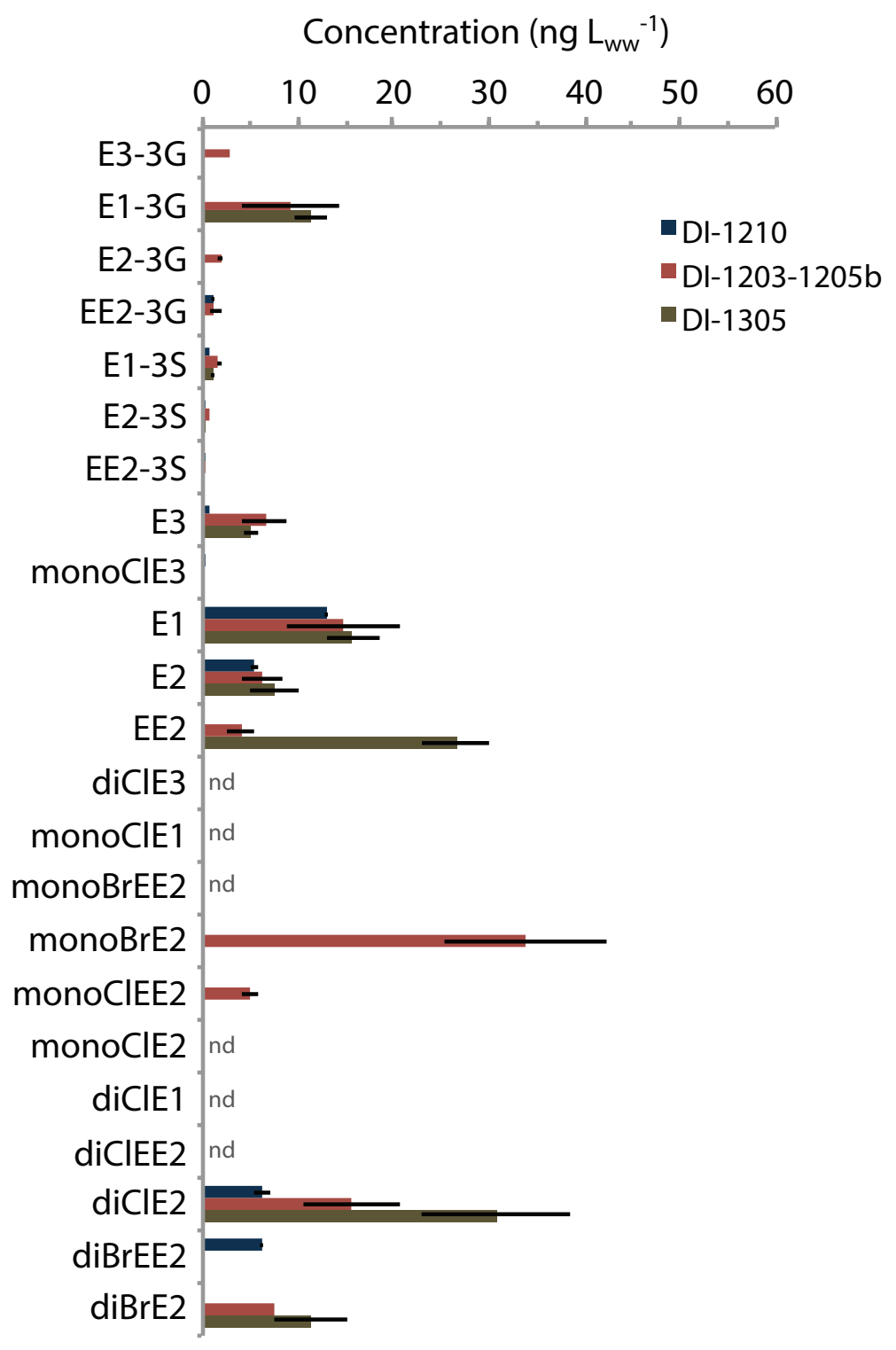


Figure 4. Estrogen concentrations in Massachusetts Bay at nearfield (PLM), downcurrent (DS1 and DS2), up-current (US), and Boston Harbor (BH) stations in May 2013 (MB-1305). Plot axis scales are identical to facilitate comparisons between stations. Note that the diClE2 at station PLM has been altered to show its full extent. The letters "nd" denote standard addition concentrations that were negative or could not be determined due to non-detects resulting in fewer than 2 spiking levels. Error bars show \pm 1 standard deviation except for those that have been truncated since they extend into negative concentration space. See Table SI-7 for values.

\section{Concentration (pg $\left.\mathrm{L}_{\mathrm{sw}}{ }^{-1}\right)$}

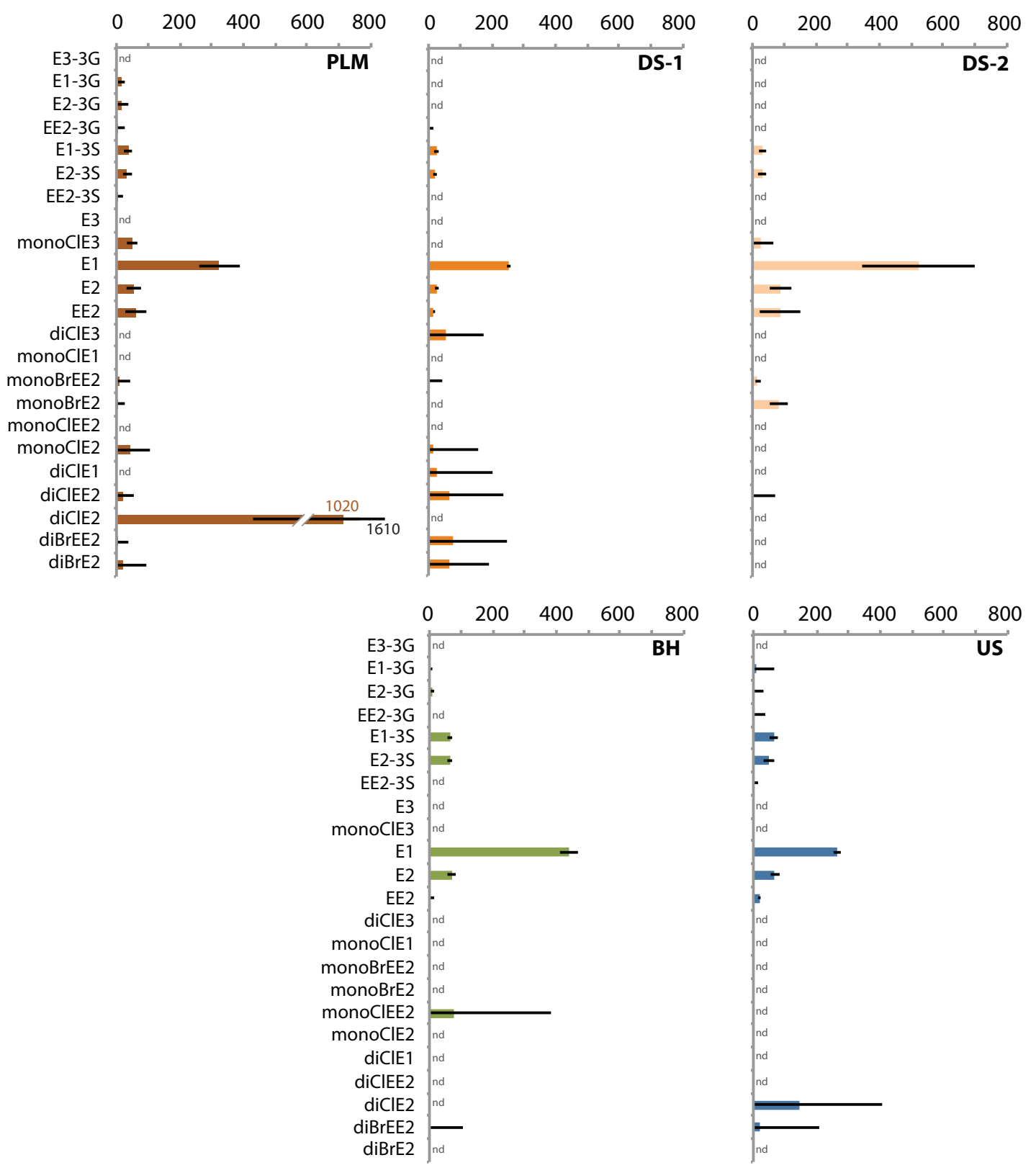


Figure 5. Sewage tracers in Massachusetts Bay (filled diamonds) were used to model dilution between station PLM and the down-current stations (DS1 and DS2) in May 2013 (MB-1305). Variability within the set of four PLM samples highlights the challenge of collecting water from equivalent locations within an effluent plume discharged into a dynamic tidal system. The variability in carbamazepine and caffeine between replicate samples at DS1 and DS2 is much smaller than the size of the symbols.
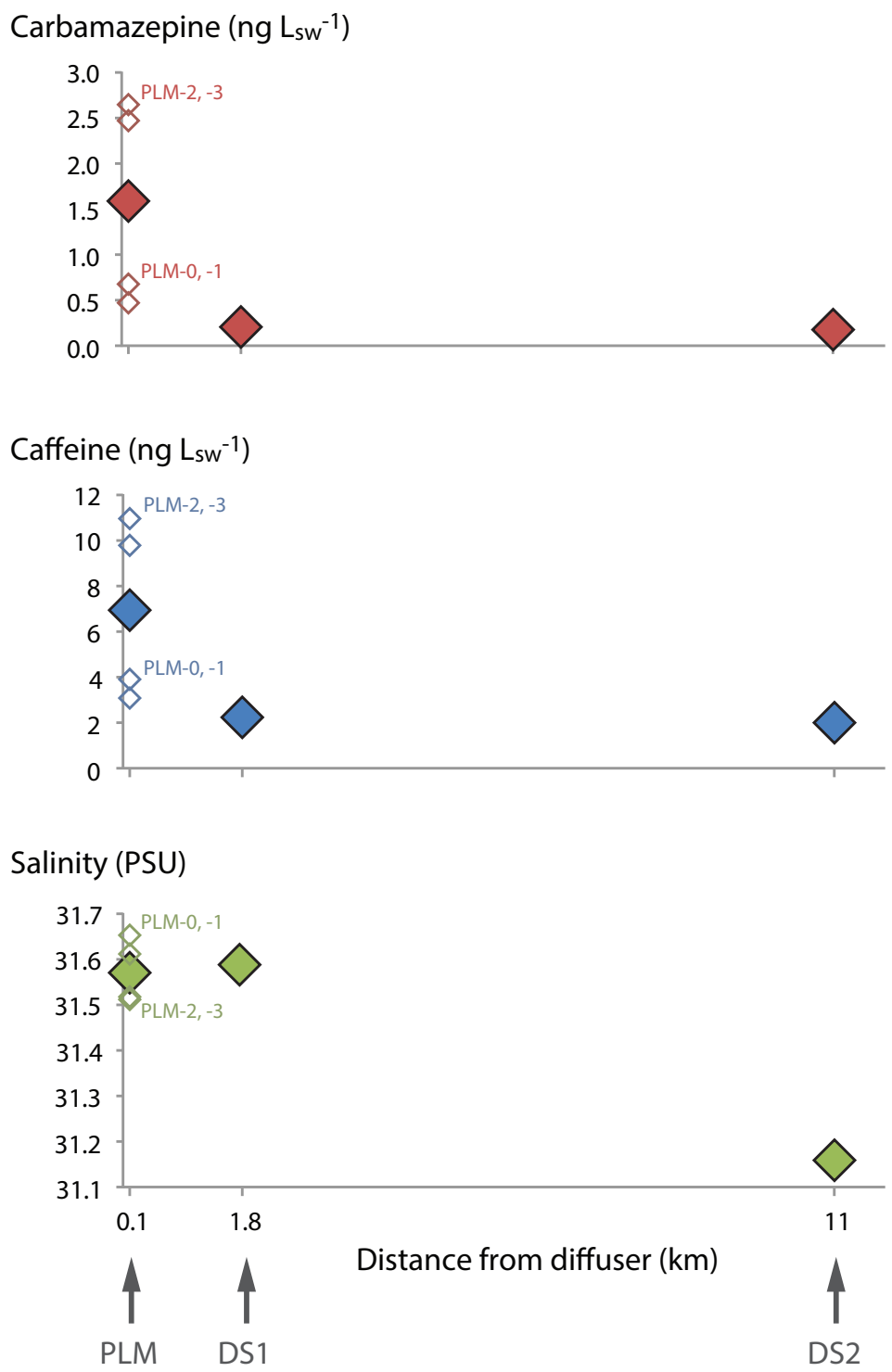
Figure 6. Estrogen concentrations at station PLM in Massachusetts Bay in October 2012 (MB-1210) and May 2013 (MB-1305). Measured values are determined by the method of standard addition. Modeled values are calculated by 535x dilution of Deer Island effluent (DI-1210 or DI-1305) into station US water (MB-1305) based on dilution of the sewage tracer, carbamazepine. The letters "nd" denote that no peaks were detected, and error bars show propagated uncertainty as \pm 1 standard deviation.

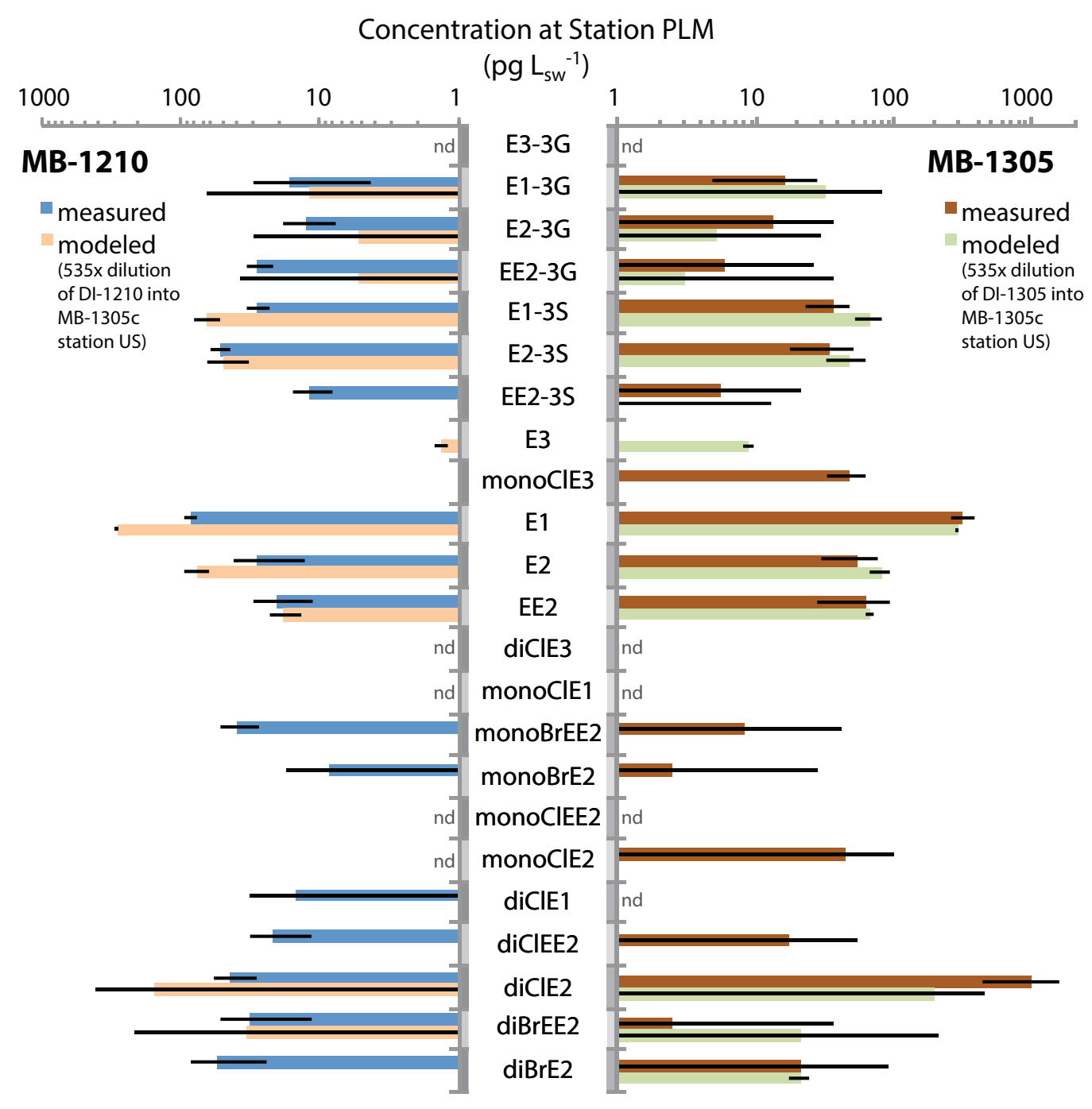


Figure 7. Measured estrogen concentrations (grey circles) are compared to modeled concentrations at stations DS1 and DS2 in Massachusetts Bay during May 2013 (MB1305). Modeled values are calculated by diluting PLM water with "clean" (zero tracer, zero estrogen) water according to carbamazepine (red circles) and caffeine (blue circles) tracer data (see Figure 5 and Table 2). Differences between modeled and measured values point to non-zero background estrogen levels and additional offshore estrogen sources. Error bars (measured values) show the propagated uncertainty ( \pm 1 standard deviation) for the method of standard addition. Note the difference in vertical scales.

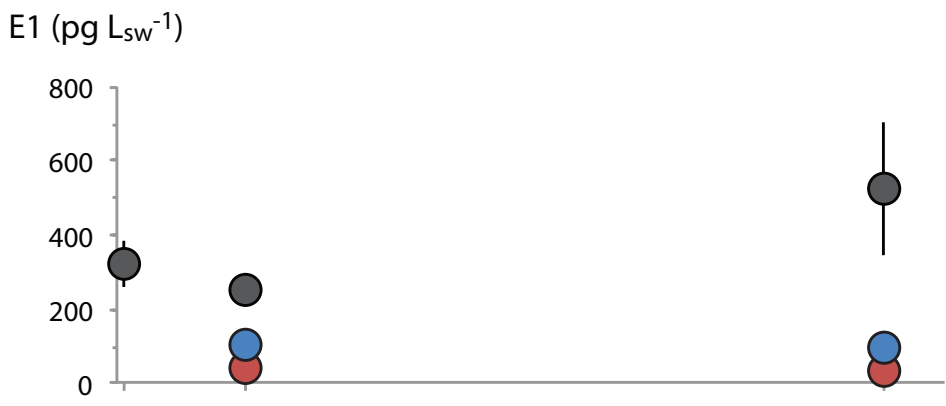

$\mathrm{E} 2\left(\mathrm{pg} \mathrm{L} \mathrm{sw}^{-1}\right)$

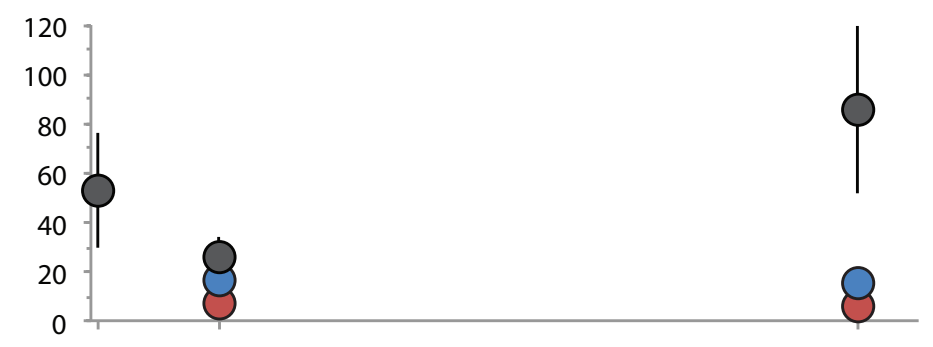

E1-3S (pg Lsw $\left.{ }^{-1}\right)$

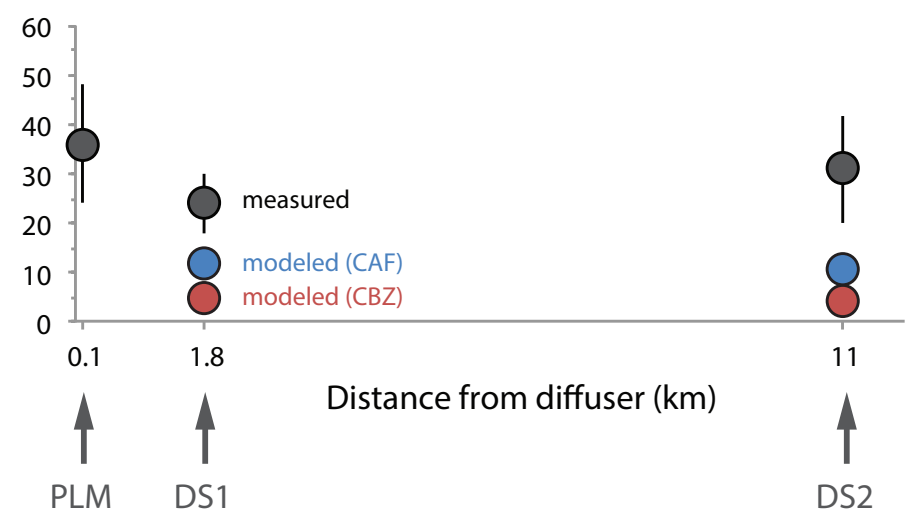


Figure SI-1. Depth profiles of temperature, salinity, dissolved oxygen, turbidity, and $\mathrm{pH}$ at the nearfield station PLM on 8 May 2013 (MB-1305a). Water samples for estrogen analysis were collected from $12 \mathrm{~m}$ depth at this station. Note the $\mathrm{x}$-axis breaks and different horizontal scales.

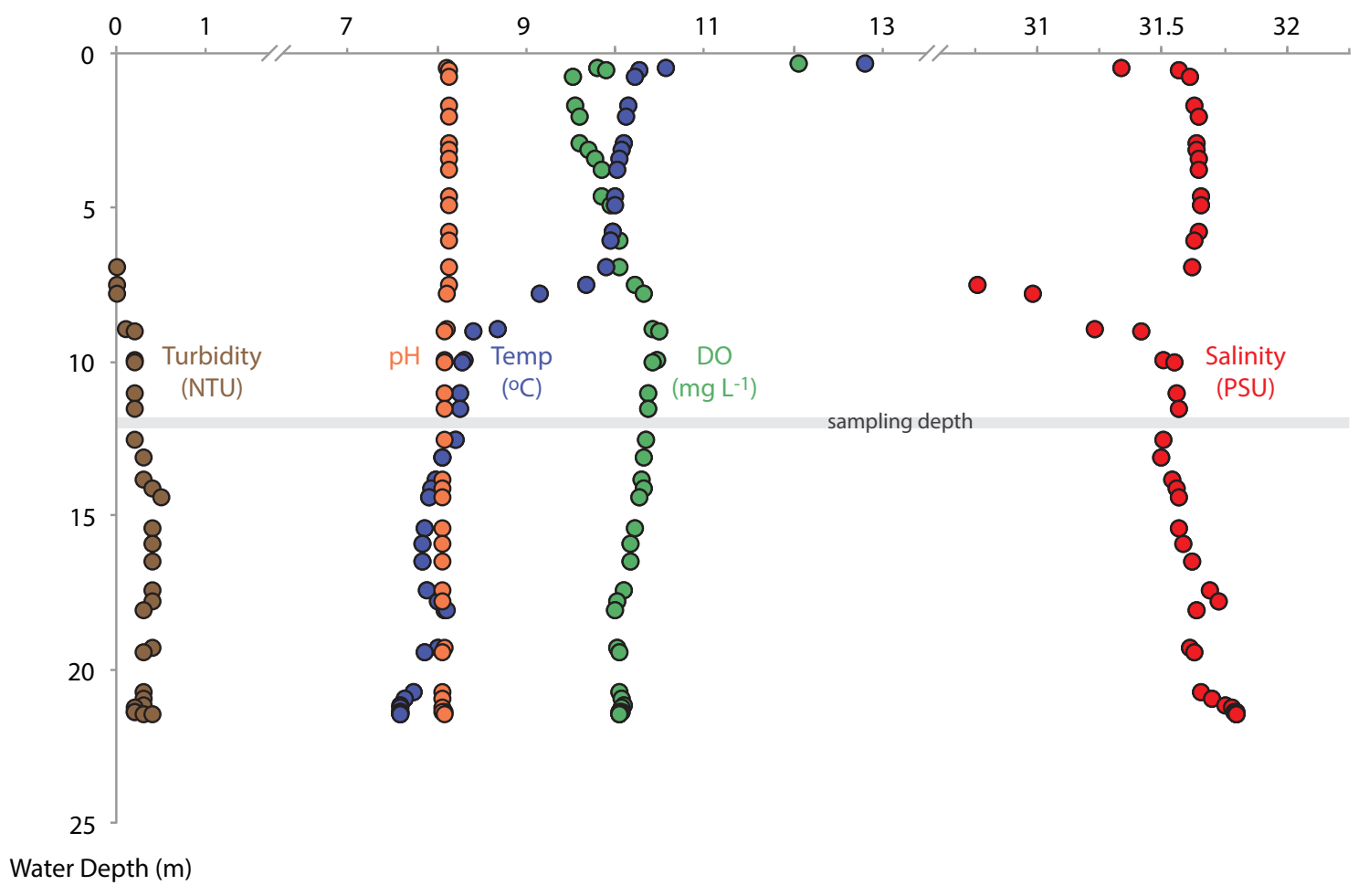


Table 1. Sewage tracer UHPLC-MS/MS analytical method parameters.

\begin{tabular}{cccccccc} 
Analyte & $\begin{array}{c}\text { RT } \\
(\mathrm{min})\end{array}$ & $\begin{array}{c}\text { precursor } \\
(\mathrm{m} / \mathrm{z})\end{array}$ & $\begin{array}{c}\text { product } \\
(\mathrm{m} / \mathrm{z})\end{array}$ & $\begin{array}{c}\mathrm{Q}= \\
\text { quant ion }\end{array}$ & $\begin{array}{c}\text { SRM } \\
\text { collision E }\end{array}$ & S-lens & polarity \\
\hline caffeine & 3.05 & 195 & 110 & & 22 & 91 & pos \\
& & 195 & 138 & $\mathrm{Q}$ & 18 & 91 & pos \\
carbamazepine & 7.03 & 237 & 179 & & 33 & 77 & pos \\
& & 237 & 194 & $\mathrm{Q}$ & 18 & 77 & pos \\
carbamazepine- $d 10$ & \multirow{2}{*}{6.95} & 247 & 187 & $\mathrm{Q}$ & 36 & 83 & pos \\
& & 247 & 204 & & 21 & 83 & pos \\
\hline
\end{tabular}


Table 2. Sewage tracer concentrations in Massachusetts Bay (MB-1305) and Deer Island Treatment Plant effluent (DI-1305).

\begin{tabular}{ccccc}
$\begin{array}{c}\text { Sampling } \\
\text { ID }\end{array}$ & Site & $\begin{array}{c}\text { Carbamazepine } \\
\left(\mathrm{ng} \mathrm{L}^{-1}\right)\end{array}$ & $\begin{array}{c}\text { Caffeine } \\
\left(\mathrm{ng} \mathrm{L}^{-1}\right)\end{array}$ & $\begin{array}{c}\text { Salinity } \\
(\text { PSU) }\end{array}$ \\
\hline MB-1305a & PLM-0 & 0.69 & 3.9 & 31.61 \\
MB-1305a & PLM-1 & 0.49 & 3.1 & 31.65 \\
MB-1305a & PLM-2 & 2.5 & 9.7 & 31.52 \\
MB-1305a & PLM-3 & 2.7 & 11 & 31.51 \\
MB-1305a & PLM (AVG) & 1.6 & 6.9 & 31.57 \\
MB-1305b & DS1 & 0.21 & 2.3 & 31.59 \\
MB-1305b & DS2 & 0.18 & 2.0 & 31.16 \\
MB-1305c & US & 1.1 & 12 & 31.74 \\
MB-1305c & BH & 0.6 & 4.8 & 31.31 \\
DI-1305 & GRAB & 249 & 863 & $0.8^{\mathrm{b}}$ \\
DI-1305 & COMP & 252 & 1720 & $0.8^{\mathrm{b}}$ \\
\hline
\end{tabular}

a used as the wastewater end-member for purposes of dilution modeling

${ }^{b}$ estimated based on DITP effluent chloride concentrations from March and May 2012 


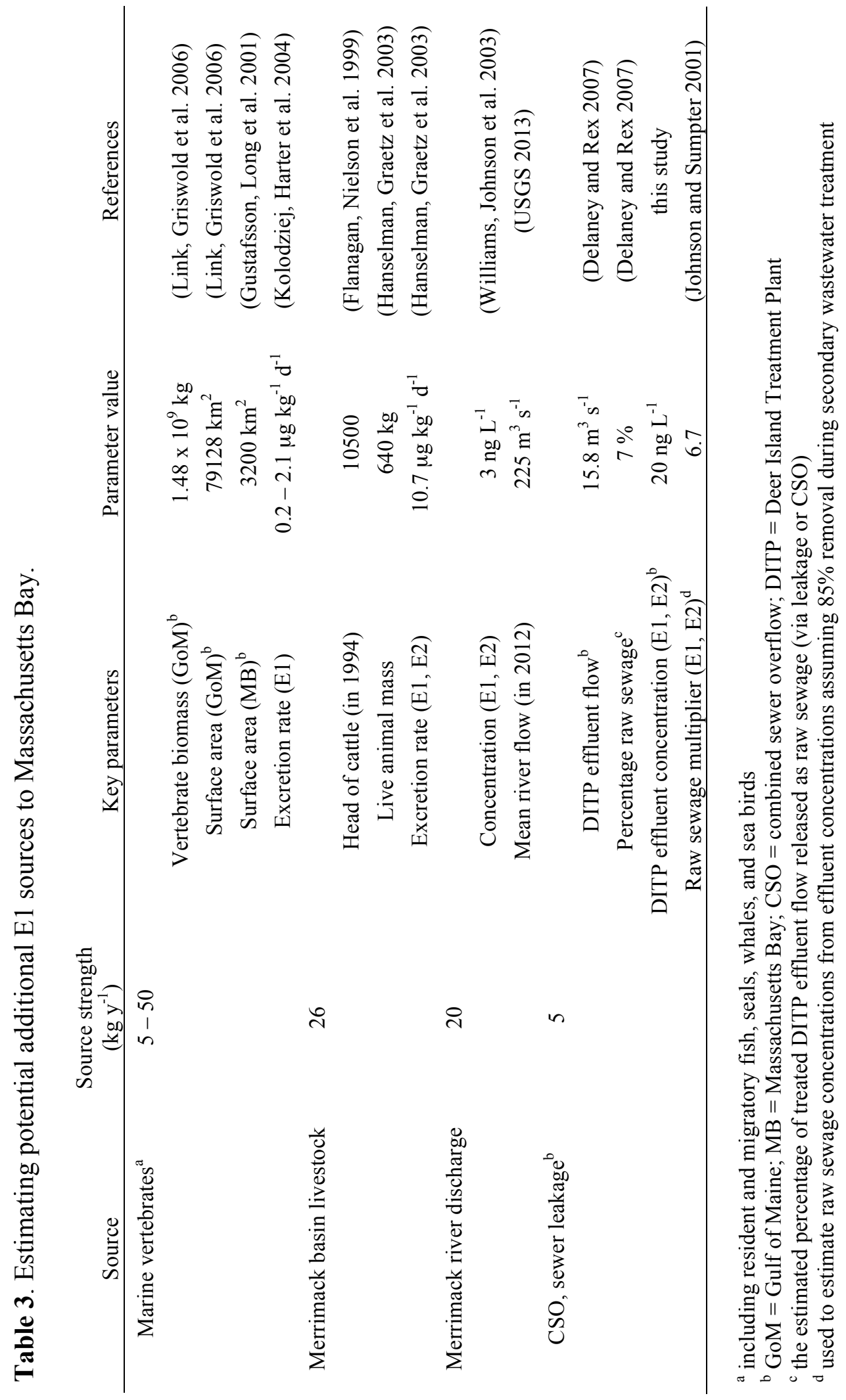


Table SI-1. Station locations during the October 2012 (MB-1210) and May 2013 (MB1305) field campaigns, and the location of the Deer Island Treatment Plant diffuser line.

\begin{tabular}{ccccc} 
Cruise ID & Station ID & Latitude & Longitude & $\begin{array}{c}\text { Sampling } \\
\text { Depth (m) }\end{array}$ \\
\hline MB-1210 & BKGD & 42.3957 & -70.7954 & 1 \\
MB-1210 & PLM-0 & 42.3830 & -70.7995 & 12 \\
MB-1210 & PLM-1 & 42.3830 & -70.7985 & 12 \\
MB-1210 & PLM-2 & 42.3841 & -70.7977 & 12 \\
MB-1210 & PLM-3 & 42.3855 & -70.7981 & 12 \\
MB-1305a & PLM-0 & 42.3825 & -70.8110 & 12 \\
MB-1305a & PLM-1 & 42.3927 & -70.7767 & 12 \\
MB-1305a & PLM-2 & 42.3943 & -70.7743 & 12 \\
MB-1305a & PLM-3 & 42.3945 & -70.7742 & 12 \\
MB-1305b & DS1 & 42.3791 & -70.7745 & 12 \\
MB-1305b & DS2 & 42.3766 & -70.6647 & 10 \\
MB-1305c & US & 42.4315 & -70.8288 & 12 \\
MB-1305c & BH & 42.3296 & -70.9734 & 5 \\
DITP & Diffuser West & 42.3843 & -70.8038 & 34 \\
DITP & Diffuser East & 42.3889 & -70.7801 & 34 \\
\hline
\end{tabular}


Table SI-2. Estrogen UHPLC-MS/MS analytical method parameters.

\begin{tabular}{|c|c|c|c|c|c|c|c|}
\hline Analyte & $\begin{array}{c}\mathrm{RT} \\
(\mathrm{min})\end{array}$ & $\begin{array}{c}\text { Precursor } \\
(\mathrm{m} / \mathrm{z})\end{array}$ & $\begin{array}{c}\text { Product } \\
(\mathrm{m} / \mathrm{z})\end{array}$ & $\begin{array}{c}\mathrm{Q}= \\
\text { Quant ion }\end{array}$ & $\begin{array}{c}\text { SRM } \\
\text { collision E }\end{array}$ & S-lens & Polarity \\
\hline \multirow[t]{2}{*}{ E3-3G } & 1.06 & 463 & 113 & & 21 & 87 & neg \\
\hline & & 463 & 287 & Q & 42 & 87 & neg \\
\hline \multirow[t]{2}{*}{ E1-3G } & 2.86 & 445 & 113 & $\mathrm{Q}$ & 21 & 90 & neg \\
\hline & & 445 & 269 & & 40 & 90 & neg \\
\hline \multirow{2}{*}{ E2-3G } & 3.07 & 447 & 113 & & 21 & 92 & neg \\
\hline & & 447 & 271 & Q & 42 & 92 & neg \\
\hline \multirow{2}{*}{ EE2-3G } & 3.21 & 471 & 113 & & 22 & 78 & neg \\
\hline & & 471 & 295 & Q & 39 & 79 & neg \\
\hline \multirow[t]{2}{*}{ E1-3S } & 3.83 & 349 & 145 & & 55 & 79 & neg \\
\hline & & 349 & 269 & Q & 33 & 79 & neg \\
\hline \multirow[t]{2}{*}{ E2-3S } & 4.07 & 351 & 145 & & 56 & 79 & neg \\
\hline & & 351 & 271 & Q & 35 & 79 & neg \\
\hline \multirow{2}{*}{$\mathrm{E} 1-3 \mathrm{~S}-d 4$} & 3.82 & 353 & 147 & Q & 55 & 73 & neg \\
\hline & & 353 & 273 & & 33 & 73 & neg \\
\hline \multirow[t]{2}{*}{ EE2-3S } & 4.17 & 375 & 145 & & 58 & 85 & neg \\
\hline & & 375 & 295 & Q & 34 & 85 & neg \\
\hline \multirow[t]{2}{*}{ E3 } & 5.15 & 287 & 143 & & 54 & 80 & neg \\
\hline & & 287 & 171 & Q & 37 & 80 & neg \\
\hline \multirow[t]{2}{*}{ monoClE3 } & 6.72 & 321 & 35 & $\mathrm{Q}$ & 31 & 81 & neg \\
\hline & & 321 & 285 & & 30 & 81 & neg \\
\hline \multirow{2}{*}{$\mathrm{E} 1$} & 7.4 & 269 & 143 & & 55 & 50 & neg \\
\hline & & 269 & 145 & Q & 39 & 50 & neg \\
\hline \multirow[t]{2}{*}{ E2 } & 7.64 & 271 & 145 & & 41 & 50 & neg \\
\hline & & 271 & 183 & Q & 42 & 50 & neg \\
\hline \multirow[t]{2}{*}{$\mathrm{E} 1-d 4$} & 7.38 & 273 & 145 & & 57 & 77 & neg \\
\hline & & 273 & 147 & Q & 39 & 77 & neg \\
\hline \multirow[t]{2}{*}{ EE2 } & 7.55 & 295 & 145 & $\mathrm{Q}$ & 40 & 50 & neg \\
\hline & & 295 & 159 & & 36 & 50 & neg \\
\hline \multirow{2}{*}{ diClE3 } & 7.68 & 355 & 323 & Q & 39 & 78 & neg \\
\hline & & 357 & 325 & & 39 & 78 & neg \\
\hline \multirow[t]{2}{*}{ monoClE1 } & 8.46 & 303 & 179 & Q & 40 & 50 & neg \\
\hline & & 303 & 267 & & 29 & 50 & neg \\
\hline \multirow[t]{2}{*}{ monoClEE2 } & 8.7 & 329 & 293 & & 30 & 50 & neg \\
\hline & & 329 & 301 & Q & 26 & 50 & neg \\
\hline \multirow[t]{2}{*}{ monoBrE2 } & 8.55 & 349 & 79 & Q & 39 & 88 & neg \\
\hline & & 351 & 81 & & 38 & 88 & neg \\
\hline \multirow[t]{2}{*}{ monoBrEE2 } & 8.4 & 373 & 79 & Q & 38 & 87 & neg \\
\hline & & 375 & 81 & & 39 & 79 & neg \\
\hline \multirow[t]{2}{*}{ monoClE2 } & 8.83 & 305 & 35 & & 27 & 76 & neg \\
\hline & & 305 & 269 & $\mathrm{Q}$ & 31 & 76 & neg \\
\hline diClE1 & 9.14 & 337 & 213 & Q & 41 & 50 & neg \\
\hline & & 339 & 215 & & 40 & 50 & neg \\
\hline diClE2 & 9.53 & 339 & 307 & Q & 38 & 85 & neg \\
\hline & & 341 & 309 & & 39 & 84 & neg \\
\hline diClEE2 & 9.34 & 363 & 335 & Q & 29 & 83 & neg \\
\hline & & 365 & 337 & & 29 & 82 & neg \\
\hline diBrE2 & 9.91 & 429 & 79 & & 44 & 50 & neg \\
\hline & & 429 & 81 & Q & 42 & 50 & neg \\
\hline diBrEE2 & 9.69 & 453 & 79 & Q & 46 & 78 & neg \\
\hline & & 453 & 81 & & 45 & 78 & neg \\
\hline
\end{tabular}


Table SI-3. The characteristics of Massachusetts Bay water (sampled for estrogen analysis) were determined by an on-board multi-probe sensor in October 2012 (MB1210) and May 2013 (MB-1305).

\begin{tabular}{ccccccc} 
Cruise ID & Station ID & $\begin{array}{c}\text { Depth } \\
(\mathrm{m})\end{array}$ & $\begin{array}{c}\text { Salinity } \\
(\%)\end{array}$ & $\begin{array}{c}\text { Temperature } \\
\left({ }^{\circ} \mathrm{C}\right)\end{array}$ & $\begin{array}{c}\text { Dissolved } \\
\text { Oxygen } \\
\left(\mathrm{mg} \mathrm{L}^{-1}\right)\end{array}$ & $\mathrm{pH}$ \\
\hline MB-1210 & BKGD & 1 & 32.45 & 13.00 & 8.60 & 8.20 \\
MB-1210 & PLM-0 & 12 & 32.51 & 13.05 & 8.72 & 8.24 \\
MB-1210 & PLM-1 & 12 & 32.49 & 13.06 & 8.09 & 8.25 \\
MB-1210 & PLM-2 & 12 & 32.49 & 13.05 & 11.25 & 8.24 \\
MB-1210 & PLM-3 & 12 & 32.50 & 13.05 & 9.36 & 8.23 \\
MB-1305a & PLM-0 & 12 & 31.61 & 9.63 & 10.70 & 8.06 \\
MB-1305a & PLM-1 & 12 & 31.65 & 8.74 & 10.71 & 8.11 \\
MB-1305a & PLM-2 & 12 & 31.52 & 8.26 & 10.54 & 8.08 \\
MB-1305a & PLM-3 & 12 & 31.51 & 8.20 & 10.35 & 8.08 \\
MB-1305b & DS1 & 12 & 31.59 & 9.53 & 10.36 & 8.16 \\
MB-1305b & DS2 & 10 & 31.16 & 10.32 & 10.41 & 8.17 \\
MB-1305c & US & 12 & 31.74 & 9.84 & 10.24 & 7.98 \\
MB-1305c & BH & 5 & 31.31 & 11.20 & 9.21 & 8.00 \\
\hline
\end{tabular}


Table SI-4. Nutrient measurements in Massachusetts Bay samples collected in October 2012 (MB-1210) and May 2103 (MB-1305).

\begin{tabular}{ccccccc} 
Cruise ID & Station ID & $\begin{array}{c}\text { Depth } \\
(\mathrm{m})\end{array}$ & $\begin{array}{c}\mathrm{NH} 4 \\
(\mu \mathrm{M})\end{array}$ & $\begin{array}{c}\mathrm{SiO} 4 \\
(\mu \mathrm{M})\end{array}$ & $\begin{array}{c}\mathrm{PO} 4 \\
(\mu \mathrm{M})\end{array}$ & $\begin{array}{c}\mathrm{NO} 2+\mathrm{NO} 3 \\
(\mu \mathrm{M})\end{array}$ \\
\hline MB-1210 & BKGD & 1 & $<0.05$ & 3.2 & 0.2 & 0.2 \\
MB-1210 & PLM-0 & 12 & $<0.05$ & 2.7 & 0.2 & 0.1 \\
MB-1210 & PLM-1 & 12 & $<0.05$ & 2.4 & 0.1 & 0.1 \\
MB-1210 & PLM-2 & 12 & $<0.05$ & 2.3 & 0.1 & $<0.05$ \\
MB-1210 & PLM-3 & 12 & $<0.05$ & 2.3 & 0.1 & $<0.05$ \\
MB-1305a & PLM-0 & 12 & 1.9 & 4.4 & $<0.05$ & $<0.05$ \\
MB-1305a & PLM-1 & 12 & $<0.05$ & 3.6 & $<0.05$ & $<0.05$ \\
MB-1305a & PLM-2 & 12 & 9.9 & 4.3 & 0.1 & 0.8 \\
MB-1305a & PLM-3 & 12 & 14.7 & 4.8 & 0.3 & 1.0 \\
MB-1305b & DS1 & 12 & $<0.05$ & 3.5 & $<0.05$ & $<0.05$ \\
MB-1305b & DS2 & 10 & $<0.05$ & 3.0 & $<0.05$ & $<0.05$ \\
MB-1305c & US & 12 & 3.0 & 2.7 & $<0.05$ & 0.3 \\
MB-1305c & BH & 5 & 0.6 & 4.1 & $<0.05$ & 0.5 \\
Mass Bay background & & 3.6 & & & \\
DITP final effluent & & & 1860 & & & \\
\hline
\end{tabular}

$<$ indicates values below the detection limit

${ }^{a}$ (Hunt, Mansfield et al. 2010) 
Table SI-5. Measurements of organic carbon and nitrogen concentrations and isotopic ratios in Massachusetts Bay samples collected in October 2012 (MB-1210) and May 2103 (MB-1305).

\begin{tabular}{|c|c|c|c|c|c|c|c|}
\hline Cruise ID & Station ID & $\begin{array}{l}\text { Depth } \\
(\mathrm{m})\end{array}$ & $\begin{array}{c}\mathrm{DOC} \\
\left(\mathrm{mg} \mathrm{L}^{-1}\right) \\
\end{array}$ & $\begin{array}{c}\mathrm{POC} \\
\left(\mathrm{mg} \mathrm{L}^{-1}\right)\end{array}$ & $\begin{array}{c}\delta^{13} \mathrm{C}_{\mathrm{POC}}{ }^{\mathrm{a}} \\
(\% \mathrm{o})^{\mathrm{b}}\end{array}$ & $\begin{array}{c}\text { PON } \\
\left(\mu \mathrm{g} \mathrm{L}^{-1}\right)\end{array}$ & $\begin{array}{c}\delta^{15} \mathrm{~N}_{\mathrm{PON}}{ }^{\mathrm{c}} \\
(\%)^{\mathrm{c}}\end{array}$ \\
\hline MB-1210 & BKGD & 1 & $\mathrm{n} / \mathrm{d}$ & 0.33 & -19.9 & 50.1 & 3.7 \\
\hline MB-1210 & PLM-0 & 12 & $\mathrm{n} / \mathrm{d}$ & 0.26 & -21.0 & 38.4 & 4.3 \\
\hline MB-1210 & PLM-1 & 12 & $\mathrm{n} / \mathrm{d}$ & 0.31 & -19.1 & 45.4 & 5.3 \\
\hline MB-1210 & PLM-2 & 12 & $\mathrm{n} / \mathrm{d}$ & 0.40 & -20.6 & 52.9 & 5.3 \\
\hline MB-1210 & PLM-3 & 12 & $\mathrm{n} / \mathrm{d}$ & 0.38 & -19.4 & 49.4 & 5.2 \\
\hline MB-1305a & PLM-0 & 12 & 1.3 & 0.21 & -22.4 & 43.4 & 3.7 \\
\hline MB-1305a & PLM-1 & 12 & 1.7 & 0.11 & -22.2 & 13.2 & 3.9 \\
\hline MB-1305a & PLM-2 & 12 & 1.4 & 0.08 & -24.4 & 14.1 & 5.0 \\
\hline MB-1305a & PLM-3 & 12 & 1.5 & 0.04 & -26.1 & 4.2 & nd \\
\hline MB-1305b & DS1 & 12 & 1.7 & 0.14 & -22.5 & 28.4 & 1.3 \\
\hline MB-1305b & DS2 & 10 & 1.6 & 0.15 & -24.4 & 26.6 & 4.7 \\
\hline MB-1305c & US & 12 & 1.6 & 0.20 & -21.2 & 41.6 & 4.1 \\
\hline MB-1305c & $\mathrm{BH}$ & 5 & 1.5 & 0.18 & -23.5 & 35.9 & 4.9 \\
\hline \multicolumn{2}{|c|}{ Mass Bay background ${ }^{\mathrm{d}}$} & & 1.2 & 0.17 & & & \\
\hline
\end{tabular}

\footnotetext{
${ }^{a}$ measured by gas chromatography-isotope ratio mass spectrometry at the MBL Stable Isotope Laboratory

${ }^{\mathrm{b}}$ versus PDB

${ }^{\mathrm{c}}$ versus AIR

d (Gustafsson, Long et al. 2001) $\mathrm{n} / \mathrm{d}$ : not determined
} 
Table SI-6. Estrogen concentrations in Deer Island Treatment Plant wastewater effluent (grab, 24-h composite) collected on 26 October 2012 (DI-1210) and 16 May 2013 (DI1305) to coincide with Massachusetts Bay samples (MB-1210 and MB-1305). See Chapter 2 (Table 1) for method limit thresholds $\left(\mathrm{L}_{\mathrm{C}}, \mathrm{L}_{\mathrm{D}}\right.$, and $\left.\mathrm{L}_{\mathrm{Q}}\right)$.

\begin{tabular}{|c|c|c|c|c|c|c|}
\hline \multirow[b]{3}{*}{ Analyte } & \multicolumn{6}{|c|}{ (ng L ${ }^{-1}$ effluent) } \\
\hline & \multicolumn{2}{|c|}{ DI-1210 GRAB } & \multicolumn{2}{|c|}{ DI-1305 GRAB } & \multicolumn{2}{|c|}{ DI-1305 COMP } \\
\hline & AVG & STDEV & AVG & STDEV & AVG & STDEV \\
\hline E3-3G & $\mathrm{n} / \mathrm{d}$ & $\mathrm{n} / \mathrm{d}$ & $\mathrm{n} / \mathrm{d}$ & $\mathrm{n} / \mathrm{d}$ & $\mathrm{n} / \mathrm{d}$ & $\mathrm{n} / \mathrm{d}$ \\
\hline E1-3G & $\mathrm{n} / \mathrm{d}$ & $\mathrm{n} / \mathrm{d}$ & 12.2 & 1.80 & 10.3 & 1.63 \\
\hline E2-3G & $\mathrm{n} / \mathrm{d}$ & $\mathrm{n} / \mathrm{d}$ & $\mathrm{n} / \mathrm{d}$ & $\mathrm{n} / \mathrm{d}$ & $\mathrm{n} / \mathrm{d}$ & $\mathrm{n} / \mathrm{d}$ \\
\hline EE2-3G & 0.96 & 0.06 & $\mathrm{n} / \mathrm{d}$ & $\mathrm{n} / \mathrm{d}$ & $\mathrm{n} / \mathrm{d}$ & $\mathrm{n} / \mathrm{d}$ \\
\hline E1-3S & $0.78^{\mathrm{c}}$ & 0.03 & $0.62^{\mathrm{c}}$ & 0.19 & 1.27 & 0.05 \\
\hline E2-3S & $0.22^{\mathrm{b}}$ & 0.03 & $0.23^{\mathrm{b}}$ & 0.06 & $0.25^{\mathrm{b}}$ & 0.07 \\
\hline EE2-3S & $0.26^{\mathrm{c}}$ & 0.02 & $\mathrm{n} / \mathrm{d}$ & $\mathrm{n} / \mathrm{d}$ & $\mathrm{n} / \mathrm{d}$ & $\mathrm{n} / \mathrm{d}$ \\
\hline E3 & 0.72 & 0.15 & 5.29 & 0.71 & 4.63 & 0.61 \\
\hline monoClE3 & $0.32^{\mathrm{c}}$ & 0.09 & $\mathrm{n} / \mathrm{d}$ & $\mathrm{n} / \mathrm{d}$ & $\mathrm{n} / \mathrm{d}$ & $\mathrm{n} / \mathrm{d}$ \\
\hline E1 & 12.9 & 0.15 & 18.1 & 4.03 & 13.2 & 1.56 \\
\hline E2 & 5.45 & 0.44 & 11.0 & 3.44 & 3.74 & 1.62 \\
\hline EE2 & $\mathrm{n} / \mathrm{d}$ & $\mathrm{n} / \mathrm{d}$ & 30.4 & 6.93 & 24.3 & 2.41 \\
\hline diClE3 & $\mathrm{n} / \mathrm{d}$ & $\mathrm{n} / \mathrm{d}$ & $\mathrm{n} / \mathrm{d}$ & $\mathrm{n} / \mathrm{d}$ & $\mathrm{n} / \mathrm{d}$ & $\mathrm{n} / \mathrm{d}$ \\
\hline monoClE1 & $\mathrm{n} / \mathrm{d}$ & $\mathrm{n} / \mathrm{d}$ & $\mathrm{n} / \mathrm{d}$ & $\mathrm{n} / \mathrm{d}$ & $\mathrm{n} / \mathrm{d}$ & $\mathrm{n} / \mathrm{d}$ \\
\hline monoBrEE2 & $\mathrm{n} / \mathrm{d}$ & $\mathrm{n} / \mathrm{d}$ & $\mathrm{n} / \mathrm{d}$ & $\mathrm{n} / \mathrm{d}$ & $\mathrm{n} / \mathrm{d}$ & $\mathrm{n} / \mathrm{d}$ \\
\hline monoBrE2 & $\mathrm{n} / \mathrm{d}$ & $\mathrm{n} / \mathrm{d}$ & $\mathrm{n} / \mathrm{d}$ & $\mathrm{n} / \mathrm{d}$ & $\mathrm{n} / \mathrm{d}$ & $\mathrm{n} / \mathrm{d}$ \\
\hline monoClEE2 & $\mathrm{n} / \mathrm{d}$ & $\mathrm{n} / \mathrm{d}$ & $\mathrm{n} / \mathrm{d}$ & $\mathrm{n} / \mathrm{d}$ & $\mathrm{n} / \mathrm{d}$ & $\mathrm{n} / \mathrm{d}$ \\
\hline monoClE2 & $\mathrm{n} / \mathrm{d}$ & $\mathrm{n} / \mathrm{d}$ & $\mathrm{n} / \mathrm{d}$ & $\mathrm{n} / \mathrm{d}$ & $\mathrm{n} / \mathrm{d}$ & $\mathrm{n} / \mathrm{d}$ \\
\hline diClE1 & $\mathrm{n} / \mathrm{d}$ & $\mathrm{n} / \mathrm{d}$ & $\mathrm{n} / \mathrm{d}$ & $\mathrm{n} / \mathrm{d}$ & $\mathrm{n} / \mathrm{d}$ & $\mathrm{n} / \mathrm{d}$ \\
\hline diClEE2 & $\mathrm{n} / \mathrm{d}$ & $\mathrm{n} / \mathrm{d}$ & $\mathrm{n} / \mathrm{d}$ & $\mathrm{n} / \mathrm{d}$ & $\mathrm{n} / \mathrm{d}$ & $\mathrm{n} / \mathrm{d}$ \\
\hline diClE2 & $6.16^{\mathrm{c}}$ & 0.87 & 35.6 & 11.5 & 26.0 & 4.28 \\
\hline diBrEE2 & $6.17^{\mathrm{b}}$ & 0.19 & $\mathrm{n} / \mathrm{d}$ & $\mathrm{n} / \mathrm{d}$ & $\mathrm{n} / \mathrm{d}$ & $\mathrm{n} / \mathrm{d}$ \\
\hline diBrE2 & $\mathrm{n} / \mathrm{d}$ & $\mathrm{n} / \mathrm{d}$ & 11.25 & 3.80 & $\mathrm{n} / \mathrm{d}$ & $\mathrm{n} / \mathrm{d}$ \\
\hline
\end{tabular}

${ }^{a}$ less than $\mathrm{L}_{\mathrm{C}}$

${ }^{\mathrm{b}}$ less than $\mathrm{L}_{\mathrm{D}}$

${ }^{c}$ less than $\mathrm{L}_{\mathrm{Q}}$

$\mathrm{n} / \mathrm{d}$ : indicates that no peak was found 


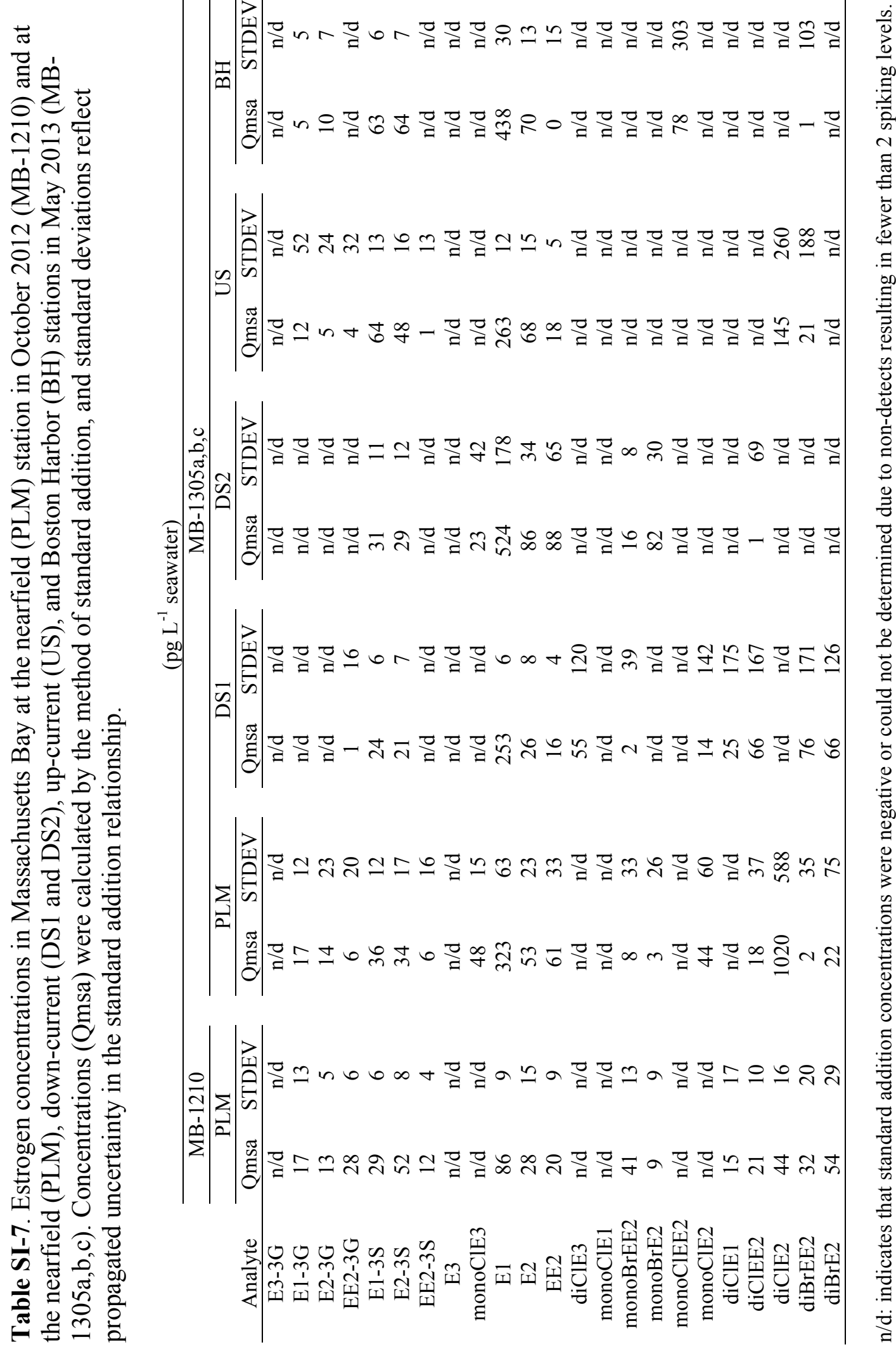




\section{REFERENCES}

Atkinson, S., M. J. Atkinson, et al. (2003). "Estrogens from sewage in coastal marine environments." Environmental Health Perspectives 111(4): 531-535.

Axelson, M., B. L. Sahlberg, et al. (1981). "Analysis of profiles of conjugated steroids in urine by ion-exchange separation and gas chromatography-mass spectrometry." Journal of Chromatography 224(3): 355-370.

Baronti, C., R. Curini, et al. (2000). "Monitoring natural and synthetic estrogens at activated sludge sewage treatment plants and in a receiving river water." Environmental Science \& Technology 34(24): 5059-5066.

Beck, I. C., R. Bruhn, et al. (2005). "Liquid chromatography-tandem mass spectrometry analysis of estrogenic compounds in coastal surface water of the Baltic Sea." Journal of Chromatography A 1090(1-2): 98-106.

Benotti, M. J. and B. J. Brownawell (2007). "Distributions of pharmaceuticals in an urban estuary during both dry- and wet-weather conditions." Environmental Science \& Technology 41(16): 5795-5802.

Borg, B. (1994). "Androgens in teleost fishes." Comparative Biochemistry and Physiology Part C: Pharmacology, Toxicology and Endocrinology 109(3): 219245.

Boyd, R. K., C. Basic, et al. (2008). Trace Quantitative Analysis by Mass Spectrometry. West Sussex, England, John Wiley \& Sons Ltd.

Buerge, I. J., T. Poiger, et al. (2003). "Caffeine, an anthropogenic marker for wastewater contamination of surface waters." Environmental Science \& Technology 37(4): 691-700.

Burgess, C. (2003). "Estrogens in coastal waters - The sewage source." Environmental Health Perspectives 111(4): A232-A232.

Chen, C. S., R. C. Beardsley, et al. (2009). The Massachusetts Bay hydrodynamic model: 2006-2007 simulation. Boston, Massachusetts Water Resources Authority: 77.

Chen, C. S., H. D. Liu, et al. (2003). "An unstructured grid, finite-volume, threedimensional, primitive equations ocean model: Application to coastal ocean and estuaries." Journal of Atmospheric and Oceanic Technology 20(1): 159-186.

Delaney, M. F. and A. C. Rex (2007). Contaminant Monitoring of Deer Island Treatment Plant Effluent: 2000-2005. Boston, Massachusetts Water Resources Authority: 40 . 
Dickenson, E. R. V., S. A. Snyder, et al. (2011). "Indicator compounds for assessment of wastewater effluent contributions to flow and water quality." Water Research 45(3): 1199-1212.

Flanagan, S. M., M. G. Nielson, et al. (1999). Water-Quality Assessment of the New England Coastal Basins in Maine, Massachusetts, New Hampshire, and Rhode Island: Environmental Settings and Implications for Water Quality and Aquatic Biota. Pembroke, NH, U.S. Geological Survey: 64.

Gomes, R. L., M. D. Scrimshaw, et al. (2009). "Fate of Conjugated Natural and Synthetic Steroid Estrogens in Crude Sewage and Activated Sludge Batch Studies." Environmental Science \& Technology 43(10): 3612-3618.

Gustafsson, O., C. M. Long, et al. (2001). "Fate of Linear alkylbenzenes released to the coastal environment near Boston Harbor." Environmental Science \& Technology 35(10): 2040-2048.

Hanselman, T. A., D. A. Graetz, et al. (2003). "Manure-borne estrogens as potential environmental contaminants: A review." Environmental Science \& Technology 37(24): 5471-5478.

Hu, J. Y., S. J. Cheng, et al. (2003). "Products of aqueous chlorination of 17 betaestradiol and their estrogenic activities." Environmental Science \& Technology 37(24): 5665-5670.

Hunt, C. D., A. D. Mansfield, et al. (2010). "Plume tracking and dilution of effluent from the Boston sewage outfall." Marine Environmental Research 70(2): 150-161.

Hwang, J., D. Montlucon, et al. (2009). "Molecular and isotopic constraints on the sources of suspended particulate organic carbon on the northwestern Atlantic margin." Deep-Sea Research Part I 56(8): 1284-1297.

Hyde, K. J. W., J. E. O'Reilly, et al. (2007). "Validation of SeaWiFS chlorophyll a in Massachusetts Bay." Continental Shelf Research 27(12): 1677-1691.

Jiang, M. S. and M. Zhou (2008). The Massachusetts Bay Hydrodynamic Model: 2005 Simulation. Boston, Massachusetts Water Resources Authority: 58.

Johnson, A. C. and J. P. Sumpter (2001). "Removal of endocrine-disrupting chemicals in activated sludge treatment works." Environmental Science \& Technology 35(24): 4697-4703.

Johnson, A. C. and R. J. Williams (2004). "A model to estimate influent and effluent concentrations of estradiol, estrone, and ethinylestradiol at sewage treatment works." Environmental Science \& Technology 38(13): 3649-3658. 
Johnson, A. C., R. J. Williams, et al. (2007). "What difference might sewage treatment performance make to endocrine disruption in rivers?" Environmental Pollution 147(1): 194-202.

Kidd, K. A., P. J. Blanchfield, et al. (2007). "Collapse of a fish population after exposure to a synthetic estrogen." Proceedings of the National Academy of Sciences of the United States of America 104(21): 8897-8901.

Kolodziej, E. P., T. Harter, et al. (2004). "Dairy wastewater, aquaculture, and spawning fish as sources of steroid hormones in the aquatic environment." Environmental Science \& Technology 38(23): 6377-6384.

Kolpin, D. W., E. T. Furlong, et al. (2002). "Pharmaceuticals, hormones, and other organic wastewater contaminants in US streams, 1999-2000: A national reconnaissance." Environmental Science \& Technology 36(6): 1202-1211.

Link, J. S., C. A. Griswold, et al. (2006). Documentation for the Energy Modeling and Analysis eXercise (EMAX). , US Dep. Commer., Northeast Fish. Sci. Cent.: 166.

Makris, N. C., P. Ratilal, et al. (2006). "Fish population and behavior revealed by instantaneous continental shelf-scale imaging." Science 311(5761): 660-663.

Miao, X.-S. and C. D. Metcalfe (2003). "Determination of carbamazepine and its metabolites in aqueous samples using liquid chromatography-electrospray tandem mass spectrometry." Analytical Chemistry 75(15): 3731-3738.

Moriyama, K., H. Matsufuji, et al. (2004). "Identification and behavior of reaction products formed by chlorination of ethynylestradiol." Chemosphere 55(6): 839847.

Mukawa, F., T. Suzuki, et al. (1988). "Estrogen and androgen receptor binding affinity of 10-beta-chloro-estrene derivatives." Journal of Steroid Biochemistry and Molecular Biology 31(5): 867-870.

Nakada, N., K. Kiri, et al. (2008). "Evaluation of pharmaceuticals and personal care products as water-soluble molecular markers of sewage." Environmental Science \& Technology 42(17): 6347-6353.

Nakada, N., T. Tanishima, et al. (2006). "Pharmaceutical chemicals and endocrine disrupters in municipal wastewater in Tokyo and their removal during activated sludge treatment." Water Research 40(17): 3297-3303.

Nakamura, H., R. Kuruto-Niwa, et al. (2007). "Formation of chlorinated estrones via hypochlorous disinfection of wastewater effluent containing estrone." Chemosphere 66(8): 1441-1448. 
Nakamura, H., T. Shiozawa, et al. (2006). "By-products produced by the reaction of estrogens with hypochlorous acid and their estrogen activities." Journal of Health Science 52(2): 124-131.

Ort, C., M. G. Lawrence, et al. (2010). "Sampling for PPCPs in Wastewater Systems: Comparison of Different Sampling Modes and Optimization Strategies." Environmental Science \& Technology 44(16): 6289-6296.

Perkins, S. (2008). Draft national pollutant discharge elimination system (NPDES) permit to discharge to waters of the United States - Fact Sheet \#MA0100501. Boston, MA, Office of Ecosystem Protection, U.S. Environmental Protection Agency: 16.

Roman, J. and J. J. McCarthy (2010). "The Whale Pump: Marine Mammals Enhance Primary Productivity in a Coastal Basin." Plos One 5(10).

Saravanabhavan, G., R. Helleur, et al. (2009). "GC-MS/MS measurement of natural and synthetic estrogens in receiving waters and mussels close to a raw sewage ocean outfall." Chemosphere 76(8): 1156-1162.

Teerlink, J., A. S. Hering, et al. (2012). "Variability of trace organic chemical concentrations in raw wastewater at three distinct sewershed scales." Water Research 46(10): 3261-3271.

USGS. (2013). "USGS current water data for the nation." National Water Information System: Web Interface Retrieved 1 August, 2013, from http://waterdata.usgs.gov/usa/nwis/rt.

Williams, R. J., A. C. Johnson, et al. (2003). "Steroid estrogens profiles along river stretches arising from sewage treatment works discharges." Environmental Science \& Technology 37(9): 1744-1750.

Wu, Q. Y., H. Y. Hu, et al. (2009). "Effect of Chlorination on the Estrogenic/Antiestrogenic Activities of Biologically Treated Wastewater." Environmental Science \& Technology 43(13): 4940-4945. 


\section{Chapter 4}

\section{Carbon isotopic $\left({ }^{13} \mathrm{C}\right.$ and $\left.{ }^{14} \mathrm{C}\right)$ composition of synthetic estrogens and progestogens}

This chapter was originally published in Rapid Communications in Mass Spectrometry by John Wiley \& Sons and is reproduced here with their permission

Carbon isotopic $\left({ }^{13} \mathrm{C}\right.$ and $\left.{ }^{14} \mathrm{C}\right)$ composition of synthetic estrogens and progestogens. Rapid Communications in Mass Spectrometry. D.R. Griffith, L. Wacker, P.M. Gschwend, T.I. Eglinton. 2012. 26: 2619-2626. doi:10.1002/rcm.6385 


\author{
David R. Griffith ${ }^{1 *}$, Lukas Wacker ${ }^{2}$, Philip M. Gschwend ${ }^{3}$ and Timothy I. Eglinton ${ }^{4}$ \\ ${ }^{1} \mathrm{MIT} / \mathrm{WHOI}$ Joint Program in Oceanography, Cambridge, MA, USA \\ ${ }^{2}$ Swiss Federal Institute of Technology (ETH), Ion Beam Physics, Zürich, Switzerland \\ ${ }^{3}$ Massachusetts Institute of Technology, Civil and Environmental Engineering, Cambridge, MA, USA \\ ${ }^{4}$ Swiss Federal Institute of Technology (ETH), Geological Institute, Zürich, Switzerland
}

RATIONALE: Steroids are potent hormones that are found in many environments. Yet, contributions from synthetic and endogenous sources are largely uncharacterized. The goal of this study was to evaluate whether carbon isotopes could be used to distinguish between synthetic and endogenous steroids in wastewater and other environmental matrices.

METHODS: Estrogens and progestogens were isolated from oral contraceptive pills using semi-preparative liquid chromatography/diode array detection (LC/DAD). Compound purity was confirmed by gas chromatography/flame ionization detection (GC/FID), gas chromatography/time-of-flight mass spectrometry (GC/TOF-MS) and liquid chromatography/mass spectrometry using negative electrospray ionization (LC/ESI-MS). The ${ }^{13} \mathrm{C}$ content was determined by gas chromatography/isotope ratio mass spectrometry (GC/IRMS) and ${ }^{14} \mathrm{C}$ was measured by accelerator mass spectrometry (AMS).

RESULTS: Synthetic estrogens and progestogens are ${ }^{13} \mathrm{C}$-depleted $\left(\delta^{13} \mathrm{C}_{\text {estrogen }}=-30.0 \pm 0.9 \% ; \delta^{13} C_{\text {progestogen }}=-30.3 \pm 2.6 \%\right.$ ) compared with endogenous hormones $\left(\delta^{13} \mathrm{C} \sim-16\right.$ to $\left.-26 \%\right)$. The ${ }^{14} \mathrm{C}$ content of the majority of synthetic hormones is consistent with synthesis from $\mathrm{C}_{3}$ plant-based precursors, amended with 'fossil' carbon in the case of $\mathrm{EE}_{2}$ and norethindrone acetate. Exceptions are progestogens that contain an ethyl group at carbon position 13 and have entirely 'fossil' ${ }^{14} \mathrm{C}$ signatures.

CONCLUSIONS: Carbon isotope measurements have the potential to distinguish between synthetic and endogenous hormones in the environment. Our results suggest that ${ }^{13} \mathrm{C}$ could be used to discriminate endogenous from synthetic estrogens in animal waste, wastewater effluent, and natural waters. In contrast, ${ }^{13} \mathrm{C}$ and ${ }^{14} \mathrm{C}$ together may prove useful for tracking synthetic progestogens. Copyright (C) 2012 John Wiley \& Sons, Ltd.

In the last two decades, thousands of studies have attempted to characterize the concentration and toxicity of endocrine disrupting chemicals (EDCs) in aquatic environments. Much of this research has focused on steroidal hormones such as estrogens, which are particularly potent EDCs, capable of negatively affecting the normal functioning of aquatic organisms and human populations at extremely low (sub ng L ${ }^{-1}$ ) concentrations. ${ }^{[1,2]}$

Steroidal hormones include a variety of familiar compounds (e.g., testosterone, progesterone, and estrogen) that are naturally produced by all vertebrates to support growth and development. Many of these so-called endogenous hormones are also synthesized for use in contraceptive, veterinary, scientific, and medical applications. ${ }^{[3]}$

Both endogenous and synthetic estrogens can enter surface waters by a variety of pathways. Major sources include wastewater treatment plant effluent, septic systems, and livestock operations. Biodegradation is responsible for significant estrogen reductions in treatment plants, septic systems,

\footnotetext{
* Correspondence to: D. R. Griffith, MIT/WHOI Joint Program in Oceanography, 15 Vassar St., Massachusetts Institute of Technology, Cambridge, MA 02139, USA.

E-mail: griffdr@mit.edu
}

and natural waters. However, $15 \%$ of the estrogen flux typically escapes treatment and is discharged directly to receiving waters. ${ }^{[4]}$ The specific organisms and mechanisms that support hormone degradation are largely unknown, but they are clearly important for managing the risks associated with EDC pollution in natural waters.

Although many studies have characterized estrogen concentrations in receiving waters, few have specifically characterized the proportions derived from synthetic versus endogenous sources. This information is valuable for evaluating and apportioning 'problem' sources, designing effective treatment schemes, and better understanding the environmental fate of synthetic and endogenous estrogens in terms of the mechanisms and byproducts of biodegradation.

Synthetic pharmaceutical hormones often have unique chemical structures that improve their pharmacokinetic profiles. For example, the active estrogen in most oral contraceptive pills, $17 \alpha$-ethynylestradiol $\left(\mathrm{EE}_{2}\right)$, contains a characteristic ethynyl group, which sets it apart from endogenous estrogens, extends its half-life in the body, and facilitates its detection in the environment by chemical means (e.g., GC/MS or LC/MS). In other cases, synthetic hormones have identical chemical structures to their endogenous counterparts, making chemical discrimination difficult. For example, some synthetic estrogens administered to cattle or used in human hormone replacement 
therapy are chemically identical to endogenous estrogens. Fortunately, natural abundance isotope measurements can help distinguish between the two. In fact, stable carbon isotopes $\left({ }^{12} \mathrm{C}\right.$ and $\left.{ }^{13} \mathrm{C}\right)$ have already been used to characterize the provenance of certain chemicals for a variety of purposes, such as verifying product labels, protecting against pharmaceutical fraud, and detecting performance enhancing substance abuse. ${ }^{[5-7]}$

This last application takes advantage of the fact that endogenous steroids typically contain significantly more ${ }^{13} \mathrm{C}$ than synthetic steroids. ${ }^{[8-11]}$ The present study was designed to test whether synthetic estrogens and progestogens, such as those found in oral contraceptive pills and commercial preparations, are similarly depleted in ${ }^{13} \mathrm{C}$.

We also hypothesized that coupled radiocarbon $\left({ }^{14} \mathrm{C}\right)$ measurements could improve our ability to characterize the source signatures of synthetic hormones. Radiocarbon (5730 years half-life) is a powerful tracer of 'fossil' carbon since petroleum and natural gas no longer contain ${ }^{14} \mathrm{C}$ while recently fixed $\mathrm{CO}_{2}$ contains much higher levels of ${ }^{14} \mathrm{C}$. This distinction has been useful in a variety of applications, including characterizing the fate of fossil fuel $\mathrm{CO}_{2}$ and discriminating between natural and synthetic chemicals in the environment.

Here we present a method for isolating the steroidal hormones from oral contraceptive pills and report results for compound-specific ${ }^{13} \mathrm{C}$ and ${ }^{14} \mathrm{C}$ measurements. The goal of this study was to characterize the ${ }^{13} \mathrm{C}$ and ${ }^{14} \mathrm{C}$ signature of numerous synthetic estrogens and progestogens (Fig. 1) in order to evaluate whether carbon isotopes could be used to help elucidate the sources of these hormones in complex environmental systems.

\section{EXPERIMENTAL}

A semi-preparative liquid chromatographic method was developed to isolate pure $\mathrm{EE}_{2}$ and progestogens from contraceptive pills for carbon isotope $\left({ }^{13} \mathrm{C}\right.$ and ${ }^{14} \mathrm{C}$ ) analysis (Fig. 2). Nine types of oral contraceptive pills and seven commercially available authentic steroid hormone standards were investigated. For the purposes of this study, we assume that these standards are representative of mass-produced synthetic estrogens and progestogens used in medical and veterinary applications. Standards were purchased from Sigma-Aldrich (St. Louis, MO, USA) (estrone ( $\left.E_{1}\right), \geq 99 \%$; 17 $\beta$-estradiol $\left(E_{2}\right), \geq 98 \%$; estriol $\left(\mathrm{E}_{3}\right), 98 \%$; $17 \alpha$-ethynylestradiol $\left(\mathrm{EE}_{2}\right), \geq 98 \%$; progesterone, $\geq 99 \%$; desogestrel, $99.7 \%$; levonorgestrel, $\geq 99 \%$ ). All solvents were Chromasolv grade from Sigma-Aldrich, and all glassware and filters were baked at $450{ }^{\circ} \mathrm{C}$ for $5 \mathrm{~h}$ prior to use.

\section{Pill preparation}

Oral contraceptive pills were crushed with an agate mortar and pestle, extracted by sonication in $15 \mathrm{~mL}$ methanol for $25 \mathrm{~min}$, and filtered through a GF/F filter (Whatman, Maidstone, UK). The filtrate was reduced to dryness under

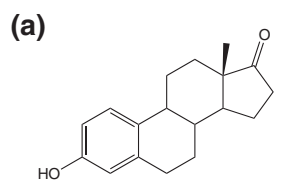

Estrone $\left(\mathrm{E}_{1}\right)$, MW 270.4

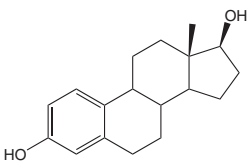

17ß-Estradiol $\left(\mathrm{E}_{2}\right)$, MW 272.4

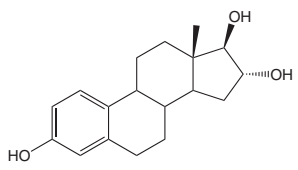

Estriol $\left(E_{3}\right), M W 288.4 \quad 17 \alpha$-Ethynylestradiol $\left(E_{2}\right)$, MW 296.4 (b)

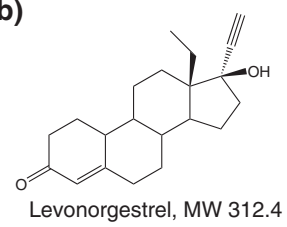

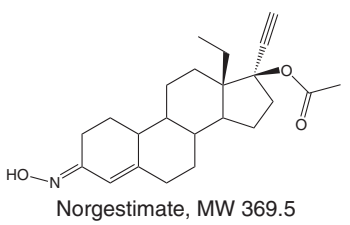

Norgestimate, MW 369.5

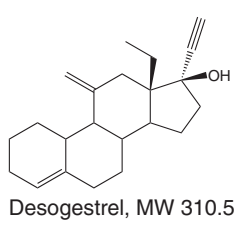

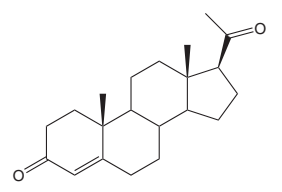

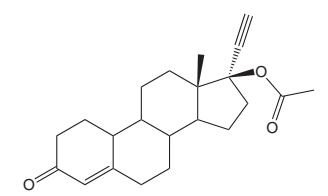

Norethindrone acetate, MW 340.5

(c)
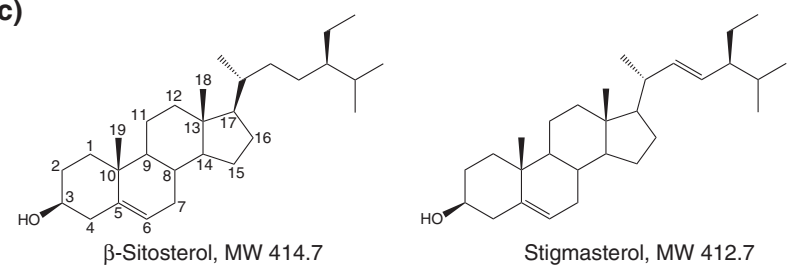

Stigmasterol, MW 412.7

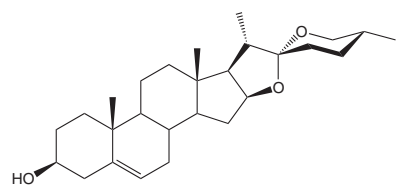

Diosgenin, MW 414.6

Figure 1. Chemical structures of (a) estrogens, (b) progestogens, and (c) steroidal precursors. Generic steroid carbon position numbers are shown on the structure of $\beta$-sitosterol. 
${ }^{13} \mathrm{C}$ and ${ }^{14} \mathrm{C}$ composition of synthetic estrogens and progestogens

elution (70-100\% methanol; $2 \% \mathrm{~min}^{-1}$ ) at a flow rate of $1.5 \mathrm{~mL} \mathrm{~min}{ }^{-1}$ and a column temperature of $25^{\circ} \mathrm{C}$. In all cases $\mathrm{EE}_{2}$ eluted first $(4.55-5.10 \mathrm{~min})$, followed by the progestogens: levonorgestrel (5.40-5.90 $\mathrm{min})$, norethindrone acetate (6.35-6.95 min), norgestimate 'a' (8.35-8.90 $\mathrm{min})$, norgestimate ' $\mathrm{b}$ ' (8.90-9.45 min), and desogestrel (14.00-14.50 min). Fractions were collected from two to four individual $100 \mu \mathrm{L}$ injections and then they were combined and stored at $-20^{\circ} \mathrm{C}$. Clean solvent (70:30 methanol/MilliQ water) was also injected $(11 \times 100 \mu \mathrm{L})$ so that corresponding fractions could be used to correct for organic interferences ('column bleed') present in the mobile phase and released from the column during each time interval.

\section{Fraction cleanup}

All sample and column bleed fractions were reduced to dryness under $\mathrm{N}_{2}\left(40{ }^{\circ} \mathrm{C}\right)$ and transferred to a ${ }^{14} \mathrm{C}$-clean laminar flow hood for clean up on $250 \mathrm{mg}$ of fully activated $\left(450{ }^{\circ} \mathrm{C} ; 8 \mathrm{~h}\right.$ ) silica gel (100-200 mesh). After sample loading, hexane $(2 \mathrm{~mL})$, ethyl acetate $(3 \mathrm{~mL})$, and methanol $(2 \mathrm{~mL})$ were successively passed through the silica gel column. All the compounds of interest eluted in the ethyl acetate fraction, from which a small aliquot ( $17 \mu \mathrm{L}$ or $\sim 0.5 \%$ ) was removed to confirm fraction purity by GC with flame ionization detection (FID) and GC coupled with time-of-flight mass spectrometry (TOF-MS). Methanol fractions were also analyzed to confirm that target compounds eluted completely in the ethyl acetate fraction.

\section{Fraction purity and blank assessment}

In addition to the LC/DAD and LC/MS analyses mentioned above, GC/FID and GC/TOF-MS analyses confirmed the identity and purity of each ethyl acetate fraction. Moreover, a blank ethyl acetate fraction collected from the silica gel cleanup step and all the column bleed fractions were indistinguishable from a GC blank injection. Non-active sugar pills included in oral contraceptive pill packaging were processed alongside sample pills and this confirmed that cross-contamination was not a problem during pill preparation. The six column bleed fractions were subsequently quantified and analyzed for ${ }^{14} \mathrm{C}$.

analyzing the carbon isotopic composition of estrogens and progestogens in oral contraceptive pills.

vacuum $\left(300 \mathrm{mbar} ; 60^{\circ} \mathrm{C}\right.$ ) then dissolved in dichloromethane $(10 \mathrm{~mL})$, washed with MilliQ water (Millipore, Billerica, MA, USA; $3 \times 5 \mathrm{~mL} ; \mathrm{pH}$ ), and dried over baked anhydrous $\mathrm{Na}_{2} \mathrm{SO}_{4}\left(450{ }^{\circ} \mathrm{C} ; 5 \mathrm{~h}\right)$. This extract was then reduced to dryness under $\mathrm{N}_{2}\left(40{ }^{\circ} \mathrm{C}\right)$ and finally reconstituted in $500 \mu \mathrm{L}$ 70:30 methanol/MilliQ water.

Liquid chromatography, coupled to mass spectrometry (LC/MS) and UV-visible diode array detection (LC/DAD), was used to confirm the identities of steroidal hormones in each extract. The LC/MS instrument (6130 single quadrupole mass spectrometer; Agilent, Santa Clara, CA, USA) was operated in negative electrospray ionization (ESI), full scan $(\mathrm{m} / z$ 120-400) mode. The LC/DAD instrument (Agilent 1260) monitored three wavelengths $(210,254$, and $280 \mathrm{~nm}$ ) and collected full UV-visible (210-400 nm) spectra at the base and apex of each chromatographic peak

\section{Fraction collection}

For compound isolation, the LC/DAD system was configured to collect fractions corresponding to the individual $\mathrm{EE}_{2}$ and progestogen peaks. Separation was achieved on a Hypersil GOLD C18 aQ column (Thermo Fisher Scientific, Waltham, MA, USA; $5 \mu \mathrm{m}, 250 \times 4.6 \mathrm{~mm}$ ) using gradient

\section{Quantification and combustion}

The remainders of each ethyl acetate fraction were transferred to a pre-baked $\left(850{ }^{\circ} \mathrm{C} ; 5 \mathrm{~h}\right)$ quartz tube and blown dry under $\mathrm{N}_{2}\left(40{ }^{\circ} \mathrm{C}\right)$. Pre-baked $\mathrm{CuO}\left(850{ }^{\circ} \mathrm{C} ; 5 \mathrm{~h}\right)$ was added and each tube was evacuated and sealed on a vacuum line, then baked at $850{ }^{\circ} \mathrm{C}$ for $5 \mathrm{~h}$. The resulting $\mathrm{CO}_{2}$ was quantified manometrically and split into three aliquots. One aliquot was measured for stable carbon isotopic composition $\left({ }^{13} \mathrm{C}\right.$ value) on a VG PRISM series II mass spectrometer (VG Isotech, defunct) at the National Ocean Sciences Accelerator Mass Spectrometry (NOSAMS) facility at Woods Hole Oceanographic Institution (Woods Hole, MA, USA). The second aliquot was used for ${ }^{14} \mathrm{C}$ analysis on the compact accelerator mass spectrometer MICADAS equipped with a gas ion source for small samples ${ }^{[12-15]}$ at the Laboratory for Ion Beam Physics at ETH (Zürich, Switzerland). The third aliquot was archived.

Small amounts $(\sim 1 \mathrm{mg})$ of authentic estrogen and progestogen standards were also submitted to NOSAMS for ${ }^{13} \mathrm{C}$ and

${ }^{14} \mathrm{C}$ analysis without preprocessing. All radiocarbon data are reported according to accepted conventions. ${ }^{[16,17]}$ 


\section{Column bleed corrections}

By the end of sample processing, the column bleed fraction corresponding to the $\mathrm{EE}_{2}$ time window contained $0.9 \mu \mathrm{g}$ carbon per LC run, or $3.7 \%$ of a typical $\mathrm{EE}_{2}$ sample. The ${ }^{14} \mathrm{C}$ content of this fraction $\left(\Delta^{14} \mathrm{C}=-947 \pm 8 \%\right.$ ) was used to correct sample $\mathrm{EE}_{2} \Delta^{14} \mathrm{C}$ values for contributions of carbon carried by the LC mobile phase. The progestogen samples were corrected similarly using the appropriate column bleed fractions, which contained $\sim 0.5 \mu \mathrm{g}$ carbon $\left(\Delta^{14} \mathrm{C}=-825 \pm 27 \%\right.$ ) per LC run, or no more than $1.5 \%$ of the smallest progestogen sample.

The reported $\Delta^{14} \mathrm{C}$ values were also corrected for instrumental blanks and normalized using the oxalic acid standard OX-II; reported errors represent propagated errors from all corrections. Due to there being insufficient carbon in the column bleed fractions, the $\delta^{13} \mathrm{C}$ values (all referenced to VPDB) were only corrected for instrumental blanks.

\section{RESULTS AND DISCUSSION}

\section{Estrogens}

The ${ }^{14} \mathrm{C}$ content of $\mathrm{EE}_{2}$ isolated from oral contraceptive pills $\left(\Delta^{14} \mathrm{C}=-189 \pm 18 \%\right.$; Table 1, Fig. 3) suggests that $\mathrm{EE}_{2}$ is synthesized from primarily plant-based steroidal starting materials amended with small amounts of fossil (natural gas or petrochemical) carbon. The mean ${ }^{13} \mathrm{C}$ content of $\mathrm{EE}_{2}$ $\left(\delta^{13} \mathrm{C}=-29.4 \pm 0.3 \%\right.$; Table 1, Fig. 3$)$ is consistent with known steroidal precursors ( $\beta$-sitosterol, stigmasterol, diosgenin; Fig. 1) found in $\mathrm{C}_{3}$ plants such as soybean (Glycine max) and wild yam (Discorea spp.). ${ }^{[18-21]}$

It is possible to quantify the fraction of $\mathrm{EE}_{2}$ carbon derived from fossil ( $\left.f_{\text {fossil }}\right)$ and modern ( $\left.f_{\text {modern }}\right)$ sources using the following equations:

$$
\begin{gathered}
\mathrm{f}_{\text {fossil }}+\mathrm{f}_{\text {modern }}=1 \\
\Delta^{14} C_{\text {measured }}=\mathrm{f}_{\text {fossil }}\left(\Delta^{14} C_{\text {fossil }}\right)+\mathrm{f}_{\text {modern }}\left(\Delta^{14} C_{\text {modern }}\right)
\end{gathered}
$$

where we assume that $\Delta^{14} C_{\text {fossil }}=-1000 \%$ and $\Delta^{14} C_{\text {modern }}=$ $50 \%$. Measured $\Delta^{14} \mathrm{C}$ values indicate that, on average, $23 \%$ (or 4.5 out of 20) of the carbon atoms in $\mathrm{EE}_{2}$ are derived from fossil sources. If we assume that both ethynyl carbon atoms in $\mathrm{EE}_{2}$ are petrochemical, the plant-based precursor compounds must also contain some fossil carbon atoms. These fossil carbons are probably derived from $\mathrm{CO}_{2}$ amendments to commercial greenhouses from natural gas heating exhaust ${ }^{[22,23]}$ and/or from plants grown in areas heavily impacted by fossil fuel emissions. ${ }^{[24]}$ It is interesting to note that Eglinton et al. ${ }^{[25]}$ found a similar ${ }^{14} \mathrm{C}$ content $\left(\Delta^{14} \mathrm{C}=-113 \%\right)$ in a sample of Crassula argentea grown in a greenhouse heated by natural gas.

In contrast, synthetic estrogens that lack an ethynyl group (such as $E_{1}, E_{2}$, and $E_{3}$ ) exhibit an entirely modern ${ }^{14} \mathrm{C}$ signature (Fig. 3), implying that fossil $\mathrm{CO}_{2}$ amendment is not universal in steroid precursor plant cultivation and that, by itself, ${ }^{14} \mathrm{C}$ cannot distinguish between synthetic estrogens (made for pharmaceutical, scientific, and veterinary applications) and their endogenous counterparts derived from dietary (and primarily modern) carbon.

In this case, ${ }^{13} \mathrm{C}$ seems to hold greater promise for discriminating between synthetic and natural sources since endogenous steroids contain significantly more ${ }^{13} \mathrm{C}$ than the synthetic estrogens $\left(\delta^{13} \mathrm{C}=-30.0 \pm 0.9 \%\right.$; Table 1 , Fig. 3$)$ analyzed in this study. In general, the synthetic steroids are more ${ }^{13} \mathrm{C}$-depleted $\left(\delta^{13} \mathrm{C} \sim-27\right.$ to $\left.-34 \%\right)$ than their endogenous counterparts $\left(\delta^{13} \mathrm{C} \sim-16\right.$ to $\left.-26 \%\right)$ because synthetic steroid precursors are typically derived from $C_{3}$ plants whereas endogenous steroids reflect dietary mixtures of $C_{3}$ (e.g., wheat, soybean, fruit, vegetables) and $C_{4}$ plants (e.g., corn, sugarcane).$^{[8-11,26,27]}$

\begin{tabular}{|c|c|c|c|c|c|}
\hline Sample & Compound & $\begin{array}{l}\text { Ethynyl group } \\
\text { at C-17 position }\end{array}$ & $\begin{array}{c}\delta^{13} C^{a} \\
(\% 0)\end{array}$ & $\begin{array}{l}\Delta^{14} \mathrm{C}^{\circ} \\
(\% 0)\end{array}$ & Lab No. \\
\hline 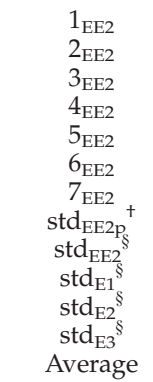 & $\begin{array}{l}\mathrm{EE}_{2} \\
\mathrm{EE}_{2} \\
\mathrm{EE}_{2} \\
\mathrm{EE}_{2} \\
\mathrm{EE}_{2} \\
\mathrm{EE}_{2} \\
\mathrm{EE}_{2} \\
\mathrm{EE}_{2} \\
\mathrm{EE}_{2} \\
\mathrm{E}_{1} \\
\mathrm{E}_{2} \\
\mathrm{E}_{3}\end{array}$ & $\begin{array}{l}\mathrm{Y} \\
\mathrm{Y} \\
\mathrm{Y} \\
\mathrm{Y} \\
\mathrm{Y} \\
\mathrm{Y} \\
\mathrm{Y} \\
\mathrm{Y} \\
\mathrm{Y} \\
\mathrm{N} \\
\mathrm{N} \\
\mathrm{N}\end{array}$ & $\begin{array}{l}-29.7 \\
-29.2 \\
-29.6 \\
-28.7 \\
-29.4 \\
-29.5 \\
-29.5 \\
-30.7 \\
-31.7 \\
-30.9 \\
-30.8 \\
-30.5 \\
-30.0 \pm 0.9\end{array}$ & $\begin{array}{c}-199 \pm 12 \\
-173 \pm 11 \\
-205 \pm 14 \\
-209 \pm 23 \\
-159 \pm 13 \\
-186 \pm 14 \\
-193 \pm 13 \\
-170 \pm 13 \\
-47 \pm 3 \\
48 \pm 4 \\
47 \pm 5 \\
50 \pm 3 \\
-116 \pm 108\end{array}$ & $\begin{array}{r}\text { ETH-43740 } \\
\text { ETH-43741 } \\
\text { ETH-43742 } \\
\text { ETH-43743 } \\
\text { ETH-43756 } \\
\text { ETH-43758 } \\
\text { ETH-43759 } \\
\text { ETH-43754 } \\
\text { OS-92452 } \\
\text { OS-92449 } \\
\text { OS-92450 } \\
\text { OS-92451 }\end{array}$ \\
\hline \multicolumn{6}{|c|}{$\begin{array}{l}{ }^{*} \text { See Fig. } 1 \text { for steroid carbon position numbering. } \\
\text { a Instrumental precision for } \delta^{13} C \text { measurements is } \pm 0.1 \% \text {. } \\
{ }^{\circ} \Delta^{14} C \text { errors }( \pm 1 \text { SD) reflect propagated instrumental errors and column bleed corrections. } \\
{ }^{+} \text {Authentic standard processed alongside oral contraceptive pill samples. } \\
{ }^{\S} \text { Authentic standards analyzed at NOSAMS without pre-processing; } \Delta^{14} C \text { errors reflect only instrumental errors; } \delta^{13} C \text { values } \\
\text { were measured on a VG Optima SIRMS instrument using a dual inlet source configuration. }\end{array}$} \\
\hline
\end{tabular}

Table 1. Estrogen-specific carbon isotope values for oral contraceptive pills and authentic standards 


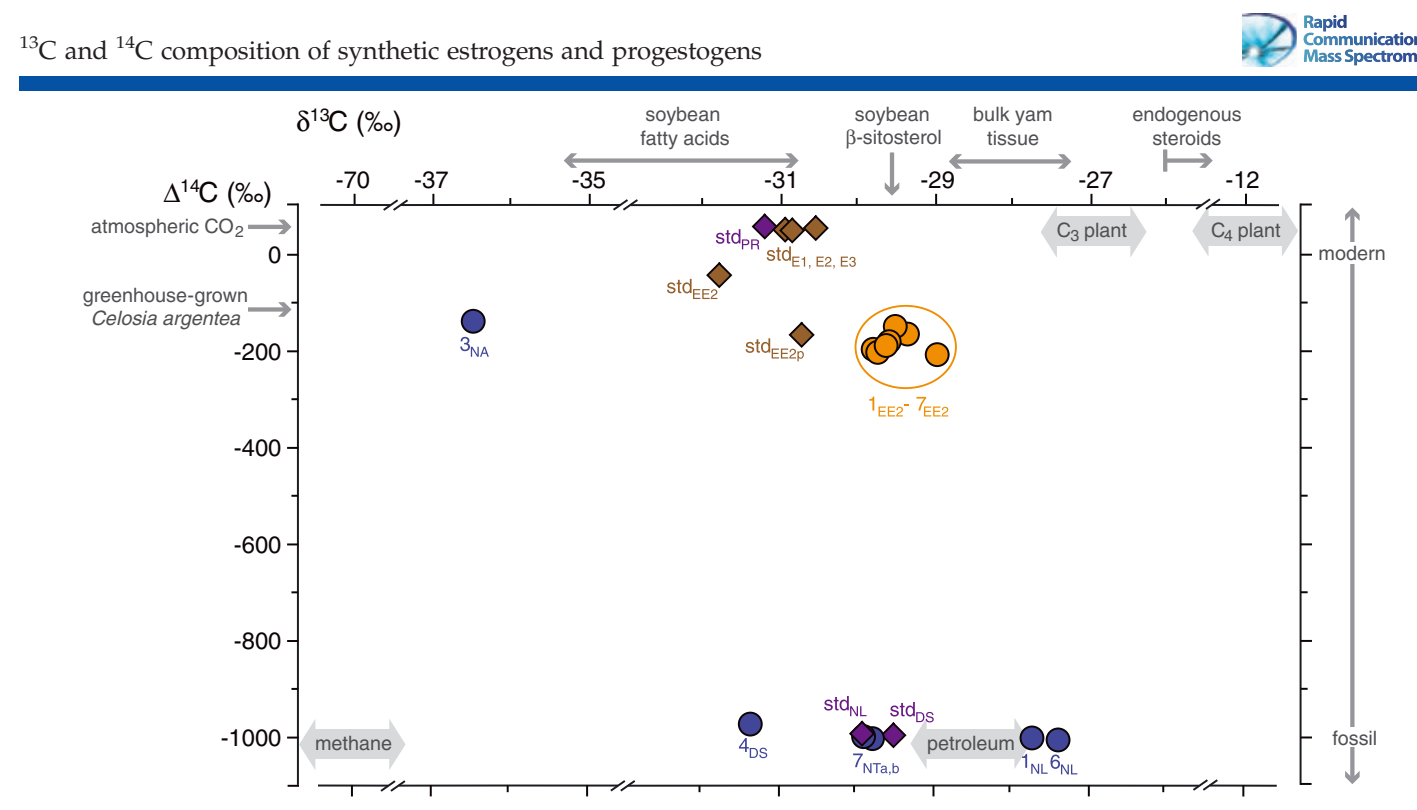

Figure 3. Characteristic carbon isotope values for a variety of estrogens (orange and brown symbols) and progestogens (blue and purple symbols) isolated from oral contraceptive pills (circles) or purchased as authentic standards (diamonds). Average end-member isotope values are shown in grey. These include bulk $C_{3}$ and $C_{4}$ plant tissue, ${ }^{[50,51]}$ soybean fatty acids, ${ }^{[2]}$ inferred soybean $\beta$-sitosterol ${ }^{[52,53]}$ bulk yam tissue, ${ }^{[21]}$ endogenous steroids, ${ }^{[10]}$ atmospheric $\mathrm{CO}_{2}{ }^{[54]}$ greenhouse-grown C. argentea, ${ }^{[25]}$ petroleum, ${ }^{[55]}$ and biogenic methane. ${ }^{[31]}$ Data points are labeled with sample numbers, and subscripts indicate the specific estrogen or progestogen according to Tables 1 and 2 . Note that $C_{3}$ and $C_{4}$ plants, petroleum, and methane have larger natural $\delta^{13} \mathrm{C}$ ranges than shown. ${ }^{[56]}$

The unique ${ }^{13} \mathrm{C}$ signature of synthetic steroids is currently used to test athletes for doping with synthetic androgens ${ }^{[28]}$ and to detect the treatment of cattle with synthetic estrogens. ${ }^{[29]}$ Our results suggest that ${ }^{13} \mathrm{C}$ could also be used to discriminate endogenous from synthetic estrogens in animal waste, wastewater effluent, and natural waters.

As synthetic estrogens (including $\mathrm{E}_{1}, \mathrm{E}_{2}, \mathrm{E}_{3}$, and $\mathrm{EE}_{2}$ ) are made from mostly plant-derived precursors this highlights an important distinction between 'synthetic' and 'anthropogenic' chemicals; ${ }^{[30]}$ that is, if synthetic chemicals with natural counterparts (such as steroids) are made from plants, the typical isotope approaches that rely on ${ }^{14} \mathrm{C}$ may fail to detect some synthetic chemicals. This calls into question approaches that use fossil carbon content $\left({ }^{14} \mathrm{C}\right)$ alone as a proxy for anthropogenic inputs to the environment. Therefore, ${ }^{14} \mathrm{C}$ data should be regarded as providing a minimum estimate of contributions from synthetic sources.

\section{Progestogens}

Like the estrogens, synthetic progestogens contain significantly less ${ }^{13} \mathrm{C}\left(\delta^{13} \mathrm{C}=-30.3 \pm 2.6 \%\right.$; Table 2, Fig. 3$)$ than endogenous steroids. In contrast, however, most progestogens are composed entirely of fossil carbon $\left(\Delta^{14} \mathrm{C}=-994 \pm 11 \%\right.$; Table 2, Fig. 3). The two exceptions are norethindrone acetate $\left(\Delta^{14} \mathrm{C}=-136 \%\right)$ and progesterone $\left(\Delta^{14} \mathrm{C}=54 \%\right)$. Like the estrogens, these two progestogens have ${ }^{14} \mathrm{C}$ contents that suggest they were synthesized from plant-derived steroidal precursors. Notably, norethindrone acetate and progesterone also share a common structural feature - a methyl group at the chiral C-13 position - with both estrogens and steroidal precursor compounds (see Fig. 1).
The measured $\Delta^{14} \mathrm{C}$ of norethindrone acetate indicates that 4 of its 22 carbon atoms are fossil-derived (as per Eqns. (1) and (2)). It is therefore likely that the ethynyl and acetyl groups are composed of fossil carbon while the steroid backbone derives from modern $\mathrm{C}_{3}$ plant precursors. However, the measured $\delta^{13} \mathrm{C}$ value of norethindrone acetate $(-36.4 \%)$ would suggest that these fossil carbon atoms derive from sources with anomalously low ${ }^{13} \mathrm{C}$ content. Since ${ }^{14} \mathrm{C}$ constrains the fraction of carbon from each source $\left(\mathrm{f}_{\text {fossil }}=0.18\right.$; $\mathrm{f}_{\text {steroid backbone }}=0.82$ ), we can use the ${ }^{13} \mathrm{C}$ analogue of Eqn. (2) to determine a range of $\delta^{13} \mathrm{C}$ values for the fossil carbon component of norethindrone acetate:

$$
\begin{aligned}
\delta^{13} C_{\text {measured }}= & f_{\text {fossil }}\left(\delta^{13} C_{\text {fossil }}\right) \\
& +f_{\text {steroid backbone }}\left(\delta^{13} C_{\text {steroid backbone }}\right)
\end{aligned}
$$

If we assume that the steroid backbone contains carbon with typical synthetic steroid $\delta^{13} \mathrm{C}$ values $(-27$ to $-34 \%)$, the calculated range of $\delta^{13} \mathrm{C}_{\text {fossil }}(-79$ to $-47 \%$ ) suggests that the fossil (i.e., ethynyl and acetyl) carbon in norethindrone acetate is probably derived from either biogenic methane, which typically has very low $\delta^{13} \mathrm{C}$ values $(-110$ to $\left.-50 \%)\right)^{[31]}$ or as the result of a strongly fractionating synthetic reaction.

The progestogens that have entirely fossil ${ }^{14} \mathrm{C}$ signatures all share an ethyl group at C-13. Indeed, total synthesis from petrochemical precursors appears to be the preferred synthetic pathway for progestogens with this structural similarity.$^{[19,20]}$ These results are also consistent with reports that many 19-norsteroids (such as the progestogens found in oral contraceptive pills) are currently synthesized from non-steroidal petrochemical precursors. ${ }^{[32]}$ Therefore, 
Table 2. Progestogen-specific carbon isotope values for oral contraceptive pills and authentic standards

\begin{tabular}{|c|c|c|c|c|c|}
\hline Sample* & Compound & $\begin{array}{l}\text { Substituent at } \\
\text { C-13 position }\end{array}$ & $\begin{array}{c}\delta^{13} C^{a} \\
(\% 0)\end{array}$ & $\begin{array}{c}\Delta^{14} C^{\circ} \\
(\% 0)\end{array}$ & Lab No. \\
\hline $\begin{array}{c}1_{\mathrm{NL}} \\
3_{\mathrm{NA}} \\
4_{\mathrm{DS}} \\
6_{\mathrm{NL}} \\
7_{\mathrm{NTa}} \\
7_{\mathrm{NTb}} \\
\operatorname{std}_{\mathrm{NL}}{ }_{\S} \\
\operatorname{std}_{\mathrm{PR}}^{\S} \\
\operatorname{std}_{\mathrm{DS}} \\
\text { Average }\end{array}$ & $\begin{array}{l}\text { levonorgesetrel } \\
\text { norethindrone acetate } \\
\text { desogestrel } \\
\text { levonorgestrel } \\
\text { norgestimate "a" } \\
\text { norgestimate "b" } \\
\text { levonorgestrel } \\
\text { progesterone } \\
\text { desogestrel }\end{array}$ & $\begin{array}{l}\text { ethyl } \\
\text { methyl } \\
\text { ethyl } \\
\text { ethyl } \\
\text { ethyl } \\
\text { ethyl } \\
\text { ethyl } \\
\text { methyl } \\
\text { ethyl }\end{array}$ & $\begin{array}{l}-27.7 \\
-36.4 \\
-31.3 \\
-27.4 \\
-29.9 \\
-29.8 \\
-29.9 \\
-31.2 \\
-29.5 \\
-30.3 \pm 2.6\end{array}$ & $\begin{aligned}-998 & \pm 4 \\
-136 & \pm 12 \\
-969 & \pm 7 \\
-1001 & \pm 2^{+} \\
-994 & \pm 5 \\
-999 & \pm 2 \\
-996 & \pm 1 \\
54 & \pm 4 \\
-999 & \pm 1 \\
-782 & \pm 423\end{aligned}$ & $\begin{array}{r}\text { ETH-43755 } \\
\text { ETH-43750 } \\
\text { ETH-43757 } \\
\text { ETH-43751 } \\
\text { ETH-43752 } \\
\text { ETH-43753 } \\
\text { OS-92455 } \\
\text { OS-92453 } \\
\text { OS-92454 }\end{array}$ \\
\hline \multicolumn{6}{|c|}{$\begin{array}{l}\text { *Samples } 2 \text { and } 5 \text { not measured. } \\
{ }^{*} \text { See Fig. } 1 \text { for steroid carbon position numbering. } \\
{ }^{\mathrm{a}} \text { Instrumental precision for } \delta^{13} \mathrm{C} \text { measurements is } \pm 0.1 \% \text {. } \\
{ }^{\circ} \Delta^{14} \mathrm{C} \text { errors }( \pm 1 \mathrm{SD}) \text { reflect propagated instrumental errors and column bleed corrections. } \\
{ }^{+} \text {calculated assuming age of } 50000 \text { years BP. } \\
{ }^{\S} \text { Authentic standards analyzed at NOSAMS without pre-processing; } \Delta^{14} \mathrm{C} \text { errors reflect only instrumental errors; } \delta^{13} \mathrm{C} \text { values } \\
\text { were measured on a VG Optima SIRMS instrument using a dual inlet source configuration. }\end{array}$} \\
\hline
\end{tabular}

together, ${ }^{13} \mathrm{C}$ and ${ }^{14} \mathrm{C}$ may prove useful for tracking this group of synthetic progestogens in human and animal urine, wastewaters, and a range of aquatic systems.

\section{Environmental forensics}

In complex environments (e.g., soils and natural waters), compound-specific isotope measurements have the potential to provide information about the sources and environmental transformations of contaminants, provided that the source signatures are sufficiently unique and the fractionation factors are known. ${ }^{[3,34]}$ However, it would be difficult to investigate steroidal hormone transformation mechanisms using ${ }^{13} \mathrm{C}$ because the fractionation of isotopes at reactive bonds would be 'diluted' by the non-reactive carbon atoms in these large molecules. ${ }^{[33]}$ Nevertheless, in cases where the isotope signatures of hormone sources are sufficiently distinct, it should be possible to apportion source inputs using compound-specific isotope measurements.

Moreover, dual (or multiple) isotope analyses can provide additional constraints on source signatures. When combined with ${ }^{13} \mathrm{C}$ measurements, compound-specific ${ }^{14} \mathrm{C}$ data typically provide an added level of specificity ${ }^{[35]}$ and are a particularly powerful tracer of 'fossil' carbon. ${ }^{[36]}$ However, in the case of plant-based synthetic chemicals such as estrogens and some progestogens, where the ${ }^{13} \mathrm{C}$ content is the strongest indicator of synthetic origin, the considerable expense and effort involved in ${ }^{14} \mathrm{C}$ measurements would not be justified. This is fortuitous because ${ }^{13} \mathrm{C}$ analyses require $\sim 100$-fold less material, which makes steroid-specific isotope measurements feasible even in complex environmental matrices.

Given typical environmental estrogen concentrations, ${ }^{[37-44]}$ we estimate that compound-specific ${ }^{13} \mathrm{C}$ analysis of individual estrogens would require the extraction of $\sim 1-5 \mathrm{~L}$ of wastewater effluent, 100-200 g of sewage-impacted coastal sediments, and 200-300 L of sewage-impacted coastal waters. By pooling the free, conjugated, and halogenated forms of estrogens, it should be possible to further reduce sample sizes by a factor of two to five. ${ }^{[45,46]}$
Taken together, carbon isotopes have proven to be a valuable tool for distinguishing between natural and synthetic chlorinated organic compounds in the ocean, $[30,47]$ apportioning sources of combustion-derived polycyclic aromatic hydrocarbons, ${ }^{[48,49]}$ and detecting hormone abuse in human athletes ${ }^{[7]}$ and cattle operations. ${ }^{[29]}$ The different $\delta^{13} \mathrm{C}$ signatures of synthetic and endogenous steroidal hormones open up the possibility for characterizing steroid sources and fate in wastewater treatment plants, rivers, lakes, and the coastal ocean.

\section{CONCLUSIONS}

We found that synthetic estrogens and progestogens in oral contraceptive pills and commercially synthesized standards contain significantly less ${ }^{13} \mathrm{C}$ than their endogenous counterparts. The majority of synthetic hormones appear to be made from $\mathrm{C}_{3}$ plant-based precursors, amended with $\sim 20 \%$ fossil carbon in the case of $\mathrm{EE}_{2}$ and norethindrone acetate. Exceptions are progestogens that contain an ethyl group at the C-13 position and are entirely synthesized from fossil precursors. Thus, there is potential to use carbon isotopes to quantify inputs of synthetic hormones to the environment, which would improve our understanding of hormone sources and fates and inform the design of effective mitigation solutions.

\section{Acknowledgements}

We thank Xiaojuan Feng, Valier Galy, Matthew Makou, Daniel Montluçon, and the staff at the Laboratory for Ion Beam Physics at ETH-Zürich and at the National Ocean Sciences Accelerator Mass Spectrometry (NOSAMS) facility at Woods Hole Oceanographic Institution for laboratory and analytical assistance. This work was supported by the Martin Family Society of Fellows for Sustainability and by a U.S. Environmental Protection Agency STAR graduate fellowship (FP-91713401). 


\section{REFERENCES}

[1] D. J. Caldwell, F. Mastrocco, T. H. Hutchinson, R. Lange, D. Heijerick, C. Janssen, P. D. Anderson, J. P. Sumpter. Derivation of an aquatic predicted no-effect concentration for the synthetic hormone, $17 \alpha$-ethinyl estradiol. Environ. Sci. Technol. 2008, 42, 7046.

[2] L. L. Johnson, D. P. Lomax, M. S. Myers, O. P. Olson, S. Y. Sol, S. M. O’Neill, J. West, T. K. Collier. Xenoestrogen exposure and effects in English sole (Parophrys vetulus) from Puget Sound, WA. Aquat. Toxicol. 2008, 88, 29.

[3] L. A. Boothby, P. L. Doering, S. Kipersztok. Bioidentical hormone therapy: a review. Menopause - J. North American Menopause Society 2004, 11, 356.

[4] A. C. Johnson, J. P. Sumpter. Removal of endocrine-disrupting chemicals in activated sludge treatment works. Environ. Sci. Technol. 2001, 35, 4697 .

[5] J. P. Jasper, B. J. Westenberger, J. A. Spencer, L. F. Buhse, M. Nasr. Stable isotopic characterization of active pharmaceutical ingredients. J. Pharm. Biomed. Anal. 2004, 35, 21.

[6] D. A. Krueger, H. W. Krueger. Carbon isotopes in vanillin and the detection of falsified natural vanillin. J. Agric. Food Chem. 1983, 31, 1265.

[7] M. Becchi, R. Aguilera, Y. Farizon, M. M. Flament, H. Casabianca, P. James. Gas chromatography combustion isotope ratio mass spectrometry analysis of urinary steroids to detect misuse of testosterone in sport. Rapid Commun. Mass Spectrom. 1994, 8, 304.

[8] M. Ueki, M. Okano. Analysis of exogenous dehydroepiandrosterone excretion in urine by gas chromatography/ combustion/isotope ratio mass spectrometry. Rapid Commun. Mass Spectrom. 1999, 13, 2237.

[9] T. Piper, U. Mareck, H. Geyer, U. Flenker, M. Thevis, P. Platen, W. Schanzer. Determination of ${ }^{13} \mathrm{C} /{ }^{12} \mathrm{C}$ ratios of endogenous urinary steroids: method validation, reference population and application to doping control purposes. Rapid Commun. Mass Spectrom. 2008, 22, 2161.

[10] U. Flenker, U. Guntner, W. Schanzer. $\delta^{13} \mathrm{C}$-Values of endogenous urinary steroids. Steroids 2008, 73, 408 .

[11] X. de la Torre, J. C. Gonzalez, S. Pichini, J. A. Pascual, J. Segura. ${ }^{13} \mathrm{C} /{ }^{12} \mathrm{C}$ isotope ratio MS analysis of testosterone, in chemicals and pharmaceutical preparations. J. Pharm. Biomed. Anal. 2001, 24, 645.

[12] L. Wacker, G. Bonani, M. Friedrich, I. Hajdas, B. Kromer, M. Nemec, M. Ruff, M. Suter, H. A. Synal, C. Vockenhuber. MICADAS: Routine and high-precision radiocarbon dating. Radiocarbon 2010, 52, 252.

[13] L. Wacker, S. M. Fahrni, I. Hajdas, M. Molnar, H. A. Synal, S. Szidat, Y. L. Zhang. A versatile gas interface for routine radiocarbon analysis with a gas ion source. Nucl. Instrum. Methods Phys. Res. Sect. B 2012, in press.

[14] H. A. Synal, M. Stocker, M. Suter. MICADAS: A new compact radiocarbon AMS system. Nucl. Instrum. Methods Phys. Res. Sect. B 2007, 259, 7.

[15] M. Ruff, S. Szidat, H. W. Gaggeler, M. Suter, H. A. Synal, L. Wacker. Gaseous radiocarbon measurements of small samples. Nucl. Instrum. Methods Phys. Res. Sect. B 2010, 268,790 .

[16] M. Stuiver, H. A. Polach. Reporting of ${ }^{14} \mathrm{C}$ data - discussion. Radiocarbon 1977, 19, 355.

[17] M. Stuiver. Workshop on ${ }^{14} \mathrm{C}$ data reporting. Radiocarbon 1980, 22, 964.

[18] R. Wiechert. Role of birth control in the survival of the human race. Angew. Chem. Int. Ed. Engl. 1977, 16, 506

[19] C. Djerassi. The manufacture of steroidal contraceptives: technical versus political aspects. Proc. Roy. Soc. London 1976, 195, 175.
[20] J. J. W. Coppen. Steroids: from plants to pills - the changing picture. Tropical Science 1979, 21, 125.

[21] D. Cornet, J. Sierra, R. Bonhomme. Characterization of the photosynthetic pathway of some tropical food yams (Dioscorea spp.) using leaf natural ${ }^{13} \mathrm{C}$ abundance. Photosynthetica 2007, 45, 303.

[22] H. L. Schmidt, A. Rossmann, S. Voerkelius, W. H. Schnitzler, M. Georgi, J. Grassmann, G. Zimmermann, R. Winkler. Isotope characteristics of vegetables and wheat from conventional and organic production. Isot. Environ. Health Stud. 2005, 41, 223.

[23] L. M. Mortensen. $\mathrm{CO}_{2}$ enrichment in greenhouses - crop responses. Scientia Horticulturae 1987, 33, 1.

[24] D. E. Pataki, J. T. Randerson, W. W. Wang, M. Herzenach, N. E. Grulke, The Carbon Isotope Composition of Plants and Soils as Biomarkers of Pollution, Springer, New York, 2010.

[25] T. I. Eglinton, L. I. Aluwihare, J. E. Bauer, E. R. M. Druffel, A. P. McNichol. Gas chromatographic isolation of individual compounds from complex matrices for radiocarbon dating. Anal. Chem. 1996, 68, 904.

[26] T. Piper, G. Opfermann, M. Thevis, W. Schanzer. Determination of ${ }^{13} \mathrm{C} /{ }^{12} \mathrm{C}$ ratios of endogenous urinary steroids excreted as sulpho conjugates. Rapid Commun. Mass Spectrom. 2010, 24, 3171.

[27] E. Strahm, C. Emery, M. Saugy, J. Dvorak, C. Saudan Detection of testosterone administration based on the carbon isotope ratio profiling of endogenous steroids: international reference populations of professional soccer players. Br. J. Sports Med. 2009, 43, 1041.

[28] T. G. Sobolevskii, I. S. Prasolov, G. M. Rodchenkov. Carbon isotope mass spectrometry in doping control. J. Anal. Chem. 2010, 65, 825 .

[29] C. Buisson, M. Hebestreit, A. P. Weigert, K. Heinrich, H. Fry, U. Flenker, S. Banneke, S. Prevost, F. Andre, W. Schaenzer, E. Houghton, B. Le Bizec. Application of stable carbon isotope analysis to the detection of $17 \beta$-estradiol administration to cattle. J. Chromatogr. A 2005, 1093, 69.

[30] C. M. Reddy, L. Xu, T. I. Eglinton, J. P. Boon, D. J. Faulkner Radiocarbon content of synthetic and natural semi-volatile halogenated organic compounds. Environ. Pollut. 2002, 120, 163.

[31] M. J. Whiticar. Carbon and hydrogen isotope systematics of bacterial formation and oxidation of methane. Chem. Geol. 1999, 161, 291.

[32] B. P. Morgan, M. S. Moynihan, in Kirk-Othmer Encyclopedia of Chemical Technology, John Wiley, New York, 2000.

[33] M. Elsner. Stable isotope fractionation to investigate natural transformation mechanisms of organic contaminants: principles, prospects and limitations. J. Environ. Monit. 2010, 12, 2005.

[34] R. P. Philp. The emergence of stable isotopes in environmental and forensic geochemistry studies: a review. Environ. Chem. Lett. 2007, 5, 57.

[35] A. E. Ingalls, A. Pearson. Ten years of compound-specific radiocarbon analysis. Oceanography 2005, 18, 18.

[36] C. M. Aelion, in Environmental Isotopes in Biodegradation and Bioremediation, (Eds: C. M. Aelion, P. Höhener, D. Hunkeler, R. Aravena), CRC Press, Boca Raton, 2010.

[37] Z. H. Liu, Y. Kanjo, S. Mizutani. Removal mechanisms for endocrine disrupting compounds (EDCs) in wastewater treatment - physical means, biodegradation, and chemical advanced oxidation: A review. Sci. Total Environ. 2009, 407, 731.

[38] D. W. Kolpin, E. T. Furlong, M. T. Meyer, E. M. Thurman, S. D. Zaugg, L. B. Barber, H. T. Buxton. Pharmaceuticals, hormones, and other organic wastewater contaminants in US streams, 1999-2000: A national reconnaissance. Environ. Sci. Technol. 2002, 36, 1202. 
[39] S. Reddy, B. J. Brownawell. Analysis of estrogens in sediment from a sewage-impacted urban estuary using high-performance liquid chromatography/time-of-flight mass spectrometry. Environ. Toxicol. Chem. 2005, 24, 1041.

[40] O. Braga, G. A. Smythe, A. I. Schafer, A. J. Feitz. Steroid estrogens in ocean sediments. Chemosphere 2005, 61, 827

[41] T. Isobe, S. Serizawa, T. Horiguchi, Y. Shibata, S. Managaki, H. Takada, M. Morita, H. Shiraishi. Horizontal distribution of steroid estrogens in surface sediments in Tokyo Bay. Environ. Pollut. 2006, 144, 632.

[42] I. C. Beck, R. Bruhn, J. Gandrass, W. Ruck. Liquid chromatography-tandem mass spectrometry analysis of estrogenic compounds in coastal surface water of the Baltic Sea. J. Chromatogr. A 2005, 1090, 98.

[43] B. J. Robinson, J. P. M. Hui, E. C. Soo, J. Hellou. Estrogenic compounds in seawater and sediment from Halifax Harbour, Nova Scotia, Canada. Environ. Toxicol. Chem. 2009, 28, 18.

[44] S. Atkinson, M. J. Atkinson, A. M. Tarrant. Estrogens from sewage in coastal marine environments. Environ. Health Perspect. 2003, 111, 531.

[45] H. Nakamura, R. Kuruto-Niwa, M. Uchida, Y. Terao. Formation of chlorinated estrones via hypochlorous disinfection of wastewater effluent containing estrone. Chemosphere 2007, $66,1441$.

[46] V. Kumar, N. Nakada, M. Yasojima, N. Yamashita, A. C. Johnson, H. Tanaka. The arrival and discharge of conjugated estrogens from a range of different sewage treatment plants in the UK. Chemosphere 2011, 82, 1124.

[47] C. M. Reddy, L. Xu, G. W. O'Neil, R. K. Nelson, T. I. Eglinton, D. J. Faulkner, R. Norstrom, P. S. Ross, S. A. Tittlemier. Radiocarbon evidence for a naturally produced, bioaccumulating halogenated organic compound. Environ. Sci. Technol. 2004, 38, 1992.
[48] C. M. Reddy, A. Pearson, L. Xu, A. P. McNichol, B. A. Benner, S. A. Wise, G. A. Klouda, L. A. Currie, T. I. Eglinton Radiocarbon as a tool to apportion the sources of polycyclic aromatic hydrocarbons and black carbon in environmental samples. Environ. Sci. Technol. 2002, 36, 1774.

[49] R. J. Sheesley, M. Krusa, P. Krecl, C. Johansson, O. Gustafsson. Source apportionment of elevated wintertime PAHs by compound-specific radiocarbon analysis. Atmos. Chem. Phys. $2009,9,3347$.

[50] B. N. Smith, S. Epstein. Two categories of ${ }^{13} \mathrm{C} /{ }^{12} \mathrm{C}$ ratios for higher plants. Plant Physiol. 1971, 47, 380.

[51] M. H. O'Leary. Carbon isotope fractionation in plants. Phytochemistry 1981, 20, 553.

[52] D. Haubert, K. Birkhofer, A. Fliessbach, M. Gehre, S. Scheu, L. Ruess. Trophic structure and major trophic links in conventional versus organic farming systems as indicated by carbon stable isotope ratios of fatty acids. Oikos 2009 , $118,1579$.

[53] Y. Chikaraishi, H. Naraoka, S. R. Poulson. Carbon and hydrogen isotopic fractionation during lipid biosynthesis in a higher plant (Cryptomeria japonica). Phytochemistry 2004, 65, 323

[54] I. Levin, B. Kromer. The tropospheric ${ }^{14} \mathrm{CO}_{2}$ level in midlatitudes of the Northern Hemisphere (1959-2003). Radiocarbon 2004, 46, 1261.

[55] H. W. Yeh, S. Epstein. Hydrogen and carbon isotopes of petroleum and related organic matter. Geochim. Cosmochim. Acta 1981, 45, 753.

[56] T. B. Coplen, J. K. Bohlke, P. De Bievre, T. Ding, N. E. Holden, J. A. Hopple, H. R. Krouse, A. Lamberty, H. S. Peiser, K. Revesz, S. E. Rieder, K. J. R. Rosman, E. Roth, P. D. P. Taylor, R. D. Vocke, Y. K. Xiao. Isotope-abundance variations of selected elements (IUPAC Technical Report). Pure Appl. Chem. 2002, 74, 1987. 


\title{
Chapter 5
}

\author{
Conclusions
}




\subsection{Summary of major findings}

As environmental chemists, we seek a better understanding of the processes that shape chemical distributions and interactions in the real world. An interesting and important component of this search is characterizing how human activities influence chemical behavior and ecosystem health.

The vast quantity of hormones produced and released to the environment by humans have been cause for concern for several decades. Steroidal hormones are extremely potent chemicals that are known to disrupt the normal development of fish and humans, alike. The fact that fish, whales, and other marine vertebrates live in a mixture of their own excreted hormones raises interesting questions about these organisms' strategies for dealing with endocrine disrupting chemicals in their surroundings. These are key questions since our understanding of the fate of hormones and synthetic chemicals in the environment lags significantly behind the race to design and produce new ones.

This work has focused on steroidal estrogens, a class of hormone produced by every human and ubiquitous in the sewage we discharge to rivers, lakes, and oceans. We have shown that treated wastewater effluent contains a much wider range of estrogens than was previously understood. These include conjugated estrogens, free estrogens, and halogenated estrogens, which were found in every effluent sample collected over the course of 14 months.

By opening this window on estrogen forms, we are now better situated to characterize the processes that determine estrogen distributions and follow their fate in complex environments such as rivers and the coastal ocean.

Estrogen concentrations near the sewage outfall in Massachusetts Bay are determined both by estrogen levels in sewage and by the extent of dilution, which is strongly influenced by the volume and residence time of water in the bay.

Further away from the sewage outfall, we expected to see estrogen levels decrease due to additional dilution and biological degradation. Instead, we observed higher concentrations of the free estrogen, estrone (E1), which suggests that background E1 
levels may, in fact, be higher than E1 levels at the sewage outfall due to sources from extant fish and whale populations.

Conjugated and halogenated estrogen derivatives are present in all Massachusetts Bay samples, but our ability to describe their fate is currently hampered by the size of propagated measurement uncertainties. It may be possible to overcome these limitations by additional clean-up steps and/or higher standard spiking levels.

Using estrogen potency data from other studies, we determined that net estrogenicity in Massachusetts Bay water due to all 23 steroidal estrogens measured here was equivalent to $0.1-0.5 \mathrm{ng}$ of estradiol (E2) in every liter of seawater. In isolation, these levels are at the known threshold for disrupting fish development. If the myriad and abundant "weak" estrogens (nonylphenol, bisphenol A, etc...) are considered, there may be heightened cause for concern. Moreover, in sewage-impacted waters, mixtures of pharmaceuticals or contaminants may have synergistic effects on organism and ecosystem health. Alternatively, populations in Massachusetts Bay may be doing just fine, having adapted mechanisms for avoiding or managing the onslaught of contaminants.

Still, our potency calculations do not consider seasonal effects (summertime concentrations), bioaccumulation of hydrophobic halogenated estrogens, net estrogenicity including weakly estrogenic chemicals, or synergistic effects with the many other chemicals and pharmaceuticals in sewage-impacted coastal waters.

If we deem that estrogens or other hormones present an unacceptable threat to human or ecosystem health, it will be necessary to target the root cause or combination of factors at work. In many cases, natural abundance isotope measurements can help us tease apart sources in complex environments. We have taken an important first step by showing that carbon isotopes, particularly ${ }^{13} \mathrm{C}$, may be used to apportion sources of estrogens from natural and synthetic sources. This will help us design effective and efficient methods for reducing concentrations in problem systems. Moreover, the unique ${ }^{13} \mathrm{C}$ signature of synthetic estrogens may further illuminate estrogen sources in systems 
like Massachusetts Bay, where we have seen evidence for non-sewage-derived E1 sources.

\subsection{Future directions}

\subsubsection{Seasonal and background estrogen sources in Massachusetts Bay}

Thus far, our study of estrogens in Massachusetts Bay has been limited to seasons when water column stratification was weak. Under these conditions, the Deer Island effluent plume is relatively well-mixed vertically. In contrast, a vertically stratified water column during the summer traps the plume at mid-depths, thus reducing dilution, and increasing the concentration of sewage-derived estrogens. At the same time, it is also possible that summertime temperature and sunlight conditions may alter biodegradation and photodegradation rates. Understanding the interplay between the competing processes of dilution and degradation in the summer would help us better model annual estrogen dynamics and shed light on background levels.

Our work exposes a need to understand the background levels of estrogen in Massachusetts Bay, the Gulf of Maine, and the open ocean. Additional sampling campaigns should be designed to characterize background marine estrogen concentrations. This information would help scientists and managers better understand the relative contributions of sewage and background sources to coastal areas influenced by both.

\subsubsection{Improving tools for predicting environmental concentrations}

It is impossible to comprehensively characterize every system that receives wastewater effluent. Therefore, we should improve our ability to predict environmental concentrations using simple models that consider loading, dilution, and degradation. Unfortunately, we currently lack fundamental information about the rate at which sunlight and/or microbial communities degrade estrogens in natural waters. Existing studies have been conducted with free estrogens spiked into natural waters at unrealistically high concentrations. Therefore, it should be a priority to apply our 
analytical method to characterizing biodegradation and photochemical degradation rate constants for conjugated, free, and halogenated estrogens at environmentally relevant (pg $\mathrm{L}^{-1}$ ) concentrations.

The results of these experiments could be used to characterize estrogen fate in any coastal area using information about effluent estrogen loads and some knowledge of the hydrodynamics and biogeochemical properties of the water body.

\subsubsection{Bioaccumulation of halogenated forms}

The speciation of estrogens between free, conjugated, and chlorinated forms has important implications for their bioaccumulation potential and, thus, the risk to human health via consumption of fish and bivalves. Given the presence of halogenated estrogens in sewage effluent and coastal water, it should be high priority to investigate the degree to which the more hydrophobic halogenated forms sorb to sediments and/or bioaccumulate. Studies that measured halogenated estrogens in bivalve, fish, and whale tissue would require new extraction methods, but there is a large body of literature that could guide this work. In addition, estrogens could be isolated from tissue extracts and analyzed for carbon isotopic composition to identify likely sources.

\subsubsection{Developing approaches that link specific compounds to net effects}

Compound-specific analysis by tandem mass spectrometry allows us to study the environmental fate of individual estrogens, but these analyses can be time consuming, difficult, and expensive. Another common approach measures the estrogenic impact of a sample of interest on an organism by proxy (Pinto, Garritano et al. 2005; Campbell, Borglin et al. 2006). Such studies measure an integrated estrogenic response, triggered by both estrogens themselves and other chemicals that mimic estrogens.

Unfortunately, many bioassay-based screening methods suffer from a lack of specificity regarding specific chemical concentrations and mechanisms of action. This leaves us without the ability to utilize the power of chemical fate models for informing intelligent regulations and cost-effective source controls. However, coupled 
measurements of specific estrogens and bioassays can provide important additional information. For example, if the total E2 equivalent estrogen activity and the integrated bioassay estrogenicity were of similar magnitude, then this would implicate steroidal estrogens were the main contributors. On the other hand, a mismatch between the two could highlight the importance of weak (but more abundant) estrogenic chemicals such as nonylphenol or bisphenol A. For example, screening methods indicate that Deer Island Treatment Plant effluent has an E2 equivalent activity of $936 \mathrm{ng} \mathrm{L}^{-1}$ (Siegener 2005), which is much larger than the activity $\left(11-50 \mathrm{ng} \mathrm{L}^{-1}\right)$ calculated based on the suite of estrogens measured in this study.

Thus, it is important to integrate compound-specific and bioassay work so that we can begin to understand the relative contribution of steroidal estrogens to the total estrogenicity of environmental samples. 


\section{REFERENCES}

Campbell, C. G., S. E. Borglin, et al. (2006). "Biologically directed environmental monitoring, fate, and transport of estrogenic endocrine disrupting compounds in water: A review." Chemosphere 65(8): 1265-1280.

Pinto, B., S. Garritano, et al. (2005). "Occurrence of estrogen-like substances in the marine environment of the Northern Mediterranean Sea." Marine Pollution Bulletin 50(12): 1681-1685.

Siegener, R. (2005). The Identification and Distribution of Environmental Endocrine Disruptors in Boston Harbor and Massachusetts Bay. Ph.D., University of Massachusetts Boston. 


\section{Appendix A}

Literature survey of coastal estrogen levels 
Appendix A: Literature survey of coastal estrogen levels

Table A-1. Summary of coastal ocean estrogen concentrations

\begin{tabular}{|c|c|c|c|c|c|c|}
\hline Location & $\begin{array}{c}\mathbf{E 1} \\
\left(\operatorname{ng~L}_{\mathrm{w}}^{-1}\right) \\
\end{array}$ & $\begin{array}{c}\text { E2 } \\
\left(\operatorname{ng~L}_{\mathrm{w}}^{-1}\right)\end{array}$ & $\begin{array}{c}\mathbf{E 3} \\
\left(\operatorname{ng~L}_{\mathrm{w}}^{-1}\right)\end{array}$ & $\begin{array}{c}\text { EE2 } \\
\left(\operatorname{ng~L}_{\mathrm{w}}^{-1}\right)\end{array}$ & $\begin{array}{c}\text { E1-3S } \\
\left(\operatorname{ng~L}_{\mathrm{w}}^{-1}\right)\end{array}$ & Reference \\
\hline Kaneohe Bay, $\mathrm{HI}^{\mp}$ & $0.04-0.6$ & & & & & [1] \\
\hline N. Pacific ${ }^{\ddagger}$ & 0.052 & & & & & {$[2]$} \\
\hline Biosphere 2 ocean $^{¥}$ & 0.066 & & & & & [2] \\
\hline Fr. Polynesia ${ }^{¥}$ & 0.17 & & & & & [2] \\
\hline S. Molokai ${ }^{\mp}$ & 0.12 & & & & & [2] \\
\hline $\operatorname{Maui}(\mathrm{n}=70)^{¥}$ & 0.16 & & & & & [2] \\
\hline Oahu & 0.58 & & & & & [2] \\
\hline Florida Keys ${ }^{\ddagger}$ & 0.26 & & & & & [2] \\
\hline Tinian Is. & 0.31 & & & & & {$[2]$} \\
\hline Tern Is. & 0.35 & & & & & [2] \\
\hline Guam (resorts) $^{¥}$ & $0.48-0.71$ & & & & & [2] \\
\hline Moorea (resort) & 0.61 & & & & & [2] \\
\hline Key Largo Shore ${ }^{*}$ & 0.85 & & & & & [2] \\
\hline Maalaea Bay ${ }^{*}$ & 0.69 & & & & & [2] \\
\hline Big Pine Key ${ }^{¥}$ & 0.66 & & & & & [2] \\
\hline Key West ${ }^{\frac{*}{*}}$ & 0.81 & & & & & [2] \\
\hline Rehoboth Bay ${ }^{\ddagger}$ & 1.87 & & & & & {$[2]$} \\
\hline Key West Harbor ${ }^{¥}$ & 1.58 & & & & & [2] \\
\hline Boston Harbor & & & & $<74$ & & [3] \\
\hline Jamaica Bay, NY & $0.07-2.52^{\S}$ & $0.05-0.53^{\S}$ & & & & [4] \\
\hline Tokyo Bay & $0.05-3.60^{\S}$ & $<0.07-0.59^{\S}$ & & & $<0.03-0.05^{\S}$ & [5] \\
\hline LA outfall site & $0.6^{\S}$ & $0.3^{\S}$ & & & & [6] \\
\hline San Diego outfall & $<0.03^{\S}$ & $0.3^{\S}$ & & & & [6] \\
\hline Orange Co. outfall ${ }^{\ddagger}$ & $<0.03^{\S}$ & $0.45^{\S}$ & & & & [6] \\
\hline Southern CA Bight & $<0.03^{\S}$ & $0.16^{\S}$ & & & & {$[6]$} \\
\hline Halifax Harbor & $4.0-6.6$ & $<0.10-0.57$ & & $<0.14 ; 0.21^{\S}$ & & {$[7,8]$} \\
\hline St. Johns Harbor ${ }^{*}$ & $1.4-1.5$ & $<0.5-1.8$ & & $<1.2$ & & [8] \\
\hline Sydney outfall ${ }^{\ddagger}$ & $0.16-1.17^{\S}$ & $0.22-2.48^{\S}$ & & $<0.05-0.5^{\S}$ & & [9] \\
\hline Baltic Sea & $0.10-0.53$ & $<0.30$ & $<1.0$ & $<0.45-17.9$ & & {$[10,11]$} \\
\hline Cape Cod ponds & ND-4.6 & $<2.0-2.2$ & & & & {$[12]$} \\
\hline W. Australia coral & & $0.55-4.2$ & & & & [13] \\
\hline Acushnet estuary ${ }^{\ddagger}$ & $0.78-1.2$ & $0.56-0.83$ & & $3.01-4.57$ & & {$[14]$} \\
\hline Biobio, Chile & $0.06-14.5^{\S}$ & $0.06-16.8^{\S}$ & $0.04-53^{\S}$ & $4.18-48.14^{\S}$ & & {$[15]$} \\
\hline Xiamen Bay, China & $1.1-7.4^{\S}$ & $1.0-2.4^{\S}$ & & $<1.3-2.2^{\S}$ & & [16] \\
\hline Massachusetts Bay & $0.09-0.52$ & $0.03-0.09$ & & $0.02-0.09$ & $0.02-0.07$ & this study \\
\hline Boston Harbor ${ }^{*}$ & 0.44 & 0.07 & & 0.0004 & 0.063 & this study \\
\hline
\end{tabular}




\section{REFERENCES}

1. Tarrant, A. M.; Atkinson, M. J.; Atkinson, S., Effects of steroidal estrogens on coral growth and reproduction. Mar. Ecol.-Prog. Ser. 2004, 269, 121-129.

2. Atkinson, S.; Atkinson, M. J.; Tarrant, A. M., Estrogens from sewage in coastal marine environments. Environ. Health Perspect. 2003, 111, (4), 531-535.

3. Siegener, R.; Chen, R. F. In Detection of pharmaceuticals entering Boston Harbor, 216th National Meeting of the American-Chemical-Society, Boston, Massachusetts, Aug 21-27, 1998; Keith, L. H.; JonesLepp, T. L.; Needham, L. L., Eds. Boston, Massachusetts, 1998; pp 125-132.

4. Reddy, S.; Brownawell, B. J., Analysis of estrogens in sediment from a sewageimpacted urban estuary using high-performance liquid chromatography/time-of-flight mass spectrometry. Environmental Toxicology and Chemistry 2005, 24, (5), 1041-1047.

5. Isobe, T.; Serizawa, S.; Horiguchi, T.; Shibata, Y.; Managaki, S.; Takada, H.; Morita, M.; Shiraishi, H., Horizontal distribution of steroid estrogens in surface sediments in Tokyo Bay. Environmental Pollution 2006, 144, (2), 632-638.

6. Schlenk, D.; Sapozhnikova, Y.; Irwin, M. A.; Xie, L. T.; Hwang, W.; Reddy, S.; Brownawell, B. J.; Armstrong, J.; Kelly, M.; Montagne, D. E.; Kolodziej, E. P.; Sedlak, D.; Snyder, S., In vivo bioassay-guided fractionation of marine sediment extracts from the Southern California Bight, USA, for estrogenic activity. Environmental Toxicology and Chemistry 2005, 24, (11), 2820-2826.

7. Robinson, B. J.; Hui, J. P. M.; Soo, E. C.; Hellou, J., Estrogenic compounds in seawater and sediment from Halifax Harbour, Nova Scotia, Canada. Environmental Toxicology and Chemistry 2009, 28, (1), 18-25.

8. Saravanabhavan, G.; Helleur, R.; Hellou, J., GC-MS/MS measurement of natural and synthetic estrogens in receiving waters and mussels close to a raw sewage ocean outfall. Chemosphere 2009, 76, (8), 1156-1162.

9. Braga, O.; Smythe, G. A.; Schafer, A. I.; Feitz, A. J., Steroid estrogens in ocean sediments. Chemosphere 2005, 61, (6), 827-833.

10. Beck, I. C.; Bruhn, R.; Gandrass, J., Analysis of estrogenic activity in coastal surface waters of the Baltic Sea using the yeast estrogen screen. Chemosphere 2006, 63, (11), 1870-1878.

11. Beck, I. C.; Bruhn, R.; Gandrass, J.; Ruck, W., Liquid chromatography-tandem mass spectrometry analysis of estrogenic compounds in coastal surface water of the Baltic Sea. Journal of Chromatography A 2005, 1090, (1-2), 98-106. 
12. Standley, L. J.; Rudel, R. A.; Swartz, C. H.; Attfield, K. R.; Christian, J.; Erickson, M.; Brody, J. G., Wastewater-contaminated groundwater as a source of endogenous hormones and pharmaceuticals to surface water ecosystems. Environmental Toxicology and Chemistry 2008, 27, (12), 2457-2468.

13. Atkinson, S.; Atkinson, M. J., Detection of estradiol-17-beta during a mass coral spawn. Coral Reefs 1992, 11, (1), 33-35.

14. Zuo, Y. G.; Zhang, K.; Deng, Y. W., Occurrence and photochemical degradation of 17 alpha-ethinylestradiol in Acushnet River Estuary. Chemosphere 2006, 63, (9), 1583-1590.

15. Bertin, A.; Inostroza, P. A.; Quiñones, R. A., Estrogen pollution in a highly productive ecosystem off central-south Chile. Marine Pollution Bulletin 2011, 62, (7), 1530-1537.

16. Zhang, X.; Li, Q. Z.; Li, G. X.; Wang, Z. S.; Yan, C. Z., Levels of estrogenic compounds in Xiamen Bay sediment, China. Marine Pollution Bulletin 2009, 58, (8), 1210-1216.

17. Pinto, B.; Garritano, S.; Reali, D., Occurrence of estrogen-like substances in the marine environment of the Northern Mediterranean Sea. Marine Pollution Bulletin 2005, $50,(12), 1681-1685$.

18. da Silva, D. A. M.; Buzitis, J.; Reichert, W. L.; West, J. E.; O’Neill, S. M.; Johnson, L. L.; Collier, T. K.; Ylitalo, G. M., Endocrine disrupting chemicals in fish bile: A rapid method of analysis using English sole (Parophrys vetulus) from Puget Sound, WA, USA. Chemosphere In Press.

19. Legler, J.; Leonards, P.; Spenkelink, A.; Murk, A. J., In vitro biomonitoring in polar extracts of solid phase matrices reveals the presence of unknown compounds with estrogenic activity. Ecotoxicology 2003, 12, (1-4), 239-249.

20. Schipper, C. A.; Lahr, J.; van den Brink, P. J.; George, S. G.; Hansen, P. D.; de Assis, H. C. D.; van der Oost, R.; Thain, J. E.; Livingstone, D.; Mitchelmore, C.; van Schooten, F. J.; Ariese, F.; Murk, A. J.; Grinwis, G. C. M.; Klamer, H.; Kater, B. J.; Postma, J. F.; van der Werf, B.; Vethaak, A. D., A retrospective analysis to explore the applicability of fish biomarkers and sediment bioassays along contaminated salinity transects. ICES J. Mar. Sci. 2009, 66, (10), 2089-2105.

21. Hashimoto, S.; Horiuchi, A.; Yoshimoto, T.; Nakao, M.; Omura, H.; Kato, Y.; Tanaka, H.; Kannan, K.; Giesy, J. P., Horizontal and vertical distribution of estrogenic activities in sediments and waters from Tokyo Bay, Japan. Archives of Environmental Contamination and Toxicology 2005, 48, (2), 209-216. 


\section{Appendix B}

Solid phase extraction disk break-through experiments 
Appendix B: Solid phase extraction disk break-through experiments

Figure B-1. Percent recovery of three estrogens (E2-3S, E2, and monoBrE2) from water using solid phase extraction disks (47 mm; Empore; 3M, St. Paul, MN, USA) varies as a function of sample volume, $\mathrm{pH}$, flow rate, disk type, elution solvent, ionic strength, and cation identity. The symbol "nf" indicates cases where estrogen was not found on the backup disk (placed below the main disk), which suggests that low recoveries from carbon disks are related to inefficient elution rather than break-though. See Chapter 2 for methodological details.
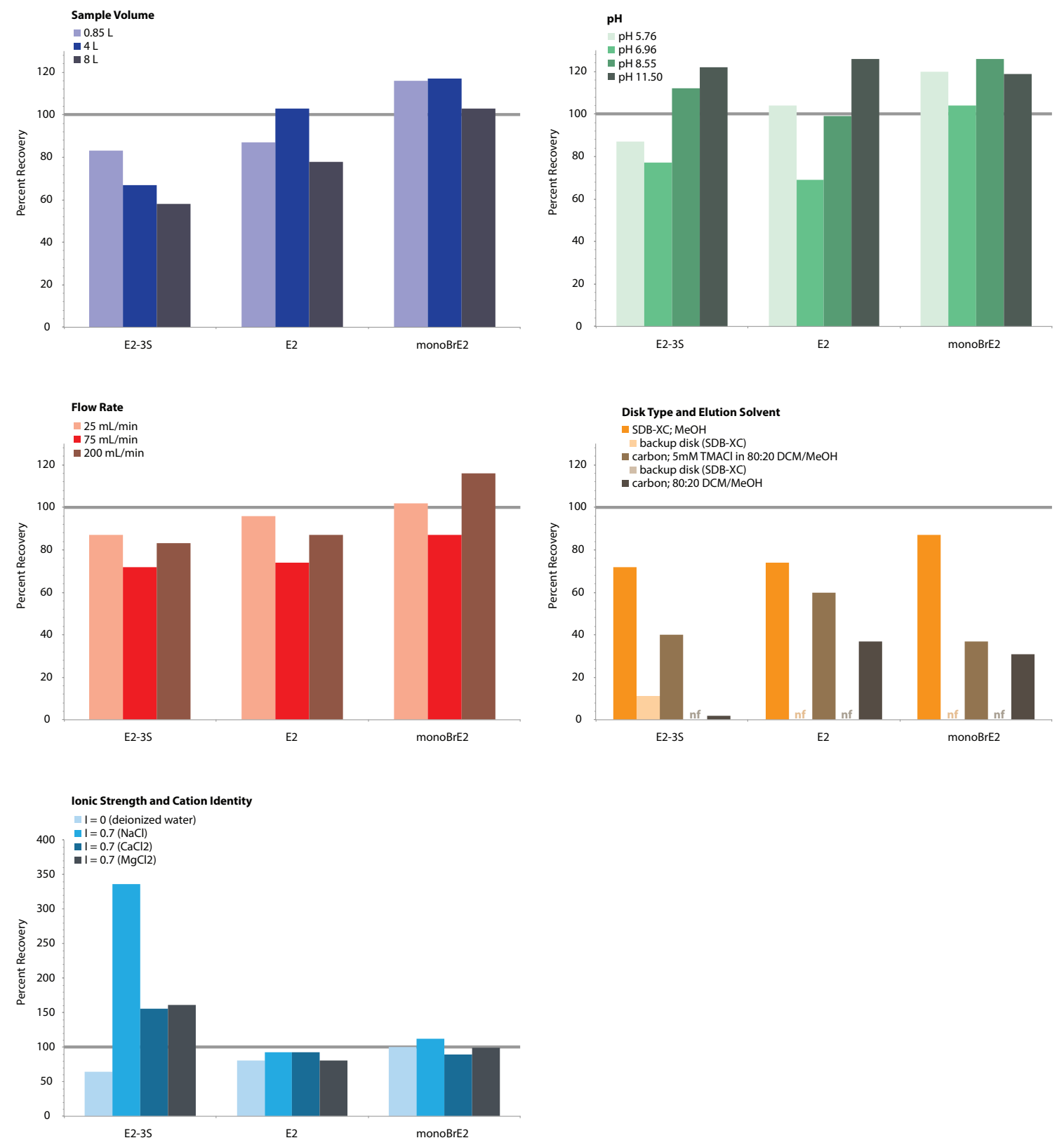


\section{Appendix C}

Pyrene sorption into cellular lipids and onto laboratory plastics 
Appendix C: Pyrene sorption into cellular lipids and onto laboratory plastics

Bioavailability and bioassay-derived estrogenicity should depend strongly on the properties of each estrogen, the $\mathrm{pH}$ and ionic strength of the culture medium, and sorption into cellular lipids and onto polymer-based vessels and pipette tips.

As a first step towards assessing these concerns, we examined the possible losses of dichloroE2 under typical experimental bioassay conditions. Partitioning calculations indicate a significant $(\sim 42 \%)$ reduction in the fraction of dissolved diClE2 due to sorption into cellular lipids alone (Table C-1). And preliminary sorption tests with pyrene, a compound having approximately the same $\mathrm{K}_{\mathrm{OW}}$ as diClE2, showed significant timedependent losses to the walls of the polystyrene vessels typically used in cellular assays. Losses of pyrene from a pure aqueous solution (10 $\mathrm{mg} \mathrm{L}^{-1}$ pyrene) to vessel walls were 46,55 , and $78 \%$ after 1,2 , and 21 hours, respectively.

Given the typical biomasses used in estrogenicity testing, one would expect some losses to the lipids of the test organisms. Assuming typical incubation times and including the partitioning into cellular lipids as well as onto vessel walls, we estimate that $81 \%$ of diClE2 would be "lost" to cells and walls during a typical test and therefore be unavailable to bind to estrogen receptors in the assay. This is a remarkable result that suggests systemic underestimates of the toxicity of hydrophobic chemicals, including halogenated estrogens. 
Table C-1. Estimated losses of estrogens from a typical cell-based reporter assay (adherent COS-7 cells within 48 well plates) due to partitioning into cellular lipids and time-dependent losses to polystyrene vessel walls.

\begin{tabular}{l|ccc}
\multicolumn{2}{c}{ E1 } & E2 & diClE2 \\
\hline Cell lipids & & & \\
Fraction in water $^{\mathrm{a}}$ & 0.994 & 0.959 & 0.584 \\
Percentage lost & $0.6 \%$ & $4 \%$ & $42 \%$ \\
\hline Cell lipids and vessel walls $^{\mathrm{b}}(2 \mathrm{~h})$ & $\mathrm{n} / \mathrm{a}$ & $\mathrm{n} / \mathrm{a}$ & 0.341 \\
Fraction in water $_{\text {Percentage lost }}$ & $\mathrm{n} / \mathrm{a}$ & $\mathrm{n} / \mathrm{a}$ & $66 \%$ \\
\hline Cell lipids and vessel walls & \\
Fraction in water & & & \\
Percentage lost & $\mathrm{n} / \mathrm{a}$ & $\mathrm{n} / \mathrm{a}$ & 0.190 \\
\hline
\end{tabular}

${ }^{\text {a }}$ Fraction in water is calculated as:

$f_{\text {water }}=\frac{1}{\left(1+\left(K_{\text {ow }} M_{\text {lipid }} / V_{\text {exp }}\right)\right)}$

where $\mathrm{K}_{\mathrm{OW}}$ is the octanol-water partition coefficient, $\mathrm{M}_{\text {lipid }}$ is the lipid mass, $\mathrm{V}_{\text {exp }}$ is the experimental volume, and estimated typical conditions are $4.2 \times 10^{-6} \mathrm{~g}^{\text {lipid } \mathrm{ml}^{-1}}$.

${ }^{\mathrm{b}}$ Time-dependent losses to polystyrene vessel walls were measured fluorometrically using a neat $10 \mathrm{mg} \mathrm{L}^{-1}$ aqueous solution of pyrene $\left(\log \mathrm{K}_{\mathrm{OW}}=5.13\right)$, a suitable sorption proxy for diClE2 $\left(\log \mathrm{K}_{\mathrm{OW}}=5.23\right)$.

$\mathrm{n} / \mathrm{a}=$ not available 


\section{Appendix D}

GC-FID and GC-TOF/MS traces of EE2 standards and pill extracts 


\section{Appendix D: GC-FID and GC-TOF/MS traces of EE2 standards and pill extracts}

Figure D-1. GC-FID chromatograms: EE2 positive control (A) pill extracts (B-H), and a column bleed blank extract (I) confirm the purity of each extract after silica gel clean up and just prior to closed-tube combustion for ${ }^{13} \mathrm{C}$ and ${ }^{14} \mathrm{C}$ analysis.
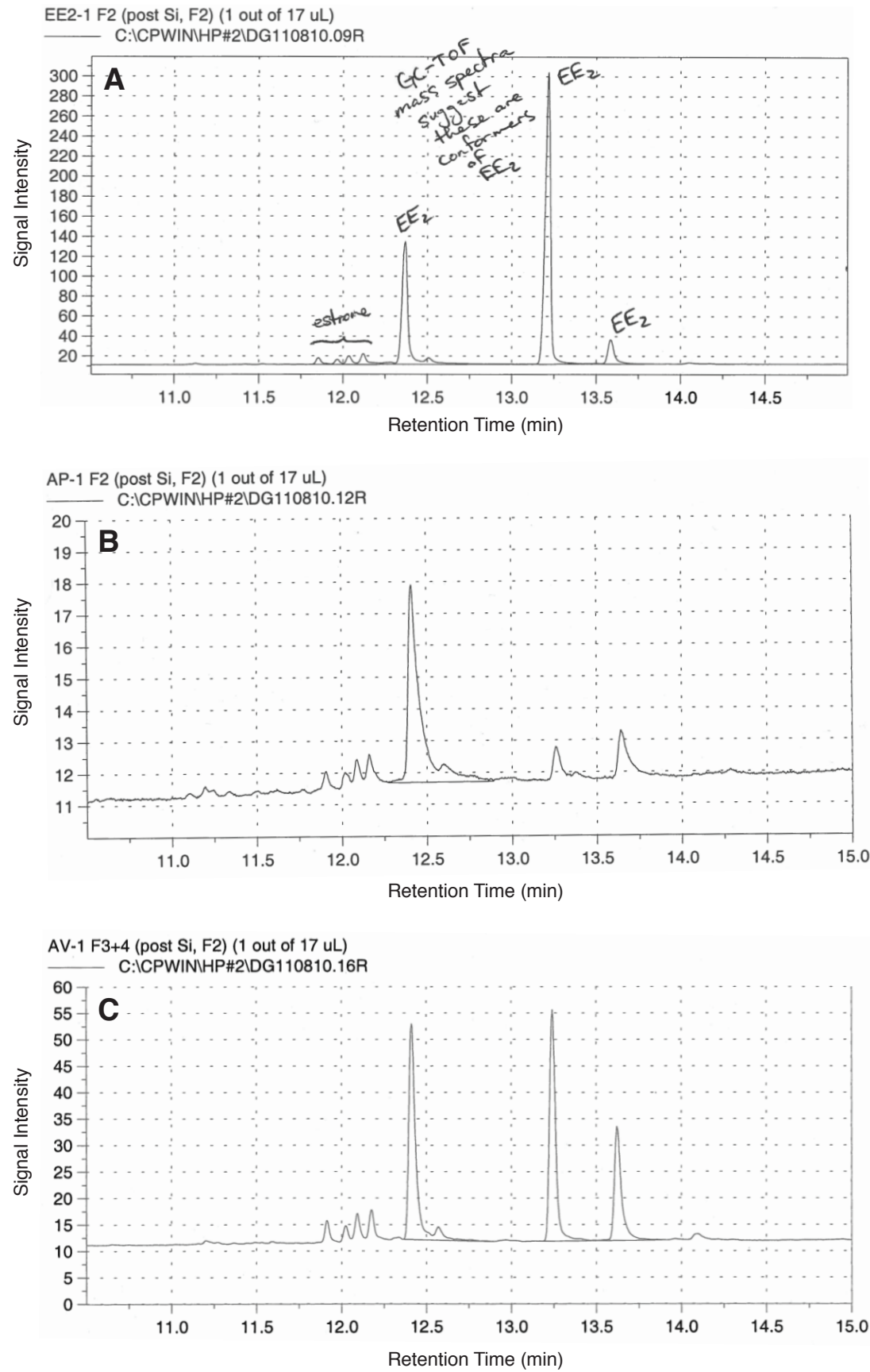
Figure D-1. (continued)
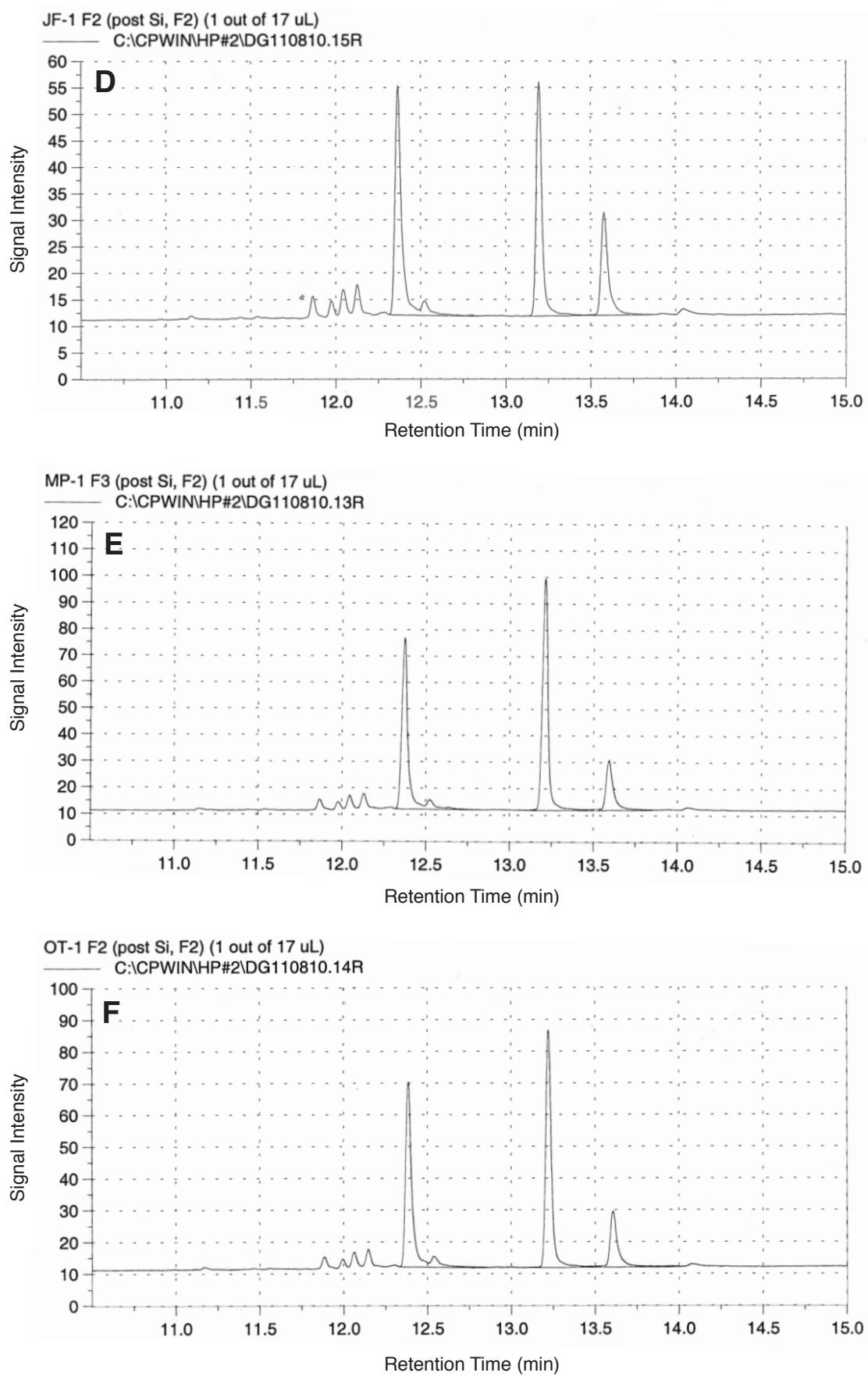
Figure D-1. (continued)
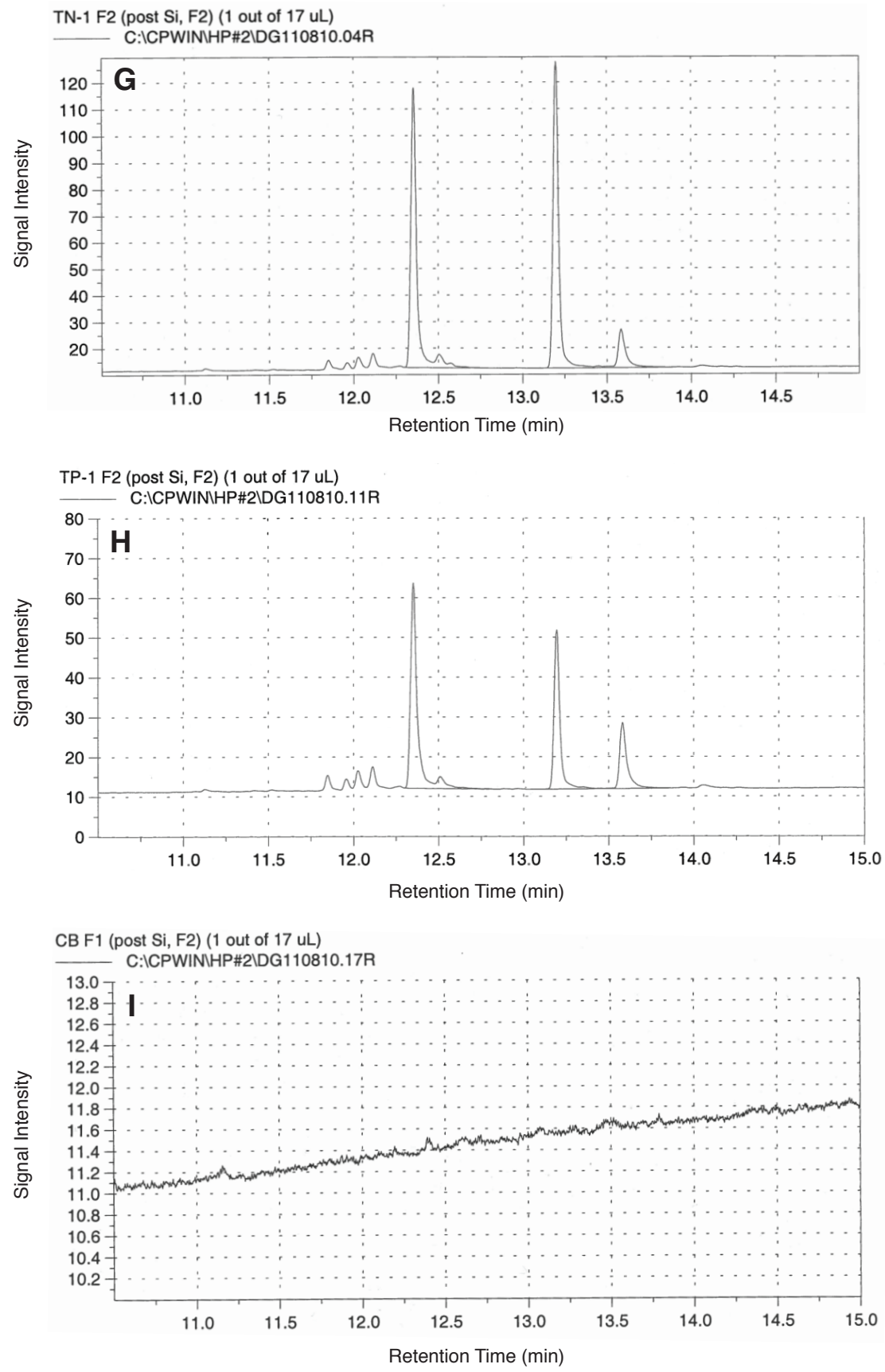
Figure D-2. GC-TOF/MS total ion chromatogram with inset mass spectra for the three peaks of the EE2 positive control sample (see panel A in Figure D-1 above) confirms the purity of extracts and suggests that $\mathrm{E} 1$ is a minor impurity, evident as four small peaks at $\sim 12$ minutes in the GC-FID chromatograms above.

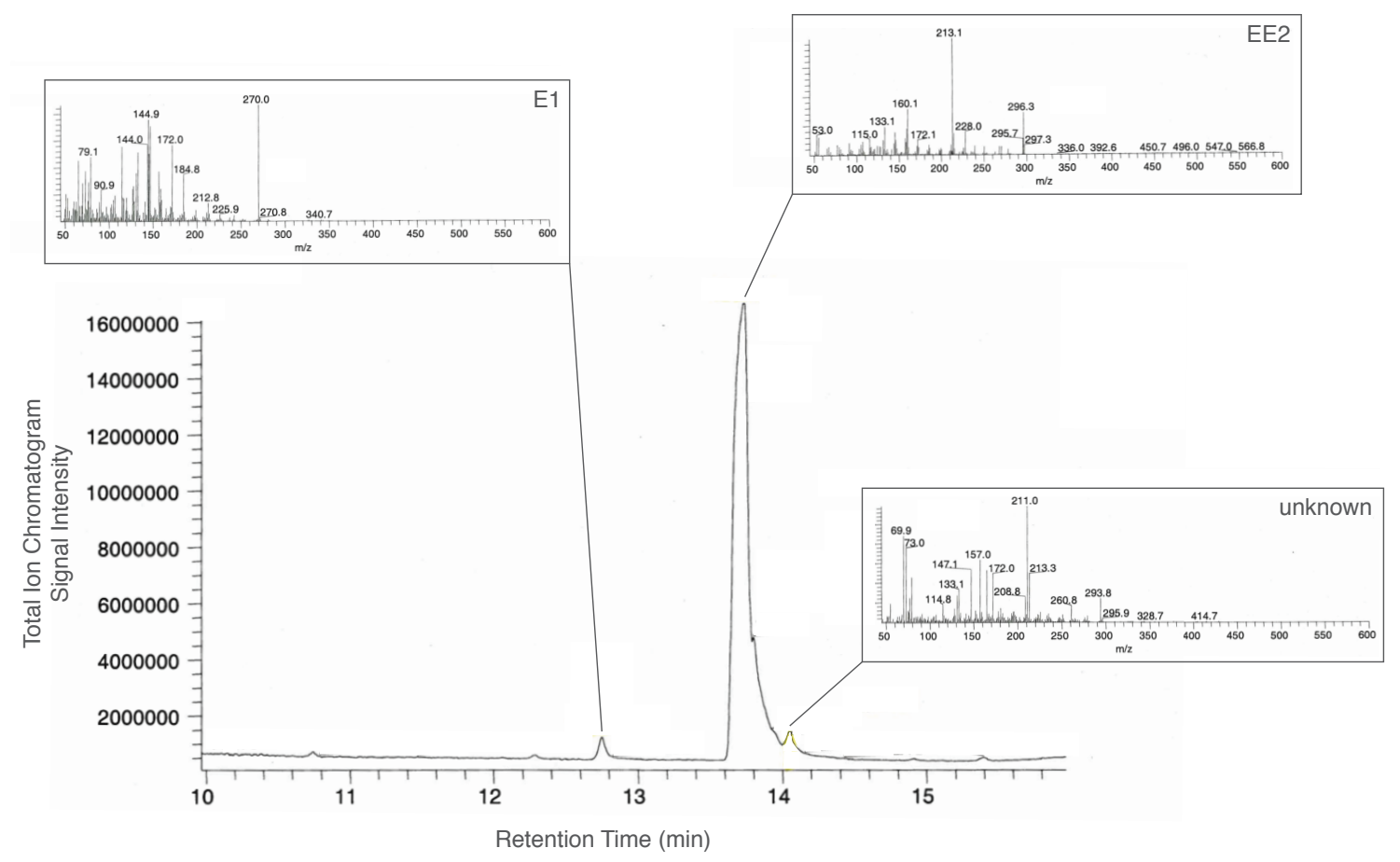




\section{Appendix E}

UV-visible spectra of conjugated, free, and brominated estrogens 
Appendix E: UV-visible spectra of conjugated, free, and brominated estrogens

\section{Stock solutions}

Estrogen standards were massed on a CAHN 25 microbalance (MIT 48-412), and dissolved in methanol in pre-baked $\left(450{ }^{\circ} \mathrm{C} ; 5 \mathrm{~h}\right)$ glass volumetric flasks. Stock solutions were inverted 30 times to mix, covered with aluminum foil, and allowed to sit at room temperature for a minimum of 2 hours before analysis by UV-visible spectroscopy. Solutions were stored at $-20^{\circ} \mathrm{C}$ when not in use.

\section{Spectroscopy}

UV-visible spectra of estrogen solutions ( $\sim 10 \mathrm{mg} \mathrm{mL}^{-1}$ in methanol) were collected through a 1-cm pathlength quartz cuvette using a DU800 spectrophotometer (Beckman Coulter; Fullerton, CA, USA). Absorbance data were recorded in $0.5 \mathrm{~nm}$ increments from $200-800 \mathrm{~nm}$. Significant uncertainty in the accuracy of absorbance data at critical wavelengths greater than $340 \mathrm{~nm}$ currently precludes reporting direct photolysis rate constant estimates based on this data. 
Figure E-1. Representative UV-visible spectra of five estrogen families.

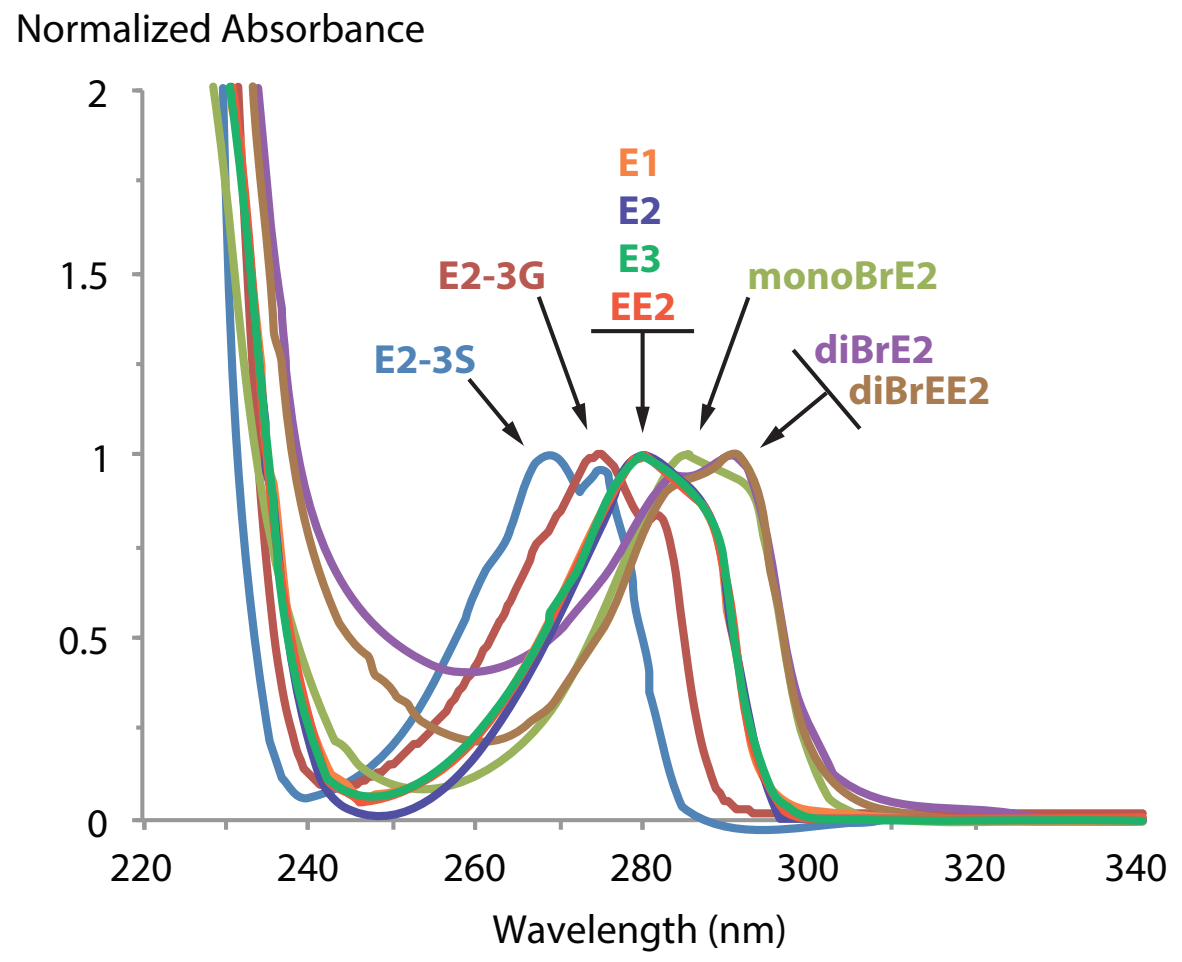


